\title{
ARSENIC REMOVAL USING IRON-MODIFIED ZEOLITES
}

\author{
by \\ Jaron Ross Andrews
}

\begin{abstract}
Submitted in Partial Fulfillment of
the Requirements for the Degree of

Master of Science in Hydrology
\end{abstract}

New Mexico Institute of Mining and Technology

Socorro, New Mexico

December 2009 


\begin{abstract}
We determined the ability of two iron-and-zeolite materials to remove arsenic from groundwater. The first material is composed of iron, surfactant-modified zeolite, and hard silicate foam, and is known as Surfactant-Modified Zeolite/ Zero-Valent Iron (SMZ/ZVI). The second material is a new formulation that consists of iron-modified zeolite (IMZ). We prepared eight different prototypes of IMZ for arsenic removal and eventually used one for further testing. The iron content, surface area, and arsenic adsorption capacity were analyzed for each fully prepared material.

Lab-based batch experiments were performed on each material to estimate the adsorption capacity. Additionally, the effect of $\mathrm{pH}$ on adsorption and the rate of adsorption were determined for the SMZ/ZVI material and one of the newly prepared IMZ. All batch tests were performed using synthetic water based on the chemistry of Socorro Springs water from Socorro, NM. Batch isotherms were performed on each IMZ material using arsenic concentrations that ranged from $10-200 \mathrm{mg} / \mathrm{L}$. Batch experiments were accompanied by small-scale column experiments in the lab, and in the case of SMZ/ZVI, a field column test was performed at a wellhead. All of the water used in the column experiments was sourced from the Socorro Springs near the city of Socorro, NM (containing 41-45 $\mu \mathrm{g} / \mathrm{L}$ arsenate, $\mathrm{pH}=8.1$, and TDS $=356$ $\mu \mathrm{S} / \mathrm{cm})$, and was transported to the lab for column testing. Influent and effluent arsenic concentrations, column flowrates, and total volume were measured in each column study. The measured parameters were used to calculate the volume of water treated below EPA arsenic concentration specifications. All arsenic concentrations were
\end{abstract}


obtained using a hydride generation method coupled with Inductively Coupled Plasma-Optical Emission Spectroscopy (ICP-OES).

The batch experiments showed that the SMZ/ZVI has a maximum arsenic adsorption capacity as calculated by the Langmuir isotherm of $512 \mathrm{mg} / \mathrm{kg}$. The $\mathrm{pH}$ study showed that maximum arsenic adsorption occurs at $\mathrm{pH} 6.5$ and that sorption decreases below or above this $\mathrm{pH}$ value. The kinetic studies showed that $95 \%$ adsorption is achieved in less than 2 minutes at low concentrations $(66 \mu \mathrm{g} / \mathrm{L})$ and within 20 minutes at high arsenic concentrations $(0.78 \mathrm{mg} / \mathrm{L})$. A Toxicity Characteristic Leaching Procedure (TCLP) analysis was performed and showed that the spent media loaded with $25 \mathrm{mg} / \mathrm{kg}$ arsenic can be safely disposed in a landfill. The field column experiments showed lower column adsorption than did batch experiments. Lab-based column studies showed that with long column residence times (40 minutes), SMZ/ZVI could treat about 200 pore volumes of the Socorro Springs water below an arsenic concentration of $10 \mu \mathrm{g} / \mathrm{L}$. With water adjusted to $\mathrm{pH} 6.6$, SMZ/ZVI treated about 1,000 pore volumes of the Socorro Springs water to reduce arsenic concentrations $10 \mu \mathrm{g} / \mathrm{L}$.

The arsenic adsorption capacity varied greatly between the different types of newly created IMZ and was heavily dependent on the procedures used for iron application. The most successful technique that resulted in good iron coating coverage, robustness, and a high arsenic adsorption capacity was a multi-step process that coated the iron on the zeolite in several smaller amounts rather than one large loading. The material chosen is labeled IMZ-8 and contained $28,400 \mathrm{mg}$ of iron per $\mathrm{kg}$ material. Compared with the raw zeolite that had a surface are of $13.8 \mathrm{~m}^{2} / \mathrm{g}$, the surface area of 
IMZ-8 increased about $150 \%$ to $21.4 \mathrm{~m}$ /g. Using the Langmuir isotherm, IMZ-8 had a maximum arsenic adsorption capacity of $654 \mathrm{mg} / \mathrm{kg}$ and a Langmuir coefficient of 4.65 L/mg. The IMZ-8 material was further tested by looking at the effects of $\mathrm{pH}$ on adsorption and by performing column breakthrough experiments with media regeneration at the end of each breakthrough cycle. The material was found to have maximum arsenic adsorption between $\mathrm{pH} 2.0$ and 7.0.

For column experiments, the IMZ-8 material was loaded into a glass column $10.5 \mathrm{~cm}$ in length and $2.5 \mathrm{~cm}$ in diameter. Using Socorro Springs water as the influent, the column effluent arsenic concentration remained below $10 \mu \mathrm{g} / \mathrm{L}$ for 800 pore volumes. The IMZ-8 column was successfully regenerated 3 times with no loss of adsorption capacity using $1 \mathrm{~L}$ of $0.25 \mathrm{M} \mathrm{NaOH}$ and $6 \mathrm{~L}$ of reverse osmosis water. The IMZ-8 material may be a viable alternative for municipal water treatment due to the low cost of zeolite, the high arsenic adsorption capacity, and the easily regenerated media. The estimated cost of treating the local water with IMZ-8 was about $\$ 0.50$ per $1,000 \mathrm{~L}$.

For both materials there was a lack of correlation between estimated adsorption capacity from batch experiments and the measured capacity during column studies. The principal reason is believed to be the availability of adsorption sites. The production of fine iron particles during batch experiment shaking may have led to an overestimation of removal capacity. Adsorptive competition with high concentrations of silica ( $25 \mathrm{mg} / \mathrm{L})$ as well as low intraparticle diffusion rates using SMZ/ZVI are believed to have led to low adsorption in those column experiments. 


\section{ACKNOWLEDGEMENTS}

This thesis would not have been possible without the guidance and support of my late advisor, Robert Bowman. He was a wonderful man and the quintessential professional scientist. His cordial behavior, friendly smile, and compassion for students will never be forgotten.

I would like to thank my family and my wife for their support and patience all throughout school.

I would like to thank my committee members, Michael Pullin, Fred Phillips, and John Wilson for all of their help and guidance after Rob had gone.

Finally, I would like to thank the following individuals for their time, their help, and friendship.

Bonnie Frey

Frederick Partey

James Quarles

Dustin Baca

Dixie Daniels

Peter Anselmo

Andre Ritchie

Vyoma Nenuji

Mark Cal
Paul Fuierer

Buvana P.

Bill Holub

Randy Everett

Josh Simpson

Jolanta Warchol

Abe Gundelier

Michael Jelavich

I would like to thank the following organizations for their financial support or equipment donation:

SMART fellowship program (DOD)

Sandia National Laboratories

City of Socorro

New Mexico Tech Graduate Student Association

New Mexico Bureau of Geology and Mineral Resources

Geological Society of America

New Mexico Geological Society

American Institute of Professional Geologists

Finally, I would like to thank Elsevier for the right to use a figure from Jarafour et al. 2005. The permission form is attached at the end of this document. 


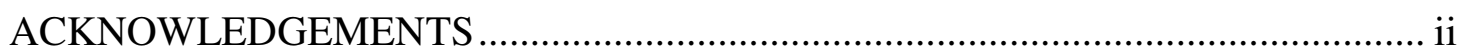

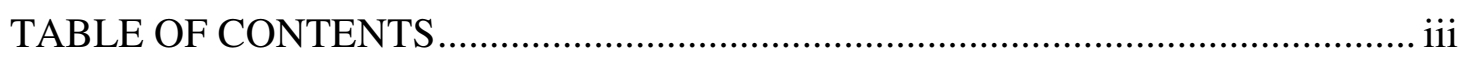

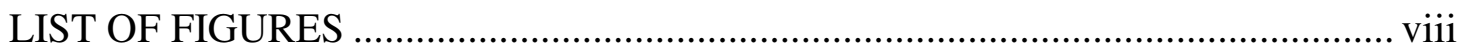

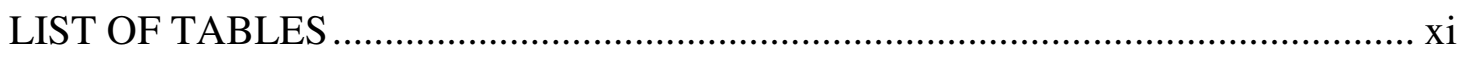

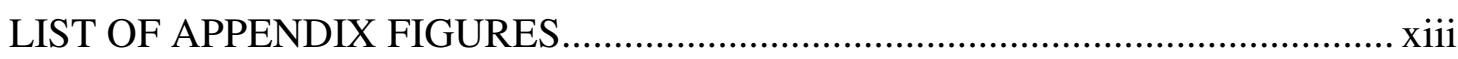

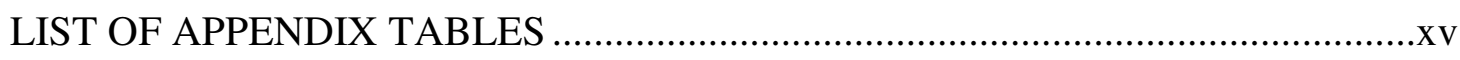

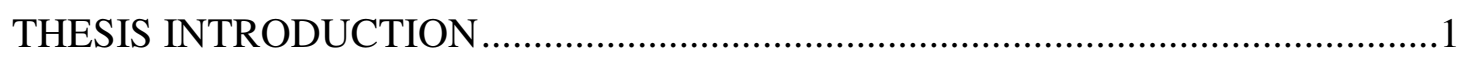

ARTICLE I.

Arsenic Removal Using Iron-Modified Zeolite/ Zero-Valent Iron (SMZ/ZVI) ..............2

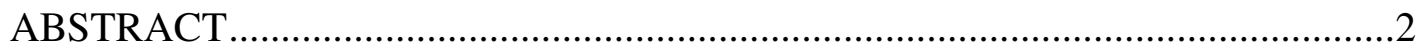

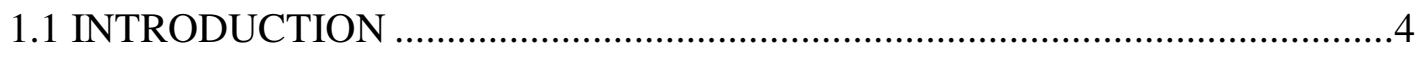

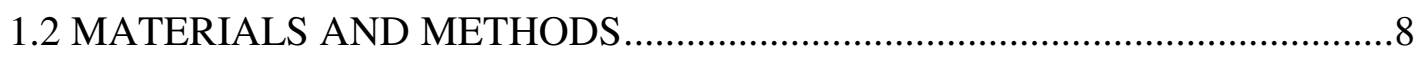

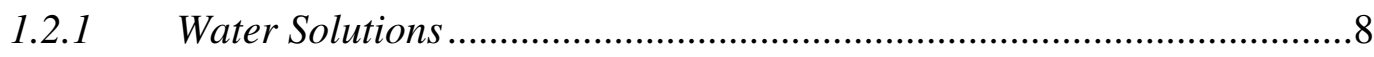

1.2.2 Arsenic Analyses .....................................................................

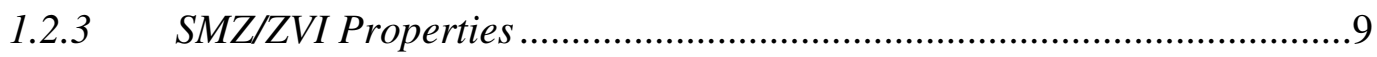

1.2.4 Batch Experiments ………………………....................................10

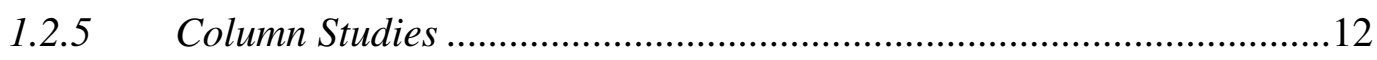

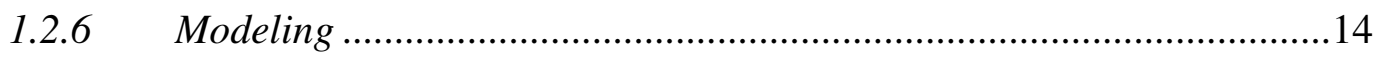

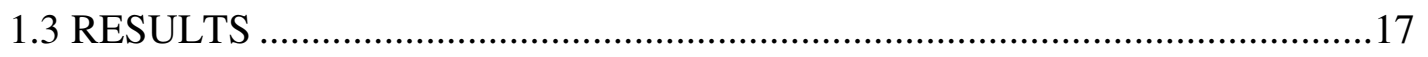


1.3.1 Kinetics ................................................................................. 17

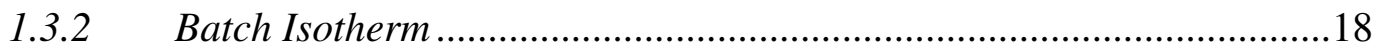

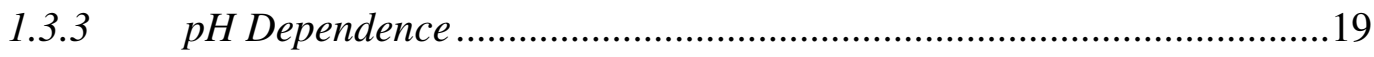

1.3.4 Toxicity Characteristic Leaching Procedure (TCLP)..........................22

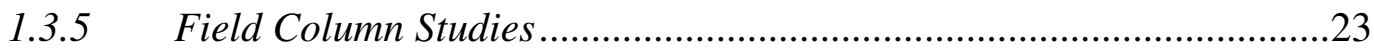

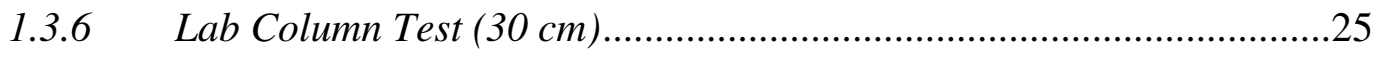

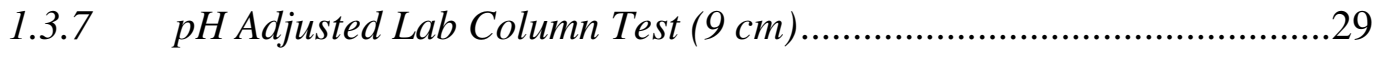

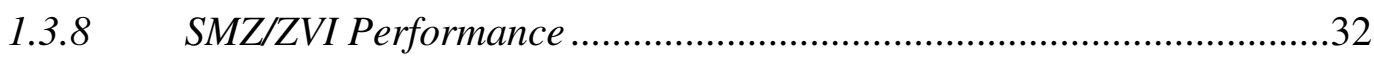

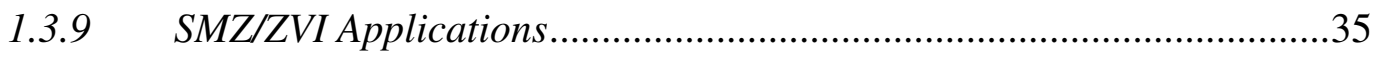

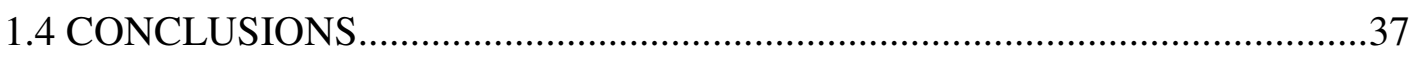

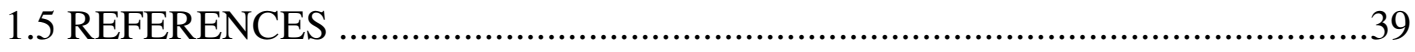

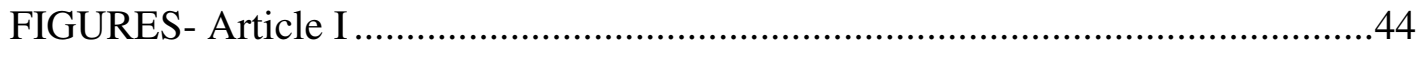

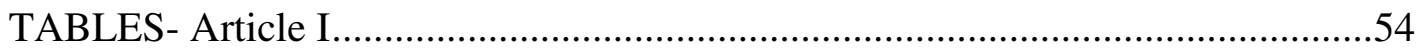

\section{ARTICLE II.}

Arsenic Removal using Iron-Modified Zeolite (IMZ) ......................................58

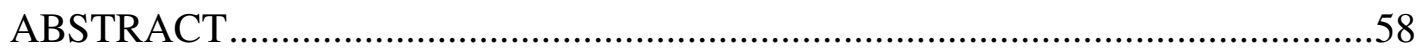

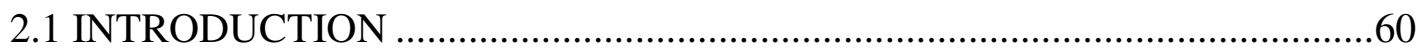

2.2. METHODS AND MATERIALS ..........................................................63

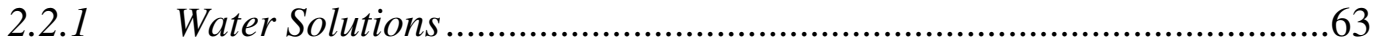

2.2.2 Material Preparation ....................................................................63

2.2.3 Surface Area Analyses ................................................................6

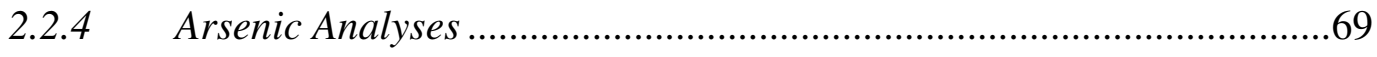




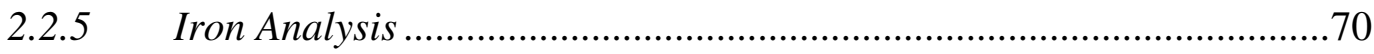

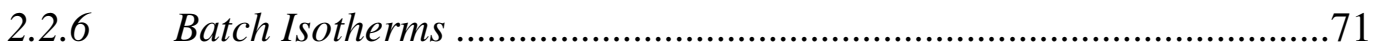

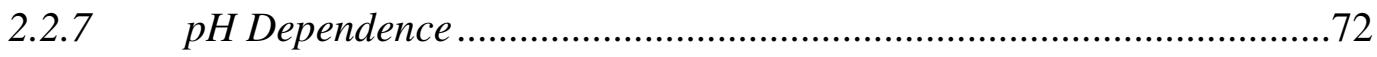

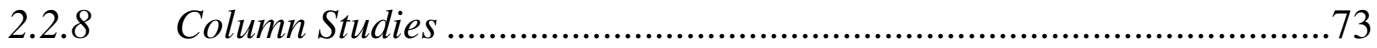

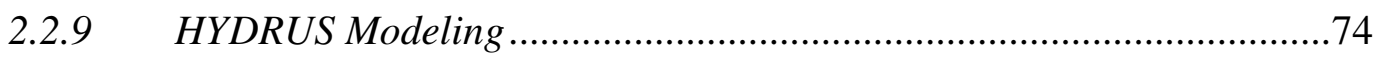

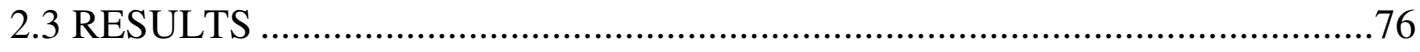

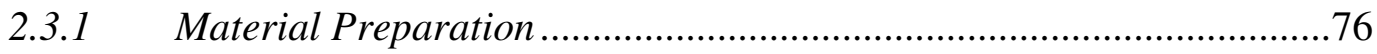

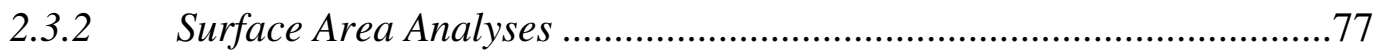

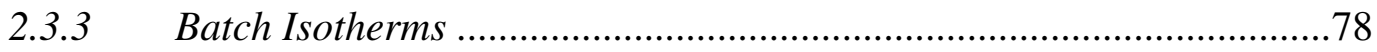

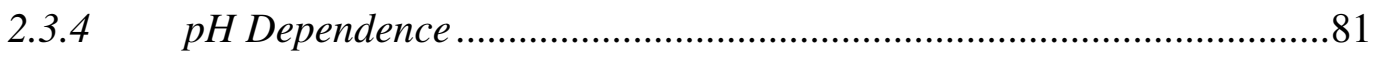

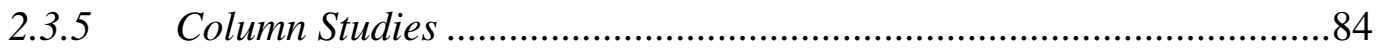

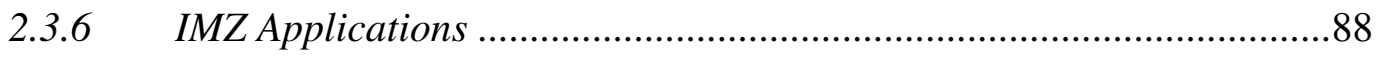

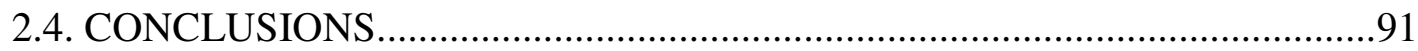

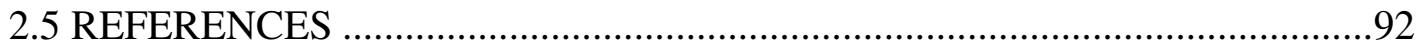

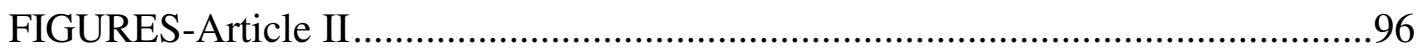

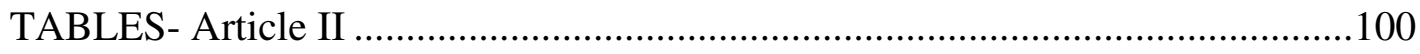

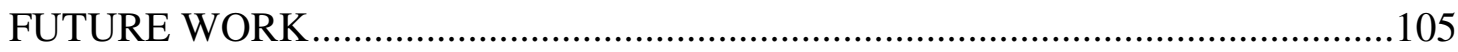

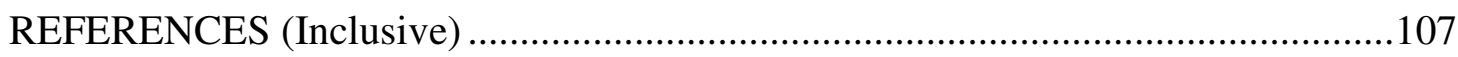

APPENDIX A - ARTICLE III

2,4-Dinitrotoluene Degradation using Surfactant-Modified Zeolite/ Zero-Valent Iron

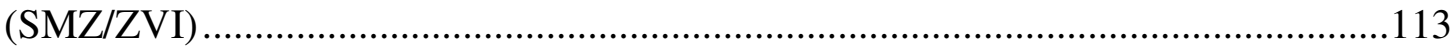

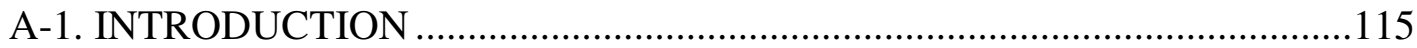


A-1.1 2,4-DNT Occurrence and Hazard................................................115

A-1.2 Iron Reduction of 2,4-DNT ...........................................................115

A-1.3 SMZ/ZVI Properties .............................................................. 116

A-1.4 Overall Experiment Goals .........................................................117

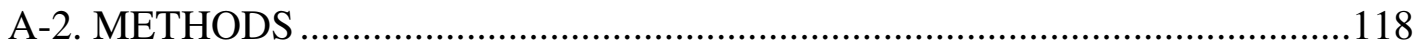

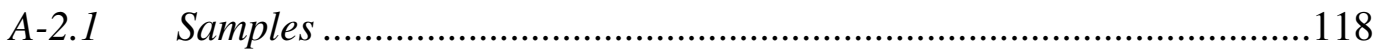

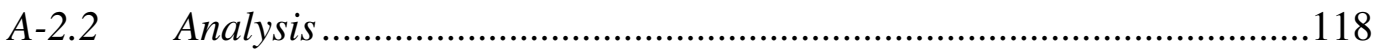

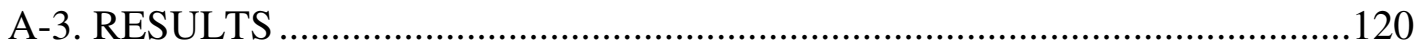

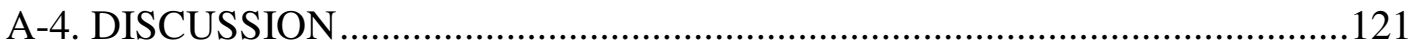

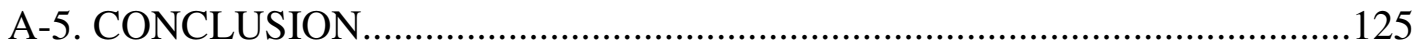

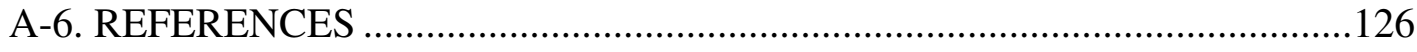

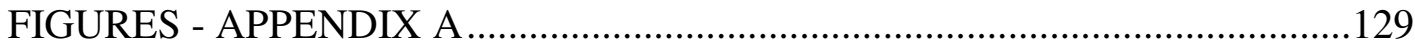

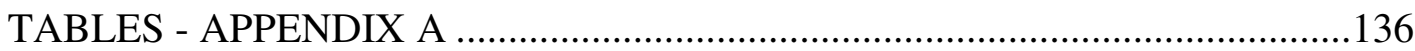

APPENDIX B - Supplementary Data for Article III. ..........................................137

APPENDIX C - Supplementary batch experiment data for Article I ........................142

APPENDIX D - Supplementary column data for Article I......................................154

APPENDIX E - Supplementary data for Article II..................................................165

APPENDIX F - Arsenic Analysis using Inductively Coupled Plasma- Optical

Emission Spectrometer (ICP-OES) and Hydride Generation ...............................176

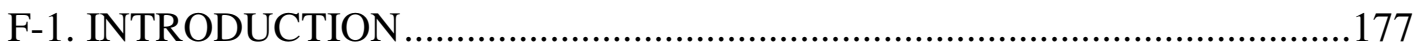




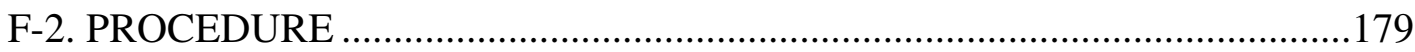

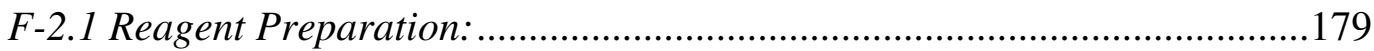

F-2.2 Sample Preparation: ....................................................................... 179

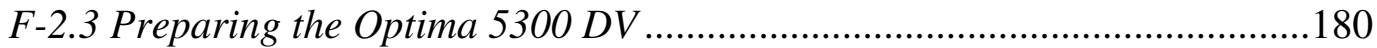

F-2.4 Installing the Hydride Generation Manifold........................................181

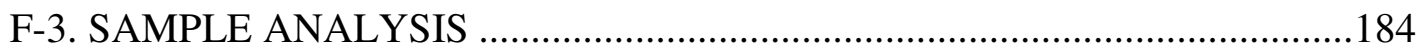

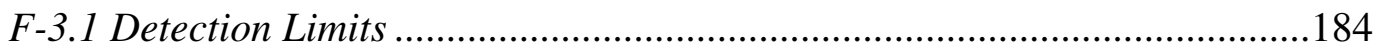

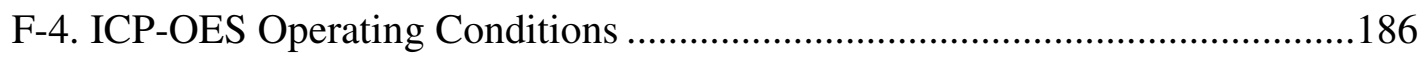

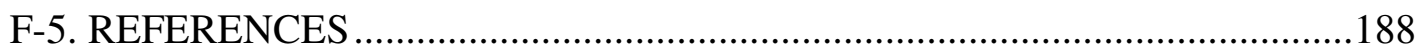




\section{LIST OF FIGURES}

Figure 1- 1: Arsenic concentrations in solution after mixing with SMZ/ZVI for various times. Each circle represents the results from an individual analysis; duplicate vials at each time were used. An initial concentration of $0.78 \mathrm{mg} / \mathrm{L} \mathrm{As}(\mathrm{V})$ was used for each vial. Concentration measurement error is $\pm 4 \%$ based on replicate analyses of a $1 \mu \mathrm{g} / \mathrm{L}$ standard.

Figure 1- 2: Arsenic concentration in solution after mixing with SMZ/ZVI for various times. Each circle represents the results from an individual analysis; duplicate vials at each time were used. An initial concentration of $66 \mu \mathrm{g} / \mathrm{L} \mathrm{As}(\mathrm{V})$ was used for each vial. Concentration measurement error is $\pm 4 \%$ based on replicate analyses of a $1 \mu \mathrm{g} / \mathrm{L}$ standard.

Figure 1- 3: Graph showing the concentrations of As in solution using three different types of water for the batch experiment. The initial As concentration was $3.3 \mathrm{mg} / \mathrm{L}$ and the equilibration time was 1 hour. The points labeled "Soco" and "Soco-Cl" represent the raw Socorro feed water and the chlorinated Socorro feed water respectively. The error bars represent the standard deviation based on triplicate analyses.

Figure 1- 4: Isotherm concentrations adsorbed and concentrations in solution plotted on a semi-log scale. Duplicate samples were sacrificed and analyzed at each concentration. The synthetic water solution was used in all batch experiments. The initial $\mathrm{pH}$ of each solution was $8.5 \pm 0.1$, while the final $\mathrm{pH}$ varied from 7.5 to 9.9 (data can be found in Appendix C). Concentration measurement error is $\pm 3 \%$ based on replicate analyses of a $10 \mu \mathrm{g} / \mathrm{L}$ USGS standard reference sample.

Figure 1- 5: Isotherm results (Figure 1-4) plotted as a Langmuir type isotherm. $\mathrm{C}=$ Arsenic concentration in solution after equilibration $(\mathrm{mg} / \mathrm{L}) ; \mathrm{S}=$ Arsenic concentration on SMZ/ZVI ( $\mathrm{mg} / \mathrm{kg})$. The best fit line is a linear fit that is used to derive the Langmuir parameters from the linearized Langmuir equation. The error values are based on standard errors from linear regression of the fitted line. Concentration measurement error is $\pm 3 \%$ based on replicate analyses of a $10 \mu \mathrm{g} / \mathrm{L}$ USGS standard reference sample...

Figure 1- 6: Semi-log plot showing the concentration in solution after equilibration with an $\sim 18 \mathrm{mg} / \mathrm{L} \mathrm{As}(\mathrm{V})$. The $\mathrm{pH}$ values plotted were measured after equilibration for 2 hours. Concentration measurement error is $\pm 3 \%$ based on replicate analyses of a $10 \mu \mathrm{g} / \mathrm{L}$ USGS standard reference sample. 
Figure 1- 7: Influent and effluent concentrations measured at the end of one of the Socorro Springs field site columns. The solid line is the best fit to the data from the inverse solver option within HYDRUS-1D. The flowrate was reduced from $\sim 0.8 \mathrm{~L} / \mathrm{min}$ to $\sim 0.3 \mathrm{~L} / \mathrm{min}$ around 3500 pore volumes. Concentration measurement error is $\pm 3 \%$ based on replicate analyses of a $10 \mu \mathrm{g} / \mathrm{L}$ USGS standard reference sample.

Figure 1- 8: Plot showing the influent and effluent concentrations measured at the end of one of the $30 \mathrm{~cm}$ columns. The solid line is the best-fit to the observed data using the HYDRUS-1D inverse solution option. Concentration measurement error is $\pm 3 \%$ based on replicate analyses of a $10 \mu \mathrm{g} / \mathrm{L}$ USGS standard reference sample.

Figure 1- 9: Measured arsenic effluent concentrations at the end of each column. The solid line is the best fit to the observed data using the inverse solver within HYDRUS-1D. The columns were run in series with the SMZ/ZVI column first, and the unmodified zeolite column second. The influent arsenic concentration was $44 \mu \mathrm{g} / \mathrm{L}$ adjusted to $\mathrm{pH}$ 6.6. Concentration measurement error is $\pm 3 \%$ based on replicate analyses of a $10 \mu \mathrm{g} / \mathrm{L}$ USGS standard reference sample.

Figure 1-10: Pictures of the physical change in appearance of the unmodified zeolite column after 200 and 800 pore volumes. Flow is from left to right. The unmodified zeolite column was in series directly after the SMZ/ZVI column.

Figure 2- 1: Measured equilibrium arsenic concentrations from batch experiment isotherms. Each symbol is the average concentration of two identical vials. The size of each of the symbols is about the amount of variation observed in each of the two measurements. The lines are presented for visual aids. IMZ-4 and IMZ-5 were not analyzed due to a lack of material for duplicate analyses. Concentration measurement error is \pm $3 \%$ based on replicate analyses of a $10 \mu \mathrm{g} / \mathrm{L}$ USGS standard reference sample.

Figure 2- 2: Measured arsenic concentrations in solution vs. final $\mathrm{pH}$ measured after equilibration for the IMZ-8 material. The initial $\mathrm{pH}$ of each solution can be found in Table 2-7. The initial starting arsenic concentration was about $104 \mathrm{mg} / \mathrm{L}$. Concentration measurement error is $\pm 3 \%$ based on replicate analyses of a $10 \mu \mathrm{g} / \mathrm{L}$ USGS standard reference sample.

Figure 2- 3: Measured effluent arsenic concentrations from the $10.5 \mathrm{~cm} \mathrm{IMZ-8}$ column. Each symbol represents a breakthrough cycle from the same column. The dashed line represents the average influent concentration which was measured at the beginning and end of each breakthrough curve. The column was regenerated three times. Concentration 
measurement error is $\pm 3 \%$ based on replicate analyses of a $10 \mu \mathrm{g} / \mathrm{L}$ USGS standard reference sample....

Figure 2- 4: Measured effluent arsenic concentrations from the column and the fitted solid line from HYDRUS-1D that was used to derive the adsorption parameters. The data is from the second breakthrough curve for the IMZ-8 material. The fit using the Langmuir and Freundlish isotherms is nearly identical and only the Langmuir fit is shown for clarity. Concentration measurement error is $\pm 3 \%$ based on replicate analyses of a $10 \mu \mathrm{g} / \mathrm{L}$ USGS standard reference sample. 


\section{LIST OF TABLES}

Table 1- 1: Measured concentrations of elements present in the Socorro Springs water and calculated concentrations of elements present in the synthetic water prepared in the lab.

Table 1- 2 : Comparison between As(V) estimated Langmuir maximum sorption capacity $\left(S_{m}\right)$ of several different kinds of media.

Table 1- 3: List of operating parameters used in the field test at the Socorro chlorination building.

Table 1-4: List of operating parameters used in the $30 \mathrm{~cm}$ columns tested in the lab.

Table 1- 5: List of operating parameters used in the $9 \mathrm{~cm} \mathrm{pH}$ adjusted column tested in the lab.

Table 1- 6: Comparison of calculated parameters from the batch experiments and the three column experiments using the inverse solver within HYDRUS-1D. $K_{A}=K_{L} \times S_{m}$ where $K_{L}$ is the Langmuir coefficient and $S_{m}$ is the estimated maximum adsorption capacity. The Socorro Springs column had a short column residence time of 3.8 minutes, was tested with ambient Socorro Springs water, and was conducted at the Socorro wellhead field site. The Lab $(30 \mathrm{~cm})$ column study had long column residence times of 40 minutes, was tested with ambient Socorro Springs water, and was performed in the lab. The lab $\mathrm{pH}$ adjusted $(9 \mathrm{~cm})$ column had residence times of 5.2 minutes, was tested with Socorro Springs water adjusted to $\mathrm{pH}$ 6.6, and was performed in the lab.

Table 1- 7: Comparison of the ratio of pore volumes treated to the indicated concentration in parentheses compared with the ratio of the $\mathrm{K}_{\mathrm{A}}$ values calculated in Table 1-6 above.

Table 1- 8: Comparison of the calculated Damkohler numbers $\left(D_{A}\right)$ for each column experiment. The Damkohler number is the ratio of the transport rate in the column to the calculated reaction rate for adsorption; it is defined as $\mathrm{D}_{\mathrm{A}}=\mathrm{kL} / \mathrm{v}$ where $\mathrm{k}$ is the reaction rate ( $\mathrm{min}^{-}$ $\left.{ }^{1}\right), \mathrm{L}$ is the column length $(\mathrm{cm})$, and $\mathrm{v}$ is the average pore water velocity $(\mathrm{cm} / \mathrm{min})$. A reaction rate of $0.18 \mathrm{~min}^{-1}$ was used in all calculations based on the kinetic data in Section 1.3.1. $\mathrm{T}_{\mathrm{R}}$ is the column residence time.

Table 2- 1: Measured concentrations of elements present in the Socorro Springs water and calculated concentrations of elements present in the synthetic water prepared in the lab. 
Table 2- 2: Measured characteristics of the $10.5 \mathrm{~cm}$ column used for testing transport breakthrough curves using IMZ-8.

Table 2- 3: Measured iron concentrations of each completed IMZ preparation. The average values and standard deviation are calculated from triplicate analyses. The iron content of each IMZ includes the natural iron that was present in the raw zeolite.

Table 2- 4: Measured iron content and surface area of prepared iron modified zeolites. Iron content is the average of triplicate analyses; surface area measurements are results from a 5 point BET method. Values in parentheses are the standard deviation based on duplicate analyses for IMZ-8 and triplicate analyses for raw zeolite. The reported surface areas from other preparations are based on a single analysis. N/M indicates the material's surface area was not measured.

Table 2- 5: Fitted isotherm parameters for the Freundlich and Langmuir isotherm equations. IMZ-4 and IMZ-5 were not analyzed due to a lack of material for duplicate analyses. Error analysis of these parameters can be found in Appendix E.

Table 2- 6: Comparison between observed Langmuir maximum sorption capacity $\left(\mathrm{S}_{\mathrm{m}}\right)$ of several different kinds of media. All of the experiments were performed near neutral $\mathrm{pH}$.

Table 2- 7: Measured initial and final $\mathrm{pH}$ values of each sample from Figure 2-2 for the $\mathrm{pH}$ dependence study.

Table 2- 8: Mass balance calculations for the three regeneration phases of the 10.5 cm IMZ-8 column. Each breakthrough phase consisted of three steps: 1) flowing Socorro Springs water through the column until the effluent concentration is above $10 \mu \mathrm{g} / \mathrm{L}$; 2) rinsing the column with $1 \mathrm{~L}$ of 0.25 $\mathrm{M} \mathrm{NaOH}$; and 3) rinsing the column with $6 \mathrm{~L}$ of Type I water. For each step, the effluent was collected and the arsenic concentration was measured. The mass of arsenic removed was estimated from the area under each breakthrough curve. The same column and media was used in each step without alteration.

Table 2- 9: Fitted adsorption parameters from the batch experiments and the column experiments. The batch experiment adsorption parameters were derived from the linear forms of each isotherm equation; the column experiment adsorption parameters were fitted using HYDRUS-1D. 


\section{LIST OF APPENDIX FIGURES}

Figure A-1: Simplified illustration of the reduction pathways and observed intermediates seen in the reduction of 2,4-DNT (used with permissionfrom Jafarpour et al., 2004).

Figure A- 2: Schematic diagram of the orientation of HDTMA surfactant molecules on the zeolite surface arranged as a bilayer. The polar head groups (ammonium) are attracted to the negatively charged zeolite surface, while the non-polar carbon tail groups are attracted to one another; this forms a surfactant bilayer.

Figure A- 3: Concentrations of 2,4-DNT and 2,4-DAT measured in solution starting from an initial concentration of $26.6 \mathrm{mg} / \mathrm{L}$. Duplicate vials were prepared and sacrificed at each time interval. Concentration error is $\pm 3 \%$ or less based on the standard deviation of multiple standard analyses.

Figure A- 4: Concentrations of the intermediate species 2A-4NT and 4A-2NT measured in solution starting from an initial concentration of 26.6 $\mathrm{mg} / \mathrm{L}$ 2,4-DNT. Duplicate vials were prepared and sacrificed at each time interval. Concentration error is $\pm 3 \%$ or less based on the standard deviation of multiple standard analyses.

Figure A- 5: Aqueous concentrations of 2,4-DAT and 2,4-DNT measured during batch experiments and total mass in solution. The concentrations of the intermediate species 2A-4NT and 4A-2NT are not shown but account for a maximum of about $10 \%$ of the mass around 60 minutes. Mass error is $\pm 3 \%$ or less based on the standard deviation of multiple standard analyses.

Figure A- 6: Aqueous concentrations of 2,4-DAT and 2,4-DNT plotted relative to an initial 2,4-DNT concentration of $26.6 \mathrm{mg} / \mathrm{L}$. The linear nature of the change in concentration shows that the reduction of 2,4-DNT and production of 2,4-DAT follows a first order kinetic reaction. An increase in apparent reaction rate occurs at a 2,4-DNT concentration below about $10 \mathrm{mg} / \mathrm{L}$. Concentration error is $\pm 3 \%$ or less based on the standard deviation of multiple standard analyses.

Figure A- 7: Plot comparing the reaction rate constants for different starting concentrations of 2,4-DNT for concentrations in solution greater than $10 \mathrm{mg} / \mathrm{L}$ and less than $10 \mathrm{mg} / \mathrm{L}$. Error bars are the standard error based on regression analysis of the slope of each line segment. A t-test analysis of the rates for concentrations above and below $10 \mathrm{mg} / \mathrm{L}$ for each starting concentrations showed that the rates were statistically different at the $99 \%$ confidence interval. 
Figure B-1: Computer image of the retention times and peak heights from the HPLC EZ Chrome Elite software. The mobile phase consisted of $45 \%$ $4 \mathrm{mM} \mathrm{KH}_{2} \mathrm{PO}_{4}$ and $55 \%$ Methanol. The concentration of each compound was about $13 \mathrm{ppm}$.

Figure F- 1: Chemifold assembly with appropriate tubing.

Figure F- 2: Plot of the measured values of the sample T-135. The USGS standard reference sample has a reported value of $10.0 \pm 1.1 \mu \mathrm{g} / \mathrm{L}$. The average value from 14 different analyses was $10.5 \mu \mathrm{g} / \mathrm{L}$.......................................185 


\section{LIST OF APPENDIX TABLES}

Table A- 1: Comparison of kinetic reaction rates observed using SMZ/ZVI and other reductive techniques.

Table B- 1: Measured concentrations in solution of DNT and its three reaction products from the batch experiment data with an initial DNT concentration of $12.2 \mathrm{mg} / \mathrm{L}$. Concentration error is $\pm 3 \%$ or less based on the standard deviation of multiple standard analyses. A detection limit of $0.01 \mathrm{mg} / \mathrm{L}$ is estimated from three times the signal to noise ratio.

Table B-2: Measured concentrations in solution of DNT and its three reaction products from the batch experiment data with an initial DNT concentration of $26.6 \mathrm{mg} / \mathrm{L}$

Table B- 3: Measured concentrations in solution of DNT and its three reaction products from the batch experiment data with an initial DNT concentration of $108 \mathrm{mg} / \mathrm{L}$

Table B- 4: Results from t-test data for comparison of the reaction rates for the 2,4DNT concentrations above $10 \mathrm{mg} / \mathrm{L}$ and concentrations below 10 $\mathrm{mg} / \mathrm{L}$. The software program Minitab 14 was used to make the analysis. In all cases, the two reaction rates were significantly different at the $99 \%$ confidence interval.

Table C- 1: Mass of reagents used in the preparation of $2 \mathrm{~L}$ of the synthetic water solution used in batch experiments. The ion concentrations of the prepared solution and the measured values from the Socorro Springs are included for comparison.

Table C- 2: Measured weights of materials used for comparison of adsorption isotherms between the synthetic water made in the lab (Syn), the Socorro Springs chlorinated feed water (Soco-Cl), and the Socorro Springs unchlorinated feed water (Soco). A 1 hour equilibration time was used.

Table C- 3: Measured arsenic concentrations for the adsorption isotherms between the synthetic water made in the lab, the Socorro Springs chlorinated feed water, and the Socorro Springs unchlorinated feed water. Concentration measurement error is $\pm 3 \%$ based on replicate analyses of a $10 \mu \mathrm{g} / \mathrm{L}$ USGS standard reference sample. The stock solution concentration was measured from dilution of each one of the starting solutions. The initial concentration (Initial Conc.) are the calculated arsenic concentration after taking into account the excess liquid from the washing step. The equilibrium concentration in solution was the 
measured concentrations of each sample from the ICP-OES. The mass of SMZ/ZVI used for calculation of the amount adsorbed is contained in Table C-2. All values are reported to two significant figures.

Table C- 4: Measured weights of test tube, SMZ/ZVI, and excess water from the rinsing step used for kinetic batch studies for 20 minutes to 720 minutes.

Table C- 5: Measured arsenic concentrations for kinetic batch studies for 20 minutes to 720 minutes. Concentration measurement error is $\pm 3 \%$ based on replicate analyses of a $10 \mu \mathrm{g} / \mathrm{L}$ USGS standard reference sample. The stock solution concentration was measured from dilution of each one of the starting solutions. The initial concentration (Initial Conc.) are the calculated arsenic concentration after taking into account the excess liquid from the washing step. The equilibrium concentration in solution was the measured concentrations of each sample from the ICP-OES. The mass of SMZ/ZVI used for calculation of the amount adsorbed is contained in Table $\mathrm{C}-4$. All values are reported to two significant figures.

Table C- 6: Measured weights of material used for kinetic batch studies at short times (0-60 minutes).

Table C- 7: Measured arsenic concentrations for kinetic batch studies at short times (0-60 minutes). Concentration measurement error is $\pm 3 \%$ based on replicate analyses of a $10 \mu \mathrm{g} / \mathrm{L}$ USGS standard reference sample. The stock solution concentration was measured from dilution of each one of the starting solutions. The initial concentration (Initial Conc.) are the calculated arsenic concentration after taking into account the excess liquid from the washing step. The equilibrium concentration in solution was the measured concentrations of each sample from the ICP-OES. The mass of SMZ/ZVI used for calculation of the amount adsorbed is contained in Table C-6. All values are reported to two significant figures

Table C- 8: Measured weights of material used for the TCLP batch experiment. ......148

Table C- 9: Measured $\mathrm{pH}$ values and arsenic concentration for the TCLP batch experiment. The samples Co-1, Co-2, etc. are the solution concentrations after initial equilibration with the $\sim 6 \mathrm{ppm}$ stock solution. The samples TCLP-1, TCLP-2, etc. are the measured values after leaching with the $\mathrm{pH} 2.88$ acetic acid solution. Concentration measurement error is $\pm 3 \%$ based on replicate analyses of a $10 \mu \mathrm{g} / \mathrm{L}$ USGS standard reference sample. The stock solution concentration was measured from dilution of each one of the starting solutions. The initial concentration (Initial Conc.) are the calculated arsenic concentration after taking into account the excess liquid from the 
washing step. The equilibrium concentration in solution was the measured concentrations of each sample from the ICP-OES. The mass of SMZ/ZVI used for calculation of the amount adsorbed is contained in Table C-8. All values are reported to two significant figures

Table C-10: Collected weights of material used for the $\mathrm{pH}$ comparison test

Table C-11: Measured $\mathrm{pH}$ values and initial solution concentrations for the $\mathrm{pH}$ comparison batch experiment. Measured $\mathrm{pH}$ values and arsenic concentration for the TCLP batch experiment. Concentration measurement error is $\pm 3 \%$ based on replicate analyses of a $10 \mu \mathrm{g} / \mathrm{L}$ USGS standard reference sample. The stock solution concentration was measured from dilution of each one of the starting solutions. The initial concentration (Initial Conc.) are the calculated arsenic concentration after taking into account the excess liquid from the washing step. The equilibrium concentration in solution was the measured concentrations of each sample from the ICP-OES. The mass of SMZ/ZVI used for calculation of the amount adsorbed is contained in Table C-10. All values are reported to two significant figures except where accuracy limited.

Table C- 12: Measured equilibration arsenic concentrations for the $\mathrm{pH}$ comparison batch experiment. Tubes with high arsenic concentrations were diluted 1:100. Concentration measurement error is $\pm 3 \%$ based on replicate analyses of a $10 \mu \mathrm{g} / \mathrm{L}$ USGS standard reference sample. The equilibrium concentration in solution was the measured concentrations of each sample from the ICP-OES. All concentration values are reported to two significant figures.

Table C-13: Measured weights of material used and final $\mathrm{pH}$ values for the batch experiment isotherm. The initial solution $\mathrm{pH}$ was $8.5 \pm 0.1$ for each concentration.

Table C-14: Measured arsenic concentrations for the batch experiment isotherm. Concentration measurement error is $\pm 3 \%$ based on replicate analyses of a $10 \mu \mathrm{g} / \mathrm{L}$ USGS standard reference sample. The stock solution concentration was measured from dilution of each one of the starting solutions. The initial concentration (Initial Conc.) are the calculated arsenic concentration after taking into account the excess liquid from the washing step. The equilibrium concentration in solution was the measured concentrations of each sample from the ICP-OES. The mass of SMZ/ZVI used for calculation of the amount adsorbed is contained in Table C-13. All values are reported to two significant figures.

Table D- 1: Example list of parameters used for HYDRUS-1D simulations. 
Table D- 2: Operating parameters for the four columns tested at the Socorro Springs field site. Columns 1 and 2 contained $8 \times 14$ mesh SMZ/ZVI while columns 3 and 4 contained 14 x 40 mesh SMZ/ZVI. Each column contained 4 liters of each sized material.

Table D- 3: Measured volumes of water treated from the Socorro Springs pilot test using SMZ/ZVI. Columns 1 and 2 contained $8 \times 14$ mesh SMZ/ZVI while columns 3 and 4 contained 14 x 40 mesh SMZ/ZVI. Each column contained 4 liters of each sized material. Error in volume measurements is about $\pm 2 \%$ based on meter calibration

Table D- 4: Measured pore volumes (PV) from the Socorro Springs pilot test using SMZ/ZVI. Columns 1 and 2 contained $8 \times 14$ mesh SMZ/ZVI while columns 3 and 4 contained 14 x 40 mesh SMZ/ZVI. Each column contained 4 liters of each sized material. Error in volume measurements is about $\pm 2 \%$ based on meter calibration.

Table D- 5: Measured arsenic concentrations from the Socorro Springs pilot test using SMZ/ZVI. Columns 1 and 2 contained 8 x 14 mesh SMZ/ZVI while columns 3 and 4 contained 14 x 40 mesh SMZ/ZVI. Each column contained $3 \mathrm{~kg}$ of each sized material. Concentration measurement error is $\pm 3 \%$ based on replicate analyses of a $10 \mu \mathrm{g} / \mathrm{L}$ USGS standard reference sample. Blank cells indicated that the parameter was not measured.

Table D- 6: Measured water quality parameters for the influent water in the Socorro Springs SMZ/ZVI field test. A range of values is listed for the free $\mathrm{Cl}_{2}$ based on the color of the test strip used for determining the free chlorine content

Table D- 7: Measured effluent water quality parameters for column 1 during the Socorro Springs SMZ/ZVI field test. Column 1 was filled with 8-14 mesh of SMZ/ZVI

Table D- 8: Measured effluent water quality parameters for column 2 during the Socorro Springs SMZ/ZVI field test. Column 2 was started at a later date due to problems with the plumbing leaking. Column 2 contained 8-14 mesh SMZ/ZVI

Table D- 9: Measured effluent water quality parameters for column 3 during the Socorro Springs SMZ/ZVI field test. Column 3 contained 14-40 mesh SMZ/ZVI.

Table D- 10: Measured effluent water quality parameters for column 4 during the Socorro Springs SMZ/ZVI field test. Column 4 was started at a later date due to leaks in the plumbing. Column 4 contained 14-40 mesh SMZ/ZVI. 
Table D- 11: List of operating parameters for the $30 \mathrm{~cm}$ lab operated column.

Three other columns nearly identical to the column listed here were tested in the same fashion, but filtering of the effluent before analysis was not conducted. Those column tests have similar results, but are not included in the data or analysis.

Table D- 12: Measured column discharge volumes, arsenic concentrations, and flowrates for the $30 \mathrm{~cm}$ lab column. Errors in volume measurements are less than $100 \mathrm{~mL}$ per day; all volumes were measured in a $1 \mathrm{~L}$ graduated cylinder. Flowrates were measured using a $25 \mathrm{~mL}$ graduated cylinder and are accurate to $\pm 0.1 \mathrm{~mL} / \mathrm{min}$. Concentration measurement error is $\pm 3 \%$ based on replicate analyses of a $10 \mu \mathrm{g} / \mathrm{L}$ USGS standard reference sample.

Table D- 13: Operating parameters measured during the operation of the $9 \mathrm{~cm} \mathrm{pH}$ adjusted SMZ/ZVI and zeolite column. The zeolite column was run in series after the SMZ/ZVI column. Concentration measurement error is $\pm 3 \%$ based on replicate analyses of a $10 \mu \mathrm{g} / \mathrm{L}$ USGS standard reference sample.

Table D- 14: Measured column discharge volumes, arsenic concentrations, and flowrates for the $9 \mathrm{~cm} \mathrm{pH}$ adjusted lab column. The measured pore volumes are in terms of the SMZ/ZVI column. The zeolite column had a slightly smaller pore volume (Table D-8) and would have had $\sim 115$ $\%$ more pore volumes. The volumes were based on measurements of a collection bottle that was weighed after each sampling. Concentration measurement error is $\pm 3 \%$ based on replicate analyses of a $10 \mu \mathrm{g} / \mathrm{L}$ USGS standard reference sample.

Table D- 15: Measured column discharge parameters for the $9 \mathrm{~cm} \mathrm{pH}$ adjusted SMZ/ZVI - raw zeolite column. The parameters were measured in a small flow cell using a PCD-650 Oakton multiparameter water meter. The $\mathrm{pH}$, conductivity, and dissolved oxygen (DO) were calibrated or checked against standards every day. The volumes were based on measurements of a collection bottle that was weighed after each sampling.

Table D- 16: Measured influent parameters for the $9 \mathrm{~cm} \mathrm{pH}$ adjusted SMZ/ZVI and raw zeolite column. The influent water consisted of Socorro Springs water that was hauled in using $50 \mathrm{~L}$ carboys and then $\mathrm{pH}$ adjusted using concentrated $\mathrm{HCl}$. Blank cells indicated that the parameter was not measured.

Table E- 1: Measured iron concentrations of each IMZ preparation. IMZ-4 preparation was not completed and no analyses on the media were performed. 
Table E- 2: Measured surface area for selected IMZ preparations. MBET stands for multi-point BET surface area analysis; SBET stands for single-point BET surface area analysis. The time and temperature listed after the sample ID is the degassing time and degassing temperature. The corrected surface area was multiplied by the average correction factor calculated each day from the quantachrome standards.

Table E- 3: Measured surface area of the supplied Quantachrome standard. The standard was measured each time with a $3 \mathrm{hr}$ degassing period at $300^{\circ}$ C. The listed surface area for the standard was $107.56 \mathrm{~m}^{2} / \mathrm{g}$. The measured surface area for each IMZ preparation was corrected based on these surface area analyses.

Table E- 4: Raw data obtained for the batch experiment isotherms. All concentrations reflect measured total arsenic. Concentration measurement error is $\pm 3 \%$ based on replicate analyses of a $10 \mu \mathrm{g} / \mathrm{L}$ USGS standard reference sample. The stock solution concentration was measured from dilution of each one of the starting solutions. The initial concentration (Initial Conc.) are the calculated arsenic concentration after taking into account the excess liquid from the washing step. The equilibrium concentration in solution was the measured concentrations of each sample from the ICP-OES. All concentration values are reported to two significant figures.

Table E- 5: Graphically fitted parameters to each isotherm using the linear Freundlich equation. Note that IMZ-2 had a very poor fit to the Freundlich Isotherm. The \pm values are based on standard errors from regression analysis.

Table E- 6: Graphically fitted parameters to each isotherm using the linear Langmuir equation. Note that the adsorption behavior of IMZ-2 and raw zeolite was poorly described by the Langmuir Isotherm. The \pm values are based on standard errors from regression analysis.

Table E- 7: Measured parameters from the $10.5 \mathrm{~cm}$ IMZ-8 column. All concentrations reflect total arsenic concentrations. Concentration measurement error is $\pm 3 \%$ based on replicate analyses of a $10 \mu \mathrm{g} / \mathrm{L}$ USGS standard reference sample. Volumes were measured by weighing an effluent container with each sampling.

Table E- 8: Measured effluent water parameters of the $10.5 \mathrm{~cm}$ IMZ-8 column. 174

Table E- 9: Measured influent parameters for the $9 \mathrm{~cm} \mathrm{pH}$ adjusted SMZ/ZVI and raw zeolite column. The influent water consisted of Socorro Springs water that was hauled in using $50 \mathrm{~L}$ carboys and then $\mathrm{pH}$ adjusted using concentrated $\mathrm{HCl}$. 


\section{THESIS INTRODUCTION}

The following manuscript contains three separate papers that have been written in a format for submission to a professional journal. In terms of chronological order, Appendix A contains the first of these papers that is entitled "2,4-Dinitrotoluene Degradation using Surfactant-Modified Zeolite/ Zero-Valent Iron (SMZ/ZVI)." The work for this paper was performed during the summer and fall of 2007. My original research for this thesis was going to look at the remediation of explosive contaminants using SMZ/ZVI. After the work performed during the summer, my advisor (Rob Bowman) and I decided to pursue a different path.

The next topic that we decided to work with was arsenic removal using SMZ/ZVI. This topic came about due to preliminary testing of the SMZ/ZVI by a group at Sandia National Laboratories testing various arsenic adsorptive media at Socorro Springs. The section in the thesis entitled Article I - "Arsenic Removal Using Surfactant-Modified Zeolite/ Zero-Valent Iron (SMZ/ZVI)" presents our findings. After looking at the results, Rob and I decided to try and develop an iron-modified zeolite that would have a higher arsenic adsorption capacity than the SMZ/ZVI. Rob died shortly after we had made this decision.

I continued on the chosen path and developed eight IMZ formulations from several different production schemes. The second section of the thesis titled Article II - "Arsenic Removal using Iron-Modified Zeolite (IMZ)" presents our findings. The attached appendices contain the data that was used in each paper. Each paper has its own abstract, methods, results, conclusion, and references. An inclusive reference for the first two chapters is also provided. 


\title{
ARTICLE I. \\ Arsenic Removal Using Iron-Modified Zeolite/ Zero-Valent Iron (SMZ/ZVI)
}

\author{
Jaron R. Andrews \\ Robert S. Bowman \\ New Mexico Institute of Mining and Technology
}

\begin{abstract}
We determined the ability of Surfactant Modified Zeolite/ Zero-Valent Iron (SMZ/ZVI) to remove arsenic from a municipal water source. Arsenic is a common natural groundwater species that has received increased attention due to the reduction of the Maximum Contaminant Level (MCL) from $50 \mu \mathrm{g} / \mathrm{L}$ to $10 \mu \mathrm{g} / \mathrm{L}$ by the Environmental Protection Agency (EPA). The SMZ/ZVI was mechanically crushed and sieved to a particle size of $1.41 \mathrm{~mm}-2.38 \mathrm{~mm}(8-14 \mathrm{mesh})$ for all batch experiments. The batch experiments were performed in the lab to estimate the adsorption capacity, the effect of $\mathrm{pH}$ on adsorption, and the rate of adsorption. All batch tests were performed using synthetic water based on the chemistry of the Socorro Springs water located near Socorro, New Mexico. Lab experiments were accompanied by a field column test at a nearby wellhead and several smaller scale column tests conducted in the lab. The water used in the column tests was sourced from the Socorro Springs wellhead in Socorro, NM and contained about $44 \mu \mathrm{g} / \mathrm{L}$ arsenate. Influent and effluent arsenic concentrations along with flowrates were measured to calculate the volume of water that can be treated to below EPA specifications. All arsenic concentrations were measured using a hydride generation method coupled with Inductively Coupled Plasma-Optical Emission Spectroscopy (ICP-OES).
\end{abstract}


The batch experiments showed that the SMZ/ZVI has a maximum arsenic adsorption capacity as calculated by the Langmuir isotherm of $512 \mathrm{mg} / \mathrm{kg}$. The $\mathrm{pH}$ study showed that maximum arsenic adsorption occurs at $\mathrm{pH} 6.5$ and that sorption decreases below or above this $\mathrm{pH}$ value. The kinetic studies showed that $95 \%$ adsorption is achieved in less than 2 minutes at low concentrations $(66 \mu \mathrm{g} / \mathrm{L})$ and within 20 minutes at high arsenic concentrations $(0.78 \mathrm{mg} / \mathrm{L})$. A Toxicity Characteristic Leaching Procedure (TCLP) analysis was performed and showed that the spent media loaded with $25 \mathrm{mg}$ arsenic per $\mathrm{kg}$ material can be safely disposed in a landfill. Lab-based column studies showed that with long column residence times (40 minutes), SMZ/ZVI could treat about 200 pore volumes of the Socorro Springs water below an arsenic concentration of $10 \mu \mathrm{g} / \mathrm{L}$. With water adjusted to $\mathrm{pH}$ 6.6, SMZ/ZVI treated about 1000 pore volumes of the Socorro Springs water below an arsenic concentration of $10 \mu \mathrm{g} / \mathrm{L}$. All column experiments showed lower arsenic adsorption than in batch experiments.

The lack of correlation between the estimated adsorption capacities from batch experiments and column studies is believed to be due to the availability of adsorption sites. The production of fine iron particles during batch experiment shaking may have led to an overestimation of removal capacity. Adsorptive competition with high concentrations of silica (25 mg/L) and low intraparticle diffusion rates are also believed to have led to low adsorption in column experiments. 


\subsection{INTRODUCTION}

The maximum contaminant level (MCL) for arsenic in drinking water was changed in 2001 by the EPA from $50 \mu \mathrm{g} / \mathrm{L}$ to $10 \mu \mathrm{g} / \mathrm{L}$ (EPA, 2001). The new drinking water regulations is estimated to affect about 3000 municipal water systems and 11 million people in the United States (EPA, 2000). Additionally, millions of people worldwide consume water with arsenic concentrations above $10 \mu \mathrm{g} / \mathrm{L}$ (WHO, 1993). Arsenic can concentrate in the liver, kidneys, and skin by ingestion of groundwater over many years (Wu et al., 1989). Several studies have found dose-response relations between arsenic consumption in drinking water and cancers of the bladder, kidneys, skin, lungs, and cancers of the prostate and liver in males (Wu et al., 1989, Bates et al. 1992).

Arsenic exists in groundwater predominantly as inorganic arsenite, As(III) $\left(\mathrm{H}_{3} \mathrm{AsO}_{3}, \mathrm{H}_{2} \mathrm{AsO}_{3}{ }^{-1}, \mathrm{HAsO}_{3}{ }^{-2}, \mathrm{AsO}_{3}{ }^{-3}\right)$, and arsenate, $\mathrm{As}(\mathrm{V})\left(\mathrm{H}_{3} \mathrm{AsO}_{4}, \mathrm{H}_{2} \mathrm{AsO}_{4}{ }^{-1}\right.$, $\mathrm{HAsO}_{4}{ }^{-2}, \mathrm{AsO}_{4}^{-3}$ ) (Ferguson and Garvis, 1972). Arsenite As(III) typically exists under anoxic conditions while arsenate $\mathrm{As}(\mathrm{V})$ typically exists under oxic conditions. Numerous remediation technologies have been developed to treat the large quantities of contaminated groundwater economically. The EPA's list of best available technologies for arsenic removal include: ion exchange, activated alumina, reverse osmosis, modified coagulation/ filtration, modified lime softening, electrodialysis reversal, and oxidation/filtration (EPA, 2000).

Several investigators have explored using zero-valent iron (ZVI) filings to remove arsenic (Su and Puls, 1997; Farrell et al., 2001; Bang et al., 2005a, 2005b; Melitas et al., 2002; Nikolaidis et al., 2003). Zero-valent iron corrodes in aqueous 
solutions to produce iron oxides such as magnetite and maghemite on the ZVI surface (Oblonsky et al., 2000). The removal mechanism for both As(III) and As(V) compounds involves adsorption by iron oxides (Su and Puls, 1997; Lackovic et al., 2000; Farrell et al., 2001; Su and Puls, 2001a). Studies using X-ray adsorption spectroscopy showed that products after arsenic adsorption consisted of inner-sphere $\mathrm{As}(\mathrm{III})$ and $\mathrm{As}(\mathrm{V})$ mono- and bi-dentate complexes between arsenic species and ferric hydroxides (Goldberg, 1986; Fendorf et al., 1997; Manning et al., 1998; Farrell et al., 2001; Manning et al., 2002; Nikolaidis et al., 2003). The actual adsorption of arsenic is thought to be controlled by two processes: generation of iron hydroxide corrosion sites and the ability of arsenic to reach adsorption sites via diffusion (Fuller et al., 1993; Melitas et al., 2002).

Elizalde- Gonzalez et al. (2001) stated that in aqueous solutions iron oxides can form oxy-hydroxides that can undergo protonation or deprotonation depending on the $\mathrm{pH}$; this can produce a positive or negative surface for arsenic adsorption:

$$
\begin{gathered}
\equiv \mathrm{Fe}-\mathrm{OH}+\mathrm{H}^{+} \leftrightarrow \equiv \mathrm{Fe}-\mathrm{OH}_{2}^{+} \\
\equiv \mathrm{Fe}-\mathrm{OH} \leftrightarrow \mathrm{H}^{+}+\equiv \mathrm{Fe}-\mathrm{O}^{-}
\end{gathered}
$$

In the first case, arsenate adsorption can occur through either non-specific columbic interactions (outer-sphere adsorption):

$$
\equiv \mathrm{Fe}-\mathrm{OH}_{2}{ }^{+}+\mathrm{H}_{2} \mathrm{AsO}_{4}{ }^{-} \leftrightarrow \equiv \mathrm{Fe}-\mathrm{OH}_{2}{ }^{+} \ldots{ }^{-} \mathrm{O}_{4} \mathrm{AsH}_{2}
$$

Or, they can undergo ligand exchange on the surface (inner-sphere adsorption) (Elizalde- Gonzalez et al., 2001; Jeon et al., 2009):

$$
\begin{aligned}
& \equiv \mathrm{Fe}-\mathrm{OH}+\mathrm{H}_{2} \mathrm{AsO}_{4}{ }^{-} \leftrightarrow \equiv \mathrm{Fe}-\mathrm{OAsO}_{3} \mathrm{H}_{2}+\mathrm{OH}^{-} \\
& \equiv \mathrm{Fe}-\mathrm{OH}_{2}{ }^{+}+\mathrm{H}_{2} \mathrm{AsO}_{4}{ }^{-} \leftrightarrow \equiv \mathrm{Fe}-\mathrm{OAsO}_{3} \mathrm{H}_{2}+\mathrm{H}_{2} \mathrm{O}
\end{aligned}
$$




$$
\begin{gathered}
\equiv \mathrm{Fe}-\mathrm{OH}+\mathrm{HAsO}_{4}{ }^{2-} \leftrightarrow \equiv \mathrm{Fe}-\mathrm{OAsO}_{3} \mathrm{H}^{-}+\mathrm{OH}^{-} \\
2 \equiv \mathrm{Fe}-\mathrm{OH}+\mathrm{HAsO}_{4}{ }^{2-} \leftrightarrow \equiv \mathrm{Fe}_{2}-\mathrm{O}_{2} \mathrm{AsO}_{2} \mathrm{H}+2 \mathrm{OH}^{-}
\end{gathered}
$$

Surfactant-modified zeolite/ zero-valent iron (SMZ/ZVI) is a proposed

medium for arsenic removal that has about $50 \% \mathrm{ZVI}$ and has shown promise in other remediation schemes. Surfactant-modified zeolite (SMZ) refers to a zeolite that has been altered by attaching long surfactant molecules to the surface. These surfactant molecules consist of a non-polar carbon chain and a polar head group (a quaternary amine); the surfactant forms a bilayer on the zeolite surface such that two surfactant molecules are attracted to one another through their non-polar tail groups and the polar head groups are exposed. The surfactant-modified zeolite (SMZ) contained within the material has been shown by Bowman (2003) to effectively remove pathogens, chlorinated hydrocarbons, chromate, and organics in oilfield waters. Sullivan et al. (2003) have also shown that SMZ is effective in removing arsenic from soil leachates. SMZ/ZVI is effective in removing and chemically reducing contaminants such as perchloroethylene (PCE) and chromate (Li et al., 1999, Zhang et al., 2002).

The combination of these two effective contaminant remediation materials may provide a low-cost adsorbent to treat several different types of contaminants. The SMZ/ZVI material used in these experiments was originally produced to be used in a permeable reactive barrier for treatment of chlorinated solvents and chromate removal.

The goal of the current study is to evaluate the ability of SMZ/ZVI to remove arsenic from a municipal water source with relatively low arsenic concentrations (10 $100 \mu \mathrm{g} / \mathrm{L})$. The water used in the study consists of natural spring water from the Socorro Springs in Socorro, NM, or synthetic lab water spiked with arsenate As(V). 
To test the capability of arsenic removal using SMZ/ZVI, several test tube shaking experiments, small-scale column transport experiments, and larger column transport experiments at a field site were conducted. 


\subsection{MATERIALS AND METHODS}

\subsubsection{Water Solutions}

Two different water solutions were used in experiments; the first solution was a synthetic water prepared in the lab and the second was spring water sourced from the Socorro Springs wellhead. The synthetic water solution was made by adding $0.42 \mathrm{~g}$ of $\mathrm{NaHCO}_{3}, 0.20 \mathrm{~g}$ of $\mathrm{CaCl}_{2}$, and $0.150 \mathrm{~g}$ of $\mathrm{MgSO}_{4}$ to $2 \mathrm{~L}$ of $18 \mathrm{M} \Omega$ reverse-osmosis water. The $18 \mathrm{M} \Omega$ reverse-osmosis water will be referred to as "Type I" water throughout the experiment. The synthetic water solution was used to simulate the major ion chemistry of the Socorro Springs water. The Socorro Springs wellhead water is a combination of water from two natural springs that is mixed upstream of the wellhead. The water is warm year-round $\left(\sim 30-35{ }^{\circ} \mathrm{C}\right)$ and has an arsenic concentration of 40-45 $\mu \mathrm{g} / \mathrm{L}$. Table 1-1 contains a comparison of the water chemistry of the synthetic water solution and the Socorro Springs water. The Socorro Springs water was transported to the lab using $20 \mathrm{~L}$ and $50 \mathrm{~L}$ carboys and was not treated or altered. The water was stored and used at room temperature $\left(21^{\circ} \mathrm{C}\right)$.

\subsubsection{Arsenic Analyses}

All water samples were analyzed for arsenic using Inductively Coupled Plasma-Optical Emission Spectroscopy (ICP-OES) with a continuous flow hydride generator (model: Optima 5300 DV, Perkin Elmer, Waltham, Massachusetts). The hydride generation manifold and reagents are described by Bosnak and Davidowski (2004); arsenic standards and reagents were made fresh for each analysis. Standard concentrations ranged from $1 \mu \mathrm{g} / \mathrm{L}$ up to $1,000 \mu \mathrm{g} / \mathrm{L}$; quality control standards from 
the United States Geological Survey (USGS) standard reference samples program were used to check the standards accuracy. An arsenic detection limit of $0.05 \mu \mathrm{g} / \mathrm{L}$ was found based on the standard deviation of 10 consecutive measurements of a 1 $\mu \mathrm{g} / \mathrm{L}$ standard. The maximum error in arsenic concentrations was $\pm 3 \%$ based on replicate analyses of a $10 \mu \mathrm{g} / \mathrm{L}$ USGS standard conducted during each arsenic analysis. The arsenic was only analyzed for total arsenic and not speciated. Further information about the instrument setup and measurement conditions can be found in Appendix F.

\subsubsection{SMZ/ZVI Properties}

The SMZ/ZVI used in this experiment was made using a silicate foam base that was then coated with a slurry of hexadecyltrimethylammonium (HDTMA) surfactant, zeolite, and iron filings (Bowman et al., 2002). The base substrate foam is composed of approximately $15 \% \mathrm{Na}_{2} \mathrm{O}, 10 \% \mathrm{CaO}, 5-8 \% \mathrm{Al}_{2} \mathrm{O}_{3}, 65 \%+\mathrm{SiO}_{2}$, plus small amount of $\mathrm{MgO}, \mathrm{TiO}_{2}, \mathrm{Fe}_{2} \mathrm{O}_{3}$, and $\mathrm{MnO}_{2}$ (Bowman et al., 2002); it is made by combing soluble sodium and aluminum silicates with recycled glass, powders, calcium powders, additional silicate minerals, special surfactants, and a gassing agent. The zeolite was sourced from the St. Cloud Mine near Winston, NM and consisted of $74 \%$ clinoptilolite, $10 \%$ feldspar, $10 \%$ quartz and cristobalite, $5 \%$ illite, and $1 \%$ smectite (Sullivan et al., 1997). The surfactant used was Carsoquat CT-429, and the iron powder was obtained from Peerless Metal Powders and Abrasive. The final SMZ/ZVI cubes $(2.5 \mathrm{~cm})$ are estimated to consist of $49 \%$ iron, $34 \%$ glass foam, $16 \%$ zeolite, and 
1\% HDTMA by mass (Bowman et al., 2002). The details of the SMZ/ZVI

production process can be found in Bowman et al. (2002).

These cubes were broken into smaller pieces using mechanical rock crushers and were then sieved to 8-14 mesh (2.4-1.4 mm) for these experiments. The crushed media has a bulk density of $0.72 \mathrm{~g} / \mathrm{cm}^{3}$ and a porosity of 0.74 .

\subsubsection{Batch Experiments}

All batch experiments were performed using $40 \mathrm{~mL}$ centrifuge tubes containing five grams of 8-14 mesh SMZ/ZVI mixed with $20 \mathrm{~mL}$ of a synthetic water solution spiked with varying arsenic concentrations. Arsenic(V) solutions were prepared from sodium arsenate heptahydrate salts $\left(\mathrm{Na}_{2} \mathrm{HAsO}_{4} \bullet 7 \mathrm{H}_{2} \mathrm{O}\right)$ diluted using the synthetic water solution. Before shaking and equilibration, each tube was rinsed four times with the synthetic water solution. The rinsing consisted of adding $30 \mathrm{~mL}$ of the synthetic water solution to the centrifuge tube containing $5 \mathrm{~g}$ of SMZ/ZVI and then gently shaking back and forth by hand. The supernatant was then poured off with all suspended iron fines. This removed on average $0.1 \mathrm{~g}$ of fine iron material from each sample. The washing pre-step was performed to simulate the type of particle removal that would occur during column experiments.

An arsenic adsorption comparison study was performed between the Socorro Springs chlorinated feed water, Socorro Springs unchlorinated feed water, and labprepared synthetic water. Each water solution was spiked with $\mathrm{As}(\mathrm{V})$ to a final concentration of $3.3 \mathrm{mg} / \mathrm{L} \mathrm{As}(\mathrm{V})$. Twenty milliliters of each solution was mixed with $5 \mathrm{~g}$ of the SMZ/ZVI material and then equilibrated for one hour at $17 \mathrm{RPM}$ at $25^{\circ} \mathrm{C}$; 
triplicates of each water sample type were tested. The samples were centrifuged at $2,200 \times \mathrm{g}$ for 5 minutes; the supernatant was then decanted and filtered through 0.2 $\mu \mathrm{m}$ filters and acidified using concentrated $\mathrm{HCl}$ to $\mathrm{pH}<2$. This analysis was conducted to verify that the synthetic water provided similar behavior compared to the natural spring water and that the chlorinated water did not interfere with the arsenic adsorption.

The rate of arsenic adsorption was determined using several different vials that were sacrificed at various time intervals. Two kinetic studies were performed; the first used a $0.87 \mathrm{mg} / \mathrm{L}$ arsenic solution with long equilibration times (20 -720 minutes) and the second used a $67 \mu \mathrm{g} / \mathrm{L}$ arsenic solution with short equilibration times (2-60 minutes). Five grams of SMZ/ZVI was mixed with $20 \mathrm{~mL}$ of a synthetic water solution; duplicate tubes were prepared for each time period of interest. The tubes were then capped and placed on an end-over-end shaker at 17 RPM; at various time intervals the tubes were removed and centrifuged at 2,200 $\times \mathrm{g}$ for 5 minutes. All samples were shaken using a New Brunswick Scientific Innova 4335 incubator/ shaker at $25^{\circ} \mathrm{C}$ and centrifuged using a Beckman J2-MI centrifuge. The supernatant was then decanted and filtered through $0.2 \mu \mathrm{m}$ filters and acidified using concentrated $\mathrm{HCl}$ to $\mathrm{pH}<2$.

Isotherms were calculated using $5 \mathrm{~g}$ of SMZ/ZVI and $20 \mathrm{~mL}$ of synthetic water solution spiked with arsenic. The concentrations ranged from $10 \mathrm{mg} / \mathrm{L}$ to $400 \mathrm{mg} / \mathrm{L}$ As(V). The SMZ/ZVI and arsenic solutions were equilibrated for 3 hours on an endover-end shaker at 17 RPM. Duplicate centrifuge tubes were then removed and centrifuged at $2200 \times \mathrm{g}$ for 5 minutes. The supernatant was then decanted and filtered 
through $0.2 \mu \mathrm{m}$ filters; the $\mathrm{pH}$ was recorded and then the samples acidified to $\mathrm{pH}<2$ using concentrated $\mathrm{HCl}$.

The $\mathrm{pH}$ dependence of the arsenic adsorption was determined by using $5 \mathrm{~g}$ of SMZ/ZVI material and $20 \mathrm{~mL}$ of a synthetic arsenic spiked water mixed in a centrifuge tube. A stock $18 \mathrm{mg} / \mathrm{L} \mathrm{As}(\mathrm{V})$ solution was prepared and divided into thirteen different beakers. Each beaker was adjusted to a specific $\mathrm{pH}$ value ranging from $\mathrm{pH} 0.15$ up to $\mathrm{pH}$ 12.0. Each solution was then added to two duplicate centrifuge tubes containing $5 \mathrm{~g}$ of SMZ/ZVI each and equilibrated for 2 hours on an end-overend shaker at 17 RPM. Each sample was then centrifuged at $2200 \times \mathrm{g}$ for five minutes, decanted, and filtered through $0.2 \mu \mathrm{m}$ filters; the final $\mathrm{pH}$ of each sample was then recorded before being acidified to $\mathrm{pH}<2$.

Finally, a Toxicity Characteristic Leaching Procedure (TCLP) test was performed on the SMZ/ZVI material to see if the media could be disposed in a landfill after use. The TCLP procedures can be found in US Environmental Protection Agency (EPA) Test Method 1311. A short summary of the method follows. Five grams of the SMZ/ZVI material that had been loaded to $25 \mathrm{mg}$ As/ $\mathrm{kg}$ media was mixed with 20 $\mathrm{mL}$ of $\mathrm{pH} 2.88$ acetic acid solution for 20 hours at 30 RPM. After centrifugation the supernatant was decanted, filtered through $0.6 \mu \mathrm{m}$ filters, then acid preserved. The resulting arsenic concentration of the supernatant is required to be less than $5 \mathrm{mg} / \mathrm{L}$ for safe disposal.

\subsubsection{Column Studies}

Two separate small scale column studies were conducted in the lab using water transported from the Socorro Springs. The first set of experiments used glass columns 
$30 \mathrm{~cm}$ in length and $5 \mathrm{~cm}$ in diameter. The SMZ/ZVI media (8-14 mesh) was drypacked in the columns and ambient water from the Socorro Springs was pumped through the column using a peristaltic pump. A volumetric flowrate of $11.3 \mathrm{~mL} / \mathrm{min}$ resulted in an average pore water velocity of $0.77 \mathrm{~cm} / \mathrm{min}$ and a column residence time of about 40 minutes. A $30 \mathrm{~mL}$ sample was collected about every 12 hours and filtered through a $0.2 \mu \mathrm{m}$ filter; the $\mathrm{pH}$ of each sample was recorded before being acidified to $\mathrm{pH}<2$.

The second set of experiments used two identical glass columns $9 \mathrm{~cm}$ in length and $2.5 \mathrm{~cm}$ in diameter. The columns were run in series with the first column containing 8-14 mesh SMZ/ZVI; the second column contained raw zeolite 14 - 40 mesh $(0.4 \mathrm{~mm}-1.4 \mathrm{~mm})$. The raw zeolite was sourced from the St. Cloud Mine and has the same chemical composition as listed in Section 1.2.3. A flowrate of 6.0 $\mathrm{mL} / \mathrm{min}$ was used and resulted in a pore water velocity of $1.7 \mathrm{~cm} / \mathrm{sec}$ and a residence time of 7.4 minutes. The $\mathrm{pH}$ of the Socorro Springs influent water was adjusted to 6.6 using concentrated $\mathrm{HCl}$. The column was operated until an effluent arsenic concentration of $10 \mu \mathrm{g} / \mathrm{L}$ was observed.

In addition to the lab-based studies, a larger pilot scale analysis was conducted at the Socorro Springs wellhead chlorination building. The tests conducted at the wellhead were performed prior to lab-based studies due to the availability of the facility. The building had been formerly used by a group at Sandia National Laboratories to evaluate arsenic removal media. The building was equipped with a pump and plumbing to conduct larger scale column tests; the columns consisted of clear PVC pipe 3 in. in diameter and $6 \mathrm{ft}$ in length. Four columns were filled with $3 \mathrm{~kg}$ 
of the SMZ/ZVI material. Each column was outfitted with a turbine flowmeter and additional valves for water sample collection. A $250 \mathrm{~mL}$ water sample was taken initially every 12 hours from each column. The frequency of sampling was reduced after 2 days. Sampling was continued every day or every other day for 16 days until the operation was stopped. The flowrate of each column was monitored with a Signet 2100 turbine flow sensor and recorded using a DI-148U data logger from DATAQ instruments. The water used for the column experiments was sourced directly from the municipal water lines after chlorination and contained $\sim 0.7 \mathrm{mg} / \mathrm{L}$ free chlorine. Further information about the design and construction of the plumbing in the building can be found in Siegel et al. (2006).

The water parameters of the effluent were continuously recorded for one of the columns during the experiment; water parameters of the influent feed water and the other three column effluents were taken with each arsenic water sample. The measured parameters included the $\mathrm{pH}$, conductivity, dissolved oxygen, and temperature; all were recorded using an Oakton PCD-650 multiparameter meter. All readings were measured in flow cell and were allowed to equilibrate for at least 10 minutes. The free chlorine of the water was analyzed using commercial pool test strips designed for a range from $0.1 \mathrm{mg} / \mathrm{L}$ to $5 \mathrm{mg} / \mathrm{L}$. Appendix D contains the measured water parameter data for each column.

\subsubsection{Modeling}

The computer modeling program HYDRUS-1D was used for simulating column experiment results and for analyzing the collected data. HYDRUS-1D was 
developed to simulate vertical flow of water, solutes, and heat in a variably saturated vadose zone. HYDRUS-1D numerically solves the Richards equation for variably saturated flow and the convection-dispersion equation for solute transport; the program uses Galerkin-type linear finite element schemes. The background information and governing equations can be found in Simunek et al. (2008). The program was used in this study to simulate arsenic breakthrough curves in the column studies and for post-data analysis for fitting adsorption parameters to the breakthrough curves. In each model scenario, the non-linear adsorption parameters were used. The general equation used to model non-linear adsorption is shown below (Simunek et al., 2008):

$$
\begin{aligned}
& \qquad s=\frac{k c^{\beta}}{1+\eta c^{\beta}} \\
& s=\text { adsorbed concentration }[\mathrm{mg} / \mathrm{kg}] \\
& c=\text { solution concentration }[\mathrm{mg} / \mathrm{L}] \\
& k=\text { empirical adsorption coefficient }[\mathrm{L} / \mathrm{mg}] \\
& \eta=\text { empirical adsorption coefficient }[\mathrm{L} / \mathrm{mg}] \\
& \beta=\text { empirical adsorption coefficient }[-]
\end{aligned}
$$

The Freundlich, Langmuir, and linear isotherm equations are all special cases of this equation. When $\eta=0$ the equation becomes the Freundlich adsorption isotherm; when $\beta=1$ the equation becomes the Langmuir isotherm, and when $\eta=0$ and $\beta=1$, the equation becomes the linear adsorption isotherm. An example set of parameters used to predict the breakthrough curves from batch experiment data is listed in Appendix D. The inverse solver option in the program allowed for the observed column effluent volume and arsenic concentration to be entered, and then the adsorption parameters were optimized to fit the observed data. In all cases, the 
dispersivity of the column was set to be the media bed length; this was used because dispersivities greater then $10^{7} \mathrm{~cm}$ were obtained if the parameter was fitted using the software.

The software was set to always have saturated flow by specifying a unit head gradient across the length of the column; this allowed for the saturated conductivity of the media to be altered to match the observed flowrate in the columns. The porosity, bulk density, and specific discharge were based on values calculated from weighing the column empty and then filled with water. In each case, the column was specified to be fully saturated and free of air. 


\subsection{RESULTS}

\subsubsection{Kinetics}

The rate of arsenic adsorption was observed to be very fast and be complete within 20 minutes of mixing during batch experiments. Figure 1-1 shows the variation in arsenic concentration in solution with time for several different samples containing SMZ/ZVI. The starting concentration was $0.78 \mathrm{mg} / \mathrm{L}$ and each vial was prepared in duplicate. The kinetic tests show that arsenic adsorption even at high environmental concentrations occurs rapidly and does not desorb with longer mixing times.

A second follow up test was performed using a lower starting concentration of $\sim 60 \mu \mathrm{g} / \mathrm{L}$ (Figure 1-2). The lower concentration test showed that $98 \%$ of the arsenic was adsorbed within 1 minute of mixing. The first 10 minutes of data obtained during the lower concentration kinetic test can be described using a pseudo-first order reaction $(\mathrm{d}[\mathrm{As}] / \mathrm{dt}=-\mathrm{k}[\mathrm{As}])$ with an $\mathrm{R}^{2}$ of 0.81 . The calculated rate constant was 0.18 $\min ^{-1}$ and is comparable to the rate constants found by Mishra and Farrell (2005) of 0.10 to $0.28 \mathrm{~min}^{-1}$ using different types of iron oxides.

The effect of water chemistry on arsenic adsorption showed that the synthetic water had qualities similar to the Socorro Springs municipal water at the concentrations studied. Seen in Figure 1-3 are the results from three different water sources and the arsenic concentration after equilibration for 1 hour; the analysis shows that the final average concentration in solution from the three samples differs by only about $5 \mu \mathrm{g} / \mathrm{L}$. This test shows that the synthetic water has approximately the same behavior as the Socorro Springs water at the arsenic concentration tested. Another conclusion that stems from these experiments is that the chlorination of the feed water 
did not interfere with arsenic adsorption. These results are important because chlorinated water may be necessary for long term treatment operations where biofouling could become a major problem.

\subsubsection{Batch Isotherm}

The batch isotherms results are shown in Figure 1-4 below. The best fit to the data was found to be the Langmuir style isotherm; the Langmuir equation for adsorption of solutes onto solids (Stumm, 1992) is:

$$
\begin{gathered}
\text { Langmuir Equation } \\
\qquad S=\frac{S_{m} K_{L} C}{1+K_{L} C} \\
S=\text { adsorbed concentration }[\mathrm{mg} / \mathrm{kg}] \\
C=\text { concentration in solution }[\mu \mathrm{g} / \mathrm{L}] \\
K_{L}=\text { empirical Langmuir coefficient }[\mathrm{L} / \mu \mathrm{g}] \\
S_{M}=\text { maximum adsorbed concentration }[\mathrm{mg} / \mathrm{kg}]
\end{gathered}
$$

The Langmuir equation above can be rearranged to form a linear equation:

$$
\frac{1}{S}=\frac{1}{S_{m}}+\frac{1}{K_{L} S_{m}} \frac{1}{C}
$$

The parameters $1 / \mathrm{S}$ and 1/C can then be plotted and the empirical coefficients can be calculated based on graphical analysis. Figure 1-5 shows the SMZ/ZVI data plotted according to the linearized Langmuir equation. The inferred maximum sorption capacity $\left(\mathrm{S}_{\mathrm{m}}\right)$ was found to be $512 \pm 251 \mathrm{mg} / \mathrm{kg}$ and the Langmuir coefficient $\left(\mathrm{K}_{\mathrm{L}}\right)$ was found to be $30.9 \pm 13.5 \mathrm{~L} / \mathrm{mg}$.

The results from the batch isotherms are similar to those for other types of adsorptive media that have been used for water treatment; Table 1-2 shows the type of material and the measured $\mathrm{As}(\mathrm{V})$ maximum sorption capacity using the Langmuir 
equation. The performance of SMZ/ZVI is very comparable to other media based on the batch experiments results and encouraged further investigation into transport tests using breakthrough curves from column studies.

\subsection{3 pH Dependence}

Arsenic adsorption onto SMZ/ZVI was found to be highly $\mathrm{pH}$ dependent.

Figure 1-6 shows the results of using 13 different starting solutions containing about $80 \mathrm{mg} / \mathrm{L} \mathrm{As}(\mathrm{V})$ that was adjusted to 13 different $\mathrm{pH}$ values. The $\mathrm{pH}$ values shown in Figure 1-6 are the final $\mathrm{pH}$ values measured after equilibration. This data shows that the maximum adsorption of arsenic onto SMZ/ZVI occurs at a final $\mathrm{pH}$ of 6.5. Further, if the final $\mathrm{pH}$ is above 9 or below 4 , the arsenic concentration is several orders of magnitude higher than at $\mathrm{pH}$ 7. The change in arsenic adsorption with $\mathrm{pH}$ is thought to be due to corrosion of ZVI and the formation of iron hydroxides, a change in the dominant arsenate species, and a change in the surface charge of iron hydroxides.

Bang et al. (2005a) found that the removal of arsenic was directly proportional to the amount of ferric hydroxide precipitate formed; Melitas et al. (2002) similarly found that arsenic adsorption was tied to the rate of formation of $\mathrm{Fe}^{2+}$. The formation of ferric hydroxide precipitates may proceed through corrosion of ZVI according to the equations below (Bang et al., 2005a):

$$
\begin{aligned}
& 2 \mathrm{Fe}^{0}+\mathrm{O}_{2}+4 \mathrm{H}^{+} \leftrightarrow 2 \mathrm{Fe}^{2+}+2 \mathrm{H}_{2} \mathrm{O} \\
& 4 \mathrm{Fe}^{2+}+4 \mathrm{H}^{+}+\mathrm{O}_{2} \leftrightarrow 4 \mathrm{Fe}^{3+}+2 \mathrm{H}_{2} \mathrm{O} \\
& \mathrm{Fe}^{3+}+3 \mathrm{H}_{2} \mathrm{O} \leftrightarrow \mathrm{Fe}(\mathrm{OH})_{3(\mathrm{~s})}+3 \mathrm{H}^{+}
\end{aligned}
$$


From these equations we see that the influence of dissolved oxygen and $\mathrm{pH}$ are important controls on the production of iron oxides. Bang et al. (2005a) found that during batch experiments $\sim 99 \%$ of $\mathrm{As}(\mathrm{V})$ was removed at a $\mathrm{pH}$ of $6,55.5 \%$ was removed at a $\mathrm{pH}$ of 7 , and only $2 \%$ was removed at a $\mathrm{pH} 8$ after 9 hours of mixing. They concluded that the $\mathrm{pH}$ of the water directly influences the production rate of iron hydroxides and ultimately arsenic adsorption. This process seems counter to research that has shown that $\mathrm{Fe}^{2+}$ to $\mathrm{Fe}^{3+}$ oxidation rate decreases two orders of magnitude with a 1 unit drop in $\mathrm{pH}$ (oxidation is quadratically dependent on $\mathrm{OH}^{-}$concentration) (Singer and Stumm, 1970). Similarly, Azher et al. (2008) showed that the time for $90 \%$ oxidation of a $10 \mathrm{mg} / \mathrm{L} \mathrm{Fe}^{2+}$ solution was 7.5 minutes at $\mathrm{pH} 7.3$, while at $\mathrm{pH} 6.8$ it took 43 minutes. However, Azher et al. (2008) also found that the presence of ferric hydroxide precipitates could lead up to a six-fold reduction in this time.

Despite the evidence for slow ferrous iron oxidation, researchers have shown that decreasing $\mathrm{pH}$ leads to increased arsenic removal. Mishra and Farrell (2005) found that with high dissolved oxygen contents $(\sim 9 \mathrm{mg} / \mathrm{L}$ and water $\mathrm{pH}=6.8)$ that the half-life of $\mathrm{Fe}^{2+}$ was only 0.36 minutes based on the kinetic rates reported by Park and Dempsey (2005). They concluded that if the dissolved oxygen content was above 3 $\mathrm{mg} / \mathrm{L}$, then the oxidation of ferrous iron was not the rate limiting step for arsenic adsorption. As long as the dissolved oxygen concentration in solution is kept high ( $>3$ $\mathrm{mg} / \mathrm{L}$ ), ferrous iron oxidation and precipitation of ferric hydroxides is not expected to be the rate limiting step (Mishra and Farrell, 2005). Though the dissolved oxygen content was not measured during batch experiments with SMZ/ZVI, there was headspace left in the centrifuge tubes and the mixing should have resulted in a high 
dissolved oxygen content of the water. Further research looking at the effects of $\mathrm{pH}$ on iron hydroxide production from $\mathrm{Fe}^{0}$ corrosion and its affect on arsenic adsorption is warranted.

The second process that is thought to lead to $\mathrm{pH}$ dependency is competition with hydroxide ions. Elizalde-Gonzalez et al. (2001) and Jeon et al. (2009) reported that arsenate was removed using iron oxi-hydroxides/ oxides through ligand exchange with hydroxide ions:

$$
\begin{aligned}
& \equiv \mathrm{Fe}-\mathrm{OH}+\mathrm{H}_{2} \mathrm{AsO}_{4}{ }^{-} \leftrightarrow \equiv \mathrm{Fe}-\mathrm{OAsO}_{3} \mathrm{H}_{2}+\mathrm{OH}^{-} \\
& \equiv \mathrm{Fe}-\mathrm{OH}_{2}{ }^{+}+\mathrm{H}_{2} \mathrm{AsO}_{4}{ }^{-} \leftrightarrow \equiv \mathrm{Fe}-\mathrm{OAsO}_{3} \mathrm{H}_{2}+\mathrm{H}_{2} \mathrm{O} \\
& \equiv \mathrm{Fe}-\mathrm{OH}+\mathrm{HAsO}_{4}{ }^{2-} \leftrightarrow \equiv \mathrm{Fe}-\mathrm{OAsO}_{3} \mathrm{H}^{-}+\mathrm{OH}^{-} \\
2 & \equiv \mathrm{Fe}-\mathrm{OH}+\mathrm{HAsO}_{4}{ }^{2-} \leftrightarrow \equiv \mathrm{Fe}_{2}-\mathrm{O}_{2} \mathrm{AsO}_{2} \mathrm{H}+2 \mathrm{OH}^{-}
\end{aligned}
$$

Under basic conditions, the iron hydroxide surface is populated with $\mathrm{OH}^{-}$ions and obtains a negative surface charge; this reduced charge results in electrostatic repulsion between iron hydroxide surfaces and arsenate anions. Under strongly acidic conditions, the availability of adsorption sites decreases due to increased iron oxide solubility. Additionally, the dominate arsenate species is the uncharged arsenate species $\left(\mathrm{H}_{3} \mathrm{AsO}_{4} \mathrm{pKa}=2.2\right)$. This uncharged species cannot partake in ligand exchange with hydroxides because it is uncharged.

The reasons listed above help explain the "U" shaped adsorption curve seen in Figure 1-6. Other authors have found that arsenate adsorption is strongly $\mathrm{pH}$ dependent and an adsorption maximum occurs around pH 5 - 7 (Jeong et al, 2007; Jeon et al., 2009). However, some studies have found that arsenic adsorption 
continually increases with decreasing pH (Dixit and Hering, 2003; Yang et al., 2007). The reason for the different $\mathrm{pH}$ dependent behavior is likely media dependent, but may also be due to authors reporting the initial $\mathrm{pH}$ values rather than $\mathrm{pH}$ after equilibration.

One final note about the $\mathrm{pH}$ behavior was the increases in $\mathrm{pH}$ after equilibration; the initial $\mathrm{pH}$ of each solution was several $\mathrm{pH}$ units lower than the final $\mathrm{pH}$ (see Table C-11). The SMZ/ZVI pellets have been shown to raise the $\mathrm{pH}$ of a synthetic water solution to above $\mathrm{pH} 9$ due to release of base from the silicate foam substrate material (Bowman et al., 2002). Additionally, adsorption reactions with arsenate release $\mathrm{OH}^{-}$groups from the iron hydroxide surfaces as a result of ligand exchange (McBride, 1994; Onyango et al., 2003; Jeon et al., 2009). The increase in pH is also expected due to the decomposition of water by ZVI ( $\mathrm{Su}$ and Puls, 2001b):

$$
2 \mathrm{Fe}^{0}+2 \mathrm{H}_{2} \mathrm{O}+\mathrm{O}_{2} \rightarrow 2 \mathrm{Fe}^{2+}+4 \mathrm{OH}^{-}
$$

All of these processes are thought to contribute to an increase in $\mathrm{pH}$ with arsenic adsorption.

\subsubsection{Toxicity Characteristic Leaching Procedure (TCLP)}

The results from the TCLP analysis were used to verify that once the media was saturated with arsenic it could be disposed in a landfill and not be hazardous to human health at a later date. Five grams of the SMZ/ZVI material was loaded with $\sim 25 \mathrm{mg}$ of arsenic per $\mathrm{kg}$ material and then leached with the acetic acid solution. The average concentration after leaching was $0.6 \pm 0.1 \mu \mathrm{g} / \mathrm{L}$ based on four replicate samples. This shows that the addition of the acetic acid solution did not leach 
significant amounts of arsenic from the SMZ/ZVI material; all concentrations after leaching were less than $5 \mu \mathrm{g} / \mathrm{L}$.

The maximum arsenic adsorption capacity was not used for this experiment because the material would only be used until the effluent concentration in water being treated reached $10 \mu \mathrm{g} / \mathrm{L}$. An effluent arsenic concentration above $10 \mu \mathrm{g} / \mathrm{L}$ corresponds with an arsenic loading capacity of about $25 \mathrm{mg} / \mathrm{kg}$ as seen in the column experiments discussed later. In all four duplicate vials, the arsenic concentration in solution was below $5 \mu \mathrm{g} / \mathrm{L}$ and should pose no leaching threat. The $\mathrm{pH}$ of all of the samples after equilibration was near 6.5 , and is closer to the maximum adsorption $\mathrm{pH}$. The neutralization capacity of the SMZ/ZVI is thought to be due to the release of hydroxide from the silicate foam in the material as discussed earlier. Further support for the arsenic remaining fixed to the iron surface even with very high arsenic loadings has been reported. Nikolaidis et al. (2003) performed a TCLP experiment on ZVI that was loaded with $4.4 \mathrm{mg} \mathrm{As} / \mathrm{g}$ of media; even at these high arsenic loadings, they found that the leachate arsenic concentration was below $100 \mu \mathrm{g} / \mathrm{L}$ and could safely be disposed.

\subsubsection{Field Column Studies}

Field column studies were conducted prior to smaller scale lab-based column studies due to the availability of the field lab. Field scale studies would have been performed again after smaller lab tests, but the results suggest that large-scale $\mathrm{pH}$ adjustment would have been necessary. The operating conditions for one of the field scale columns is shown in Table 1-3; four separate columns were run for two weeks at the site, but due to poor performance the field tests were discontinued. 
The results from one of the field columns is shown below in Figure 1-7; the three other field columns had similar results and are included in Appendix D. Overall, the SMZ/ZVI material performed poorly during the field tests. The effluent arsenic concentration immediately rose above $10 \mu \mathrm{g} / \mathrm{L}$ and continued to increase thereafter. The flowrate and lack of $\mathrm{pH}$ adjustment are thought to be the underlying factors for the poor performance. The poor fit using HYDRUS-1D for the field column at early pore volumes may be due to channeling in the column that leads to arsenate ions bypassing available adsorption sites. The column flowrates were based on personal contact between the author and the previous operators of the column at Sandia National Laboratory.

The flowrate of the column was reduced to about $0.3 \mathrm{~L} / \mathrm{min}$ (around 3500 pore volumes) and the effluent arsenic concentration was reduced as well. This observation is consistent with other authors' findings that arsenic adsorption is limited by the rate of transport of arsenic to available adsorption sites. Melitas et al. (2002) found in a column experiment that the amount of iron corrosion products was not the limiting factor in arsenic removal rates, but that arsenic removal was limited by mass transfer within the column. This mass transfer is the ability of the arsenate ion to reach an available adsorption site.

Badruzzaman et al. (2004) described arsenate adsorption onto granular porous metal oxides as occurring through four sequential steps: 1) diffusion through the bulk liquid 2) diffusion through the boundary layer film around the particle 3) intraparticle diffusion and 4) adsorption onto the solid surface. They note that the diffusion through the bulk liquid and adsorption onto the ZVI surface are not the rate limiting steps, but 
the film diffusion and intraparticle diffusion are rate limiting. In their description, they note that film diffusion is a function of the particle size and column hydraulics, while the intraparticle diffusion rate is a function of the type of iron oxide, thickness of the

oxide rind, and pore shape of the oxide surface. They implied that even though ZVI filings have significant amounts of iron corrosion products available, the arsenic adsorption is limited by a thick corrosion rind on the iron surface. This surface leads to mass-transfer resistance for arsenic removal. Further, significant rates of iron corrosion may detrimentally affect the iron oxide porosity and availability of adsorption sites. These reasons would explain the observed relation between the flowrate and the effluent arsenic concentration. With higher flowrates, the arsenic does not have enough time to diffuse into the unoccupied iron hydroxide adsorption sites and is swept through the column via large pore spaces. To look further at the effects of the flowrate and $\mathrm{pH}$, several smaller scale column studies were conducted in the lab.

\subsubsection{Lab Column Test $(30 \mathrm{~cm})$}

The first column test consisted of three $30 \mathrm{~cm}$ glass columns that were filled with SMZ/ZVI and then used with water brought in from the Socorro Springs. The water was stored in $20 \mathrm{~L}$ and $50 \mathrm{~L}$ carboys at room temperature $\left(21^{\circ} \mathrm{C}\right)$. The column operating parameters and characteristics are found in Table 1-4; Figure 1-8 shows the arsenic breakthrough curve for one of the $30 \mathrm{~cm}$ lab columns. The flowrate in these smaller lab columns was reduced in comparison to the field columns and resulted in a lower effluent concentration initially. The SMZ/ZVI lowered the effluent concentrations to below $10 \mu \mathrm{g} / \mathrm{L}$ for the first 200 pore volumes and continued to remove arsenic for the duration of the test (1000 pore volumes). Based on the batch 
experiment data (Figure 4), at an arsenic loading of $\sim 150 \mathrm{mg} / \mathrm{kg}$ the solution concentration should be $\sim 10 \mu \mathrm{g} / \mathrm{L} \mathrm{As}(\mathrm{V})$. Extrapolating these results to the $30 \mathrm{~cm}$ column experiment indicates that the SMZ/ZVI should have removed $\sim 56 \mathrm{mg}$ of arsenic and lasted for over 3,200 pore volumes before the effluent concentration rose above $10 \mu \mathrm{g} / \mathrm{L}$. Based on these column experiments it would seem that the kinetics of the reaction are very slow and contradictory to the batch experiments, or that the batch experiment data cannot be correlated with column transport.

The disagreement between batch experiment results and column studies is not uncommon. Langmuir (1997) notes that the difference is usually due to experimental conditions in batch experiments that do not mimic column behavior. The conditions that are believed to lead to the discrepancy in this case are 1) the rate of mixing and generation of fine iron particles; 2) the diffusion rate of arsenic into the iron hydroxide coating; and 3) the lack of silica anions in the batch experiments.

The physical mixing that occurs during batch experiments caused abrasion of the SMZ/ZVI material and the production of fine iron particles. Even though the media was prewashed to try and eliminate these particles, the iron was not well affixed to the silicate substrate. During column experiments, none of these small particles were present and the effective particle size was larger compared with the batch experiments. Badruzzaman et al. (2004) found that the particle size of granular ferric hydroxide played a key role in the amount of arsenic adsorbed. In a test using several different ZVI size ranges, they found that even though all sample sizes had nearly the same surface area $\left(\sim 240 \mathrm{~m}^{2} / \mathrm{g}\right)$, two of their sample sizes ( 30 x 60 mesh and 10 x 30 mesh) had 50\% and 85\% respectively lower arsenic adsorption capacitates than two 
smaller fractions (60 x 80 mesh and $100 \times 140$ mesh) after 18 days of equilibration. They attributed this large loss of adsorption capacity to intraparticle mass transfer rate limitations.

During batch experiments diffusion of the arsenic into the iron oxides is less limiting because of the high degree of physical mixing and the suspension of fine iron particles in solution. During column experiments there is much less agitation and diffusion becomes much more limiting. This is why the kinetics during batch experiments appear to occur so rapidly, while during column experiments the arsenic appears to adsorb very slowly.

Another possible explanation for the discrepancy with batch experiment data is an inconsistency in the water chemistry. Though a water comparison study was conducted and found that there was not a major difference in the adsorption behavior of the synthetic water and the Socorro Springs water, this was in a batch experiment setting. The differences in water chemistry appear more pronounced in a column setting where there is less physical mixing. Mishra and Farrell (2005) attributed poor arsenic adsorption onto different types of iron oxides due to high concentrations of silica $(30 \mathrm{mg} / \mathrm{L})$. They showed that there is a near linear decrease in arsenic adsorption with increasing silica content and that a silica content of only $0.4 \mathrm{mg} / \mathrm{L}$ caused a $98 \%$ reduction in the amount of arsenic adsorbed. The two major competitors for arsenic removal are the anions of orthosilicic acid $\left(\mathrm{H}_{4} \mathrm{SiO}_{4}\right)$ and phosphate $\left(\mathrm{PO}_{4}{ }^{3-}\right)$. Arsenate, phosphate, and silica species can exist as tetrahedral anions that form inner-sphere complexes with the functional groups at the surface of iron oxides (Su and Puls, 2001b). Phosphate has been shown in previous studies to greatly inhibit arsenate 
adsorption (Su and Puls, 2001b). However, the phosphate concentration in the Socorro Springs water was reported by Partey (2008) to be less than $1 \mathrm{mg} / \mathrm{L}$ and is not thought to be an important competitor.

The Socorro Springs does contain 24.9 ppm silica (Table 1-1); this high silica concentration may compete with arsenic for adsorption and may partly explain the difference in adsorption capacity between the batch experiments and the column experiments. Su and Puls (2001b) found that a $1 \mathrm{mM}$ silica solution had the greatest reduction in arsenic adsorption kinetics compared with phosphate, bicarbonate, chromate, molybdate, nitrate, and sulfate compared to chloride. The SMZ/ZVI material is also composed of a silicate based foam. The combination of the high $\mathrm{pH}$ in the Socorro Springs water and the increase in amorphous silica solubility above $\mathrm{pH} 8$ (Faure, 1998) may have lead to increased adsorptive competition with silica. Though the silica concentration of the batch experiment solutions or the column effluent was not measured, it is hypothesized that the silicate foam was continually dissolved into solution during the column experiments and silica anions were readsorbed by iron hydroxides. The arsenic was in continuous competition with silica species for easily available surface sites; the only available surface sites are deep within the iron hydroxide rind and have limited availability due to slow intraparticle diffusion rates (Westerhoff et al., 2005). These two factors likely contributed to reduced arsenic adsorption and early column breakthrough. The silicate substrate foam is not an optimal choice for arsenic removal, and the use of materials with high soluble silica contents has been discouraged by other authors (Su and Puls, 2001b). 


\subsection{7 pH Adjusted Lab Column Test $(9 \mathrm{~cm})$}

The final column study investigated the effect of $\mathrm{pH}$ on adsorption in a column setting. The test was designed to have optimal conditions for arsenic adsorption and to evaluate the maximum number of pore volumes that could be treated. The influent Socorro Springs water was adjusted to $\mathrm{pH}$ of 6.6 based on the batch experiment data in Figure 1-6. In addition to the lower $\mathrm{pH}$, a second column filled with unmodified zeolite was placed in series after the SMZ/ZVI column. A study by Bang et al. (2005a) showed that the addition of a sand particulate filter at the end of a ZVI column greatly enhanced arsenic removal. They went from being able to treat $\sim 500$ pore volumes with only a ZVI column, to being able to treat over 30,000 pore volumes below $10 \mu \mathrm{g} / \mathrm{L}$ with a ZVI and a sand column. This enhanced removal ability stemmed from the precipitation of dissolved iron onto the sand grains that were then oxidized and precipitated as ferric hydroxides. The ferric hydroxides acted as a new adsorption site and reduced arsenic concentrations coming from the ZVI column from $20-60 \mu \mathrm{g} / \mathrm{L}$ to less than $5 \mu \mathrm{g} / \mathrm{L}$ at the end of the sand column. A similar setup as theirs was implemented by using an unmodified zeolite column in series with a SMZ/ZVI column.

The arsenic breakthrough curve of the dual column system is shown in Figure 1-9. The lower $\mathrm{pH}$ influent water had a dramatic effect on the arsenic removal capacity as now about 1,000 pore volumes were treated to below $10 \mu \mathrm{g} / \mathrm{L}$. This reflects nearly a five-fold increase in arsenic removal capacity compared with the $30 \mathrm{~cm}$ columns. The reason for the large increase in removal capacity is thought to be due to more $\mathrm{Fe}^{0}$ corrosion and reduced competition from silica and $\mathrm{OH}^{-}$anions. 
Several researchers have seen an increase in column performance with lower influent water pH. An experiment conducted by Mishra and Farrell (2005) consisted of using ZVI in a column setting with a column residence times of 8 minutes, an influent $\mathrm{pH}$ of 6.5 , and an influent arsenic concentration of $50 \mu \mathrm{g} / \mathrm{L}$. They concluded that if the dissolved oxygen content was above $3 \mathrm{mg} / \mathrm{L}$, then the oxidation of ferrous iron was not the rate limiting step in the adsorption of arsenic. They noted that an $\mathrm{Fe}^{2+}$ generation 15 times the influent arsenic concentration is sufficient for arsenic removal without competing ions. Additionally, an $\mathrm{Fe}^{2+}$ generation rate at least two orders of magnitudes higher than the influent arsenic flux is necessary with high concentrations (30 mg/L) of competing ions such as silica. Bang et al. (2005a) also found that during ZVI column experiments that lowering the $\mathrm{pH}$ from near 8 to 6.5 decreased effluent arsenic concentrations from near $10 \mu \mathrm{g} / \mathrm{L}$ to less than $1 \mu \mathrm{g} / \mathrm{L}$ and increased soluble iron concentrations from less than $0.1 \mathrm{mg} / \mathrm{L}$ to over $10 \mathrm{mg} / \mathrm{L}$.

In this study it is hypothesized that lowering the influent water $\mathrm{pH}$ increased the rate of $\mathrm{Fe}^{2+}$ production. This $\mathrm{Fe}^{2+}$ was then oxidized fast enough that there were more iron hydroxides available for adsorption. As discussed in Section 1.3.3, the rates of iron hydroxide formation should decrease 100-fold with a 1 unit decrease in $\mathrm{pH}$. However, Mishra and Farrell (2005) found that as long as the dissolved oxygen concentration in solution is kept high $(>3 \mathrm{mg} / \mathrm{L})$, ferrous iron oxidation and precipitation of ferric hydroxides is not expected to be the rate limiting step. The dissolved oxygen concentration during the $\mathrm{pH}$ adjusted column test was always greater than $5.3 \mathrm{mg} / \mathrm{L}$ (see Table D-16). Further research looking at the rates of iron hydroxide production during column experiments is needed. 
The other process responsible for increased arsenate adsorption with lower $\mathrm{pH}$ is reduced competition with $\mathrm{OH}^{-}$. Arsenate adsorption is thought to occur through ligand exchange with hydroxide ions on the iron hydroxide surface. The decreased $\mathrm{pH}$ results in a lower hydroxide ion activity in solution, which results in decreased competition with arsenate ions. The decreased $\mathrm{pH}$ also causes reduced solubility of amorphous silica and a decrease in the adverse effects on arsenate adsorption (Bang et al., 2005a).

The zeolite column in series with the SMZ/ZVI column had a similar effect to that observed by Bang et al. (2005a). Rubification of the zeolite was observed throughout the experiment as seen in Figure 1-10. Soluble iron was adsorbed onto the raw zeolite column and then oxidized to iron hydroxides; this created a new adsorption surface for arsenic removal. Previous batch studies conducted by the author (data not shown) as well as other studies (Elizalde-Gonzalez, 2001; Jeon et al., 2009) have shown that raw zeolite has almost no adsorption capacity for arsenate. The unmodified zeolite column continually adsorbed iron and lowered arsenic concentrations until about 800 pore volumes. The arsenic concentration in solution then began to rise rapidly after this time and actually became higher than the influent (Figure 1-9), indicating that arsenic may be desorbing from the zeolite column. Further investigations with larger unmodified zeolite columns may provide a better arsenic adsorption capacity, and a greater number of pore volumes until breakthrough. 


\subsubsection{SMZ/ZVI Performance}

Based on the fitted parameters using the HYDRUS-1D inverse option, a relationship between the pore volumes treated and the observed adsorption parameters was observed. Table 1-6 shows the three adsorption parameters calculated for each column experiment and the batch isotherm study. The large range in values shows that the SMZ/ZVI media did not perform the same in each experiment. It appears that the SMZ/ZVI media is very susceptible to environmental factors and optimal conditions must be used to treat water successfully.

Though the maximum sorption capacity $\left(\mathrm{S}_{\mathrm{m}}\right)$ is typically used to describe the media's adsorption capacity, it is not a very good proxy for adsorption during column experiments using SMZ/ZVI. Table 1-6 provides the fitted coefficients to the batch experiment isotherm, and the results from using HYDRUS-1D for the column experiments. There was almost immediate breakthrough during the Socorro Springs column testing, but it has the largest maximum sorption value. The $9 \mathrm{~cm} \mathrm{pH}$ adjusted column experiment had the greatest number of pore volumes until breakthrough, but had the lowest calculated maximum adsorption value. It was found that the product of the maximum sorption capacity $\left(\mathrm{S}_{\mathrm{m}}\right)$ and the Langmuir coefficient $\left(\mathrm{K}_{\mathrm{L}}\right)$ is a better proxy to describe column adsorption performance. The product of $\mathrm{S}_{\mathrm{m}}$ and $\mathrm{K}_{\mathrm{L}}$ will now be referred to as the Langmuir adsorption parameter $\left(\mathrm{K}_{\mathrm{A}}\right)$. The parameter $\mathrm{K}_{\mathrm{A}}$ is a better descriptor of column performance because the arsenic concentrations in solution are relatively low compared with batch experiments. These low arsenic concentrations lend to the Langmuir isotherm being approximated by the linear isotherm. As the concentration in solution becomes very small $(\mathrm{C} \rightarrow 0)$ the denominator of the 
Langmuir equation approaches $1\left(\left[1+\mathrm{K}_{\mathrm{L}} \mathrm{C}\right] \rightarrow 1\right)$, and the Langmuir equation becomes:

$$
\mathrm{S}=\mathrm{S}_{\mathrm{m}} \mathrm{K}_{\mathrm{L}} \mathrm{C}
$$

This is essentially the linear isotherm equation. The reason the individual Langmuir parameters $\left(\mathrm{S}_{\mathrm{m}}\right.$ and $\left.\mathrm{K}_{\mathrm{L}}\right)$ don't describe the adsorption behavior well is an artifact of the fitting routine. Small changes in the shape of the breakthrough curve when using HYDRUS-1D results in large changes in each individual parameter, but little change in product of the two parameters.

Looking at Table 1-7, we see that the ratio of the pore volumes treated to an equivalent concentration is nearly the same as the ratio of the $\mathrm{K}_{\mathrm{A}}$ values for each breakthrough experiment. The SMZ/ZVI used in the Socorro Springs test and the 30 cm lab column treated $\sim 1,250$ and $\sim 800$ pore volumes respectively until the effluent reached $30 \mu \mathrm{g} / \mathrm{L}$. The ratio of the $\mathrm{K}_{\mathrm{A}}$ values are nearly identical to the ratio of pore volumes treated to $30 \mu \mathrm{g} / \mathrm{L}$. Similarly, the $9 \mathrm{~cm} \mathrm{pH}$ adjusted column and the $30 \mathrm{~cm}$ lab column had similar findings. These values show that for comparison of relative performance in column experiments, a linear type isotherm equation is better.

Using the kinetic data from Section 1.3.1 and the observed reaction rate for the low concentration kinetic experiment $\left(\mathrm{C}_{0}=66 \mu \mathrm{g} / \mathrm{L}\right)$, the Damkohler number for each column test was calculated. The Damkohler number $\left(D_{A}\right)$ used in this article is defined as: 


$$
\begin{aligned}
& \qquad D_{A}=\frac{k L}{v} \\
& k=\text { reaction rate }\left(\mathrm{min}^{-1}\right) \\
& L=\text { media bedlength }(\mathrm{cm}) \\
& v=\text { average pore } \text { water velocity }(\mathrm{cm} / \mathrm{min})
\end{aligned}
$$

The Damkohler number is the ratio of the fluid transport rate to the calculated reaction rate for arsenic adsorption. Weerd et al. (1998) noted that there is a lower and upper limit on the range of values for the Damkohler number. At the lower limit, no significant change occurs because the kinetic rate is so slow the reaction becomes insignificant; at the upper limit no change occurs because the system has reached equilibrium. Additionally, Weerd et al. (1998) note that these upper and lower limits are reaction specific and cannot be compared outside of the specific system of interest. Though a comprehensive study of the upper and lower bounds has not been performed, the $\mathrm{D}_{\mathrm{A}}$ gives insight into the relative rates for the column studies conducted.

Table 1-8 compares the calculated Damkohler number for each column study. For the Socorro Springs study, the $\mathrm{D}_{\mathrm{A}}$ is less than 1, and may confirm that the flowrates used during those column studies were too high. The $\mathrm{D}_{\mathrm{A}}$ number for the 30 $\mathrm{cm}$ lab-based column is greater than one and may indicate that there was enough time for adsorption to occur. For the $9 \mathrm{~cm} \mathrm{pH}$ adjusted column the $\mathrm{D}_{\mathrm{A}} \approx 1$, showing the two rates are approximately equal. However, the reported $\mathrm{D}_{\mathrm{A}}$ for each column should be considered as an upper maximum value due to the discrepancy between column and batch adsorption parameters. It is likely the high degree of mixing and the production of fine iron particles in batch experiments led to increased reaction rates. With further 
testing of the effect of flowrate on arsenic adsorption, the $\mathrm{D}_{\mathrm{A}}$ may provide the optimal flowrates and column sizes that could be used for large-scale water treatment facility design.

\subsubsection{SMZ/ZVI Applications}

Even though SMZ/ZVI treated about 1,000 pore volumes with $\mathrm{pH}$ adjustment, these results are much less than other studies using ZVI. Nikolaidis et al. (2003) found that in a large-scale field test ZVI treated 21,600 pore volumes before breakthrough above $20 \mu \mathrm{g} / \mathrm{L}$. However, they also found that about $73 \%$ of the iron was leached from solution. Therefore, another iron removal system would be needed for municipal water treatment. Siegel et al. (2007) tested several different types of commercial media using the same Socorro Springs facilities used in this experiment. They found that several different commercial media treated 8,000 to 50,000 pore volumes without $\mathrm{pH}$ adjustment. Similarly, Partey (2008) found that natural laterite concretions could treat nearly 5,000 pore volumes with $\mathrm{pH}$ adjustment. The SMZ/ZVI is similar in composition to some of these media except for the presence of the silicate foam substrate. The original purpose of the silicate substrate was for rigidity to maintain open pore spaces and a high hydraulic conductivity of the medium for use in permeable reactive barriers. It is believed that the silicate substrate is counterproductive in the current application because it introduces high levels of silica in the water that compete with arsenate for adsorption onto the iron hydroxide surfaces. 
Though SMZ/ZVI may not be the best media for municipal water treatment, the current study has shown that SMZ/ZVI does have the capability to reduce arsenic concentrations in contaminated water. If the presence of competing ions such as phosphate and silica are relatively low, and the amount of silica leaching from the foam substrate is low, the SMZ/ZVI should be effective in reducing the arsenic concentration to below $10 \mu \mathrm{g} / \mathrm{L}$.

The SMZ/ZVI media does however have comparable performance based on a cost analysis. In the pilot study conducted by Siegel et al. (2007) the media with the highest performance treated $\sim 50,000$ bed volumes ( 5 min residence time) at a cost of $\$ 200$ per cubic foot with no $\mathrm{pH}$ treatment. SMZ/ZVI costs about $\$ 10$ per cubic foot (Bowman et al., 2002). Based on these results, water treatment using SMZ/ZVI costs about twice as much as treatment using a different commercial media. However, the initial investment for $\mathrm{pH}$ treatment and the labor costs for removal and replacement of the media would likely result in even higher long-term expenses. 


\subsection{CONCLUSIONS}

The study showed that SMZ/ZVI could reduce arsenic concentrations in a municipal water supply to below $10 \mu \mathrm{g} / \mathrm{L}$. The environmental factors used during treatment such as the flowrate, water $\mathrm{pH}$, and the presence of competing ions have a large effect on arsenic removal. The SMZ/ZVI media has optimal adsorption at $\mathrm{pH} 6.5$ and adsorption occurs within 20 minutes for solutions with arsenic concentrations below $1 \mathrm{mg} / \mathrm{L}$. Column studies showed that the SMZ/ZVI can treat about 200 pore volumes of Socorro Springs water to below an arsenic concentration of $10 \mu \mathrm{g} / \mathrm{L}$ with a column residence time of about 30 minutes. Socorro Springs water that was adjusted to $\mathrm{pH} 6.5$ could be treated to about 1,000 pore volumes with a residence time of about 7.5 minutes.

The SMZ/ZVI media has a high adsorption capacity based on batch experiment results. However, the batch experiment adsorption parameters over-predicted adsorption in a column setting. The discrepancy between the batch and column experiments is believed to be the result of intraparticle mass diffusion rates and the presence of competing ions. During batch experiments, the media is physically shaken and causes fine iron particles to slough off of the granular material; these fine iron particles allow for greater adsorption. During column experiments the fine iron particles are not in suspension and the arsenic adsorption is limited by the arsenate diffusion into the iron hydroxide rind on the SMZ/ZVI material surface.

The presence of high concentrations of silica in the Socorro Springs water may have caused significant competition with arsenate for adsorption and led to early column breakthrough. Additionally, the silicate substrate in the structure of the 
SMZ/ZVI pellets is believed to release silica ions that also compete with arsenate for adsorption.

The SMZ/ZVI media does not have the adsorption capacity of some commercial media and may not be the best solution for municipal water treatment. However, the SMZ/ZVI media is still a viable in-situ treatment option for permeable reactive barriers and has now been shown to be effective in removing arsenic at low environmental levels. 


\subsection{REFERENCES}

Azher, N. E.; Gourich, B.; Vial, C.; Soulami, M.B.; Ziyad, M. 2008. Study of ferrous iron oxidation in Morocco drinking water in an airlift reactor. Chemical Engineering and Processing 47, pp. 1877-1886

Badruzzaman, M.; Westerhoff, P.; Knappe, D. R. U. 2004. Intraparticle diffusion and adsorption of arsenate onto granular ferric hydroxide. Water Res. 38, pp. 40024012.

Bang, S.; Korfiatis, G.P.; Meng, X. 2005a. Removal of arsenic from water by zerovalent iron. Journal of Hazardous Materials 121, pp. 61-67

Bang, S.; Johnson, M.D.; Korfiatis, G.P.; Meng, X. 2005b. Chemical Reactions between arsenic and zero-valent iron in water. Water Research 39, pp. 763-770

Bates, M.N.; Smith, A.H.; Hopenhayn-Rich, C. 1992. Arsenic ingestion and internal cancers: A review. American Journal of Epidemiology Vol. 135, No. 5

Bosnak, C.O.; Davidowski, L. 2004. Continuous Flow Hydride Generation Using the Optima ICP. Perkin Elmer Filed Application Report. Perkin Elmer

Bowman, R.S. 2003. Applications of surfactant-modified zeolites to environmental remediation. Microporous Mesoporous Mat. 61, pp.43-56.

Bowman, R.S.; Zhang, P.; T, X. 2002. Surface-altered zeolites as permeable barriers for in situ treatment of contaminated groundwater. Phase II Topical Report. New Mexico Institute of Mining and Technology, Socorro, NM

Chang, Y.Y.; Kim, K.S.; Jung, J.H.; Yang, J.K.; Lee, S.M. 2007. Application of ironcoated sand and manganese-coated sand on the treatment of both As(III) and As(V). Water Science and Technology (1-2), pp.69-75

Dixit, S.; Hering, J. G. 2003. Comparison of arsenic(V) and arsenic(III) sorption onto iron oxide minerals: Implications for arsenic mobility. Environ. Sci. Technol. 37, pp. 4182-4189.

Elizalde-Gonzalez, M.P.; Mattusch, J.; Wennrich, R.; Morgenstern, P. 2001. Uptake of arsenite and arsenate by clinoptilolite-rich tuffs. Microporous Mesoporous Mat. 46, pp. 277-286

U.S. Environmental Protection Agency (EPA). 2000. Technologies and costs for removal of arsenic from drinking water, EPA 815-R-00-028, Washington, D.C.

U.S. Environmental Protection Agency (EPA). 2001. Federal Registry. 66 (14), 6976 
Farrell, J.; Wang, J. P.; O’Day, P.; Conklin,M. 2001. Electrochemical and Spectroscopic Study of Arsenate Removal from Water Using Zero-Valent Iron Media. Environ. Sci. Technol. 35, pp. 2026-2032

Faure, G. 1998. Principles and Applications of Geochemistry. $2^{\text {nd }}$ ed. Upper Saddle River, NJ. Prentice Hall

Fendorf, S.; Eick, M. J.; Grossl, P. Sparks, D. L. 1997. Arsenate and chromate retention mechanisms on goethite. 1: Surface structure. Environ. Sci. Technol. 31, pp. 315-320.

Ferguson, J.F.; Garvis, J. 1972. Review of the arsenic cycle in natural waters. Water Res. 6, pp.1259-1274

Fuller, C. C.; Davis, J. A.; Waychunas, G. A. 1993.Surface-chemistry of ferrihydrite 2. kinetics of arsenate adsorption and coprecipitation. Geochim. Cosmochim. Acta 1993, 57, pp. 2271-2282

Goldberg, S. 1986. Chemical modeling of arsenate adsorption on aluminum and iron oxide minerals. Soil Sci. Soc. Am. J. 5, pp.1154-1157.

Grossl, P. R.; Eick, M.; Sparks, D. L.; Goldberg, S.; Ainsworth, C.C. 1997. Arsenate and chromate retention mechanisms on goethite. 2: Kinetic evaluation using a pressure-jump relaxation technique. Environ. Sci. Technol. 31, pp.321-326.

Jain, A.; Raven, K. P.; Loeppert, R. H. 1999. Arsenate and arsenite adsorption on ferrihydrite: Surface charge reduction and net $\mathrm{OH}$ - release stoichiometry. Environ. Sci. Technol., 33, pp. 1179-1184.

Jeon, C.; Baek, K.; Park, J.; Oh, Y.; Lee, S. 2009 Adsorption characteristics of As(V) on iron-coated zeolite. Journal of Hazardous Material 163 pp. 804-808

Jeong Y.; Fan, M.; Singh, S.; Chuang, C.-L.; Saha, B.; Hans van Leeuwen, J. 2007. Evaluation of iron oxide and aluminum oxide as potential arsenic(V) adsorbents. Chemical Engineering and Processing: Process Intensification, 46 (10), pp. 1030-1039.

Lackovic, J. A.; Nikolaidis, N. P.; Dobbs, G. M. 2000. Inorganic arsenic removal by zero-valent iron. Environ. Eng. Sci., 17, pp. 29-39

Langmuir, D. 1997. Aqueous Environmental Geochemistry. Prentive Hall, Upper Saddle River, NJ

Li, Z.; Bowman, R.S. 1997. Counterion Effects of the sorption of cationic surfactant and chromate on natural clinoptilolite. Environ. Sci. Technol. 31, pp. 24072412. 
Li, Z., Jones, H.K., Bowman, R.S., Helferich, R., 1999. Enhanced reduction of chromate and PCE by pelletized surfactant-modified zeolite/ zerovalent iron. Environ. Sci. Technol. 33, pp. 4326-4330

Manning, B.; A., Fendorf, S. E.; Goldberg, S. 1998. Surface structures and stability of arsenic(III) on goethite: Spectroscopic evidence for inner-sphere complexes. Environ. Sci. Technol. 32, pp. 2383-2388.

Manning, B. A.; Hunt, M.; Amrhein, C.; Yarmoff, J. A. 2002. Arsenic(III) and $\operatorname{arsenic}(\mathrm{V})$ reactions with zerovalent iron corrosion products. Environ. Sci. Technol. 36, pp. 5455-5461.

McBride, M. B. 1997. Environmental chemistry of soils; Oxford University Press: New York, p. 136

Melitas, N.; Wang, J.; Conklin, M.; O’Day, P.; Farrell, J. 2002. Understanding soluble arsenate removal kinetics by zerovalent iron media. Environ. Sci. Technol. 36, pp.2074-2801

Nikolaidis, N.P.; Dobbs G.M.; Lackovic, J.A. 2003. Arsenic removal by zero-valent iron: field, laboratory and modeling studies. Water Research. 37, pp. 14171425

Oblonsky, L. J.; Ryan, M. P.; Isaacs, H. S. 2000. In situ XANES study of the formation and reduction of the passive film formed on $\mathrm{Fe}$ in acetate solution Corros. Sci. 42, pp. 229-241.

Onyango, M.S.; Kojima, Y.; Matsuda, H.; Ochieng, A. 2003. Adsorption kinetics of arsenic removal from groundwater by iron-modified zeolite. Journal of Chemical Engineering of Japan, Vol. 36 pp. 1519-1522

Park , B.; Dempsey, B.A. 2005. Heterogeneous oxidation of Fe(II) on ferric oxide at neutral $\mathrm{pH}$ and a low partial pressure of $\mathrm{O}_{2}$. Environ. Sci. Technol. 39, pp. 6494-6500

Partey, F.K. 2007. Mechansim of arsenic sorption onto laterite iron conceretions. PhD Dissertation. New Mexico Tech. Socorro, NM

Siegel, M.; Marbury, J.; Everett, R.; Dwyer, B.; Collins, S.; Aragon, M.; Aragon, A. 2006 Pilot test specific test plan for the removal of arsenic from Socorro, New Mexico. Sandia National Laboratories. SAND2006-1324. Sandia National Laboratories. Albuquerque, NM

Siegel, M.; Aragon, A.; Zhao, H.; Everett, R.; Dwyer, B.; Aragon, M.; Nocon, M.; Dwyer, B.; Marbury, J.; Kirby, C.; North, K. 2007 Pilot test of arsenic 
adsorptive media treatment technologies at Socorro Springs, New Mexico. Sandia National Laboratories. SAND2007-0161. Sandia National Laboratories. Albuquerque, NM

Šimunek, J.; Huang K.; van Genuchten, M. Th. 1998. The HYDRUS code for simulating the one-dimensional movement of water, heat, and multiple solutes in variably-saturated media. Version 6.0, Research Report No. 144, U.S. Salinity Laboratory, USDA, ARS, Riverside, California, p. 164

Šimunek, J.; Sejna, H.; Saito, M.; Sakai, M.; van Genuchten, M. Th. 2008. The HYDRUS-1D software package for simulating the one-dimensional movement of water, heat, and multiple solutes in variably saturated media. Version 4.0 Dept. of Env. Sciences. University of California Riverside, Riverside, p. 315.

Singer, P.C.; Stumm, W. 1970. Acid mine drainage: the rate determining step: Science, v. 167, p. 1121-1123.

Su, C.; Puls, R. W. 1997. Retention of arsenic by elemental iron and iron oxides. In Proceedings of the 1997 International Containment Technology Conference, February 9-12, Tallahassee, FL.

Su, C.; Puls, R. W. 2001a. Arsenate and arsenite removal by zerovalent iron: kinetics, redox transformation, and implications for in situ groundwater remediation. Environ. Sci. Technol. 35, pp. 1487-1492.

Su, C.; Puls, R. W. 2001b. Arsenate and arsenite removal by zerovalent iron: Effects of phosphate, silica, carbonate, borate, sulfate, chromate, molybdate, and nitrate, relative to chloride. Environ. Sci. Technol. 2001, 35, pp. 4562-4568.

Sullivan, E.J., Bowman, R.S., Legiec, I.A. 2003. Sorption of arsenic from soilwashing leachate by surfactant-modified zeolite. J. Environ. Qual. 32, pp. 2387-2391

Stumm, W.; 1992. Chemistry of the solid-water interface. New York: WileyInterscience

Thirunavukkarasu, O.S., Viraraghavan, T., Subramanian, K.S. 2001. Removal of arsenic in drinking water by iron-oxide coated sand and ferrihydrite- batch studies. Water Quality Research Journal of Canada 36, pp. 55-70

Thirunavukkarasu, O.S., Viraraghavan, T., Subramanian, K.S. 2003. Arsenic removal from drinking water using iron-oxide coated sand. Water, Air, and Soil Pollution 142, pp. 95-111 
Weerd, H.; Leijnse, A.; Reimskijk, W.H. 1998. Transport of reactive colloids and contaminants in groundwater: effect of nonlinear kinetic interactions. Journal of Contaminant Hydrology, 332, pp. 313-331

Westerhoff, P.; Highfield, D.; Badruzzaman, M.; Yoon, Y. 2005.Rapid small-scale column test for arsenate removal in iron oxide packed bed columns. J. Environ. Eng. 2005, 131, pp. 262-271.

World Health Organization (WHO). 1993 Guidelines for drinking-water quality, 2nd ed. Geneva. vol. 1

Wu, M. M.; Kuo, T.L.; Hwang Y.H.; Chen, C.J. 1989. Does-response relation between arsenic concentration in well water and mortality from cancers and vascular disease. American Journal of Epidemiology Vol. 130, No. 6

Zhang, P., X. Tao, Z. Li, and R.S. Bowman. 2002. Enhanced perchloroethylene reduction in column systems using surfactant-modified zeolite/zero-valent iron pellets. Environ. Sci. Technol. 36, pp. 3597-3603. 


\section{FIGURES- Article I}

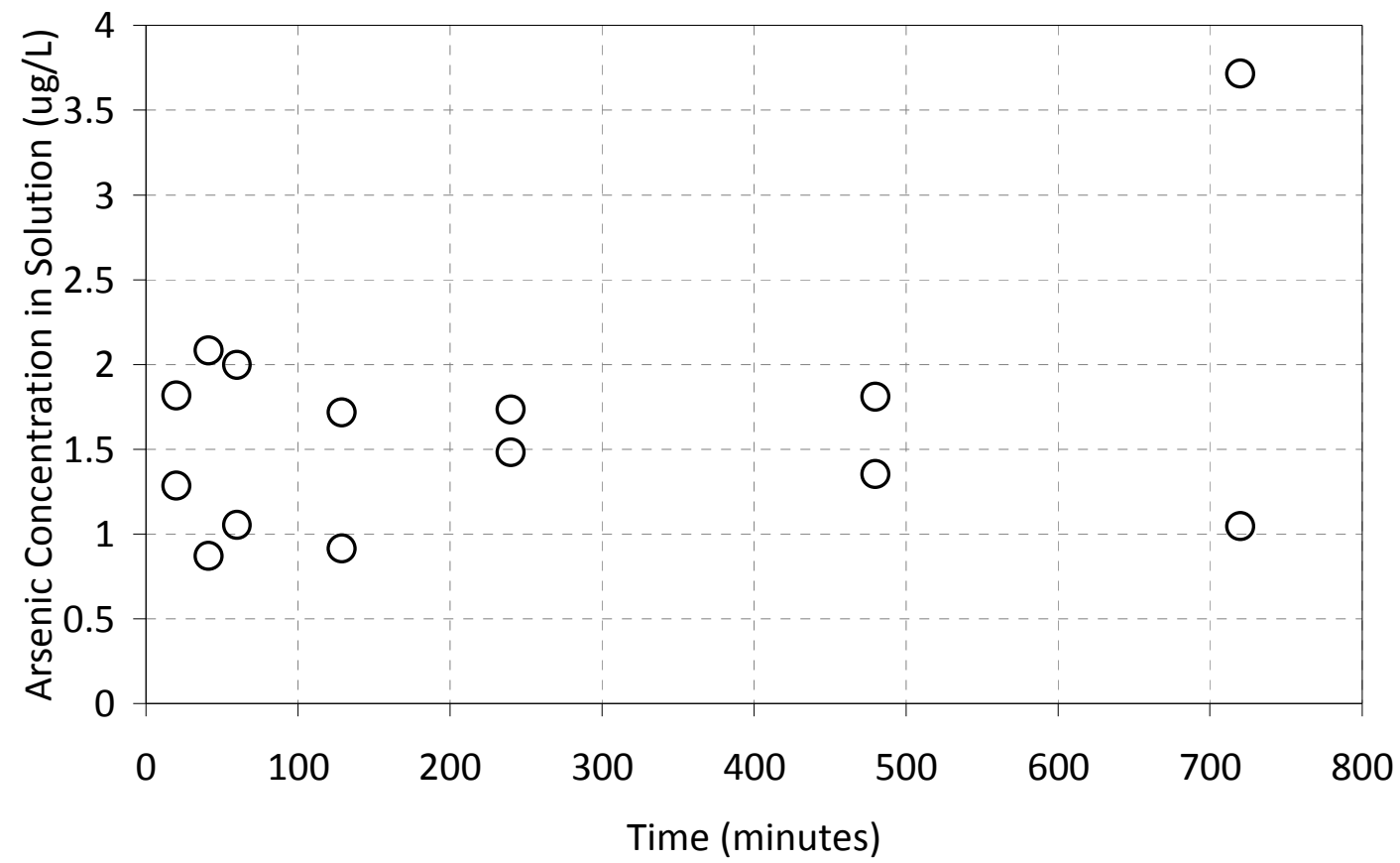

Figure 1- 1: Arsenic concentrations in solution after mixing with SMZ/ZVI for various times. Each circle represents the results from an individual analysis; duplicate vials at each time were used. An initial concentration of $0.78 \mathrm{mg} / \mathrm{L} \mathrm{As}(\mathrm{V})$ was used for each vial. Concentration measurement error is \pm $4 \%$ based on replicate analyses of a $1 \mu \mathrm{g} / \mathrm{L}$ standard. 


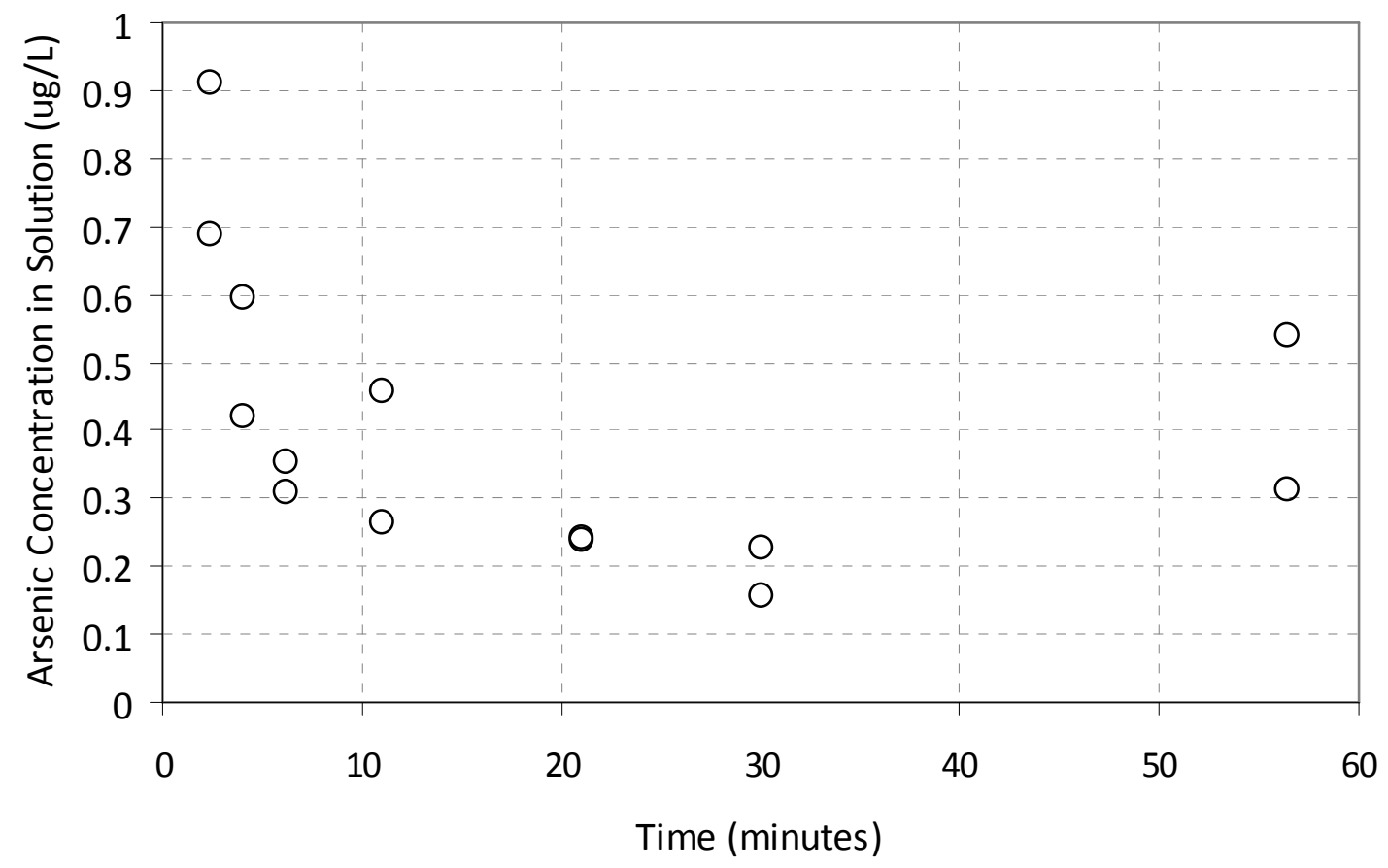

Figure 1- 2: Arsenic concentration in solution after mixing with SMZ/ZVI for various times. Each circle represents the results from an individual analysis; duplicate vials at each time were used. An initial concentration of $66 \mu \mathrm{g} / \mathrm{L} \mathrm{As}(\mathrm{V})$ was used for each vial. Concentration measurement error is $\pm 4 \%$ based on replicate analyses of a $1 \mu \mathrm{g} / \mathrm{L}$ standard. 


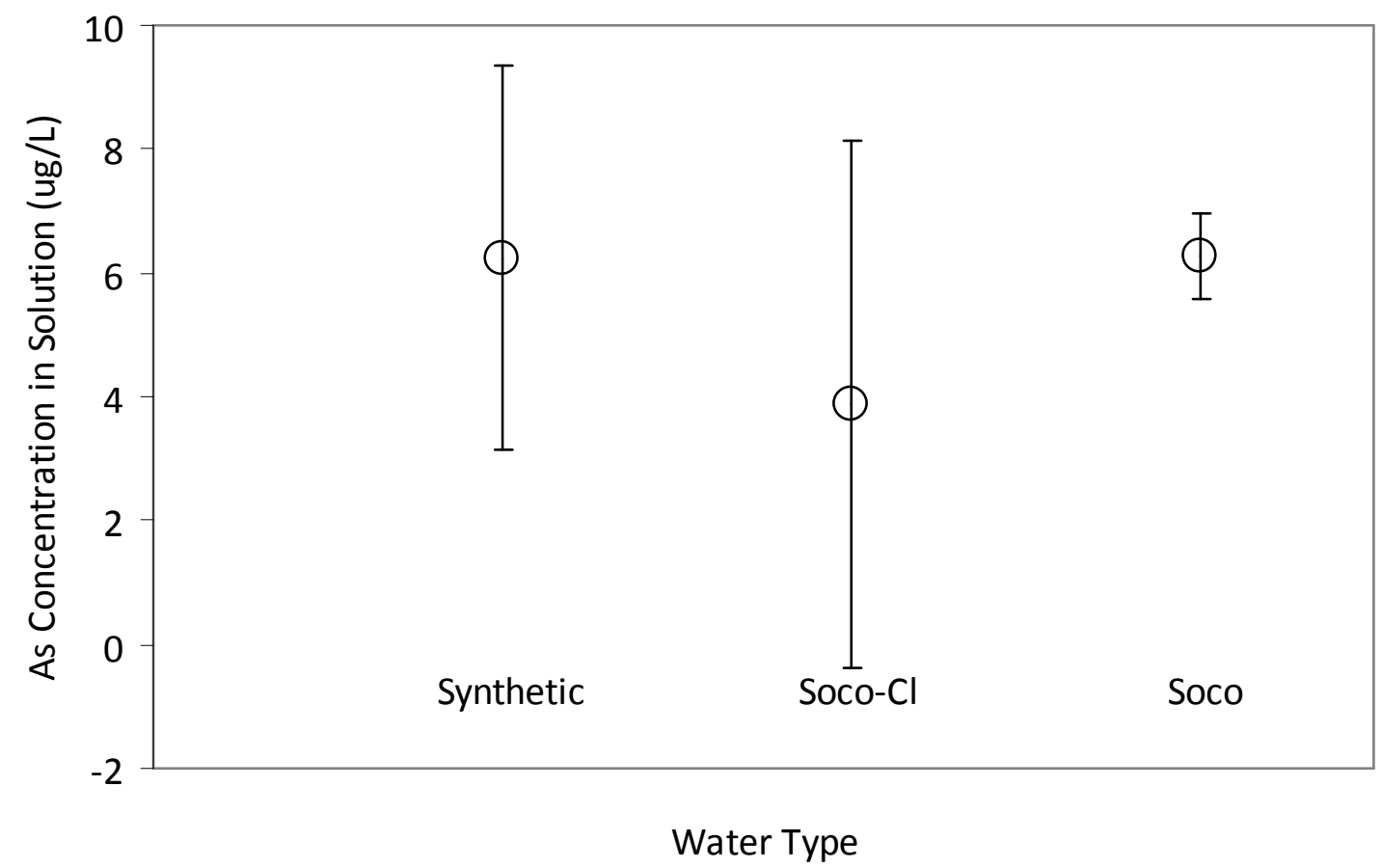

Figure 1- 3: Graph showing the concentrations of As in solution using three different types of water for the batch experiment. The initial As concentration was $3.3 \mathrm{mg} / \mathrm{L}$ and the equilibration time was 1 hour. The points labeled "Soco" and "Soco-Cl" represent the raw Socorro feed water and the chlorinated Socorro feed water respectively. The error bars represent the standard deviation based on triplicate analyses. 


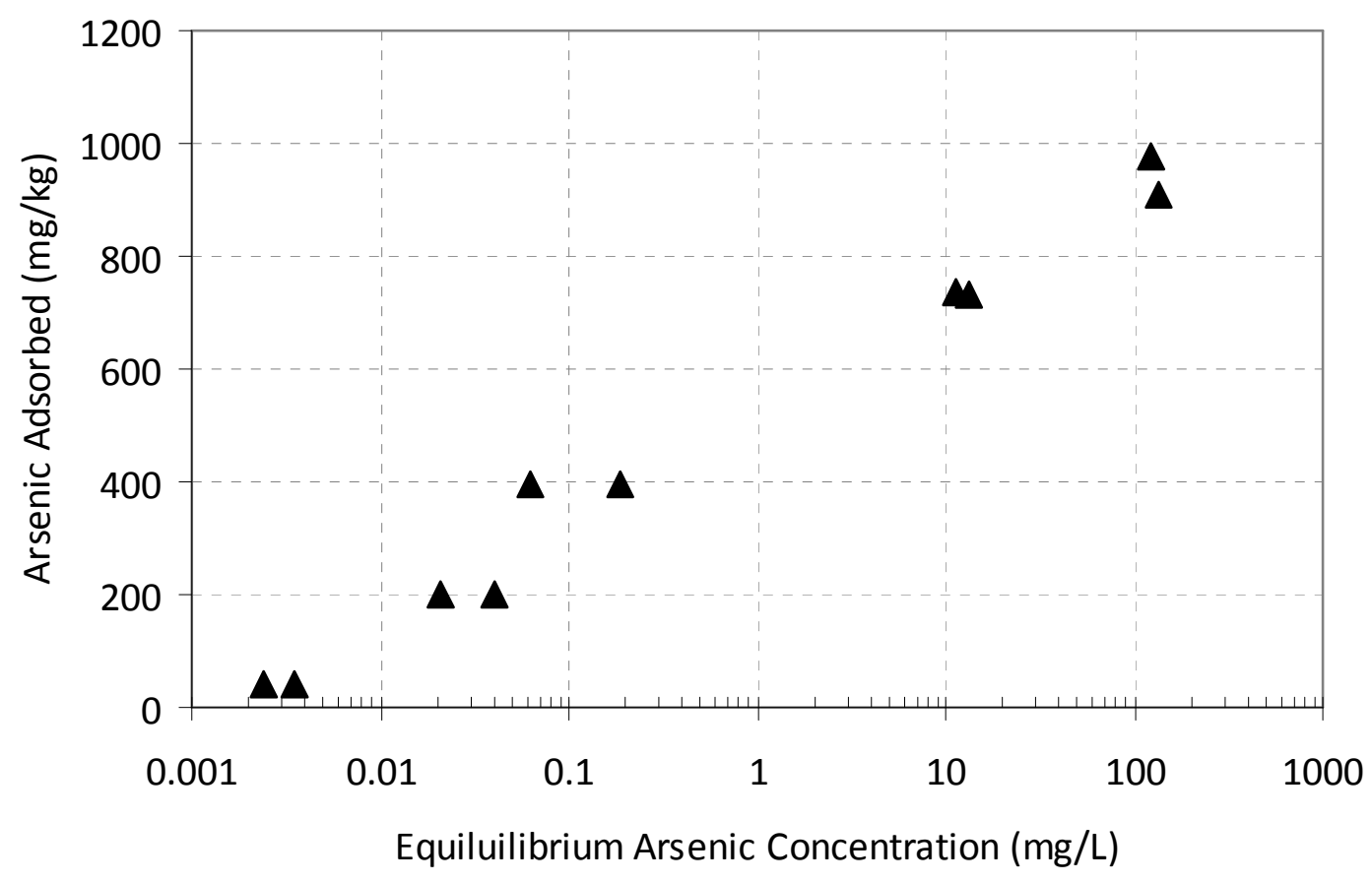

Figure 1- 4: Isotherm concentrations adsorbed and concentrations in solution plotted on a semi-log scale. Duplicate samples were sacrificed and analyzed at each concentration. The synthetic water solution was used in all batch experiments. The initial $\mathrm{pH}$ of each solution was $8.5 \pm 0.1$, while the final $\mathrm{pH}$ varied from 7.5 to 9.9 (data can be found in Appendix C). Concentration measurement error is $\pm 3 \%$ based on replicate analyses of a $10 \mu \mathrm{g} / \mathrm{L}$ USGS standard reference sample. 


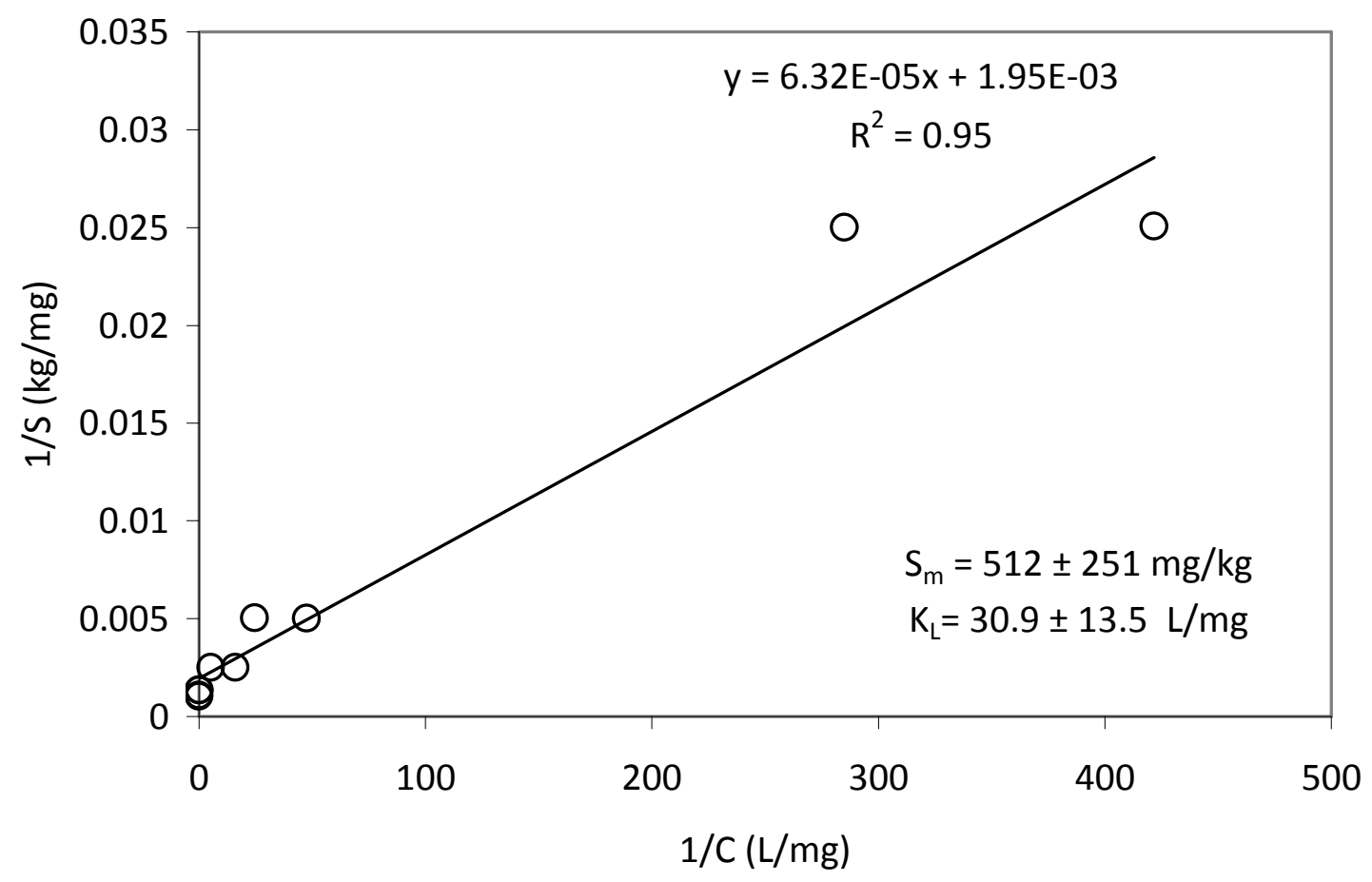

Figure 1- 5: Isotherm results (Figure 1-4) plotted as a Langmuir type isotherm. $\mathrm{C}=$ Arsenic concentration in solution after equilibration $(\mathrm{mg} / \mathrm{L}) ; \mathrm{S}=$ Arsenic concentration on SMZ/ZVI (mg/kg). The best fit line is a linear fit that is used to derive the Langmuir parameters from the linearized Langmuir equation. The error values are based on standard errors from linear regression of the fitted line. Concentration measurement error is $\pm 3 \%$ based on replicate analyses of a $10 \mu \mathrm{g} / \mathrm{L}$ USGS standard reference sample. 


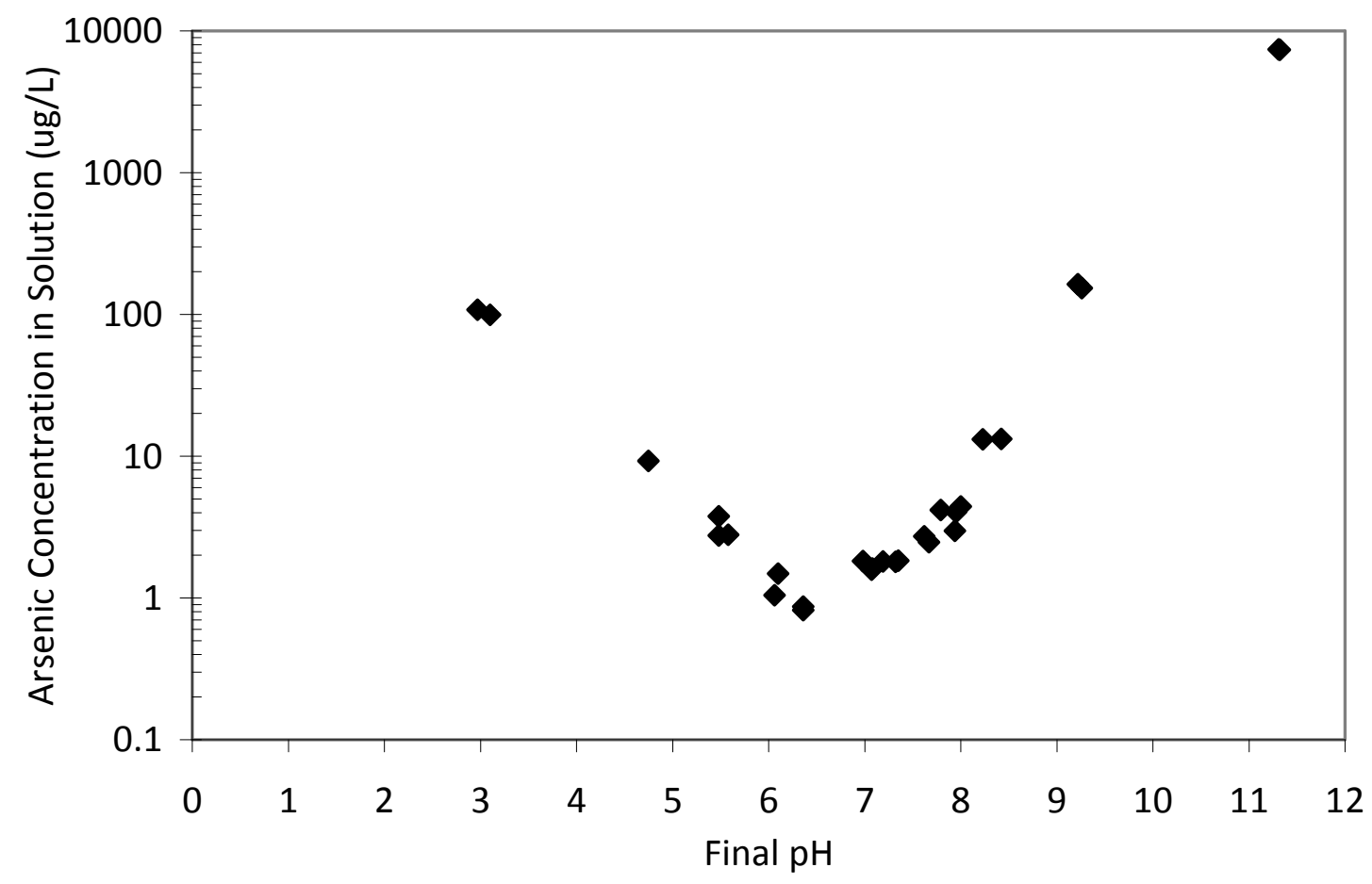

Figure 1- 6: Semi-log plot showing the concentration in solution after equilibration with an $\sim 18 \mathrm{mg} / \mathrm{L}$ $\mathrm{As}(\mathrm{V})$. The $\mathrm{pH}$ values plotted were measured after equilibration for 2 hours. Concentration measurement error is $\pm 3 \%$ based on replicate analyses of a $10 \mu \mathrm{g} / \mathrm{L}$ USGS standard reference sample. 


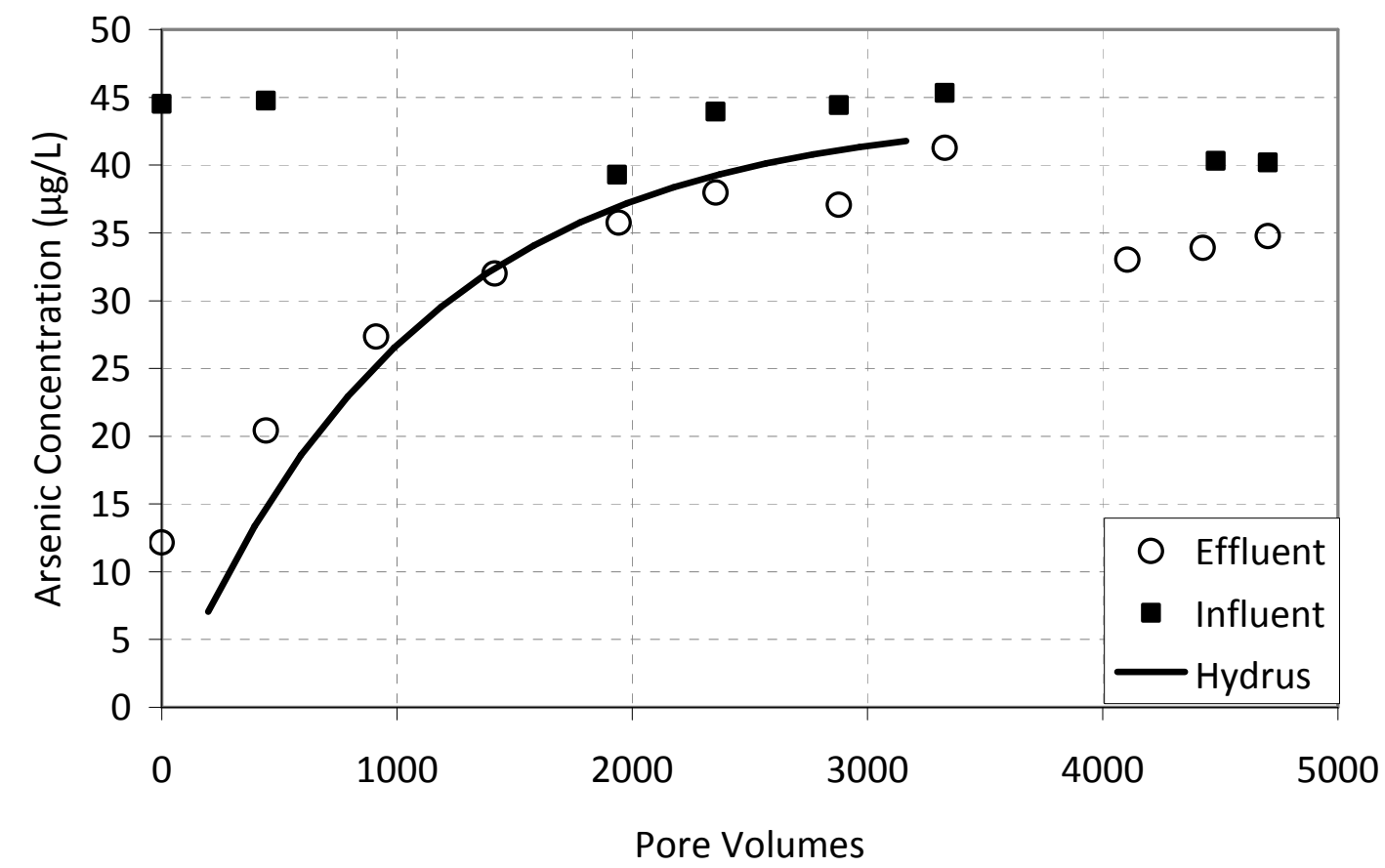

Figure 1- 7: Influent and effluent concentrations measured at the end of one of the Socorro Springs field site columns. The solid line is the best fit to the data from the inverse solver option within HYDRUS-1D. The flowrate was reduced from $\sim 0.8 \mathrm{~L} / \mathrm{min}$ to $\sim 0.3 \mathrm{~L} / \mathrm{min}$ around 3500 pore volumes. Concentration measurement error is $\pm 3 \%$ based on replicate analyses of a $10 \mu \mathrm{g} / \mathrm{L}$ USGS standard reference sample. 


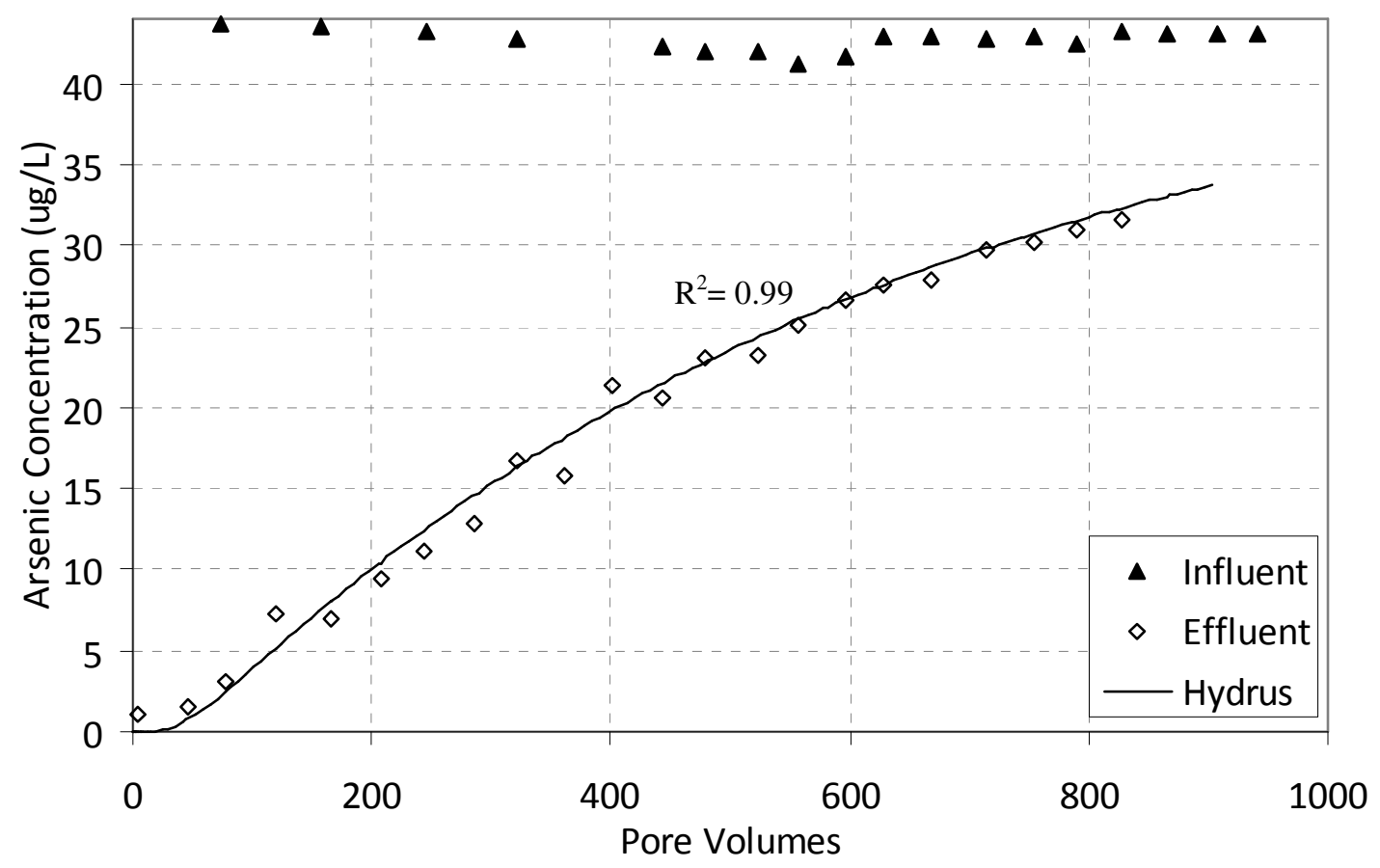

Figure 1- 8: Plot showing the influent and effluent concentrations measured at the end of one of the 30 $\mathrm{cm}$ columns. The solid line is the best-fit to the observed data using the HYDRUS-1D inverse solution option. Concentration measurement error is $\pm 3 \%$ based on replicate analyses of a $10 \mu \mathrm{g} / \mathrm{L}$ USGS standard reference sample. 


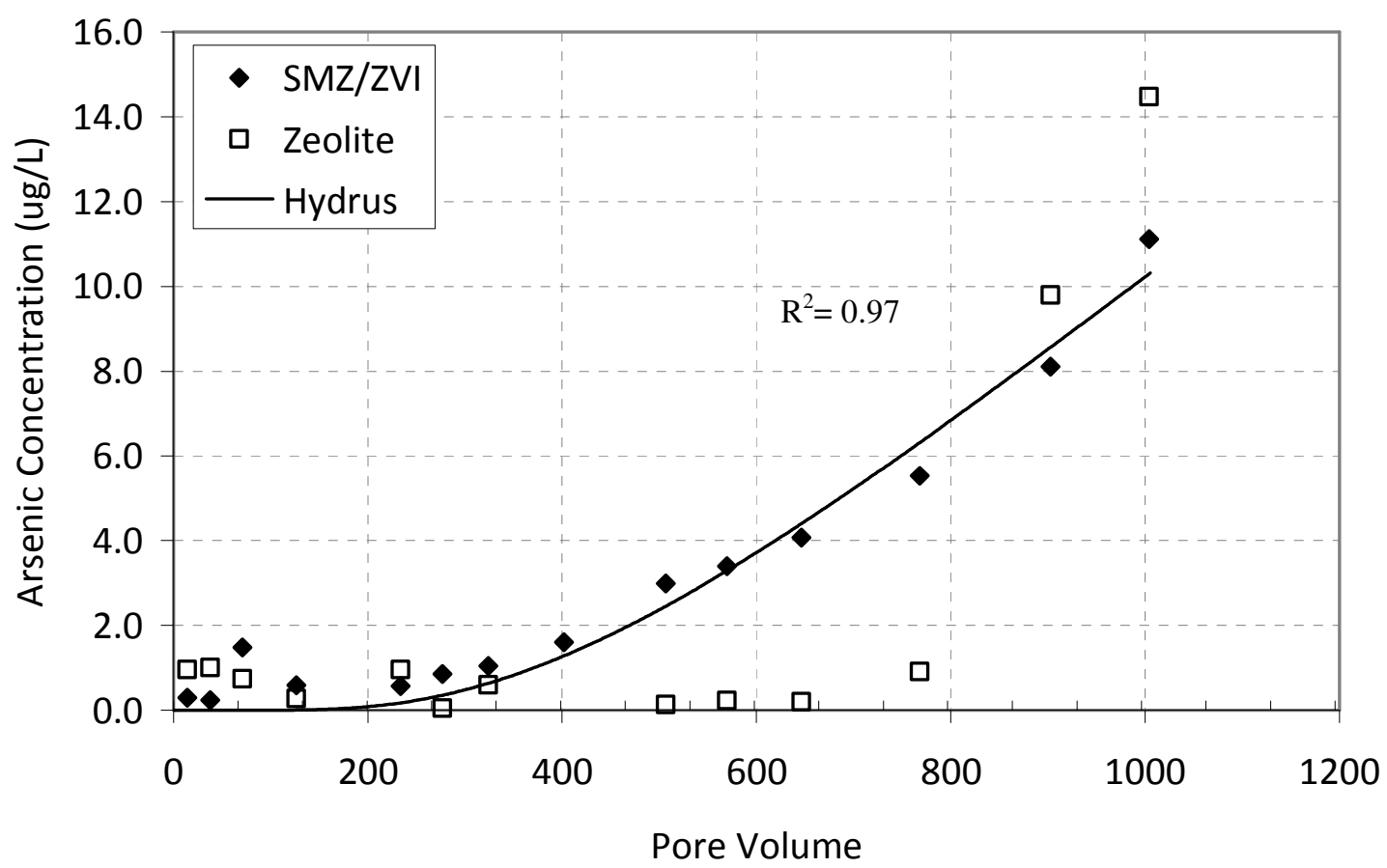

Figure 1- 9: Measured arsenic effluent concentrations at the end of each column. The solid line is the best fit to the observed data using the inverse solver within HYDRUS-1D. The columns were run in series with the SMZ/ZVI column first, and the unmodified zeolite column second. The influent arsenic concentration was $44 \mu \mathrm{g} / \mathrm{L}$ adjusted to $\mathrm{pH}$ 6.6. Concentration measurement error is $\pm 3 \%$ based on replicate analyses of a $10 \mu \mathrm{g} / \mathrm{L}$ USGS standard reference sample. 


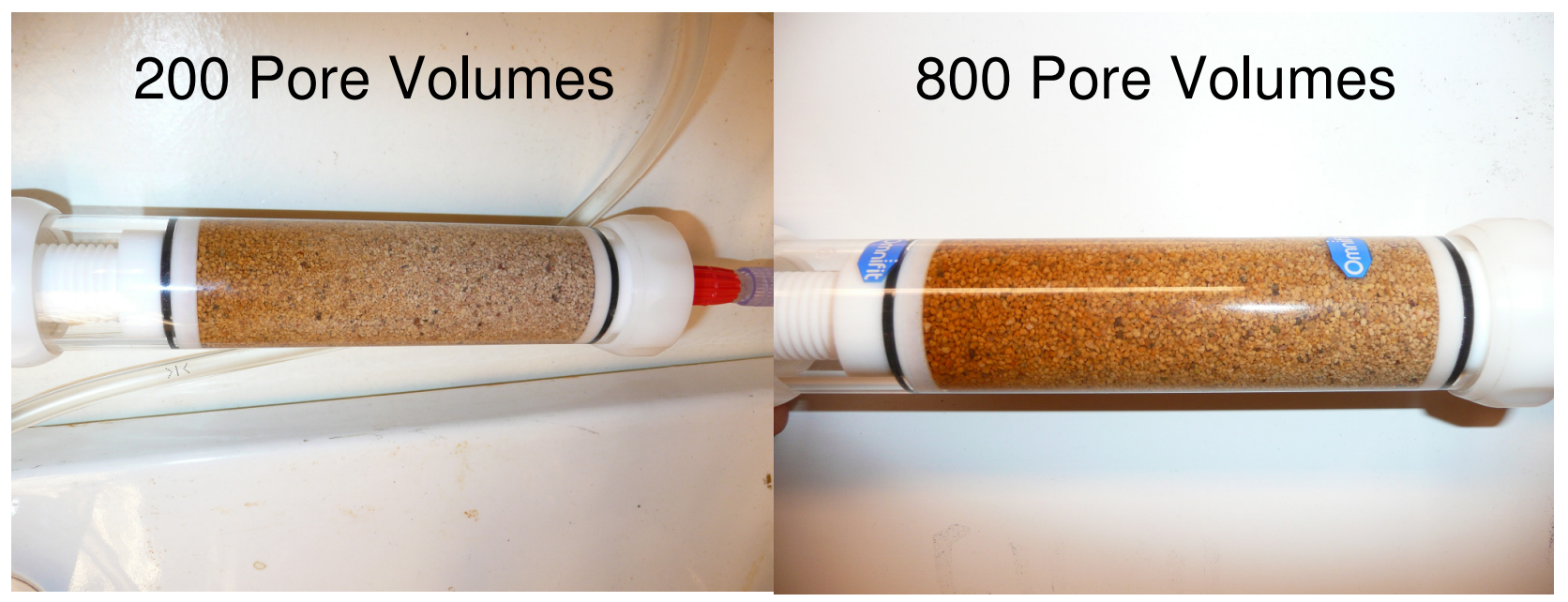

Figure 1- 10: Pictures of the physical change in appearance of the unmodified zeolite column after 200 and 800 pore volumes. Flow is from left to right. The unmodified zeolite column was in series directly after the SMZ/ZVI column. 


\section{TABLES- Article I}

Table 1- 1: Measured concentrations of elements present in the Socorro Springs water and calculated concentrations of elements present in the synthetic water prepared in the lab.

\begin{tabular}{|c|c|c|}
\hline & Chlorinated Feed Water $^{1}$ & Synthetic Water \\
\hline Conductivity $(\mu \mathrm{S} / \mathrm{cm})$ & 356 & 502 \\
\hline Temperature $\left({ }^{\circ} \mathrm{C}\right)$ & 30.1 & 19.5 \\
\hline $\mathrm{pH}$ & 7.9 & 8.48 \\
\hline Free Chlorine (ppm as $\mathrm{Cl}_{2}$ ) & 0.74 & 0 \\
\hline Iron (ppb) & 38.2 & 0 \\
\hline Total Arsenic (ppb) & 42.9 & 0 \\
\hline \multicolumn{3}{|l|}{ Speciated Arsenic } \\
\hline Particulate Arsenic (ppb) & 1.9 & 0 \\
\hline As (III) (ppb) & 2.04 & 0 \\
\hline As (V) (ppb) & 39 & 0 \\
\hline Alkalinity (ppm) & 125 & 76.3 \\
\hline Nitrate (ppm) & 0.4 & 0 \\
\hline Vanadium (ppb) & 11.3 & 0 \\
\hline Aluminum (ppb) & 23.2 & 0 \\
\hline Fluoride (ppm) & 0.52 & 0 \\
\hline Chloride (ppm) & 12.7 & 24.1 \\
\hline Sulfate (ppm) & 30.1 & 29.9 \\
\hline Sodium (ppm) & 57.1 & 28.8 \\
\hline Magnesium (ppm) & 4.05 & 7.6 \\
\hline Calcium (ppm) & 17.4 & 13.6 \\
\hline Silica (ppm) & 24.9 & 0 \\
\hline TOC (ppm) & 0.364 & 0 \\
\hline
\end{tabular}


Table 1- 2 : Comparison between $\mathrm{As}(\mathrm{V})$ estimated Langmuir maximum sorption capacity $\left(\mathrm{S}_{\mathrm{m}}\right)$ of several different kinds of media.

\begin{tabular}{lcl}
\hline Material & $\mathbf{S}_{\mathbf{m}}(\mathbf{m g} / \mathbf{k g})$ & Source \\
\hline Iron-Oxide Coated Sand & 18.3 & Thirunavukkarasu et al. (2001) \\
Iron-Oxide Coated Sand & 42.6 & Thirunavukkarasu et al. (2002) \\
Iron-Coated Sand & 165 & Chang et al. (2007) \\
Aluminum Oxide & 170 & Jeong et al. (2007) \\
Ferrihydrite & 285 & Thirunavukkarasu et al. (2001) \\
SMZ/ZVI & 512 & This study \\
Iron-Coated Zeolite & 600 & Jeon et al. (2009) \\
Iron Oxide & 660 & Jeong et al. (2007) \\
\hline
\end{tabular}

Table 1- 3: List of operating parameters used in the field test at the Socorro chlorination building.

\begin{tabular}{lr}
\hline \multicolumn{2}{c}{ Field Column Parameters } \\
\hline Column diameter (cm) & 7.62 \\
Media Height (cm) & 91 \\
Mass SMZ/ZVI (kg) & 3.0 \\
Media Volume (L) & 4.1 \\
Measured Porosity & 0.71 \\
Pore Volume Size (L) & 2.9 \\
Avg. flowrate (L/min) & 0.78 \\
Specific discharge (cm/min) & 17.1 \\
Pore water velocity (cm/min) & 24.1 \\
Residence Time (min) & 3.8 \\
\hline
\end{tabular}

Table 1- 4: List of operating parameters used in the $30 \mathrm{~cm}$ columns tested in the lab.

\begin{tabular}{lr}
\hline \multicolumn{2}{c}{ Column Parameters } \\
\hline Column diameter $(\mathrm{cm})$ & 5.0 \\
Media Mass $(\mathrm{g})$ & 369.9 \\
Bedlength $(\mathrm{cm})$ & 30.0 \\
SMZ/ZVI Bulk Density $\left(\mathrm{g} / \mathrm{cm}^{\wedge} 3\right)$ & 0.70 \\
Porosity & 0.74 \\
Pore Volume $(\mathrm{mL})$ & 395 \\
Avg. Flowrate $(\mathrm{mL} / \mathrm{min})$ & 10.9 \\
Specific Discharge $(\mathrm{cm} / \mathrm{min})$ & 0.56 \\
Pore Velocity $(\mathrm{cm} / \mathrm{min})$ & 0.75 \\
Residence Time $(\mathrm{min})$ & 40.0 \\
\hline
\end{tabular}


Table 1- 5: List of operating parameters used in the $9 \mathrm{~cm} \mathrm{pH}$ adjusted column tested in the lab.

\begin{tabular}{|l|c|c|}
\hline & SMZ/ZVI & Raw Zeolite \\
\hline Column diameter $(\mathrm{cm})$ & 2.5 & 2.5 \\
\hline Empty Column weight $(\mathrm{g})$ & 222.5 & 221.5 \\
\hline Filled Column weight $(\mathrm{g})$ & 263.2 & 265.8 \\
\hline Media Mass $(\mathrm{g})$ & 40.7 & 44.31 \\
\hline Bedlength $(\mathrm{cm})$ & 9.0 & 9.2 \\
\hline Porosity & 0.71 & 0.60 \\
\hline Column wet $(\mathrm{g})$ & 294.6 & 292.9 \\
\hline Pore Volume $(\mathrm{mL})$ & 31.5 & 27.1 \\
\hline Flowrate $(\mathrm{mL} / \mathrm{min})$ & 6.0 & 6.0 \\
\hline Specific Discharge $(\mathrm{cm} / \mathrm{min})$ & 1.2 & 1.2 \\
\hline Residence Time $(\mathrm{min})$ & 5.2 & 4.5 \\
\hline Pore Velocity $(\mathrm{cm} / \mathrm{min})$ & 1.7 & 2.0 \\
\hline
\end{tabular}

Table 1- 6: Comparison of calculated parameters from the batch experiments and the three column experiments using the inverse solver within HYDRUS-1D. $\mathrm{K}_{\mathrm{A}}=\mathrm{K}_{\mathrm{L}} \times \mathrm{S}_{\mathrm{m}}$ where $\mathrm{K}_{\mathrm{L}}$ is the Langmuir coefficient and $\mathrm{S}_{\mathrm{m}}$ is the estimated maximum adsorption capacity. The Socorro Springs column had a short column residence time of 3.8 minutes, was tested with ambient Socorro Springs water, and was conducted at the Socorro wellhead field site. The Lab $(30 \mathrm{~cm})$ column study had long column residence times of 40 minutes, was tested with ambient Socorro Springs water, and was performed in the lab. The lab $\mathrm{pH}$ adjusted $(9 \mathrm{~cm})$ column had residence times of 5.2 minutes, was tested with Socorro Springs water adjusted to $\mathrm{pH} 6.6$, and was performed in the lab.

\begin{tabular}{cccc}
\hline Experiment & $\mathbf{S}_{\mathbf{m}}(\mathbf{m g} / \mathbf{k g})$ & $\mathbf{K}_{\mathbf{L}}(\mathbf{L} / \mathbf{m g})$ & $\mathbf{K}_{\mathbf{A}}(\mathbf{L} / \mathbf{k g})$ \\
\hline Batch Isotherm & 512 & $3.09 \mathrm{E}+01$ & 15800 \\
Socorro Springs $(90 \mathrm{~cm})$ & 18500 & $5.17 \mathrm{E}-02$ & 956 \\
Lab $(30 \mathrm{~cm})$ & 2654 & $2.28 \mathrm{E}-01$ & 605 \\
Lab pH adjusted $(9 \mathrm{~cm})$ & 224 & $1.51 \mathrm{E}+01$ & 3380 \\
\hline
\end{tabular}

Table 1- 7: Comparison of the ratio of pore volumes treated to the indicated concentration in parentheses compared with the ratio of the $\mathrm{K}_{\mathrm{A}}$ values calculated in Table 1-6 above.

\begin{tabular}{ccc}
\hline Columns Compared & Pore Volume Ratio & $\mathbf{K}_{\mathrm{A}}$ ratio \\
\hline $\begin{array}{c}\text { Socorro Springs/ } \\
\text { Lab } 30 \mathrm{~cm}(30 \mu \mathrm{g} / \mathrm{L})\end{array}$ & 1.6 & 1.6 \\
\hline $\begin{array}{c}\text { Lab } 9 \mathrm{~cm} \mathrm{pH} \mathrm{adj} . / \\
\text { Lab } 30 \mathrm{~cm}-(10 \mu \mathrm{g} / \mathrm{L})\end{array}$ & 4.0 & 5.6 \\
\hline
\end{tabular}


Table 1- 8: Comparison of the calculated Damkohler numbers $\left(D_{A}\right)$ for each column experiment. The Damkohler number is the ratio of the transport rate in the column to the calculated reaction rate for adsorption; it is defined as $\mathrm{D}_{\mathrm{A}}=\mathrm{kL} / \mathrm{v}$ where $\mathrm{k}$ is the reaction rate $\left(\mathrm{min}^{-1}\right), \mathrm{L}$ is the column length $(\mathrm{cm})$, and $\mathrm{v}$ is the average pore water velocity $(\mathrm{cm} / \mathrm{min})$. A reaction rate of $0.18 \mathrm{~min}^{-1}$ was used in all calculations based on the kinetic data in Section 1.3.1. $\mathrm{T}_{\mathrm{R}}$ is the column residence time.

\begin{tabular}{ccccc}
\hline Column Experiment & $\mathbf{L}(\mathrm{cm})$ & $\mathbf{v}(\mathrm{cm} / \mathrm{min})$ & $\mathbf{T}_{\mathbf{R}}(\mathbf{m i n})$ & $\mathbf{D}_{\mathbf{A}}$ \\
\hline Socorro Springs $(90 \mathrm{~cm})$ & 91 & 24 & 3.8 & 0.68 \\
Lab $(30 \mathrm{~cm})$ & 30 & 0.75 & 40 & 7.2 \\
Lab pH adjusted $(9 \mathrm{~cm})$ & 9.5 & 1.7 & 5.4 & 0.99 \\
\hline
\end{tabular}


ARTICLE II.

Arsenic Removal using Iron-Modified Zeolite (IMZ)

\author{
Jaron R. Andrews \\ Robert S. Bowman \\ New Mexico Institute of Mining and Technology
}

\begin{abstract}
We evaluated the ability of iron-modified zeolite (IMZ) to remove arsenic from a municipal water source. Eight different types of IMZ were prepared by coating 14 x 40 mesh zeolite (74\% clinoptilolite, 10\% feldspar, 10\% quartz and cristobalite, $5 \%$ illite, and $1 \%$ smectite) with $\mathrm{FeCl}_{2}$ or $\mathrm{FeCl}_{3}$ and then precipitating iron hydroxides with $\mathrm{NaOH}$. Each fully prepared IMZ was physically characterized by its iron content, surface area, and arsenic adsorption capacity. An arsenic batch isotherm was performed on each IMZ material using arsenic concentrations that ranged from $10-$ $200 \mathrm{mg} / \mathrm{L}$. The arsenic adsorption capacity varied greatly between the different types of IMZ and was heavily dependent on the procedures used for iron application. The most successful technique that resulted in good iron coating coverage, robustness, and a high arsenic adsorption capacity was a multi-step process that coated the iron on the zeolite in several smaller amounts rather than one large loading. The material chosen for further testing is labeled IMZ-8 and contained 28,400 $\pm 2600 \mathrm{mg}$ of iron per $\mathrm{kg}$. Compared with the raw zeolite that had a surface are of $13.8 \pm 0.1 \mathrm{~m}^{2} / \mathrm{g}$, the surface area of IMZ-8 increased about $50 \%$ to $21.4 \pm 2.6 \mathrm{~m}^{2} / \mathrm{g}$. Using the Langmuir Isotherm, IMZ-8 had a maximum arsenic adsorption capacity of $654 \mathrm{mg} / \mathrm{kg}$ and a Langmuir coefficient of $4.65 \mathrm{~L} / \mathrm{mg}$.

The IMZ-8 material was further tested by looking at the effects of $\mathrm{pH}$ on adsorption and by performing column breakthrough experiments. The material was
\end{abstract}


found to have maximum arsenic adsorption between $\mathrm{pH} 2.0$ and 7.0. For the column experiments, the IMZ-8 material was loaded into a glass column $10.5 \mathrm{~cm}$ in length and $2.5 \mathrm{~cm}$ in diameter. Water sourced from the Socorro Springs near the city of Socorro, $\mathrm{NM}$ (containing 41-45 $\mu \mathrm{g} / \mathrm{L}$ arsenate, $\mathrm{pH}=8.1$, and $\mathrm{TDS}=356 \mu \mathrm{S} / \mathrm{cm}$ ) was transported to the lab for column tests. The IMZ-8 column effluent arsenic concentration remained below $10 \mu \mathrm{g} / \mathrm{L}$ for 800 pore volumes. The IMZ-8 column was successfully regenerated 3 times with no loss of adsorption capacity using 1 L of 0.25 $\mathrm{M} \mathrm{NaOH}$ and $6 \mathrm{~L}$ of reverse osmosis water. However, the volume of water treated in the column experiment was less than that predicted by batch experiment results. The production of fine iron particles due to shaking and abrasion in batch experiments is thought to lead to an overestimation of the arsenic adsorption capacity. Additionally, high silica concentrations ( $25 \mathrm{mg} / \mathrm{L})$ in the Socorro Springs water are thought to inhibit arsenic adsorption in the column experiments. The IMZ-8 material may be a viable alternative for municipal water treatment due to the low cost of zeolite, the high arsenic adsorption capacity, and the easily regenerated media. The estimated cost of treating the local water was about $\$ 0.50$ per $1,000 \mathrm{~L}$. 


\subsection{INTRODUCTION}

The maximum contaminant level (MCL) for arsenic in drinking water was recently changed by the Environmental Protection Agency (EPA) from $50 \mu \mathrm{g} / \mathrm{L}$ to 10 $\mu \mathrm{g} / \mathrm{L}$ (EPA, 2001). The new drinking water regulation is estimated to affect about 3,000 municipal water systems and 11 million people in the United States (EPA, 2000). Arsenic is classified as a human carcinogen by the International Agency for Research on Cancer and the National Research Council (IARC, 1980; NRC, 2002). Arsenic can concentrate in the liver, kidneys, and skin by ingestion of groundwater over many years (Wu et al., 1989). Several studies have found dose-response relations between arsenic consumption in drinking water and cancers of the bladder, kidney, skin, lungs, and cancers of the prostate and liver in males (Wu et al., 1989, Bates et al. 1992).

Arsenic exists in groundwater predominantly as inorganic arsenite, As (III) $\left(\mathrm{H}_{3} \mathrm{AsO}_{3}, \mathrm{H}_{2} \mathrm{AsO}_{3}{ }^{-1}, \mathrm{HAsO}_{3}{ }^{-2}\right)$, and arsenate, $\mathrm{As}(\mathrm{V})\left(\mathrm{H}_{3} \mathrm{AsO}_{4}, \mathrm{H}_{2} \mathrm{AsO}_{4}{ }^{-1}, \mathrm{HAsO}_{4}{ }^{-2}\right)$ (Ferguson and Garvis, 1972). Arsenite As(III) species tend to dominate in anoxic environments, whereas arsenate $\mathrm{As}(\mathrm{V})$ species tend to dominate in oxic environments. Numerous remediation technologies have been developed to treat the large quantities of groundwater that contain high arsenic concentrations. The EPA's list of best available technologies for arsenic removal include: ion exchange, activated alumina, reverse osmosis, modified coagulation/ filtration, modified lime softening, electrodialysis reversal, and oxidation/filtration (EPA, 2000).

Zero-valent iron (ZVI) filings have been used by several investigators as

effective adsorbents for arsenic removal (Su and Puls, 1997; Farrell et al., 2001; Bang 
et al. 2005; Melitas et al., 2002; Nikolaidis et al., 2003). Zero-valent iron media and granular oxides are effective adsorbents, but there are many problems with their use (Mishra and Farrell, 2005). Maintaining a high arsenic adsorption capacity requires high porosity, which results in granules that are friable and easily compacted. If the media becomes compacted, frequent backwashings are necessary to maintain a high hydraulic conductivity. Granular ferric hydroxides also suffer from slow adsorption kinetics (Mishra and Farrell, 2005). Additionally, diffusion of arsenic species into large ferric hydroxide grains is very slow; effective intragranular diffusion coefficients are 5 to 7 orders of magnitude smaller than diffusion coefficients for the arsenic species in bulk solution (Badruzzaman et al., 2004). This indicates arsenic diffuses through the solution to the adsorbent surface, but is not able to effectively reach open adsorbent sites. Hence, having a thick iron oxide rind does not produce an effective media for arsenic adsorption.

This problem with intragranular arsenic diffusion was also noted in the previous article using Surfactant-Modified Zeolite/ Zero-Valent Iron (SMZ/ZVI). To alleviate problems with mass diffusion due to thick iron oxide rinds, several investigators have applied a coating of iron hydroxides/ oxides to the surface of materials such as sand (Joshi and Chaudhuri, 1996; Thirunavukkarasu et al., 2001; Ko et al., 2007), activated carbon (Jang et al., 2008), and zeolite (Onyango et al. 2003; Jeon et al., 2009). These materials are typically 1-5\% iron by mass and are prepared by coating the substrate media with a soluble iron solution and then drying, or precipitating iron hydroxides and then drying. 
The current paper presents 8 different methods of preparing iron-modified zeolite (IMZ) for arsenic removal. Zeolites are aluminosilicate minerals that are formed from groundwater interaction with volcanic ash. Zeolites have been used before for wastewater treatment due to their high cation-exchange capacity (CEC) and rigid structure. Applications of zeolite include removing cationic species such as ammonium and heavy metals from water (Bowman, 2003). The zeolite has also been modified to aid adsorption, and in some cases the degradation of contaminants. Bowman (2003) summarizes the use of surfactant-modified zeolites (SMZ) for the treatment of contaminants such as organic species from produced oil waters, pathogens, anionic contaminants, and chlorinated solvents.

The current work builds upon this knowledge and now looks at modifying zeolites with iron oxides for arsenic removal. Several different formulations of IMZ were prepared and evaluated for their arsenic removal characteristics. The iron content, surface area, and arsenic removal properties of each prepared media was analyzed. One of the IMZ formulations was chosen for further testing by looking at arsenic removal in a column transport setting, and the effect of $\mathrm{pH}$ on arsenic removal. Additionally, the column was regenerated several times to evaluate long-term removal characteristics. The overall goal of the experiment was study the physical and chemical properties of IMZ for arsenic removal. 


\subsection{METHODS AND MATERIALS}

\subsubsection{Water Solutions}

Two different water solutions were used in experiments; the first solution was a synthetic water prepared in the lab and the second was spring water sourced from the Socorro Springs wellhead. The synthetic water solution was made by adding $0.42 \mathrm{~g}$ of $\mathrm{NaHCO}_{3}, 0.20 \mathrm{~g}$ of $\mathrm{CaCl}_{2}$, and $0.150 \mathrm{~g}$ of $\mathrm{MgSO}_{4}$ into $2 \mathrm{~L}$ of $18 \mathrm{M} \Omega$ reverse osmosis water. The $18 \mathrm{M} \Omega$ reverse osmosis water will be referred to as "Type I" water throughout the experiment. The synthetic water solution was made to try and simulate the chemistry of the Socorro Springs water that would be used in column studies. The Socorro Springs wellhead water is a combination of water from two natural springs (Socorro Springs and Sedillo Springs) that is mixed upstream of the wellhead. The water is warm year-round $\left(\sim 30-35^{\circ} \mathrm{C}\right)$ and has an arsenic concentration of $40-45 \mu \mathrm{g} / \mathrm{L}$. Table 2-1 contains a comparison of the water chemistry of the synthetic water solution and the Socorro Springs water. The Socorro Springs water was transported to the lab using $20 \mathrm{~L}$ and $50 \mathrm{~L}$ carboys and was not treated or altered. The water was stored and used in column experiments at room temperature $\left(21^{\circ} \mathrm{C}\right)$.

\subsubsection{Material Preparation}

Eight different IMZ formulations were created to test the effects of arsenic adsorption using different preparation procedures and to optimize the material for arsenic adsorption. In each case, the material was prepared by using either anhydrous ferric chloride $\mathrm{FeCl}_{3}$ (Acros Organics), or hydrated ferrous chloride $\mathrm{FeCl}_{2} \bullet 4 \mathrm{H}_{2} \mathrm{O}$ (Acros Organics), along with sodium hydroxide pellets (Fischer Scientific). The 
zeolite used in all formulations was sourced in 2007 from the St. Cloud Zeolite Mine near Winston, NM. The zeolite was sorted at the mine to $14-40$ mesh $(0.4 \mathrm{~mm}-1.4$ $\mathrm{mm}$ ) and no further preparation was performed. The mineral content of the St. Cloud zeolite based on X-Ray Diffraction (XRD) analysis was 74\% clinoptilolite, $5 \%$

smectite, $10 \%$ quartz plus cristobalite, and 1\% illite (Bowman, 2003). The zeolite had an internal cation exchange capacity (CEC) of $800 \mathrm{meq} / \mathrm{kg}$ and an external CEC of $100 \mathrm{meq} / \mathrm{kg}$ (Bowman, 2003).

After coating, all zeolite and iron solutions were dried in a Fischer Model $13 \mathrm{~F}$ laboratory oven at $140{ }^{\circ} \mathrm{C}$ in glass pyrex baking pans. All samples were shaken using a New Brunswick Scientific Innova 4335 incubator/ shaker at $25^{\circ} \mathrm{C}$ and centrifuged using a Beckman J2-MI centrifuge. The zeolite prepared in each preparation scheme will be referred to as IMZ-1, IMZ-2, etc.

The basic goal in each preparation was to precipitate any adsorbed ferrous or ferric iron onto the zeolite surface to form an amorphous iron hydroxide by application of $\mathrm{NaOH}$.

$$
\begin{aligned}
& \mathrm{Fe}^{2+}+2\left(\mathrm{OH}^{-}\right) \rightarrow \mathrm{Fe}(\mathrm{OH})_{2} \\
& \mathrm{Fe}^{3+}+3\left(\mathrm{OH}^{-}\right) \rightarrow \mathrm{Fe}(\mathrm{OH})_{3}
\end{aligned}
$$

The following preparation schemes list the steps and materials used to make each IMZ material.

\section{Preparation 1}

A glass column $30 \mathrm{~cm}$ in length and $5 \mathrm{~cm}$ in diameter was filled with $527 \mathrm{~g}$ of raw zeolite. The column was flooded with $\mathrm{CO}_{2}$ for one hour to remove any air, and 
then $2 \mathrm{~L}$ of a $10 \%$ by mass $\mathrm{FeCl}_{2} \cdot 4 \mathrm{H}_{2} \mathrm{O}$ solution was passed through the column at a flowrate of $5.3 \mathrm{~mL} / \mathrm{min}$ using a peristaltic pump. The ferrous iron chloride solution was followed by $2.5 \mathrm{~L}$ of Type I water at the same flowrate. This was then followed by 2 L of Type I water adjusted to $\mathrm{pH} 11.0$ using $1 \mathrm{M}$ sodium hydroxide. After all of the basic water had passed through, the column was drained and air-dried overnight. The air-dried IMZ was then oven-dried for 4 hours.

\section{Preparation 2}

A glass column $30 \mathrm{~cm}$ in length and $5 \mathrm{~cm}$ in diameter was filled with $550 \mathrm{~g}$ of raw zeolite. The column was rinsed with $700 \mathrm{~mL}$ of Type I water and then the influent was switched to $500 \mathrm{~mL}$ of a $10 \% \mathrm{FeCl}_{2} \cdot 4 \mathrm{H}_{2} \mathrm{O}$ solution at a flowrate of 5.6

$\mathrm{mL} / \mathrm{min}$. The $10 \% \mathrm{FeCl}_{2} \bullet 4 \mathrm{H}_{2} \mathrm{O}$ solution was allowed to sit in the column for 5 days after which the column was drained. Compressed air was then pumped through the column at a flowrate of about $5 \mathrm{~L} / \mathrm{min}$ until the column was dry (6 hours elapsed time). The column was again flooded with $\mathrm{CO}_{2}$ for 1 hour and then rinsed with $1 \mathrm{~L}$ Type I water adjusted to $\mathrm{pH} 13.25$ with $1 \mathrm{M}$ sodium hydroxide. The column was then drained, air-dried in a pan overnight, and then oven-dried for 4 hours.

\section{Preparation 3}

Two-hundred and fifty grams of raw zeolite was mixed with $250 \mathrm{~mL}$ of a $10 \%$ $\mathrm{FeCl}_{3}$ solution. The $\mathrm{pH}$ of the solution was then adjusted to greater than 10 using a 0.1 $\mathrm{M} \mathrm{NaOH}$ solution, consuming $\sim 500 \mathrm{~mL}$ of the $0.1 \mathrm{M} \mathrm{NaOH}$ solution. The solution was allowed to sit for several hours and allow the iron particles to settle; part of the 
supernatant was then poured off. The slurry was then placed into an oven and dried overnight.

\section{Preparation 4}

A glass column $30 \mathrm{~cm}$ in length and $5 \mathrm{~cm}$ in diameter was filled with $552 \mathrm{~g}$ of raw zeolite. The column was purged with $\mathrm{CO}_{2}$ for 1 hour and was then rinsed with 1.5 $\mathrm{L}$ of Type I water. The column influent was then changed to $1 \mathrm{~L}$ of $10 \% \mathrm{FeCl}_{3}$ solution. The column was then rinsed with $500 \mathrm{~mL}$ of Type I water and then $2 \mathrm{~L}$ of a 0.1 M NaOH solution. This was followed again by $500 \mathrm{~mL}$ of Type I water. The column was then flooded with $500 \mathrm{~mL}$ of the same $10 \% \mathrm{FeCl}_{3}$ solution and then drained. The influent was then switched to the $0.1 \mathrm{M} \mathrm{NaOH}$ solution. During this last step, the column became plugged with iron hydroxides; the column was then abandoned and the preparation of IMZ-4 was incomplete. IMZ-4 was not used in any further experiments.

\section{Preparation 5}

This preparation was a repeat of preparation 3 except that slightly more of the $10 \%$ iron chloride solution was added to the zeolite. Two-hundred and fifty grams of raw zeolite was mixed with $350 \mathrm{~mL}$ of a $10 \% \mathrm{FeCl}_{3}$ solution. The $\mathrm{pH}$ of the solution was then adjusted to greater than 10 using a $0.1 \mathrm{M}$ sodium hydroxide solution (consumed $\sim 500 \mathrm{~mL}$ of the $0.1 \mathrm{M}$ solution). The solution was allowed to sit for several hours and part of the excess fluid was poured off. The slurry was then placed into an oven and dried overnight. 


\section{Preparation 6}

This preparation used $400 \mathrm{~g}$ of the IMZ from preparation 5 and then recoated the zeolite a second time. Four hundred grams of preparation 5 zeolite was placed in a baking pan. Four hundred milliliters of a $10 \% \mathrm{FeCl}_{3}$ was mixed with $70 \mathrm{~mL}$ of a $6 \mathrm{~N}$ $\mathrm{NaOH}$ solution to reach a final $\mathrm{pH}$ of 10.9 ; the $\mathrm{pH}$ adjusted $\mathrm{FeCl}_{3}$ solution was then poured over the zeolite from preparation 5 and placed in the oven and dried overnight.

\section{Preparation 7}

One-hundred grams of raw zeolite was placed in a $500 \mathrm{~mL}$ beaker and mixed with $60 \mathrm{~mL}$ of a $10 \% \mathrm{FeCl}_{3}$ solution. After 2-3 minutes of stirring the slurry was poured into a large vacuum funnel fitted with a 60 mesh $(0.23 \mathrm{~mm})$ stainless steel screen. The $\mathrm{FeCl}_{3}$ solution was collected and the solid material was air dried and then rinsed with $200 \mathrm{~mL}$ of a $1 \mathrm{M} \mathrm{NaOH}$ solution. The zeolite was then air-dried and the steps above were repeated two more times such that the zeolite was rinsed with the $\mathrm{FeCl}_{3}$ and $\mathrm{NaOH}$ solutions three times. The material was then placed into a baking sheet and placed in the oven for 4 hours.

\section{Preparation 8}

Two-hundred and fifty grams of raw zeolite was mixed with $250 \mathrm{~mL}$ of a $10 \%$ $\mathrm{FeCl}_{3}$ solution and placed into a $500 \mathrm{~mL}$ plastic bottle. The bottle was then shaken at 125 RPM on an orbital shaker for 6 hours. After 6 hours the bottle was removed and centrifuged at $1,000 \times \mathrm{g}$ for 5 minutes and the supernatant was decanted. Then, 175 $\mathrm{mL}$ of a $1 \mathrm{M} \mathrm{NaOH}$ solution was added to the bottle. The mixture was then shaken at 
125 RPM for 3 more hours. The mixture was then poured into a large baking pan and dried for 12 hours. This procedure was repeated two more times such that the zeolite went through three rinse-shaking steps. After the last drying step, the material was placed again in a large baking pan and then covered with $200 \mathrm{~mL}$ of a fresh $10 \% \mathrm{FeCl}_{3}$ solution. Fifty milliliters of a $6 \mathrm{~N} \mathrm{NaOH}$ solution were then poured over the material and the slurry was thoroughly mixed; the final $\mathrm{pH}$ of the slurry was near 10.0. The material was then placed in an oven for drying and stirred every hour to mix in any precipitated iron hydroxide. After drying, the material was sieved through a 14 mesh screen to eliminate clumps. This procedure was repeated several times to produce about $3 \mathrm{~kg}$ of material.

\subsubsection{Surface Area Analyses}

Surface area analyses were performed using a Quantachrome NOVA 2200e Surface area and Pore Analyzer with the Brunauer-Emmett-Teller (BET) method (Brunauer, 1938). The adsorbate gas was ultra high purity nitrogen and the coolant used was liquid nitrogen. Samples were analyzed using calibrated $9 \mathrm{~mm}$ by $150 \mathrm{~mm}$ sample cells without filler rods. A Quantachrome surface area reference material was analyzed at the beginning and end of each day to determine the instrument's accuracy. The standard was degassed under vacuum for 3 hours at $200{ }^{\circ} \mathrm{C}$ prior to analysis. All sample surface areas were adjusted based on the reported surface area of the standard. All sample weights were determined after degassing.

Several raw zeolite samples were analyzed at different temperatures and degassing times. Similar to the results of other authors (Sullivan, 1997), the surface 
area was a function of temperature and degassing time. A degassing time of 3 hours and a temperature of $200{ }^{\circ} \mathrm{C}$ was used to match similar experiments by Sullivan (1997), and because no change in sample weight occurred with longer degassing times. A five-point multiple-point BET analysis as well as a single-point BET analysis was conducted on each sample. The multi-point BET analysis was conducted in the pressure range $\mathrm{P} / \mathrm{Po}=0.05$ to 0.3 , while the single $\mathrm{BET}$ analysis was conducted at a relative pressure of 0.3 .

\subsubsection{Arsenic Analyses}

All water samples were analyzed for arsenic using Inductively Coupled Plasma-Optical Emission Spectroscopy (ICP-OES) with a continuous flow hydride generator (model: Optima 5300 DV, Perkin Elmer, Waltham, Massachusetts). The hydride generation manifold and reagents are described by Bosnak and Davidowski (2004). Arsenic standards and reagents were made fresh for each analysis; standard concentrations ranged from 1 to $1,000 \mu \mathrm{g} / \mathrm{L}$. Quality control standards from the United States Geological Survey (USGS) standard reference samples program were used to check the standards accuracy. An arsenic detection limit of $0.05 \mu \mathrm{g} / \mathrm{L}$ was found based on the standard deviation of 10 consecutive measurements of a $1 \mu \mathrm{g} / \mathrm{L}$ standard. The maximum error in arsenic concentrations was $\pm 3 \%$ based on replicate analyses of a 10 $\mu \mathrm{g} / \mathrm{L}$ USGS standard conducted during each arsenic analysis.

The arsenic was only analyzed for total arsenic and not speciated; this nonspeciated analysis technique is supported by the work of Farrell et al. (2001) and Nikolaidis et al. (2003) as they found that there was no change in arsenic speciation 
upon adsorption. The Socorro Springs water contains $~ 95 \%$ As(V) (see Table 2-1) and the arsenic species is not expected to change; $\mathrm{As}(\mathrm{III})$ is easily converted to $\mathrm{As}(\mathrm{V})$ by oxidizing agents such as oxygen, ozone, free chlorine, hypochlorite, permanganate, and hydrogen peroxide (Frank and Clifford, 1986). The majority of arsenic species that occur after chlorination in municipal water supplies should be the $\mathrm{As}(\mathrm{V})$ arsenate species.

Further information about the instrument setup and measurement conditions can be found in Appendix F.

\subsubsection{Iron Analysis}

Iron-modified zeolite formulations were evaluated for their iron content by acid leaching the iron from the zeolite surface. Two grams of each material was placed in a $50 \mathrm{~mL}$ beaker and $10 \mathrm{~mL}$ of concentrated $\mathrm{HCl}$ was added to each. Each beaker was then covered with a watch glass and refluxed for 30 minutes at $90{ }^{\circ} \mathrm{C}$. The resulting liquid was light to dark orange in color while the zeolite material turned bleached white at the end of the refluxing. The resulting zeolite and acid solution was filtered through a Whatman \#2 filter paper $(8 \mu \mathrm{m})$. The beaker and left-over solids contained in the filter were washed 5 times with Type I water adjusted to $\mathrm{pH} 1.9$ with concentrated $\mathrm{HCl}$. The filtrate was then transferred to a $1 \mathrm{~L}$ volumetric flask and diluted to $1 \mathrm{~L}$ with Type I water. The resulting liquid was stored in $50 \mathrm{~mL}$ polyethylene bottles until analysis. Each iron leaching analysis was repeated in triplicate and a blank acid and Type I water solution was analyzed at the beginning of each run. 
The IMZ extract was analyzed via flame atomic absorption spectrophotometry (FAAS) using an Instrumentation Laboratory Video 12 flame atomic absorption spectrophotometer. An acetylene style burner torch was used with a hallow cathode iron lamp. The wavelength for analysis was $372 \mathrm{~nm}$; the lamp current was 10 milliamps and the voltage was 460 millivolts. The fuel was acetylene while the oxidant was compressed air sourced from the building. The measured flowrate of the liquid nebulizer tube was found to be $2.2 \mathrm{~mL} / \mathrm{min}$.

Standards ranged from $1 \mathrm{mg} / \mathrm{L}$ to $100 \mathrm{mg} / \mathrm{L}$ and were made from dilution of $\mathrm{FeCl}_{3} \cdot 6 \mathrm{H}_{2} \mathrm{O}$ salt solution made to $1,000 \mathrm{mg} / \mathrm{L}$. All standards were diluted with $\mathrm{pH}$ 2.0 Type I water. A commercial $1,000 \mathrm{mg} / \mathrm{L}$ multi-element standard was measured using the salt-prepared standards and was within $4 \%$ of the reported value. A quadratic fit was used for all calculations. Each measured standard and sample was the average of 5 repeated measurements. A standard was re-measured every three samples to check for instrument drift.

\subsubsection{Batch Isotherms}

A batch isotherm was performed on each IMZ formulation to look at the effect of the preparation procedure on the iron adsorption capacity. Each isotherm consisted of adding $5 \mathrm{~g}$ of the IMZ material to a $40 \mathrm{~mL}$ centrifuge tube and then adding $20 \mathrm{~mL}$ of a synthetic water solution that was spiked with arsenic. The initial arsenic concentrations used in solution were 10, 25, 50, 100, and $200 \mathrm{mg} / \mathrm{L}$. Arsenic solutions were prepared from sodium arsenate heptahydrate salts $\left(\mathrm{Na}_{2} \mathrm{HAsO}_{4} \cdot 7 \mathrm{H}_{2} \mathrm{O}\right)$ and diluted using the synthetic water solution. Each solution was adjusted to an initial $\mathrm{pH}$ 
of $7.00 \pm .05$ using concentrated $\mathrm{HCl}$ to eliminate variable initial $\mathrm{pH}$ values due to the high arsenate concentrations. The $\mathrm{pH}$ values were measured using an Orion $15 \mathrm{pH}$ meter that was calibrated daily with commercial $\mathrm{pH} 4.01$ and 7.00 buffers.

Each centrifuge tube was made in duplicate and equilibrated for 4 hours on an end-over-end shaker at $17 \mathrm{RPM}$ and $25^{\circ} \mathrm{C}$. Each tube was then centrifuged at $2500 \times$ $\mathrm{g}$ for 5 minutes; the supernatant was then filtered through a $0.2 \mu \mathrm{m}$ filter. The $\mathrm{pH}$ of each solution was recorded, and then the filtered solution was acidified to less than $\mathrm{pH}$ 2 using concentrated $\mathrm{HCl}$. The samples were then analyzed on an ICP-OES for total arsenic.

\subsection{7 pH Dependence}

A study to determine the effect of $\mathrm{pH}$ on arsenic adsorption was conducted by making 12 different solutions of varying $\mathrm{pH}$. One liter of $100 \mathrm{ppm}$ arsenic solution was made using synthetic water solution and divided into twelve $50 \mathrm{~mL}$ portions. Each portion was adjusted to a $\mathrm{pH}$ ranging from 1.5 to 12 using concentrated $\mathrm{HCl}$ or $1 \mathrm{M}$ $\mathrm{NaOH}$. The volume of acid or base added was recorded and used in calculating the starting concentration. Twenty milliliters of the $\mathrm{pH}$-adjusted arsenic solutions was then added to $5 \mathrm{~g}$ of IMZ-8 in a $40 \mathrm{~mL}$ centrifuge tube. The centrifuge tubes were placed on an end-over-end shaker at $17 \mathrm{RPM}$ at $25^{\circ} \mathrm{C}$ and left to equilibrate for 3 hours. After equilibration, the samples were removed and centrifuged at $2500 \times \mathrm{g}$ for 5 minutes. The samples were then filtered using $0.2 \mu \mathrm{m}$ filters and the final $\mathrm{pH}$ was measured. The samples were acidified to less than $\mathrm{pH} 2.0$ using concentrated $\mathrm{HCl}$ and stored in plastic vials until analyzed. 


\subsubsection{Column Studies}

A single column study was performed to investigate the arsenic removal properties in a transport setting. A glass column $10.5 \mathrm{~cm}$ in length and $2.5 \mathrm{~cm}$ in diameter was filled with $51.1 \mathrm{~g}$ of IMZ-8 and then flooded with $\mathrm{CO}_{2}$ for two hours. The column influent was then switched to water sourced from the Socorro Springs wellhead. The measured column parameters can be found in Table 2-2. The column effluent was sampled every 12 hours or about 100 pore volumes. Sampling consisted of removing the effluent drain hose and filling a plastic $30 \mathrm{~mL}$ vial. No filtering of the effluent was performed; analysis of samples that were filtered through $0.2 \mu \mathrm{m}$ filters and unfiltered sample showed less than $1 \%$ difference in arsenic concentrations. The collected sample was then acidified to less than $\mathrm{pH} 2.0$ using concentrated $\mathrm{HCl}$. The column was sampled until the effluent concentration was above $10 \mu \mathrm{g} /$; in some cases, the column effluent was allowed to reach higher than $10 \mu \mathrm{g} / \mathrm{L}$ to observe the full breakthrough curve. After each arsenic breakthrough curve, the column was regenerated.

The column regeneration consisted of eluting $1 \mathrm{~L}$ of $0.25 \mathrm{M} \mathrm{NaOH}$ through the column at a flowrate of $5.6 \mathrm{~mL} / \mathrm{min}$. The $\mathrm{NaOH}$ solution was then followed by $6 \mathrm{~L}$ of Type I water to rinse the excess $\mathrm{NaOH}$ from the column. After the $6 \mathrm{~L}$ of Type I water, the conductivity of the effluent was less than $50 \mu \mathrm{S} / \mathrm{cm}$. The $\mathrm{NaOH}$ effluent and subsequent rinse water was collected and the arsenic concentration of each rinse portion was analyzed for mass balance calculations. The column was regenerated a total of three times and treated over $150 \mathrm{~L}$ of water. 


\subsubsection{HYDRUS Modeling}

The computer modeling program HYDRUS-1D was used for simulating column experiment results and for analyzing the collected data. HYDRUS-1D was originally developed to simulate vertical flow of water, solutes, and heat in a variably saturated vadose zone. HYDRUS-1D numerically solves the Richards equation for variably saturated flow and the convection-dispersion equation for solute transport; the program uses Galerkin-type linear finite element schemes. The background information and governing equations can be found in Simunek et al. (2008). The program was used in this study for post-data analysis for fitting adsorption parameters to the breakthrough curves. Non-linear solute adsorption was used in this study and the general adsorption equation is shown below (Simunek et al., 2008):

$$
\begin{aligned}
& \qquad s=\frac{k c^{\beta}}{1+\eta c^{\beta}} \\
& s=\text { adsorbed concentration }[\mathrm{mg} / \mathrm{kg}] \\
& c=\text { solution concentration }[\mathrm{mg} / \mathrm{L}] \\
& k=\text { empirical adsorption coefficient }[\mathrm{L} / \mathrm{mg}] \\
& \eta=\text { empirical adsorption coefficient }[\mathrm{L} / \mathrm{mg}] \\
& \beta=\text { empirical adsorption coefficient }[-]
\end{aligned}
$$

The Freundlich, Langmuir, and linear isotherm equation are all special cases of the equation above. When $\eta=0$ the equation becomes the Freundlich adsorption isotherm; when $\beta=1$ the equation becomes the Langmuir isotherm, and when $\eta=0$ and $\beta=1$, the equation become the linear adsorption isotherm. An example of the parameters used to predict the breakthrough curves from batch experiment is listed in Appendix D. The inverse solver option allowed for the observed column effluent volume and arsenic concentration to be entered, and then the adsorption parameters 
were optimized to fit the observed data. . In all cases, the dispersivity of the column was set to be the media bed length; this was set because dispersivities greater then $10^{7}$ $\mathrm{cm}$ were obtained with the parameter fitted to the data.

The software was set to always have saturated flow by specifying a unit head gradient across the length of the column; this allowed for the saturated conductivity of the media to be altered to match the observed flowrate in the columns. The porosity, bulk density, and specific discharge were based on values calculated from weighing the column empty and then filled with water. The column was specified to be fully saturated, free of air, and vertically oriented. 


\subsection{RESULTS}

\subsubsection{Material Preparation}

The preparation schemes outlined in the methods section produced zeolites that had various amounts of iron and various degrees of adhesion of iron particles. Quantitative measurements of the iron content showed that the iron loading caused a two-fold to near six-fold increase in the iron content of the zeolite. Table 2-3 presents the results from the acid leaching experiments. The raw zeolite was less than $1 \%$ iron oxide, while the material with the highest iron loading was over $4 \%$ iron oxide by mass. Jeon et al. (2009) used a 1-step coating process in a rotary evaporator and found the superficial iron content was $22,300 \mathrm{mg} / \mathrm{kg}$ or $2.32 \mathrm{wt} \% \mathrm{Fe}_{2} \mathrm{O}_{3}$. The multi-step coating process employed in this study resulted in a higher iron concentration and should theoretically provide more adsorption sites.

Several qualitative robustness tests were performed via mixing each one of the prepared IMZ's in a beaker with $50 \mathrm{~mL}$ of water. Gentle stirring of each beaker showed that large amounts of very fine iron particles were washed off IMZ-3, 5, and 6. This loss of available adsorption sites is undesirable for column transport as the iron (and any adsorbed arsenic) will be washed away. Therefore, the preparation schemes were changed in the preparation of IMZ-7 and IMZ-8, such that the iron was applied in several smaller doses initially. This led to better attachment of the iron onto the zeolite surface and little loss of iron particles was observed during rinse tests. The heavier applications that occurred later in the preparation of IMZ-7 and IMZ-8 appeared to precipitate onto the iron hydroxides already on the surface of the zeolite, rather than being just suspended in solution and then drying on the zeolite surface. 
This robustness of the material is an important factor for column settings where the iron and adsorbed arsenic need to remain within column and not wash away in solution. For these reasons, the IMZ-8 material was produced in bulk and used in further column experiments.

\subsubsection{Surface Area Analyses}

The surface area measurements for several of the IMZ formulation are presented in Table 2-4. The raw zeolite was found to have a surface area of $13.8 \pm 0.1$ $\mathrm{m}^{2} / \mathrm{g}$; this value is slightly lower than the reported value of $15.7 \mathrm{~m}^{2} / \mathrm{g}$ by Sullivan (1997), but within the range as reported by Bowman (2003) of 13.3 to $15.2 \mathrm{~m}^{2} / \mathrm{g}$. The surface area of a typical sand is about $0.044 \mathrm{~m}^{2} / \mathrm{g}$, while that for a typical smectite clay is $750 \mathrm{~m}^{2} / \mathrm{g}$ (Jury and Horton, 2004). In terms of the use in water treatment, sand offers a high hydraulic conductivity, but has a low surface area; clays have very high surface areas, but they have such low hydraulic conductivities that they are not very useful for water treatment. The primary reasons zeolite was chosen to be coated with iron was for its high surface area, high CEC, and rigid three dimensional structure that maintains high hydraulic conductivity.

After coating with the iron hydroxides, it was found that the surface area increased with iron content (see Table 2.4). Interestingly, the surface area of some of the altered zeolites was actually reduced after iron modification. It is speculated that the iron hydroxides adsorbed to the surface have acted as a type of plug that has blocked off some of the internal pore spaces of the zeolite. Once the iron content has become large enough, the surface area increases due to the presence of a more uniform 
iron hydroxide coating. The surface area of some other common adsorptive materials for comparison are $\mathrm{Fe}_{2} \mathrm{O}_{3}-5.05 \mathrm{~m}^{2} / \mathrm{g}$, iron oxide-coated sand $-5.1 \mathrm{~m}^{2} / \mathrm{g}$, and ferrihydrite - $141 \mathrm{~m}^{2} / \mathrm{g}$ (Jeong et al., 2007; Thirunavukkarasu et al., 2001). The high surface area of the IMZ-8 compared with that of plain iron oxide or iron-oxide coated sand shows the advantageous nature of using zeolite as the base substrate. The zeolite's relatively high surface area allows for the adsorption and precipitation of iron hydroxides over a much larger area than sand or plain iron oxides. The larger number of adsorption sites should lead to a higher arsenic adsorption capacity.

\subsubsection{Batch Isotherms}

The batch isotherm results showed wide variability in the arsenic adsorption capacity for each media. The method in which the iron was applied had a great impact on the adsorption behavior. Figure 2-1 contains a summary of all of the isotherm results from the IMZ preparations. The media with the highest arsenic adsorption capacity was found to be IMZ-6, while the media with the lowest adsorption capacity was IMZ-2. Both the Freundlich and Langmuir equations were fit to the data for ease of comparison with other published studies. The basic assumption underlying the Langmuir isotherm model are 1) that the molecules are adsorbed on definite sites on the surface of the adsorbent; 2) each site can accommodate only one molecule (monolayer), and the area of each site is a fixed quantity determined by the geometry of the surface; and 3) the adsorption energy is the same at all sites (Faust and Aly, 1987). The Freundlich equation is an empirical expression that encompasses the 
heterogeneity of the surface and the exponential distribution of sites and their energies (Thirunavukkarasu et al., 2001).

It was found that the Freundlich isotherm best described the adsorption behavior of some of the media, while the Langmuir equation had a better fit with other formulations. The Freundlich and Langmuir isotherm equations are as follows (Drever, 1997):

$$
\begin{aligned}
& \text { Freundlich Equation } \\
& \qquad S=K_{F} C^{N} \\
& S=\text { concentration adsorbed }[\mu g / \mathrm{kg}] \\
& K_{F}=\text { Freunlich emperical coefficient }\left[\mu \mathrm{g}^{(1-N)} \mathrm{kg}^{-1} \mathrm{~L}^{N}\right] \\
& C=\text { equilbrium concentration }[\mu \mathrm{g} / \mathrm{L}] \\
& N=\text { emperical coefficient }
\end{aligned}
$$

The linear form of the Freundlich equation that was used to calculate adsorption parameters and is obtained by taking the logarithm of each side:

$$
\log (S)=\log \left(K_{F}\right)+N \log (C)
$$

The Langmuir equation is written as:

$$
\begin{gathered}
\text { Langmuir Equation } \\
S=\frac{S_{m} K_{L} C}{1+K_{L} C} \\
S=\text { adsorbed concentration }[\mathrm{mg} / \mathrm{kg}] \\
C=\text { concentration in solution }[\mu \mathrm{g} / \mathrm{L}] \\
K_{L}=\text { empirical Langmuir coefficient }[\mathrm{L} / \mu \mathrm{g}] \\
S_{M}=\text { maximum adsorbed concentration }[\mathrm{mg} / \mathrm{kg}]
\end{gathered}
$$


The linear form of the Langmuir equation that was used to calculate adsorption parameters is obtained by rearranging the equation as follows:

$$
\frac{1}{S}=\frac{1}{S_{m}}+\frac{1}{K_{L} S_{m}} \frac{1}{C}
$$

Table 2-5 presents the results from fitting the linearized forms of both equations to each IMZ isotherm. For detailed fitting results see Appendix E. The adsorption capacity of raw zeolite was very low and is negligible in terms of the arsenic adsorbed by the iron hydroxides. Table 2-5 shows that there is a weak correlation between the iron content and the surface area of the media. There are no strong correlations between the iron content of the media and the arsenic adsorption capacity, or the surface area and the arsenic adsorption capacity. Siegel et al. (2007) also found in a test of several different types of commercial media that the surface area did not determine the adsorption capability. It was originally thought that the arsenic adsorption capacity would be directly related to the iron content due to the number of available adsorption sites. This lack of correlation shows that the manner in which the zeolite is coated with iron has a large impact on the arsenic removal capabilities of the final product.

The reason that some of the media with lower iron content had high adsorption capacity is thought to be due to the release of small iron particles due to abrasion during the batch experiments. The end-over-end shaking in the centrifuge tubes during batch experiments caused iron particles that are not firmly attached to the surface to slough off and be released in solution. This is particularly seen in IMZ-6 and IMZ-8. The preparation for IMZ-6 first precipitated the iron particles in solution and then 
dried the slurry that was poured over the zeolite. This left the iron particles loosely attached to the iron surface and easily washed off. These tiny iron particles are thought to have lead to the high adsorption coefficient for IMZ-6.

The preparation for IMZ-8 is thought to have allowed $\mathrm{Fe}^{3+}$ to be adsorbed to the zeolite surface first, and then the iron hydroxides were precipitated with $\mathrm{NaOH}$. This procedure resulted in the iron hydroxide particles being more firmly attached to the zeolite surface and reduced the number of fines released during the batch experiments. Though this did not produce as high of an arsenic adsorption capacity based on batch experiments, IMZ-8 was chosen for further column experiments because of its robustness and still relatively high arsenic adsorption capacity. Qualitative column experiments using IMZ-6 material showed that most of the iron particles could be washed off with high flowrates and lead to early column breakthrough.

The IMZ formulations had similar or slightly higher maximum arsenic adsorption capacities $\left(\mathrm{S}_{\mathrm{m}}\right)$ as those of other media previously reported by several authors. Table 2-6 relates the maximum arsenic adsorption capacities as calculated by the linear Langmuir equation from batch isotherm results with those of other adsorptive media.

\subsection{4 pH Dependence}

The adsorption of arsenic onto the IMZ-8 material was found to be highly pH dependent. Figure 2-2 shows the arsenic concentrations in solution after equilibration with an arsenic solution at several different $\mathrm{pH}$ values. The measured values in Figure 
2-2 are the final $\mathrm{pH}$ values after equilibration; the initial $\mathrm{pH}$ values can be found in Table 2-7. The gap in data from $\mathrm{pH} 2$ to $\mathrm{pH} 6$ is an artifact of the initial $\mathrm{pH}$ of the solutions and the buffering capacity of the medium. The initial solutions varied by about $1 \mathrm{pH}$ unit for each sample. Solutions with initial $\mathrm{pH}$ values from about 1.5 to 7.0 had a final $\mathrm{pH}$ near 7.0. Several solutions with initial starting $\mathrm{pH}$ values lower than 1.5 were used, but all of the iron hydroxides were dissolved into solution and the arsenic concentration of these samples was not measured. A final solution $\mathrm{pH}$ of about 2.5 was the highest $\mathrm{pH}$ that was observed after equilibration with the media still intact.

The trends in $\mathrm{pH}$ dependent behavior are thought to be due to hydroxide ligand exchange during adsorption. Elizalde- Gonzalez et al. (2001) and Jeon et al. (2009) reported that arsenate was removed using iron oxi-hydroxides/ oxides through ligand exchange with hydroxide ions through the following reactions:

$$
\begin{aligned}
& \equiv \mathrm{Fe}-\mathrm{OH}+\mathrm{H}_{2} \mathrm{AsO}_{4}{ }^{-} \leftrightarrow \equiv \mathrm{Fe}-\mathrm{OAsO}_{3} \mathrm{H}_{2}+\mathrm{OH}^{-} \\
& \equiv \mathrm{Fe}-\mathrm{OH}_{2}{ }^{+}+\mathrm{H}_{2} \mathrm{AsO}_{4}{ }^{-} \leftrightarrow \equiv \mathrm{Fe}-\mathrm{OAsO}_{3} \mathrm{H}_{2}+\mathrm{H}_{2} \mathrm{O} \\
& \equiv \mathrm{Fe}-\mathrm{OH}+\mathrm{HAsO}_{4}{ }^{2-} \leftrightarrow \equiv \mathrm{Fe}-\mathrm{OAsO}_{3} \mathrm{H}^{-}+\mathrm{OH}^{-} \\
& 2 \equiv \mathrm{Fe}-\mathrm{OH}+\mathrm{HAsO}_{4}{ }^{2-} \leftrightarrow \equiv \mathrm{Fe}_{2}-\mathrm{O}_{2} \mathrm{AsO}_{2} \mathrm{H}+2 \mathrm{OH}^{-}
\end{aligned}
$$

Thirunavukkarasu et al. (2003) represented arsenic adsorption onto goethite as follows:

$$
\begin{gathered}
\alpha-\mathrm{FeOOH}+\mathrm{H}_{2} \mathrm{AsO}_{4}{ }^{-}+3 \mathrm{H}^{+} \leftrightarrow \mathrm{FeH}_{2} \mathrm{AsO}_{4}+\mathrm{H}_{2} \mathrm{O} \\
\alpha-\mathrm{FeOOH}+\mathrm{H}_{3} \mathrm{AsO}_{4}+2 \mathrm{H}^{+} \leftrightarrow \mathrm{FeH}_{2} \mathrm{AsO}_{3}+\mathrm{H}_{2} \mathrm{O}
\end{gathered}
$$

As the $\mathrm{pH}$ is decreased, there is less competition for adsorption from hydroxide ions and arsenate adsorption should be more favorable. A study by Benjamin et al. 
(1996) found that the point of zero-charge (PZC) of iron-oxide coated sand was 9.8. If the PZC of IMZ is similar, then the iron hydroxide surface should be positively charged until $\mathrm{pH}$ 9.8. In solutions with $\mathrm{pH}$ values higher than 10 , little arsenic adsorption is expected to occur. Under these basic conditions, the iron hydroxide surface is populated with $\mathrm{OH}^{-}$ions and obtains a negative or slightly positive surface charge; this reduced charge results in less affinity for the arsenate anion and less adsorption. Under acidic conditions, the IMZ surface is less populated with $\mathrm{OH}^{-}$ions and obtains a greater positive charge; the larger positive charge causes greater affinity for the arsenate anion and leads to greater adsorption. At very low $\mathrm{pH}$ values, the dominant arsenate species is uncharged $\left(\mathrm{H}_{3} \mathrm{AsO}_{4} \mathrm{pKa}=2.2\right)$. This uncharged species is less likely to partake in hydroxide ligand exchange and reduced adsorption occurs. Additionally, iron hydroxides become soluble at low $\mathrm{pH}$ values and the number of adsorption sites decreases as iron oxides/hydroxides are dissolved.

Several authors have shown that arsenic adsorption increases with decreasing pH. Pierce and Moore (1980) showed that amorphous iron hydroxide has an adsorption maximum at $\mathrm{pH} 7.0$; arsenic adsorption decreased when the $\mathrm{pH}$ was higher or lower than $\mathrm{pH}$ 7.0. Jeon et al. (2009) found that the initial solution $\mathrm{pH}$ had negligible effects on arsenic adsorption from $3<\mathrm{pH}<10$. Though there is a general trend in increasing adsorption with decreasing $\mathrm{pH}$, over $99 \%$ of the arsenic was removed in the $\mathrm{pH}$ range used in this experiment. 


\subsubsection{Column Studies}

The results from the column study and regeneration phases are seen below in Figure 2-3. The IMZ-8 material treated over 800 pore volumes of the Socorro Springs water until the effluent arsenic concentration rose above $10 \mu \mathrm{g} / \mathrm{L}$. The column continued to remove arsenic until about 2,500 pore volumes when the effluent and influent arsenic concentrations were within $10 \%$ of each other. The IMZ-8 material was successfully regenerated 3 times without any loss in arsenic adsorption capacity. Similar tests conducted by Joshi and Chaudhuri (1996) found that iron-oxide coated sand could be regenerated over 10 times with little loss in adsorption capacity.

For the IMZ-8 material, an arsenic mass balance was calculated for each breakthrough and regeneration step to account for the arsenic removed and then recollected. A simple trapezoidal integration of the breakthrough curve was employed to estimate the mass of arsenic removed. The mass of arsenic recovered is based on the measured arsenic concentrations of the $\mathrm{NaOH}$ solution and rinse water after passing through the columns. Table 2-8 contains the mass of arsenic adsorbed and desorbed from the column. These tests show that the arsenic is not permanently bound to the surface, and that a simple rinse with $\mathrm{NaOH}$ can restore adsorption capacity. The total recovery greater than $100 \%$ is likely due to errors made in estimating the amount of arsenic removed using the trapezoidal integration method.

Using HYDRUS-1D, the adsorption parameters were fitted to the second breakthrough curve from the $10.5 \mathrm{~cm}$ column. Figure 2-4 shows the best fit line to the observed data. Table 2-9 compares the results from fitting both the Langmuir and Freundlich equations to the observed arsenic breakthrough curve versus the batch 
experiments. In the two cases, all of the column flow parameters were held constant and the adsorption parameters were varied. The calculated adsorption parameters in the column experiment are considerably less than those found in the batch experiments. Based on forward prediction simulation with the batch experiment results, the column should have lasted until about 2,000 pore volumes until the effluent arsenic concentration reached $10 \mu \mathrm{g} / \mathrm{L}$. This same discrepancy was seen using the SMZ/ZVI material in Chapter 1; early breakthrough during column studies and discrepancies between batch results has also been noted by other authors (Melitas et al., 2002; Badruzzaman et al., 2004).

The disagreement between batch experiment results and column studies is not uncommon. Langmuir (1997) notes that the difference is usually due to experimental conditions in batch experiments that do not mimic in-situ behavior. Ko et al. (2007) noted that the column-calculated adsorption parameters for iron-oxide-coated sand were several hundred times less than the column parameters and attributed the difference to limited availability of adsorption sites. The conditions ranked in order of importance that are believed to lead to the discrepancy between batch and column arsenic adsorption data in this study are: 1) the rate of mixing and generation of fine iron particles in batch experiments; 2) the lack of silica ions in the batch experiments; and 3) the $\mathrm{pH}$ of the batch experiment vs. column experiment water.

The mixing during the batch experiments leads to abrasion and the production of fine iron particles. These fine iron particles increase the surface area of the medium and the number of available adsorption sites. Several researchers have reported that the rate and extent of adsorption are significantly affected by particle size (Mathews 
and Zayas, 1989; Wilmanski and Lipinski, 1989; Lin and Wu, 2001) while others have found that the affect of particle size and surface area were negligible (Onyango et al., 2003). It is thought that the increased number of adsorption sites due to the very small iron particles led to artificially high batch experiment adsorption parameters when compared with in situ results.

It is important to note that the Langmuir coefficient $\left(\mathrm{K}_{\mathrm{l}}\right)$ and the exponential coefficient $(\mathrm{N})$ for the Langmuir and Freundlich isotherms remain nearly the same for the batch and column experiments (see Table 2-9). The Langmuir coefficient is a descriptor of the binding energy of the adsorption sites, while $\mathrm{N}$ is related to the intensity of adsorption (Thirunavukkarasu et al., 2001). The two parameters that changed significantly, the maximum adsorption capacity $\left(\mathrm{S}_{\mathrm{m}}\right)$ and empirical Freundlich coefficient $\left(\mathrm{K}_{\mathrm{f}}\right)$, are related to the adsorption capacity of the media. This may indicate that the interactions between the adsorbent and adsorbate do not change significantly from the batch experiments to the column experiments, but that the number of adsorption sites has increased in the batch experiments. The source of these apparent extra adsorption sites is likely due to the creation of fine iron particles from shaking and the absence of competing ions such as silica.

The second reason for the discrepancy between the batch and column experiments is the presence of silica in the Socorro Springs water. The synthetic water used in the batch experiments did not contain silica, while the Socorro Springs water contains about $25 \mathrm{mg} / \mathrm{L}$ silica. Silica has been shown to be the leading competitor with arsenate for adsorption onto iron hydroxides (Su and Puls, 2001). Mishra and Farrell (2005) attributed poor arsenic adsorption onto different types of iron oxides due to 
high concentrations of silica $(30 \mathrm{mg} / \mathrm{L})$. They showed that there is a near-linear decrease in arsenic adsorption with increasing silica content from 0 up to $400 \mu \mathrm{g} / \mathrm{L}$ silica. They found that at a silica concentration as low as $400 \mu \mathrm{g} / \mathrm{L}$ caused a $98 \%$ decrease in the amount of arsenic removed in column studies. Further, Vaishya and Gupta (2003) noted that arsenic removal decreased from $98 \%$ to $48 \%$ when the silica concentration was raised from near 0 to $10 \mathrm{mg} / \mathrm{L}$ using iron-impregnated sand. The high silica concentrations in the Socorro Springs water may have had a detrimental affect on arsenic adsorption. The solubility of silicic acid $\left(\mathrm{H}_{4} \mathrm{SiO}_{4}\right)$ and its anion $\mathrm{H}_{3} \mathrm{SiO}_{4}{ }^{-}$decreases rapidly below $\mathrm{pH} 8.0$ (Faure, 1998). For larger treatment operations, the water $\mathrm{pH}$ could be lowered to reduce the adverse affects of silica adsorption, or a silica-removal pretreatment step could be implemented for maximum arsenic removal. Su and Puls (2001) showed that a reduction in $\mathrm{pH}$ from 10.12 to 7.73 for a $1.0 \mathrm{mM}$ silica solution, spiked with $2,000 \mu \mathrm{g} / \mathrm{L}$ arsenic, increased arsenic adsorption from $\sim 5 \%$ to near $80 \%$ after 120 hours.

Finally, the solution used in the batch experiments was adjusted to $\mathrm{pH} 7.0$ to eliminate differences in $\mathrm{pH}$ due to the variable arsenate concentration; the $\mathrm{pH}$ of the Socorro Springs water was 8.2. Figure 2-2 clearly shows that the difference in $\mathrm{pH}$ of the two solutions will have an effect on arsenic adsorption.

The IMZ-8 removed about 1,200 $\mu \mathrm{g}$ of arsenic until the effluent concentration rose above $10 \mu \mathrm{g} / \mathrm{L}$. This results in an arsenic loading of about $22 \mathrm{mg} / \mathrm{kg}$. Thirunavukkarasu et al. (2003) prepared iron-oxide coated sand (IOCS) that had a similar iron content of about $4 \%$ by mass; the IOCS removed $330 \mathrm{mg} / \mathrm{kg}$ until breakthrough above $5 \mu \mathrm{g} / \mathrm{L}$. Though it seems that IMZ had much poorer performance 
compared with the IOCS in the column settings, the experimental conditions and water chemistry were not the same. The $\mathrm{pH}$ and presence of competing ions have a large control on arsenic adsorption. Inter-media comparisons should only be performed with similar experimental conditions. If comparing arsenic adsorption capacities from batch experiments, then the IMZ-8 has several times the adsorption capacity of the IOCS.

\subsubsection{IMZ Applications}

The IMZ-8 treated about 800 pore volumes until the effluent concentration became higher than $10 \mu \mathrm{g} / \mathrm{L}$. No loss of adsorption capacity was observed with regeneration. The simple regeneration procedure shows that the IMZ-8 could treat large quantities of water without having to be replaced. For the $150 \mathrm{~L}$ of influent water at $44 \mu \mathrm{g} / \mathrm{L}$ average influent arsenic concentration, the IMZ-8 material used in total $3 \mathrm{~L}$ of $0.25 \mathrm{M} \mathrm{NaOH}$ solution, and $18 \mathrm{~L}$ of Type I water for regeneration.

The zeolite material costs only about $\$ 100-\$ 150$ per metric ton; $\mathrm{FeCl}_{3}$ costs about $\$ 340$ per ton, and $\mathrm{NaOH}$ costs about $\$ 165-\$ 180$ per ton (Innovation Group, 2002). The final estimated material costs per metric ton based on IMZ-8 preparation would be about $\$ 250$ per metric ton, or about $\$ 250$ per cubic meter (bulk density $\sim 1$ $\left.\mathrm{g} / \mathrm{cm}^{3}\right)$. Based on the column experiment where 800 pore volumes $(25.7 \mathrm{~L})$ was treated to below $10 \mu \mathrm{g} / \mathrm{L}$ using $51.1 \mathrm{~g}$ of IMZ-8, the total cost for arsenic removal of Socorro Springs water is about $\$ 0.50$ per $1,000 \mathrm{~L}$. With media regeneration, this cost would be significantly lower.

A downside to this regeneration treatment option is the presence of concentrated arsenic liquid waste that would have to be disposed. However, this 
disposal process is no different than current remediation technologies that employ coagulation filtration with liquid $\mathrm{FeCl}_{3}$ and an oxidant (Mishra and Farrell, 2005). However, the IMZ-8 material could simply be used until exhausted, and then disposed in a landfill. A study by Nikolaidis et al. (2003) found that with an arsenic loading of $4.4 \mathrm{mg}$ arsenic per gram of iron oxide, the TCLP concentrations are several orders of magnitude less than the $5 \mathrm{mg} / \mathrm{L}$ limit for landfill disposal. Though this would require large amounts of material and maintenance, it may be a viable option based on the low cost of production.

Ideally, a system would be devised that contains several columns in parallel. Each individual column could be isolated for regeneration once the media is spent, while other columns are still in use. This would result in continuous water treatment without the need for media exchange. The regeneration could be setup could be automated and allow sodium hydroxide injection that occurs after a set volume has passed through the column. This would result in a system that requires little maintenance and results in low-cost for consumables. Further, by mixing the effluent of columns that have high arsenic concentrations with effluent from columns that have low arsenic effluent concentrations, each column could be used for much longer than 800 pore volumes.

The range of applications for this kind of treatment include point-of-use treatments for rural communities with no centralized water distribution system, private communities and groups of homeowners, and small public municipalities without large centralized water treatment facilities. The major advantage of IMZ-8 in these small scale treatments facilities are the low upfront costs. IMZ-8 applications for large 
treatment facilities may be impractical because commercial medias such as Adedge, Purolite, Metsorb, etc. are available that can treat more pore volumes without backwashing. As larger volumes of media are used, the amount of arsenic that is desorbed during regeneration becomes very large and special treatment ponds and holding tanks may become necessary. For smaller treatment facilities, the regeneration discharge water may be disposed at the local wastewater treatment facility. As long as the concentrated arsenic wastewater is mixed with homeowner wastewater from the treatment facility, arsenic concentrations should not be different from untreated tapwater wastewater. However, state regulations will dictate the proper disposal method. 


\subsection{CONCLUSIONS}

Several iron-modified zeolites were prepared that had various physical and chemical properties. The method of iron application was found to be very important for physical robustness and arsenic adsorption parameters. The best production process for IMZ was found by using several smaller applications of iron that was followed by a more concentrated dose as a final step. The IMZ-8 material had a high surface area, a high arsenic adsorption capacity, and was mechanically robust enough to be used in column treatment. The IMZ has a maximum arsenic adsorption at around $\mathrm{pH}$ 2.0-7.0, although it is very effective from $\mathrm{pH} 3-10$.

A column study was performed using water from a local municipal source that contained arsenic at $\sim 43 \mu \mathrm{g} / \mathrm{L}$. The IMZ- 8 media was able to treat about 800 pore volumes of the water before the effluent arsenic concentration reached $10 \mu \mathrm{g} / \mathrm{L}$ at a column residence time of about 5 minutes. The column could be regenerated using $\mathrm{NaOH}$ and rinsing the column thereafter with water. No loss of adsorption capacity was observed over 3 regeneration cycles. The influence of $\mathrm{pH}$ and the presence of competing ions such as silica are the major challenges to using the adsorptive media. The IMZ-8 media may be a competitive alternative to current arsenic treatment technologies due to its low cost of materials and simple preparation procedure. 


\subsection{REFERENCES}

Badruzzaman, M.; Westerhoff, P.; Knappe, D. R. U. 2004. Intraparticle diffusion and adsorption of arsenate onto granular ferric hydroxide. Water Res. 38, pp. 40024012.

Bang, S.; Korfiatis, G.P.; Meng, X. 2005. Removal of arsenic from water by zerovalent iron. Journal of Hazardous Materials 121, pp. 61-67

Bates, M.N.; Smith, A.H.; Hopenhayn-Rich, C. 1992. Arsenic ingestion and internal cancers: A review. American Journal of Epidemiology Vol. 135, No. 5

Benjamin, M. M.; Sletten, R. S.; Bailey, R. P.; Bennet, T. 1996, Sorption and filtration of metals using iron oxide coated sand, Water. Resources. 30 (11), pp. 26092620 .

Bosnak, C.O.; Davidowski, L. 2004. Continuous flow hydride generation using the optima ICP. Perkin Elmer Field Application Report. Perkin Elmer

Bowman, R.S. 2003. Applications of surfactant-modified zeolites to environmental remediation. Microporous Mesoporous Mat. 61, pp.43-56.

Brunauer, S.; Emmett, P.; Teller, E. 1938. Adsorption of gases in multimolecular layers J. Amer. Chem. Soc., 60, p. 309

Drever, J. I. 1997. The geochemistry of natural waters $3^{\text {rd }}$ ed. Prentice Hall, Upper Saddle River, NJ

U.S. Environmental Protection Agency (EPA). 2000. Technologies and costs for removal of arsenic from drinking water, EPA 815-R-00-028, Washington, D.C.

Farrell, J.; Wang, J. P.; O’Day, P.; Conklin,M. 2001. Electrochemical and spectroscopic study of arsenate removal from water using zero-valent iron media. Environ. Sci. Technol. 35, pp. 2026-2032

Faure, G. 1998. Principles and applications of geochemistry. $2^{\text {nd }}$ ed. Upper Saddle River, NJ. Prentice Hall

Faust, S.D.; Aly O.M. 1987. Adsorption processes for water treatment. Butterworths, Boston, MA

Frank, P.; Clifford, D. 1986. As(III) oxidation and removal from drinking water. USEPA Project Summary 600/S2-86/021, 
The Innovation Group. 2002. Price list of chemicals. Accessed Online October 1, 2009. http://www.the-innovation-group.com/chemprofile.htm

International Agency for Research on Cancer (IARC). 1980. Monographs on the evaluation of the carcinogenic chemicals to humans, Vol. 20. International Agency for Research on Cancer

Jain, A.; Raven, K. P.; Loeppert, R. H. 1999. Arsenate and arsenite adsorption on ferrihydrite: Surface charge reduction and net $\mathrm{OH}$ - release stoichiometry. Environ. Sci. Technol., 33, pp. 1179-1184.

Jang, M.; Chen, W.; Cannon, F.S. 2008. Preloading hydrous ferric oxide into granular activated carbon for arsenic removal. Environ. Sci. Technol., 42 (9), pp. 33693374

Jeon, C.; Baek, K.; Park, J.; Oh, Y.; Lee, S. 2009 Adsorption characteristics of As(V) on iron-coated zeolite. Journal of Hazardous Material 163, pp. 804-808

Jeong Y.; Fan, M.; Singh, S.; Chuang, C.-L.; Saha, B.; Hans van Leeuwen, J. 2007. Evaluation of iron oxide and aluminum oxide as potential arsenic(V) adsorbents. Chemical Engineering and Processing: Process Intensification, 46 (10), pp. 1030-1039.

Joshi, A.; Chaudhuri, M. 1996. Removal of arsenic from ground water by iron oxidecoated sand. Journal of Environmental Engineering, Vol. 122, No. 8, pp. 769771

Jury, W. A.; Horton, R. 2004. Soil physics $6^{\text {th }}$ ed. John Wiley and Sons. Hoboken, NJ

Ko, I.; Davis, A.P.; Kim, J.Y.; Kim, K.W. 2007. Arsenic removal by a colloidal iron oxide coated sand. Journal of Environmental Engineering, Vol. 133 No. 9, pp. 891-898

Lin, T.F.; Wu, J.K. 2001. Adsorption of arsenite and arsenate within activated alumina grains: Equilibrium and kinetics. Water Resources 36, pp. 1609-1619

Mathews, A. P.; Zayas, I. 1989. Particle size and shape effects on adsorption rate parameters. Journal of Environmental Engineering, 115, pp. 41-45

Melitas, N.; Wang, J.; Conklin, M.; O’Day, P.; Farrell, J. 2002. Understanding soluble arsenate removal kinetics by zerovalent iron media. Environ. Sci. Technol. 36, pp. 2074-2801

Mishra, D.; Farrell, J. 2005. Evaluation of mixed valent iron oxides as reactive adsorbents for arsenic removal. Environmental Science \& Technology 39 (24), pp. 9689-9694 
National Research Council (NRC). 2002. Arsenic in drinking water. NRC subcommittee to update the 1999 committee on toxicology

Nikolaidis, N.P.; Dobbs G.M.; Lackovic, J.A. 2003. Arsenic removal by zero-valent iron: field, laboratory and modeling studies. Water Research. 37, pp. 14171425

Onyango, M.S.; Kojima, Y.; Matsuda, H.; Ochieng, A. 2003. Adsorption kinetics of arsenic renoval from groundwaters by iron-modified zeolite. Journal of Chemical Engineering of Japan, Vol. 36, No. 12, pp. 1516-1522

Siegel, M.; Aragon, A.; Zhao, H.; Everett, R.; Dwyer, B.; Aragon, M.; Nocon, M.; Dwyer, B.; Marbury, J.; Kirby, C.; North, K. 2007 Pilot test of arsenic adsorptive media treatment technologies at Socorro Springs, New Mexico. Sandia National Laboratories. SAND2007-0161. Sandia National Laboratories. Albuquerque, NM

Šimunek, J.; Sejna, H.; Saito, M.; Sakai, M.; van Genuchten, M. Th. 2008. The HYDRUS-1D software package for simulating the one-dimensional movement of water, heat, and multiple solutes in variably saturated media. Version 4.0 Dept. of Env. Sciences. University of California Riverside, Riverside, p. 315

Su, C.; Puls, R. W. 1997. Retention of arsenic by elemental iron and iron oxides. In Proceedings of the 1997 International Containment Technology Conference, February 9-12, Tallahassee, FL.

Su, C.; Puls, R. W. 2001. Arsenate and arsenite removal by zerovalent iron: Effects of phosphate, silica, carbonate, borate, sulfate, chromate, molybdate, and nitrate, relative to chloride. Environ. Sci. Technol. 2001, 35, pp. 4562-4568.

Sullivan, E. J. 1997 Surfactant and chromate sorption to clinoptilolite zeolite: Mechanisms and surface configuration. PhD Dissertation. New Mexico Tech. Socorro, p. 204

Thirunavukkarasu, O.S., Viraraghavan, T., Subramanian, K.S. 2001. Removal of arsenic in drinking water by iron-oxide coated sand and ferrihydrite- batch studies. Water Quality Research Journal of Canada 36, pp. 55-70

Viashya, R. C.; Gupta, S.K. 2003. Arsenic removal from groundwater by iron impregnated sand. Journal of Environmental Engineering, 129, pp. 89-92

Wilmanski, K.; Lipinski, K. 1989. Adsorption kinetics in GAC systems for water treatment. Journal of Environmental Engineering, 115, pp. 91-108 
Wu, M. M.; Kuo, T.L.; Hwang Y.H.; Chen, C.J. 1989. Does-response relation between arsenic concentration in well water and mortality from cancers and vascular disease. American Journal of Epidemiology Vol. 130, No. 6 


\section{FIGURES-Article II}

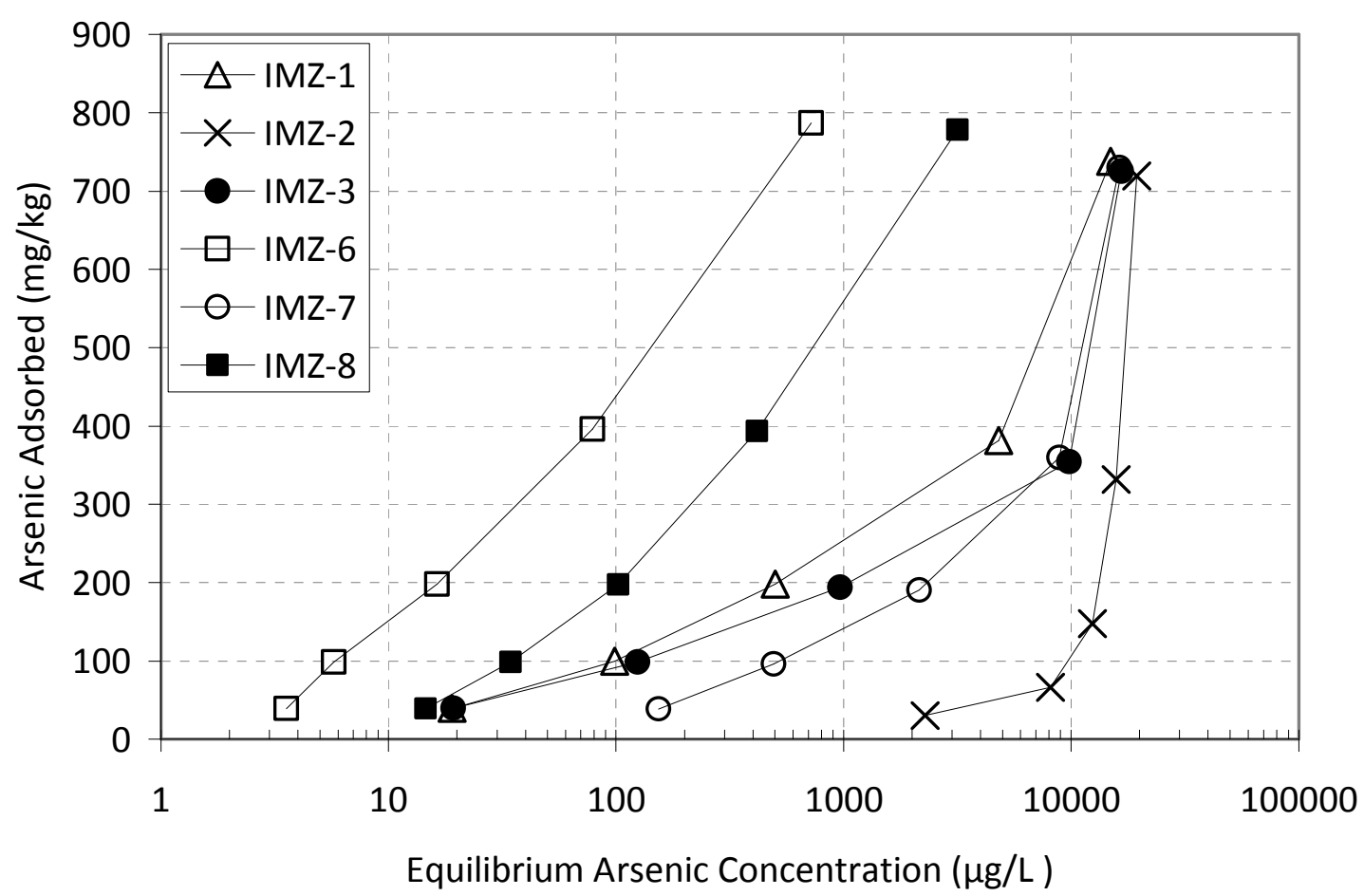

Figure 2- 1: Measured equilibrium arsenic concentrations from batch experiment isotherms. Each symbol is the average concentration of two identical vials. The size of each of the symbols is about the amount of variation observed in each of the two measurements. The lines are presented for visual aids. IMZ-4 and IMZ-5 were not analyzed due to a lack of material for duplicate analyses. Concentration measurement error is $\pm 3 \%$ based on replicate analyses of a $10 \mu \mathrm{g} / \mathrm{L}$ USGS standard reference sample. 


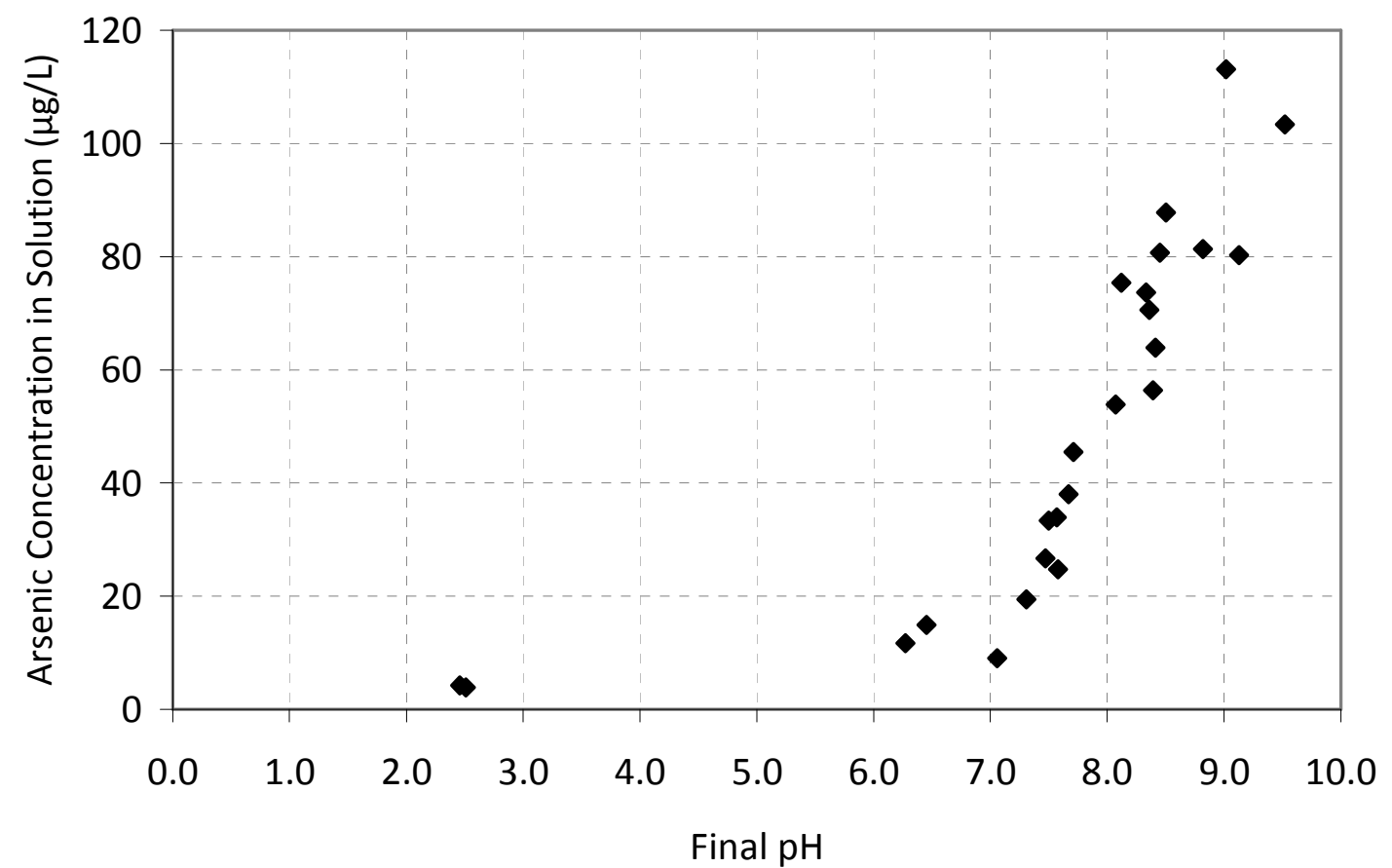

Figure 2- 2: Measured arsenic concentrations in solution vs. final $\mathrm{pH}$ measured after equilibration for the IMZ-8 material. The initial $\mathrm{pH}$ of each solution can be found in Table 2-7. The initial starting arsenic concentration was about $104 \mathrm{mg} / \mathrm{L}$. Concentration measurement error is $\pm 3 \%$ based on replicate analyses of a $10 \mu \mathrm{g} / \mathrm{L}$ USGS standard reference sample. 


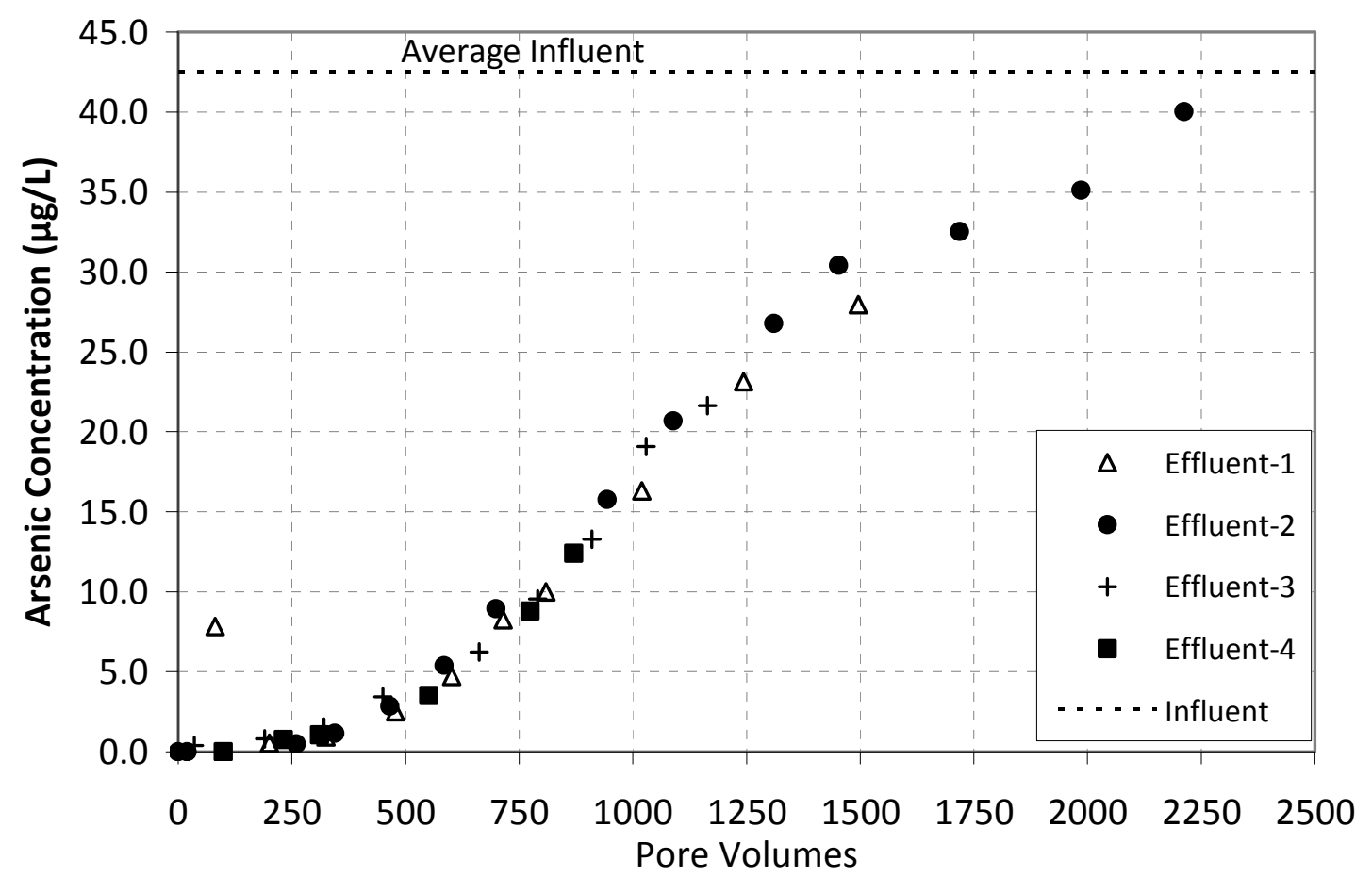

Figure 2- 3: Measured effluent arsenic concentrations from the $10.5 \mathrm{~cm} \mathrm{IMZ-8} \mathrm{column.} \mathrm{Each} \mathrm{symbol}$ represents a breakthrough cycle from the same column. The dashed line represents the average influent concentration which was measured at the beginning and end of each breakthrough curve. The column was regenerated three times. Concentration measurement error is $\pm 3 \%$ based on replicate analyses of a $10 \mu \mathrm{g} / \mathrm{L}$ USGS standard reference sample. 


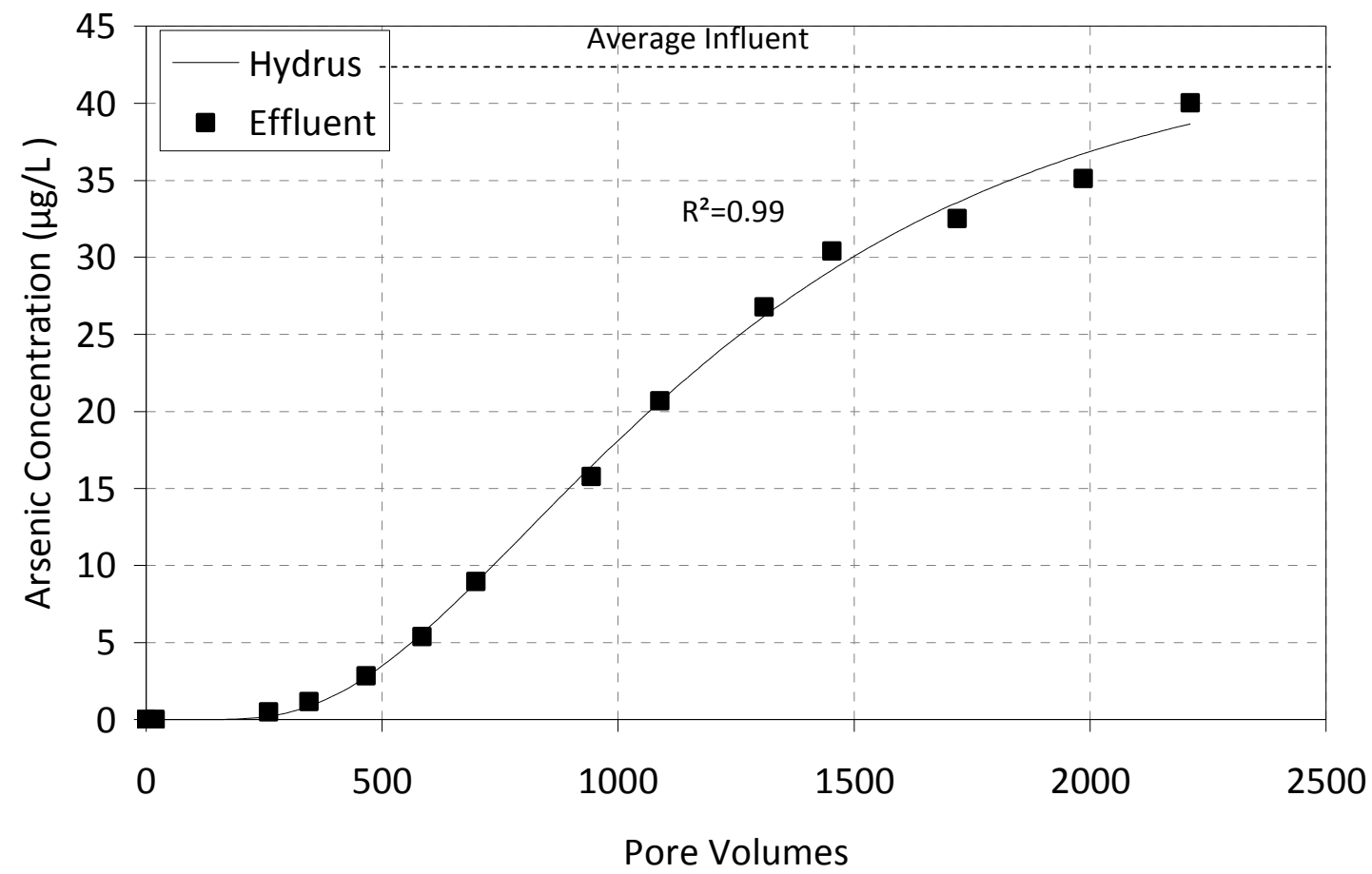

Figure 2- 4: Measured effluent arsenic concentrations from the column and the fitted solid line from HYDRUS-1D that was used to derive the adsorption parameters. The data is from the second breakthrough curve for the IMZ-8 material. The fit using the Langmuir and Freundlich isotherms is nearly identical and only the Langmuir fit is shown for clarity. Concentration measurement error is \pm $3 \%$ based on replicate analyses of a $10 \mu \mathrm{g} / \mathrm{L}$ USGS standard reference sample. 


\section{TABLES- Article II}

Table 2- 1: Measured concentrations of elements present in the Socorro Springs water and calculated concentrations of elements present in the synthetic water prepared in the lab.

\begin{tabular}{|c|c|c|}
\hline & Chlorinated Feed Water ${ }^{1}$ & Synthetic Water \\
\hline Conductivity $(\mu \mathrm{S} / \mathrm{cm})$ & 356 & 502 \\
\hline Temperature $\left({ }^{\circ} \mathrm{C}\right)$ & 30.1 & 19.5 \\
\hline $\mathrm{pH}$ & 7.9 & 8.48 \\
\hline Free Chlorine (ppm as $\mathrm{Cl}_{2}$ ) & 0.74 & 0 \\
\hline Iron (ppb) & 38.2 & 0 \\
\hline Total Arsenic (ppb) & 42.9 & 0 \\
\hline \multicolumn{3}{|l|}{ Speciated Arsenic } \\
\hline Particulate Arsenic (ppb) & 1.9 & 0 \\
\hline As (III) (ppb) & 2.04 & 0 \\
\hline As (V) (ppb) & 39 & 0 \\
\hline Alkalinity (ppm) & 125 & 76.3 \\
\hline Nitrate (ppm) & 0.4 & 0 \\
\hline Vanadium (ppb) & 11.3 & 0 \\
\hline Aluminum (ppb) & 23.2 & 0 \\
\hline Fluoride (ppm) & 0.52 & 0 \\
\hline Chloride (ppm) & 12.7 & 24.1 \\
\hline Sulfate (ppm) & 30.1 & 29.9 \\
\hline Sodium (ppm) & 57.1 & 28.8 \\
\hline Magnesium (ppm) & 4.05 & 7.60 \\
\hline Calcium (ppm) & 17.4 & 13.6 \\
\hline Silica (ppm) & 24.9 & 0 \\
\hline TOC (ppm) & 0.364 & 0 \\
\hline
\end{tabular}

${ }^{1}$ from Siegel et al. (2006) -measured in January of 2005

Table 2- 2: Measured characteristics of the $10.5 \mathrm{~cm}$ column used for testing transport breakthrough curves using IMZ-8.

\begin{tabular}{lc}
\hline \multicolumn{2}{c}{ Column Parameters } \\
\hline Mass IMZ $(\mathrm{g})$ & 51.1 \\
IMZ Bedlength $(\mathrm{cm})$ & 10.5 \\
Column diameter $(\mathrm{cm})$ & 2.5 \\
Column Volume $(\mathrm{mL})$ & 51.5 \\
Bulk Density $\left(\mathrm{g} / \mathrm{cm}^{3}\right)$ & 0.99 \\
Measured Pore Volume $(\mathrm{mL})$ & 32.1 \\
Measured Porosity & 0.62 \\
Pump Flowrate $(\mathrm{mL} / \mathrm{min})$ & 6.0 \\
Specific Discharge $(\mathrm{cm} / \mathrm{min})$ & 1.22 \\
Pore Velocity $(\mathrm{cm} / \mathrm{min})$ & 1.95 \\
Residence Time $(\mathrm{min})$ & 5.38 \\
\hline
\end{tabular}


Table 2- 3: Measured iron concentrations of each completed IMZ preparation. The average values and standard deviation are calculated from triplicate analyses. The iron content of each IMZ includes the natural iron that was present in the raw zeolite.

\begin{tabular}{cccc}
\hline Preparation $^{\mathrm{t}}$ & Average Iron Content $(\mathbf{m g} / \mathbf{k g})$ & Std. Dev. $\mathbf{( m g} / \mathbf{k g})$ & $\mathbf{\% ~ F e}_{\mathbf{2}} \mathbf{O}_{\mathbf{3}}$ by mass* \\
\hline $\mathbf{1}$ & 9500 & 1600 & 1.4 \\
$\mathbf{2}$ & 8500 & 500 & 1.2 \\
$\mathbf{3}$ & 8600 & 1000 & 1.2 \\
$\mathbf{5}$ & 9100 & 700 & 1.3 \\
$\mathbf{6}$ & 23000 & 1900 & 3.3 \\
$\mathbf{7}$ & 12000 & 200 & 1.7 \\
$\mathbf{8}$ & 28000 & 2600 & 4.1 \\
Raw Zeolite & 4800 & 300 & 0.7 \\
\hline
\end{tabular}

*Assuming that all iron is in the form $\mathrm{Fe}_{2} \mathrm{O}_{3}$

${ }^{\mathrm{t}}$ IMZ-4 preparation was incomplete and no further analyses were performed

Table 2- 4: Measured iron content and surface area of prepared iron modified zeolites. Iron content is the average of triplicate analyses; surface area measurements are results from a 5 point BET method. Values in parentheses are the standard deviation based on duplicate analyses for IMZ-8 and triplicate analyses for raw zeolite. The reported surface areas from other preparations are based on a single analysis. N/M indicates the material's surface area was not measured.

\begin{tabular}{ccc}
\hline Preparation & Average Iron Content $(\mathrm{mg} / \mathbf{k g})$ & Surface Area $\left(\mathbf{m}^{\mathbf{2}} / \mathbf{g}\right)$ \\
\hline IMZ-1 & 9500 & 10.6 \\
IMZ-2 & 8500 & $\mathrm{~N} / \mathrm{M}$ \\
IMZ-3 & 8600 & 12.9 \\
IMZ-5 & 9100 & 13.6 \\
IMZ-6 & 23000 & 14.8 \\
IMZ-7 & 12000 & $\mathrm{~N} / \mathrm{M}$ \\
IMZ-8 & 28000 & $21.4( \pm 2.6)$ \\
Raw Zeolite & 4800 & $13.8( \pm 0.1)$ \\
\hline
\end{tabular}


Table 2- 5: Fitted isotherm parameters for the Freundlich and Langmuir isotherm equations. IMZ-4 and IMZ-5 were not analyzed due to a lack of material for duplicate analyses. Error analysis of these parameters can be found in Appendix E.

\begin{tabular}{|c|c|c|c|c|c|c|c|c|}
\hline Preparation & $\begin{array}{c}\text { Average } \\
\text { Iron } \\
\text { Content } \\
(\mathrm{mg} / \mathrm{kg})\end{array}$ & $\begin{array}{c}\text { Surface } \\
\text { Area } \\
\left(\mathrm{m}^{2} / \mathrm{g}\right)\end{array}$ & $\begin{array}{c}\mathrm{K}_{\mathrm{f}} \\
\begin{array}{c}\text { Freundlich } \\
\text { coefficient } \\
\left(\mu \mathrm{g}^{(1-N)} \mathrm{kg}^{-1}\right. \\
\left.\mathrm{L}^{\mathrm{N}}\right)\end{array} \\
\end{array}$ & $\begin{array}{c}\mathbf{N} \\
\text { (Exponential } \\
\text { Coefficient) }\end{array}$ & $\begin{array}{l}\text { Freundlich } \\
\qquad \mathbf{R}^{2}\end{array}$ & $\begin{array}{c}\mathrm{K}_{\mathrm{I}} \\
\text { Langmuir } \\
\text { Coefficient } \\
\text { (L/mg) }\end{array}$ & $\begin{array}{c}\mathrm{S}_{\mathrm{m}} \\
\text { Langmuir } \\
\text { Sorption } \\
\text { Maximum } \\
\text { (mg/kg) } \\
\end{array}$ & $\begin{array}{c}\text { Langmuir } \\
\mathbf{R}^{\mathbf{2}}\end{array}$ \\
\hline IMZ-1 & 9500 & 10.6 & 13500 & 0.41 & 0.98 & 9.66 & 271 & 0.91 \\
\hline IMZ-2 & 8500 & $\mathrm{~N} / \mathrm{M}$ & 1.0 & 1.3 & 0.92 & 0.0297 & 526 & 0.80 \\
\hline $\mathrm{IMZ}-3$ & 8600 & 12.9 & 13800 & 0.38 & 0.97 & 11.4 & 239 & 0.88 \\
\hline IMZ-6 & 23000 & 14.8 & 33900 & 0.052 & 0.91 & 5.42 & 2330 & 0.93 \\
\hline IMZ-7 & 12000 & $\mathrm{~N} / \mathrm{M}$ & 2240 & 0.58 & 0.98 & 8.60 & 405 & 0.99 \\
\hline IMZ-8 & 28000 & 21.4 & 13200 & 0.53 & 0.76 & 4.65 & 654 & 0.97 \\
\hline Raw Zeolite & 4800 & 13.8 & 2 & 0.79 & 0.95 & 0.0535 & 12 & 0.41 \\
\hline
\end{tabular}

Table 2- 6: Comparison between observed Langmuir maximum sorption capacity $\left(\mathrm{S}_{\mathrm{m}}\right)$ of several different kinds of media. All of the experiments were performed near neutral $\mathrm{pH}$.

\begin{tabular}{lcl}
\hline Material & $\mathbf{S}_{\mathbf{m}} \mathbf{( m g / k g )}$ & Source \\
\hline Iron-Oxide Coated Sand & 18.3 & Thirunavukkarasu et al. (2001) \\
Iron-Oxide Coated Sand & 42.6 & Thirunavukkarasu et al. (2002) \\
Iron-Coated Sand & 165 & Chang et al. (2007) \\
Aluminum Oxide & 170 & Jeong et al. (2007) \\
Ferrihydrite & 285 & Thirunavukkarasu et al. (2001) \\
SMZ/ZVI & 512 & Article I \\
Iron-Coated Zeolite & 600 & Jeon et al. (2009) \\
IMZ-8 & 654 & This study \\
Iron Oxide & 660 & Jeong et al. (2007) \\
\hline
\end{tabular}


Table 2- 7: Measured initial and final $\mathrm{pH}$ values of each sample from Figure 2-2 for the $\mathrm{pH}$ dependence study.

\begin{tabular}{ccc}
\hline Sample ID & Initial pH & Final pH \\
\hline $1.5-1$ & 1.4 & 2.5 \\
$1.5-2$ & 1.4 & 2.5 \\
$2-1$ & 1.9 & 6.3 \\
$2-2$ & 1.9 & 7.1 \\
$3-1$ & 3.0 & 7.3 \\
$3-2$ & 3.0 & 6.5 \\
$4-1$ & 3.6 & 7.5 \\
$4-2$ & 3.6 & 7.6 \\
$5-1$ & 5.1 & 7.5 \\
$5-2$ & 5.1 & 7.6 \\
$6-1$ & 5.9 & 7.7 \\
$6-2$ & 5.9 & 7.7 \\
$7-1$ & 7.0 & 8.1 \\
$7-2$ & 7.0 & 8.1 \\
$8-1$ & 8.0 & 8.8 \\
$8-2$ & 8.0 & 8.5 \\
$9-1$ & 9.0 & 8.4 \\
$9-2$ & 9.0 & 8.3 \\
$10-1$ & 10.1 & 8.5 \\
$10-2$ & 10.1 & 8.4 \\
$11-1$ & 11.0 & 8.4 \\
$11-2$ & 11.0 & 9.1 \\
$12-1$ & 12.0 & 9.5 \\
$12-2$ & 12.0 & 9.0 \\
\hline & &
\end{tabular}

Table 2- 8: Mass balance calculations for the three regeneration phases of the $10.5 \mathrm{~cm}$ IMZ-8 column. Each breakthrough phase consisted of three steps: 1) flowing Socorro Springs water through the column until the effluent concentration is above $10 \mu \mathrm{g} / \mathrm{L} ; 2$ ) rinsing the column with $1 \mathrm{~L}$ of $0.25 \mathrm{M} \mathrm{NaOH}$; and 3 ) rinsing the column with $6 \mathrm{~L}$ of Type I water. For each step, the effluent was collected and the arsenic concentration was measured. The mass of arsenic removed was estimated from the area under each breakthrough curve. The same column and media was used in each step without alteration.

\begin{tabular}{cccc}
\hline $\begin{array}{c}\text { Breakthrough } \\
\text { Phase }\end{array}$ & $\begin{array}{c}\text { Mass Arsenic } \\
\text { Removed (mg) }\end{array}$ & $\begin{array}{c}\text { Mass Arsenic Recovered in } \\
\text { Regeneration }(\mathbf{m g})\end{array}$ & $\begin{array}{c}\text { Percent } \\
\text { Recovery }\end{array}$ \\
\hline 1 & 1.48 & 1.15 & $78 \%$ \\
2 & 1.62 & 1.78 & $110 \%$ \\
3 & 1.10 & 1.36 & $124 \%$ \\
Total & 4.19 & 4.30 & $103 \%$ \\
\hline
\end{tabular}


Table 2- 9: Fitted adsorption parameters from the batch experiments and the column experiments. The batch experiment adsorption parameters were derived from the linear forms of each isotherm equation; the column experiment adsorption parameters were fitted using HYDRUS-1D.

\begin{tabular}{lcc}
\hline \multicolumn{1}{c}{ Equation } & Batch Experiments & Column Experiment \\
\hline Freundlich & & \\
$\mathrm{K}_{\mathrm{f}}(\mathrm{L} / \mathrm{mg})$ & 13200 & 5380 \\
$\mathrm{~N}$ & 0.53 & 0.52 \\
\hline Langmuir & & \\
$\mathrm{K}_{\mathrm{l}}(\mathrm{L} / \mathrm{mg})$ & 4.65 & 4.87 \\
$\mathrm{~S}_{\mathrm{m}}(\mathrm{mg} / \mathrm{kg})$ & 654 & 221 \\
\hline
\end{tabular}




\section{FUTURE WORK}

For both of the materials tested, future work looking at the effect of silica is essential. Several studies have shown that silica competes with arsenic for adsorption sites on iron oxides. Further tests looking at the quantitative effects of silica competition and ways to overcome the problem would be beneficial. Further, for SMZ/ZVI a study needs to be performed that analyzes how much silica (if any) is leached from the material. It has been hypothesized that the silicate foam substrate is a source of silica, but no tests have been performed to quantify the concentrations in solution.

Secondly, for SMZ/ZVI a more detailed analysis of the rates of iron oxidation relative to the formation of adsorption sites is warranted. Several researchers have shown that higher rates of $\mathrm{Fe}^{2+}$ production is correlated with higher arsenic removal. Higher rates of $\mathrm{Fe}^{2+}$ production are achieved by lowering the solution $\mathrm{pH}$. This however results in markedly lower $\mathrm{Fe}^{2+}$ oxidation to form iron hydroxides. A comprehensive study that finds the optimum conditions for iron hydroxide production from ZVI could greatly benefit arsenic removal and other treatment options using ZVI.

Additionally, a more detailed analysis of the types of iron compounds present, their relative adsorption performance that are attached to the IMZ surfaces is also needed. For further development of iron modified zeolites, the preparation procedure and the type of iron produced from the specific preparation needs to be better documented. The relative differences in arsenic adsorption performance for each IMZ material likely depends on the type of iron species that is deposited on the zeolite, and not just the average iron content. X-ray Diffraction (XRD) and Scanning Electron 
Microscopy (SEM) analyses may provide insight into how different preparation procedures produce different iron compounds and lead to different adsorption behavior.

Several different preparation techniques could be tried for future preparations of IMZ. Specifically, precipitating iron oxides/hydroxides that had a much higher surface area. For example, ferrihydrite has been shown to have a surface area of $\sim 150$ $\mathrm{m}^{2} / \mathrm{g}$ and when applied to zeolite may greatly increase the arsenic removal ability. Further, having a smaller base zeolite mesh size may result in a greater arsenic adsorption capacity and increased column performance due to decreased film diffusion.

Finally, it should be investigated if the iron alteration affects the cation exchange properties of the zeolite. If the zeolite's exchange capacity is not diminished, the material could be marketed for its multiple uses for water softening, arsenic removal, heavy metal removal, etc. For example, the regeneration procedure with $\mathrm{NaOH}$ is similar to the regeneration of zeolite for water softening. Though this could be view as a "silver bullet" marketing ploy, IMZ may have multiple uses in water filtration. 


\section{REFERENCES (Inclusive)}

Azher, N. E.; Gourich, B.; Vial, C.; Soulami, M.B.; Ziyad, M. 2008. Study of ferrous iron oxidation in Morocco drinking water in an airlift reactor. Chemical Engineering and Processing 47, pp. 1877-1886

Badruzzaman, M.; Westerhoff, P.; Knappe, D. R. U. 2004. Intraparticle diffusion and adsorption of arsenate onto granular ferric hydroxide. Water Res. 38, pp. 40024012.

Bang, S.; Korfiatis, G.P.; Meng, X. 2005a. Removal of arsenic from water by zerovalent iron. Journal of Hazardous Materials 121, pp. 61-67

Bang, S.; Johnson, M.D.; Korfiatis, G.P.; Meng, X. 2005b. Chemical Reactions between arsenic and zero-valent iron in water. Water Research 39, pp. 763-770

Bates, M.N.; Smith, A.H.; Hopenhayn-Rich, C. 1992. Arsenic ingestion and internal cancers: A review. American Journal of Epidemiology Vol. 135, No. 5

Benjamin, M. M.; Sletten, R. S.; Bailey, R. P.; Bennet, T. 1996, Sorption and filtration of metals using iron oxide coated sand, Water. Resources. 30 (11), pp.26092620 .

Bosnak, C.O.; Davidowski, L. 2004. Continuous flow hydride generation using the optima ICP. Perkin Elmer Field Application Report. Perkin Elmer

Bowman, R.S. 2003. Applications of surfactant-modified zeolites to environmental remediation. Microporous Mesoporous Mat. 61, pp.43-56.

Bowman, R.S.; Zhang, P.; T, X. 2002. Surface-altered zeolites as permeable barriers for in situ treatment of contaminated groundwater. Phase II Topical Report. New Mexico Institute of Mining and Technology, Socorro, NM

Brunauer, S.; Emmett, P.; Teller, E. 1938. Adsorption of gases in multimolecular layers J. Amer. Chem. Soc., 60, p. 309

Chang, Y.Y.; Kim, K.S.; Jung, J.H.; Yang, J.K.; Lee, S.M. 2007. Application of ironcoated sand and manganese-coated sand on the treatment of both As(III) and As(V). Water Science and Technology (1-2), pp.69-75

Dixit, S.; Hering, J. G. 2003. Comparison of arsenic(V) and arsenic(III) sorption onto iron oxide minerals: Implications for arsenic mobility. Environ. Sci. Technol. 37, pp. 4182-4189.

Drever, J. I. 1997. The geochemistry of natural waters $3^{\text {rd }}$ ed. Prentice Hall, Upper Saddle River, NJ 
Elizalde-Gonzalez, M.P.; Mattusch, J.; Wennrich, R.; Morgenstern, P. 2001. Uptake of arsenite and arsenate by clinoptilolite-rich tuffs. Microporous Mesoporous Mat. 46, pp. 277-286

U.S. Environmental Protection Agency (EPA). 2000. Technologies and costs for removal of arsenic from drinking water, EPA 815-R-00-028, Washington, D.C.

U.S. Environmental Protection Agency (EPA). 2001. Federal Registry. 66 (14), 6976

Farrell, J.; Wang, J. P.; O’Day, P.; Conklin,M. 2001. Electrochemical and spectroscopic study of arsenate removal from water using zero-valent iron media. Environ. Sci. Technol. 35, pp. 2026-2032

Faure, G. 1998. Principles and applications of geochemistry. $2^{\text {nd }}$ ed. Upper Saddle River, NJ. Prentice Hall

Faust, S.D.; Aly O.M. 1987. Adsorption processes for water treatment. Butterworths, Boston, MA

Fendorf, S.; Eick, M. J.; Grossl, P. Sparks, D. L. 1997. Arsenate and chromate retention mechanisms on goethite. 1: Surface structure. Environ. Sci. Technol. 31, pp. 315-320.

Ferguson, J.F.; Garvis, J. 1972. Review of the arsenic cycle in natural waters. Water Res. 6, pp.1259-1274

Frank, P.; Clifford, D. 1986. As(III) oxidation and removal from drinking water. USEPA Project Summary 600/S2-86/021

Fuller, C. C.; Davis, J. A.; Waychunas, G. A. 1993.Surface-chemistry of ferrihydrite 2. kinetics of arsenate adsorption and coprecipitation. Geochim. Cosmochim. Acta 1993, 57, pp. 2271-2282

Goldberg, S. 1986. Chemical modeling of arsenate adsorption on aluminum and iron oxide minerals. Soil Sci. Soc. Am. J. 5, pp. 1154-1157.

Grossl, P. R.; Eick, M.; Sparks, D. L.; Goldberg, S.; Ainsworth, C.C. 1997. Arsenate and chromate retention mechanisms on goethite. 2: Kinetic evaluation using a pressure-jump relaxation technique. Environ. Sci. Technol. 31, pp.321-326.

The Innovation Group. 2002. Price list of chemicals. Accessed Online October 1, 2009. http://www.the-innovation-group.com/chemprofile.htm 
International Agency for Research on Cancer (IARC). 1980. Monographs on the evaluation of the carcinogenic chemicals to humans, Vol. 20. International Agency for Research on Cancer

Jain, A.; Raven, K. P.; Loeppert, R. H. 1999. Arsenate and arsenite adsorption on ferrihydrite: Surface charge reduction and net $\mathrm{OH}$ - release stoichiometry. Environ. Sci. Technol., 33, pp. 1179-1184.

Jang, M.; Chen, W.; Cannon, F.S. 2008. Preloading hydrous ferric oxide into granular activated carbon for arsenic removal. Environ. Sci. Technol., 42 (9), pp. 33693374

Jeon, C.; Baek, K.; Park, J.; Oh, Y.; Lee, S. 2009 Adsorption characteristics of As(V) on iron-coated zeolite. Journal of Hazardous Material 163, pp. 804-808

Jeong Y.; Fan, M.; Singh, S.; Chuang, C.-L.; Saha, B.; Hans van Leeuwen, J. 2007. Evaluation of iron oxide and aluminum oxide as potential arsenic(V) adsorbents. Chemical Engineering and Processing: Process Intensification, 46 (10), pp. 1030-1039.

Joshi, A.; Chaudhuri, M. 1996. Removal of arsenic from ground water by iron oxidecoated sand. Journal of Environmental Engineering, Vol. 122, No. 8, pp. 769771

Jury, W. A.; Horton, R. 2004. Soil physics $6^{\text {th }}$ ed. John Wiley and Sons. Hoboken, NJ

Ko, I.; Davis, A.P.; Kim, J.Y.; Kim, K.W. 2007. Arsenic removal by a colloidal iron oxide coated sand. Journal of Environmental Engineering, Vol. 133 No. 9, pp. 891-898

Lackovic, J. A.; Nikolaidis, N. P.; Dobbs, G. M. 2000. Inorganic arsenic removal by zero-valent iron Environ. Eng. Sci., 17, pp. 29-39

Langmuir, D. 1997. Aqueous Environmental Geochemistry. Prentive Hall, Upper Saddle River, NJ

Li, Z.; Bowman, R.S. 1997. Counterion Effects of the sorption of cationic surfactant and chromate on natural clinoptilolite. Environ. Sci. Technol. 31, pp. 24072412.

Li, Z., Jones, H.K., Bowman, R.S., Helferich, R., 1999. Enhanced reduction of chromate and PCE by pelletized surfactant-modified zeolite/ zerovalent iron. Environ. Sci. Technol. 33, pp. 4326-4330

Lin, T.F.; Wu, J.K. 2001. Adsorption of arsenite and arsenate within activated alumina grains: Equilibrium and kinetics. Water Resources 36, pp. 1609-1619 
Manning, B.; A., Fendorf, S. E.; Goldberg, S. 1998. Surface structures and stability of arsenic(III) on goethite: Spectroscopic evidence for inner-sphere complexes. Environ. Sci. Technol. 32, pp. 2383-2388.

Manning, B. A.; Hunt, M.; Amrhein, C.; Yarmoff, J. A. 2002. Arsenic(III) and arsenic(V) reactions with zerovalent iron corrosion products. Environ. Sci. Technol. 36, pp. 5455-5461.

Mathews, A. P.; Zayas, I. 1989. Particle size and shape effects on adsorption rate parameters. Journal of Environmental Engineering, 115, pp. 41-45

McBride, M. B. 1997 Environmental chemistry of soils; Oxford University Press: New York, p. 136

Melitas, N.; Wang, J.; Conklin, M.; O’Day, P.; Farrell, J. 2002. Understanding soluble arsenate removal kinetics by zerovalent iron media. Environ. Sci. Technol. 36, pp. 2074-2801

Mishra, D.; Farrell, J. 2005. Evaluation of mixed valent iron oxides as reactive adsorbents for arsenic removal. Environmental Science \& Technology 39 (24), pp. $9689-9694$

National Research Council (NRC). 2002. Arsenic in drinking water. NRC subcommittee to update the 1999 committee on toxicology

Nikolaidis, N.P.; Dobbs G.M.; Lackovic, J.A. 2003. Arsenic removal by zero-valent iron: field, laboratory and modeling studies. Water Research. 37, pp. 14171425

Oblonsky, L. J.; Ryan, M. P.; Isaacs, H. S. 2000. In situ XANES study of the formation and reduction of the passive film formed on $\mathrm{Fe}$ in acetate solution Corros. Sci. 42, pp. 229-241.

Onyango, M.S.; Kojima, Y.; Matsuda, H.; Ochieng, A. 2003. Adsorption kinetics of arsenic removal from groundwater by iron-modified zeolite. Journal of Chemical Engineering of Japan, Vol. 36, pp. 1519-1522

Partey, F.K. 2007. Mechansim of arsenic sorption onto laterite iron conceretions. PhD Dissertation. New Mexico Tech. Socorro, NM

Park , B.; Dempsey, B.A. 2005. Heterogeneous oxidation of Fe(II) on ferric oxide at neutral $\mathrm{pH}$ and a low partial pressure of $\mathrm{O}_{2}$. Environ. Sci. Technol. 39, pp. 6494-6500 
Siegel, M.; Marbury, J.; Everett, R.; Dwyer, B.; Collins, S.; Aragon, M.; Aragon, A. 2006 Pilot test specific test plan for the removal of arsenic from Socorro, New Mexico. Sandia National Laboratories. SAND2006-1324. Sandia National Laboratories. Albuquerque, NM

Siegel, M.; Aragon, A.; Zhao, H.; Everett, R.; Dwyer, B.; Aragon, M.; Nocon, M.; Dwyer, B.; Marbury, J.; Kirby, C.; North, K. 2007 Pilot test of arsenic adsorptive media treatment technologies at Socorro Springs, New Mexico. Sandia National Laboratories. SAND2007-0161. Sandia National Laboratories. Albuquerque, NM

Šimunek, J.; Huang K.; van Genuchten, M. Th. 1998. The HYDRUS code for simulating the one-dimensional movement of water, heat, and multiple solutes in variably-saturated media. Version 6.0, Research Report No. 144, U.S. Salinity Laboratory, USDA, ARS, Riverside, California, p. 164

Šimunek, J.; Sejna, H.; Saito, M.; Sakai, M.; van Genuchten, M. Th. 2008. The HYDRUS-1D software package for simulating the one-dimensional movement of water, heat, and multiple solutes in variably saturated media. Version 4.0 Dept. of Env. Sciences. University of California Riverside, Riverside, p. 315

Singer, P.C.; Stumm, W. 1970. Acid mine drainage: the rate determining step: Science, v. 167, p. 1121-1123.

Su, C.; Puls, R. W. 1997. Retention of arsenic by elemental iron and iron oxides. In Proceedings of the 1997 International Containment Technology Conference, February 9-12, Tallahassee, FL.

Su, C.; Puls, R. W. 2001a. Arsenate and arsenite removal by zerovalent iron: kinetics, redox transformation, and implications for in situ groundwater remediation. Environ. Sci. Technol. 35, pp. 1487-1492.

Su, C.; Puls, R. W. 2001b. Arsenate and arsenite removal by zerovalent iron: Effects of phosphate, silica, carbonate, borate, sulfate, chromate, molybdate, and nitrate, relative to chloride. Environ. Sci. Technol. 2001, 35, pp. 4562-4568.

Sullivan, E.J., Bowman, R.S., Legiec, I.A. 2003. Sorption of arsenic from soilwashing leachate by surfactant-modified zeolite. J. Environ. Qual. 32, pp. 2387-2391

Stumm, W.; 1992. Chemistry of the solid-water interface. New York: WileyInterscience

Thirunavukkarasu, O.S., Viraraghavan, T., Subramanian, K.S. 2001. Removal of arsenic in drinking water by iron-oxide coated sand and ferrihydrite- batch studies. Water Quality Research Journal of Canada 36, pp. 55-70 
Thirunavukkarasu, O.S., Viraraghavan, T., Subramanian, K.S. 2003. Arsenic removal from drinking water using iron-oxide coated sand. Water, Air, and Soil Pollution 142, pp. 95-111

Viashya, R. C.; Gupta, S.K. 2003. Arsenic removal from groundwater by iron impregnated sand. Journal of Environmental Engineering, 129, pp. 89-92

Weerd, H.; Leijnse, A.; Reimskijk, W.H. 1998. Transport of reactive colloids and contaminants in groundwater: effect of nonlinear kinetic interactions. Journal of Contaminant Hydrology, 332, pp. 313-331

Westerhoff, P.; Highfield, D.; Badruzzaman, M.; Yoon, Y. 2005.Rapid small-scale column test for arsenate removal in iron oxide packed bed columns. J. Environ. Eng. 2005, 131, pp. 262-271.

Wilmanski, K.; Lipinski, K. 1989. Adsorption kinetics in GAC systems for water treatment. Journal of Environmental Engineering, 115, pp. 91-108

World Health Organization (WHO). 1993 Guidelines for drinking-water quality, 2nd ed. Geneva. vol. 1

Wu, M. M.; Kuo, T.L.; Hwang Y.H.; Chen, C.J. 1989. Does-response relation between arsenic concentration in well water and mortality from cancers and vascular disease. American Journal of Epidemiology Vol. 130, No. 6

Zhang, P., X. Tao, Z. Li, and R.S. Bowman. 2002. Enhanced perchloroethylene reduction in column systems using surfactant-modified zeolite/zero-valent iron pellets. Environ. Sci. Technol. 36, pp. 3597-3603. 


\section{APPENDIX A - ARTICLE III \\ 2,4-Dinitrotoluene Degradation using Surfactant-Modified Zeolite/ Zero-Valent Iron (SMZ/ZVI)}

Appendix A contains the third article that looks at removal of 2,4

Dinitrotoluene using SMZ/ZVI. The work was originally going to be the topic of my thesis, but the thesis topic was changed after completion of this work. The supporting data for this work can be found in Appendix B. 


\title{
2,4-Dinitrotoluene Degradation using Surfactant-Modified Zeolite/ Zero-Valent Iron (SMZ/ZVI)
}

\begin{abstract}
Surfactant-modified zeolite (SMZ) and zero-valent iron (ZVI) have been combined and used as a filter media for the reduction of 2,4-dinitrotoluene (2,4-DNT). Batch experiments were performed to test the effectiveness of SMZ/ZVI as a filter medium. 2,4-DNT solutions of $100 \mathrm{mg} / \mathrm{L}, 25 \mathrm{mg} / \mathrm{L}$, and $10 \mathrm{mg} / \mathrm{L}$ were mixed with 2.5 $\mathrm{g}$ of SMZ/ZVI in a no headspace vial and shaken for 2-3 hours. The SMZ/ZVI reduced all of the 2,4-DNT in the batch vials in 80,60 , and 60 minutes respectively to below $1 \mathrm{mg} / \mathrm{L}$. The 2,4-DNT reduction was observed by looking at two intermediates, 2-amino-4-nitrotoluene (2A-4NT), and 4-amino-2-nitrotoluene (4A-2NT). 4A-2NT was found to be the dominant intermediate and shows that reduction of the para nitro group was the dominant mechanism. The rate of 2,4-DNT reduction increased by a factor of two to four times once the concentration of 2,4-DNT in solution fell below $10 \mathrm{mg} / \mathrm{L}$. The first order rate constant was found to be $0.015 \mathrm{~min}^{-1}$ starting with an initial concentration of $100 \mathrm{mg} / \mathrm{L}$ 2,4-DNT. Overall, SMZ/ZVI reduction rates are very comparable with those of iron filings and ozone, and is a viable medium for remediation of water contaminated with 2,4-DNT.
\end{abstract}




\section{A-1. INTRODUCTION}

\section{A-1.1 2,4-DNT Occurrence and Hazard}

2,4-Dinitrotoluene (2,4-DNT) is a chemical byproduct of the well-known explosive 2,4,6-trinitrotoluene (TNT). 2,4-DNT is produced in the production of TNT and smokeless gunpowder (Hartley et al., 1994), and an estimated 99\% of 2,4-DNT is produced from the production of polyurethane foams (HSDB, 2004). Further, 2,4DNT is used as an azo dye intermediate, as a plasticizer in propellants, as a gelatinizing agent, and in vehicle airbags (HSDB, 2004; ATSDR 1998). Although 2,4DNT itself is not an explosive, it has similar chemical geometry to TNT and in this study 2,4-DNT was used as a pre-experiment indicator for the treatment of wastewater from munitions plants.

2,4-DNT has been shown to have adverse effects on human health and is implicated in the occurrence of cancer, nausea, vertigo, methemoglobinemia, cyanosis, pain or paresthesia in extremities, tremors, paralysis, chest pain, and unconsciousness (Etnier, 1987; Levine et al., 1985b; Ellis et al., 1979). Brüning et al. (1999, 2001, 2002) found that over long durations (> 5 months), mine workers exposed to 2,4-DNT had increased cases of kidney, urinary tract, and pelvis cancers.

\section{A-1.2 Iron Reduction of 2,4-DNT}

Previous studies (Jafarpour et al., 2004; Patapas et al., 2007; Oh et al., 2002) have used zero-valent iron (ZVI) in powdered form to reduce 2,4-DNT to 2,4diaminotoluene (2,4-DAT). This reduction process has been shown to go through two 
intermediates: 4-amino-2-nitrotoluene (4A-2NT) and 2-amino-4-nitrotoluene (2A4NT). A simplified schematic shown below in Figure A-1 shows the reduction process, while the overall reduction reaction is given in Equation A-1 (Patapas et al., 2007).

$$
2,4-\mathrm{DNT}+6 \mathrm{Fe}^{0}+12 \mathrm{H}^{+} \rightarrow 2,4-\mathrm{DAT}+6 \mathrm{Fe}^{2+}+4 \mathrm{H}_{2} \mathrm{O}
$$

Oh et al. (2002) noticed that high purity ZVI dominantly produced 4A-2NT as the reduction intermediate, while scrap iron dominantly produced $2 \mathrm{~A}-4 \mathrm{NT}$ as the reduction intermediate. Barrows et al. (1996) suggested that the reduction of the para nitro group was due to the shielding effect of the methyl group on the ortho nitro group; this leads to preferred reduction of the unshielded para nitro group. Oh et al. (2002) believed that the scrap iron dominantly produced 2A-4NT because of the minor amounts of graphite present in the scrap iron. They hypothesized that the graphite acts as a reactive site and 2,4-DNT absorbed to the graphite primarily went through ortho rather than para reduction.

\section{A-1.3 SMZ/ZVI Properties}

Surfactant-modified zeolite (SMZ) refers to a zeolite that has been altered by attaching surfactant molecules to the surface. These surfactant molecules consist of a non-polar carbon chain and a polar head group (a quaternary amine); the surfactant can form a bilayer on the zeolite surface such that two surfactant molecules are attracted to one another through their non-polar tail groups and the polar head groups are exposed (Figure A-2). SMZ has been used to treat several contaminants in 
groundwater and a synopsis can be found in Bowman (2003). The SMZ/ZVI used in this experiment was made using a silicate foam base that was then coated with a slurry of hexadecyltrimethylammonium (HDTMA) surfactant, zeolite, and iron filings (Bowman et al., 2002). The zeolite consisted of $74 \%$ clinoptilolite, $10 \%$ feldspar, $10 \%$ quartz and cristobalite, $5 \%$ illite, and 1\% smectite (Sullivan et al., 1997). The surfactant used was Carsoquat CT-429, and the iron powder was obtained from Peerless Metal Powders and Abrasive (Bowman et al., 2002). The final SMZ/ZVI material is estimated to consist of $49 \%$ iron, $34 \%$ glass foam, $16 \%$ zeolite, and $\sim 1 \%$ HDTMA by mass (Bowman et al., 2002).

\section{A-1.4 Overall Experiment Goals}

This experiment focused on the utility of SMZ/ZVI as a reactive media to adsorb and chemically reduce 2,4-DNT. SMZ/ZVI has been show to remove other toxic chemicals such as chromate (Li et al., 1999) and perchloroethylene (Zhang et al., 2002). SMZ/ZVI costs $\sim \$ 350$ per cubic meter and is a competitive alternative to using charcoal filters and ion exchange resins (Bowman et al., 2002). The utility of SMZ adsorbance and retention combined with the reductive capability of $\mathrm{Fe}^{0}$ make SMZ/ZVI a prominent candidate for remediation of water contaminated with explosives. 


\section{A-2. METHODS}

\section{A-2.1 Samples}

SMZ/ZVI cubes $(2.5 \mathrm{~cm})$ were broken into smaller pieces using mechanical rock crushers and were then sieved to 8-14 mesh (2.4-1.4 mm). 2,4-DNT solutions were made fresh weekly in $5 \mathrm{mM} \mathrm{CaCl}_{2}$ from a stock $100 \mathrm{mg} / \mathrm{L}$ solution made using 2,4-DNT solid. $2.5 \mathrm{~g}$ of the crushed SMZ/ZVI was placed in a $10 \mathrm{~mL}$ headspace vial and filled with $~ 10 \mathrm{~mL}$ of a 2,4-DNT solution. Each vial was capped with a Teflonlined butyl septum and weighed to determine the amount of solution used. Each vial was then placed on an end-over-end shaker. Twenty to 40 vials were made for each experiment and duplicate samples were sacrificed at each time interval. The sacrificed vials were centrifuged at $4800 \times \mathrm{g}$ for one minute and then $1 \mathrm{~mL}$ of the supernatant was removed and placed in an amber auto-sampler vial for analysis. Samples were analyzed within 3-5 hours from the starting time.

\section{A-2.2 Analysis}

All samples were analyzed using a Waters Model 481 UV Detector, a Waters Model 510 dual piston HPLC pump, a Waters Model 717+ auto-sampler, and EZ Chrome Elite Software. A Phenomex $5 \mu \mathrm{m} 150 \mathrm{~mm} \times 4.6 \mathrm{~mm}$ C-18 Octadecyl Silane (ODS) column was used in all the experiments with a mobile phase consisting of $45 \%$ $8 \mathrm{mM} \mathrm{KH}_{2} \mathrm{PO}_{4}$ solution and $55 \%$ methanol. The mobile phase was prepared using HPLC grade methanol and $18 \mathrm{M} \Omega$ (Type I) Milli-Q water. The pump flow rate was set at $1 \mathrm{~mL} / \mathrm{min}$, the detector wavelength was set at $254 \mathrm{~nm}$, and the sample injection volume was $25 \mu \mathrm{L}$. Compounds were analyzed using peak height and approximate 
retention times were 2-4 DAT (2.1 min.), 4A-2NT (3.5 min.), 2A-4NT (4.0 min.), and 2,4-DNT (7.25 min.) (see Appendix B for example chromatogram). Detection limits calculated from three times the signal to noise ratio were $0.01 \mathrm{mg} / \mathrm{L}$. The standard concentrations ranged from $100 \mathrm{mg} / \mathrm{L}$ to $0.01 \mathrm{mg} / \mathrm{L}$ and were made in a $5 \mathrm{mM} \mathrm{CaCl} 2$ background electrolyte solution. Standards were prepared fresh for each analysis from refrigerated stock solutions. Standards were run every $10^{\text {th }}$ sample to check for instrument drift and showed changes of less than $1 \%$ for each standard throughout the analysis. Prolonged exposure experiments at ambient conditions using a $5 \mathrm{mM} \mathrm{CaCl} 2$ background solution without any SMZ/ZVI showed that 2,4-DNT, 2A-4NT, and 4A2NT did not significantly degrade within one week, while 2,4-DAT had significant changes in concentration in less than a day. According to these results, fresh 2,4-DAT stock solutions were used in each experiment. 


\section{A-3. RESULTS}

Batch kinetic tests showed that 2,4-DNT is quickly degraded to at least two intermediates, 2A-4NT, and 4A-2NT within $\sim 30$ minutes, while the final end-product 2,4-DAT was not detected until about 1 hour. Figures A-3 and A-4 show the concentration of all measured species starting from an initial 2,4-DNT concentration of $26.6 \mathrm{mg} / \mathrm{L}$. All other initial concentrations showed a similar pattern where the dominant intermediate compound was found to be $4 \mathrm{~A}-2 \mathrm{NT}$ and the onset of the final end product DAT took about 1 hour to observe. Sample vials were not analyzed for 2,4-DNT past 2-3 hours since the concentration was below detection limits. 


\section{A-4. DISCUSSION}

The relative abundances of the intermediate compounds measured in the experiment provides insight into the reduction mechanism of 2,4-DNT. Since the dominant intermediate is $4 \mathrm{~A}-2 \mathrm{NT}$, the initial reductive step is the reduction of the para nitro group. This type of behavior was seen by Oh et al. (2002) when using a high purity iron powder to reduce 2,4-DNT. They found that reduction of the para nitro group dominated when using high purity iron and reduction of the ortho nitro group dominated when using scrap metal iron that contained graphite impurities. Though the SMZ/ZVI pellets contain scrap iron provided by Peerless metals, the dominant reduction mechanism follows the high-purity iron scheme. The reason for this difference in intermediate reduction compound is unknown and warrants further investigation.

The mass recovery was found to be about $60 \%$ based on a mass balance of the four compounds analyzed. Figure A-5 shows the mass recovery based on the aqueous concentrations of 2,4-DNT and 2,4-DAT. The intermediate compounds account for only about $10 \%$ of the mass in the system during their peak concentrations around one hour elapsed time. The low mass recoveries seen in the system are attributed to species that were adsorbed to the SMZ/ZVI surface. Surface concentrations were not measured in this experiment. Oh et al. (2002), who used high purity and scrap iron for their experiments, saw mass recoveries ranging from 80-99\% from measuring both surface and aqueous concentrations. The low mass recoveries after all of the 2,4-DNT and intermediate compounds have been consumed is again attributed to adsorption on the zeolite, iron, and silicate foam surfaces. 
The reduction of 2,4-DNT and the production of 2,4-DAT both appear to follow a first order kinetic reaction. Seen in Figure A-6 is a logarithmic plot of the relative concentration vs. time for both compounds along with linear fits to the data. Also seen in Figure A-6 is that there is a jump in the rate of 2,4-DNT reduction. This change in slope shows that the rate of 2,4-DNT reduction increased after the concentration in solution fell below $10 \mathrm{mg} / \mathrm{L}$. The increase in reduction rate is counter to previous behavior seen using SMZ/ZVI. Li et al. (1999) used SMZ/ZVI to treat perchloroethylene (PCE) solutions and initially saw a rapid removal of PCE that was thought to correspond with adsorption onto the SMZ surface; this rapid adsorption rate was followed by a slower reduction reaction of the PCE via iron.

This same behavior of increasing reduction rates once the concentration in solution fell below $10 \mathrm{mg} / \mathrm{L}$ was seen in other batch experiments where the initial 2,4DNT concentration was varied. Figure A-7 shows the reaction rates of three different batch studies where the starting 2,4-DNT concentrations were $12.1 \mathrm{mg} / \mathrm{L}, 26.6 \mathrm{mg} / \mathrm{L}$, and $109 \mathrm{mg} / \mathrm{L}$. In each case, the rate of 2,4-DNT disappearance increased once the concentration fell below about $10 \mathrm{mg} / \mathrm{L}$. A t-test of the rates above and below $10 \mathrm{mg} / \mathrm{L}$ showed that they were significantly different at the $99 \%$ confidence interval in each case (see Appendix B for results). The reaction rate also increases with increasing initial 2,4-DNT concentration.

The reason for the increase in reaction rates once the concentration has fallen below $10 \mathrm{mg} / \mathrm{L}$ is unknown. It is speculated that the initial reduction of 2,4-DNT at higher concentrations produces soluble iron according to Eqn. A-1 that is then precipitated as iron hydroxides. These iron oxide surfaces may aid in the adsorption 
and reduction 2,4-DNT. A study by Hofstetter et al. (1999) showed that adsorbed reactive $\mathrm{Fe}(\mathrm{II})$ compounds were able to reduce polynitroaromatic compounds to aminotoluenes within hours. These newly created adsorption and reaction sites may account for the apparent increase in reaction rates. Similarly, the formation of iron hydroxide surfaces from $\mathrm{Fe}^{0}$ corrosion may lead to increased 2,4-DNT adsorption as well. Measurements of the surface concentrations of 2,4-DNT and its reaction products, as well as iron speciation analyses may provide more insight into these processes.

The $\mathrm{pH}$ of the system was found to be an important control on the reaction kinetics in previous experiments; Patapas et al. (2007) found that in a $\mathrm{pH} 8.0$ controlled environment, an initial 2,4-DNT solution of $1.0 \mathrm{mM}(\sim 180 \mathrm{mg} / \mathrm{L})$ took longer than two hours to reduce the 2,4-DNT below $0.1 \mathrm{mM}(\sim 18 \mathrm{mg} / \mathrm{L})$, while at $\mathrm{pH}$ 6.0, complete reduction of 2,4-DNT only took 20 minutes. Oh et al. (2002) found that a pH near neutral (7.4), that an initial 2,4-DNT solution of concentration $.250 \mathrm{mM}$ ( $45 \mathrm{mg} / \mathrm{L}$ ) took 1 hour using pure iron powder, and 2 hours using scrap iron powder. In this experiment, significant changes in $\mathrm{pH}$ were not observed over the reaction time length and ranged from $\mathrm{pH} 7$ initially to a final $\mathrm{pH}$ of 7.5.

Table A-1 contains a comparison between the observed reaction rates in this study and those of other reductive media techniques. Overall, the effectiveness of 2,4DNT reduction using SMZ/ZVI is very comparable to or better than the reduction rates of ozonation by itself, ozonation in the presence of other filter material (Bower and Miller, 2002), and high purity iron filings (Oh et al., 2002). These results show 
that SMZ/ZVI is an effective media for 2,4-DNT removal, and may also be effective for removal of other explosive contaminants.

Though SMZ/ZVI is effective in reducing 2,4-DNT to 2,4-DAT, this method or reduction does not eliminate all health concerns. 2,4-DAT has been shown to be carcinogenic to mammals, and is considered a direct mutagen (National Cancer Institute, 1978; Chung et al., 1997). Though the compound may have adverse health effects, the fate of 2,4-DAT is on the order of days in natural environments. Recent work by Yang et al. (2008) showed that under oxic conditions (marine sediments) 2,4DAT was completely removed from the aqueous solution in 3 days. Under anaerobic conditions, 2,4-DAT remained stable and soluble for greater than 20 days (Yang et al., 2008). Simple standard analyses conducted in this experiment showed that a $50 \mathrm{mg} / \mathrm{L}$ 2,4-DATstandard degraded $\sim 20 \%$ within one day. Therefore, the environmental fate of 2,4-DAT may be negligible under oxic conditions, but be of greater concern in anaerobic environments. 


\section{A-5. CONCLUSION}

In summary, SMZ/ZVI successfully reduces 2,4-DNT to its most reduced form 2,4-DAT within $~ 2$ hours. The reduction of 2,4-DNT using SMZ/ZVI initially follows a first order kinetic reaction and has comparable rates to those of other water treatment practices. The SMZ/ZVI appears to follow a high-purity iron pathway as evidenced by the dominant intermediate $4 \mathrm{~A}-2 \mathrm{NT}$, even though the material is made with scrap iron. More work is needed to determine the reason for the apparent shift in reduction pathway and the change in reaction rate with concentration. However, this work confirms that SMZ/ZVI could be used as a filtration media or permeable reactive barrier for the cleanup of munitions waste water or industrial waste that contains 2,4DNT. 


\section{A-6. REFERENCES}

Agency for Toxic Substances and Disease Registry (ATSDR). 1998. Toxicological Profile for 2,4- and 2,6-Dinitrotoluene. Atlanta, GA: U.S. Department of Health and Human Services, Public Health Service, ATSDR.

Bower, K.C.; Miller, C.M., 2002. Filter sand-phosphate buffer effect on 2,4dinitrotoluene ozonation. J. of Eviron. Eng. 128 No. 2, pp.131-136

Bowman, R.S.; Zhang P.; Tao, X.; Johnson, R.L.; Wolf, D. 2002. Surface-altered zeolites as permeable barriers for in situ treatment of contaminated groundwater. Phase IIB Topical Report. U.S. Department of Energy, National Energy Technology Laboratory, Pittsburgh, PA, p.33

Bowman, R.S. 2003. Applications of surfactant-modified zeolites to environmental remediation. Microporous Mesoporous Mat. 61, pp. 43-56.

Brüning, T.; Chronz, C.; Their, R.; Havelka, J.; Ko, Y.; Bolt., H. M. 1999. Occurrence of urinary tract tumors in miners highly exposed to dinitrotoluene. $\mathrm{J}$ Occup Environ Med. 41(3), pp. 144-149.

Brüning, T.; Thier, R.;Mann, H.; Melzer, H.; Brode, P.; Dallner, G., Bolt, H.M. 2001. Pathological excretion patterns of urinary proteins in miners highly exposed to dinitrotoluene. J Occup Environ Med 43(7), pp. 610-615.

Brüning, T.; Thier, R.; Bolt, H.M. 2002. Nephrotoxicity and nephrocarcinogenicity of dinitrotoluene: new aspects to be considered. Rev Environ Health 17(3), pp.163-172.

Chung, K.T.; Kirkovsky, L.; Kirkovsky, A. Purcell, W.P. 1997. Review of mutagenicity of monocyclic aromatic amines: quantitative structure-activity relationships. Mutation Research- Reviews in Mutation Research Vol. 387-1, pp. 1-16

Ellis, H.V. ; Hagensen, J.H. ; Hodgson, J.R. 1979. Mammalian toxicity of munitions compounds. Phase BI: Effects of lifetime exposure. Part I. 2,4-Dinitrotoluene. Final Report No. 7. Kansas City, MO: Midwest Research Institute. Contract No. DAMD 17-74-C-4073, ADA077 692

Etnier, E.L. 1987. Water quality criteria for 2,4-dinitrotoluene and 2,6-dinitrotoluene. Oak Ridge, TN: Oak Ridge National Laboratory. U.S. Army Medical Research and Development Command. Project Order No. 84PP4845

Hartley, W.R.; Roberts, W.C.; Commons, B.J. 1994. Drinking Water Health Advisory: Munitions II. Professional Administrative Services, Office of Drinking Water Health, U.S. Environmental Protection Agency. 
Hazardous Substances Data Bank (HSDB). 2004. 2,4-Dinitrotoluene.

On-line access, 12-14-07. National Library of Medicine. Bethesda, MD. http://toxnet.nlm.nih.gov/cgi-bin/sis/search/f?./temp/ SPM8B5:1

Hofstetter, T. B.; Heijman, C.G.; Haderlein, S.B.; Holliger, C.; Schwarzenbach, R.P. 1999. Complete reduction of TNT and other (poly)nitroaromatic compounds under iron-reducing subsurface conditions

Jafarpour, B.; Imhoff, P.T.; Chiu, P.C. 2005. Quantification and modeling of 2,4dintrotoluene reduction with high purity and cast iron. Jour. Cont. Hydrology. 76 , pp. $87-107$

Levine, R.J.; Corso, R.D.; Blunden, P.B.; 1985. Fertility of workers exposed to dinitrotoluene and TDA at three chemical plants. In: Rickert, D.E. (ed). Toxicity of nitroaromatic compounds. Chemical Industry Institute of Toxicology Series. Washington, DC: Hemisphere Publishing Corporation, pp. 243-254

Li, Z.; Jones, H.K.; Bowman, R.S.; Helferich, R. 1999. Enhanced Reduction of Chromate and PCE by pelletized Surfactant-Modified Zeolite/ Zerovalent Iron. Environ. Sci. Tech. 33, pp. 4326-4330

National Cancer Institute. 1978. Bioassay of 5-Nitro-o-toluidine for possible carcinogenicity. National Cancer Institute of Health Carcinogenesis Technical Report Series No. 107, DHEW Publ. N (NIH), Bethesda, MD, 78-1357.

Oh, S.Y.; Cha, D.K.; Chiu P.C. 2002. Graphite Mediated Reduction of 2,4Dinitrotoluene with elemental iron. Environ. Sci. Tech. 36, pp. 2178-2184

Patapas, J.; Al-Ansari, M.M.;Taylor, K.E.; Bewtra, J.K.; Biswas, N. 2007. Removal of dinitrotoluenes from water via reduction with iron and peroxidase-catalyzed oxidative polymerization: A comparison between Arthromyces ramosus peroxidase and soybean peroxidase. Chemosphere, 67, pp.1485-1491

Ranck, J.M.; Bowman, R.S.; Weeber, J.L.; Katz, L.E.; Sullivan, E.J. 2005. BTEX removal from produced water using surfactant-modified zeolite. J. Environ. Eng. 131(3), pp.434-442. doi:10.1061/(ASCE)0733-9372(2005)131:3(434)

Schulze-Makuch, D.; Pillai, S. D.; Guan, H.; Bowman, R.S.; Couroux, E.; Hielscher, F.; Totten, J.; Espinosa, I.Y.; Kretzschmar, T. 2002. Surfactant-modified zeolite can protect drinking water wells from viruses and bacteria, Eos Trans. $A G U, 83(18)$, pp. 193-201.

Sullivan, E.J.; Hunter, D.B.; Bowman, R.S. 1997. Topological and thermal properties of surfactant-modified clinoptilolite studied by tapping-mode atomic force 
microscopy and high-resolution thermogravimetric analysis. Clays Clay Min. 45 , pp. $42-53$.

Zhang, P.; Tao, X.; Li, Z.; Bowman, R.S. 2002. Enhanced perchloroethylene reduction in column systems using surfactant-modified zeolite/zero-valent iron pellets. Environ. Sci. Technol. 36, pp. 3597-3603. 


\section{FIGURES - APPENDIX A}

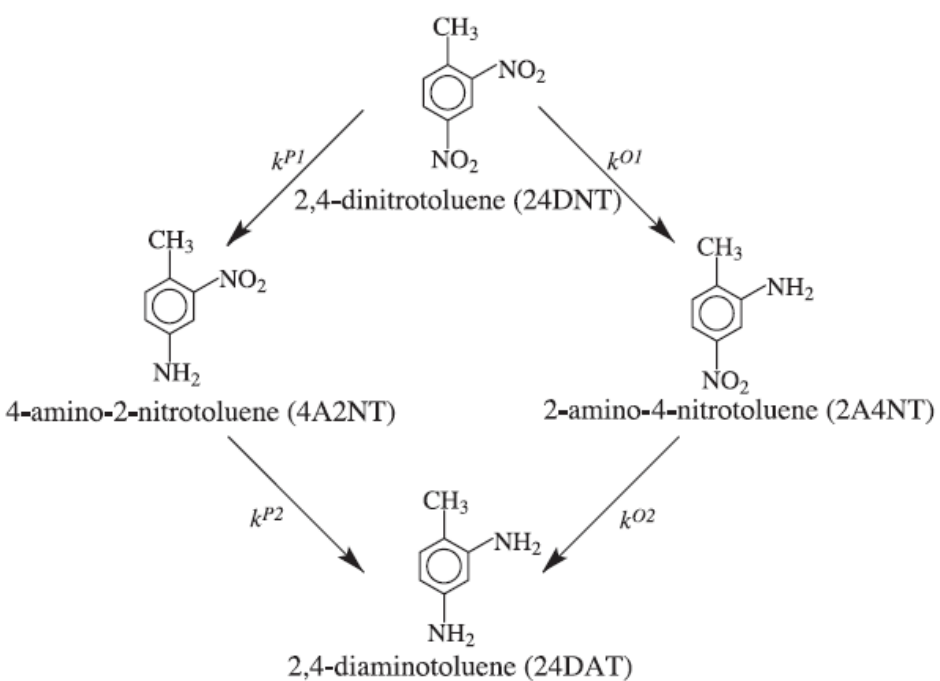

Figure A- 1: Simplified illustration of the reduction pathways and observed intermediates seen in the reduction of 2,4-DNT (used with permission- from Jafarpour et al., 2004). 


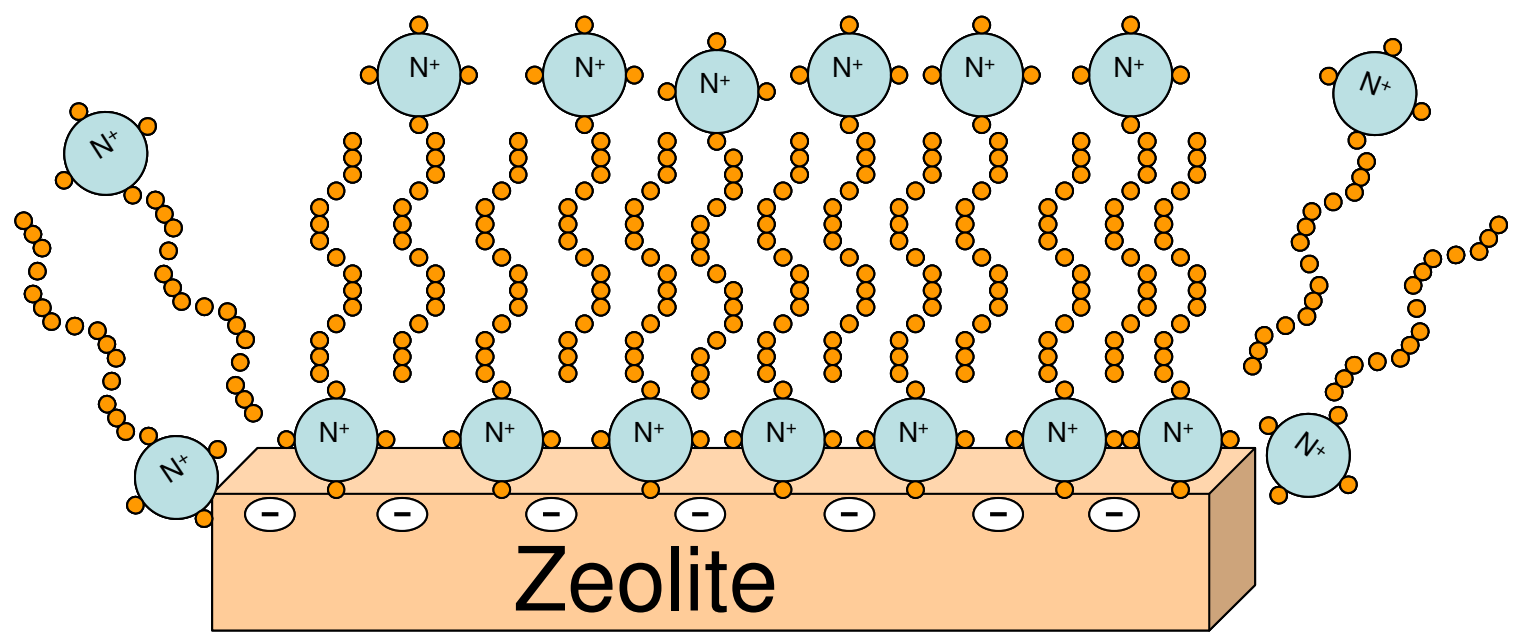

Figure A- 2: Schematic diagram of the orientation of HDTMA surfactant molecules on the zeolite surface arranged as a bilayer. The polar head groups (ammonium) are attracted to the negatively charged zeolite surface, while the non-polar carbon tail groups are attracted to one another; this forms a surfactant bilayer. 


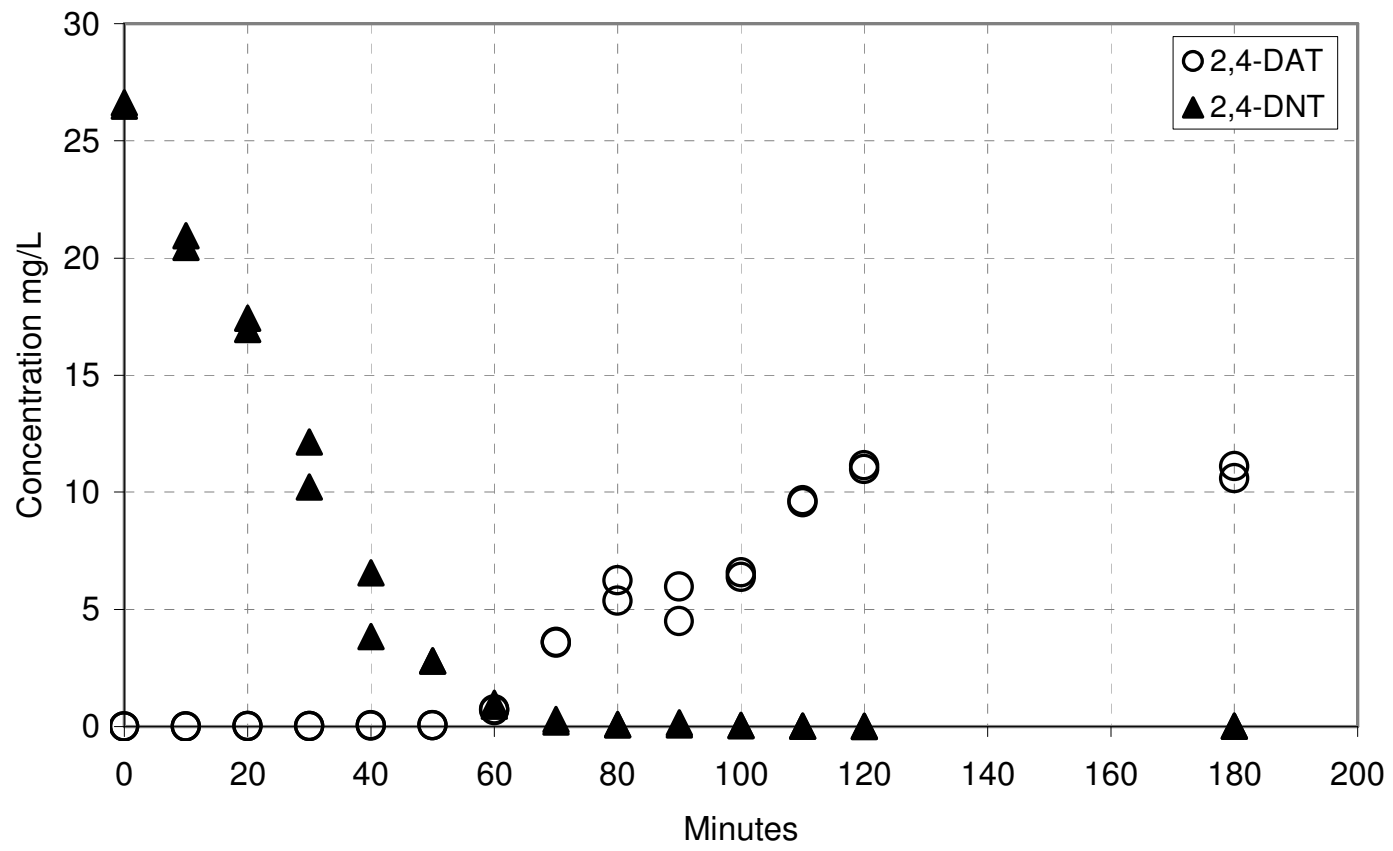

Figure A- 3: Concentrations of 2,4-DNT and 2,4-DAT measured in solution starting from an initial concentration of $26.6 \mathrm{mg} / \mathrm{L}$. Duplicate vials were prepared and sacrificed at each time interval. Concentration error is $\pm 3 \%$ or less based on the standard deviation of multiple standard analyses. 


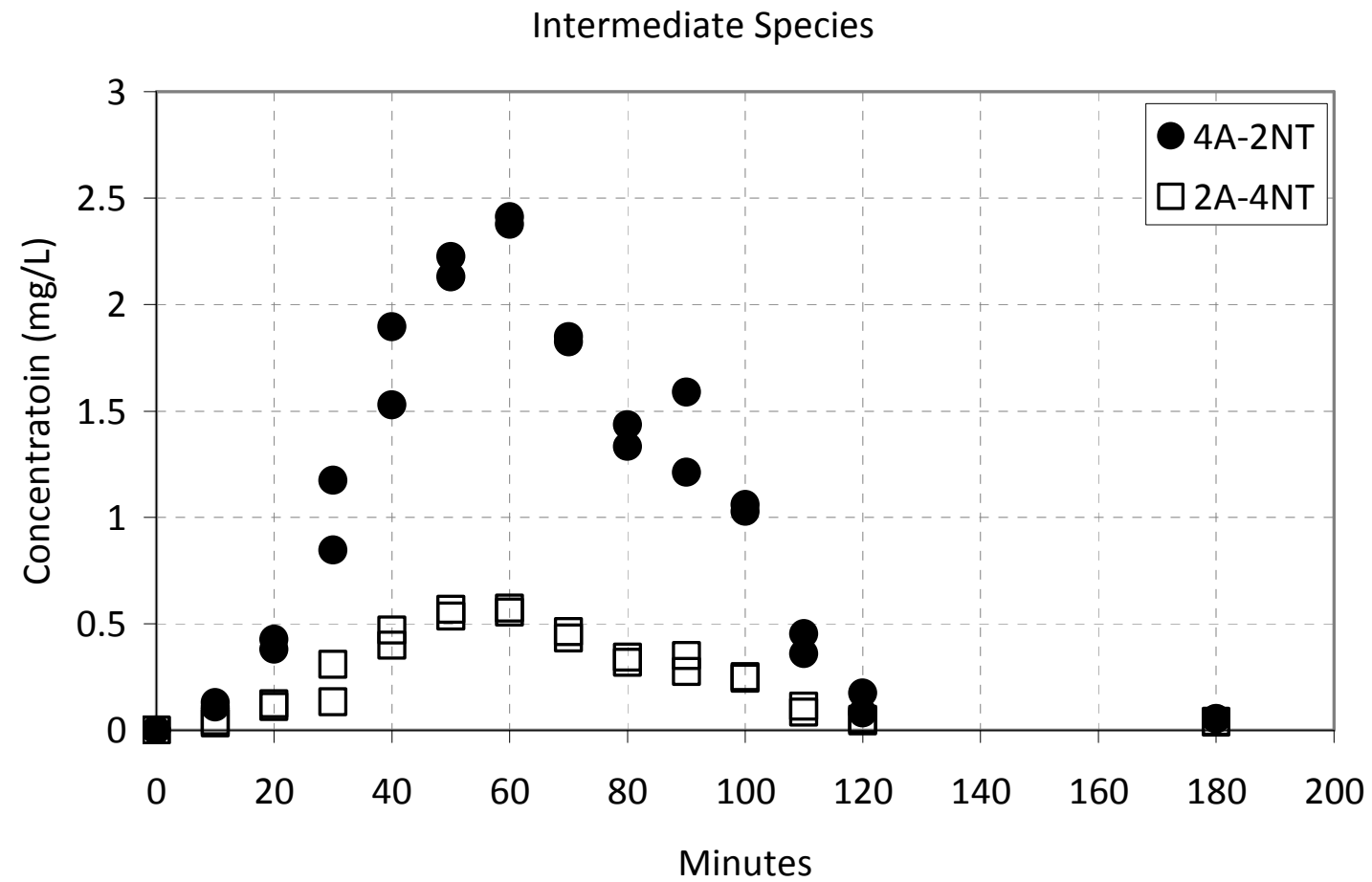

Figure A- 4: Concentrations of the intermediate species 2A-4NT and 4A-2NT measured in solution starting from an initial concentration of $26.6 \mathrm{mg} / \mathrm{L} 2,4-\mathrm{DNT}$. Duplicate vials were prepared and sacrificed at each time interval. Concentration error is $\pm 3 \%$ or less based on the standard deviation of multiple standard analyses. 


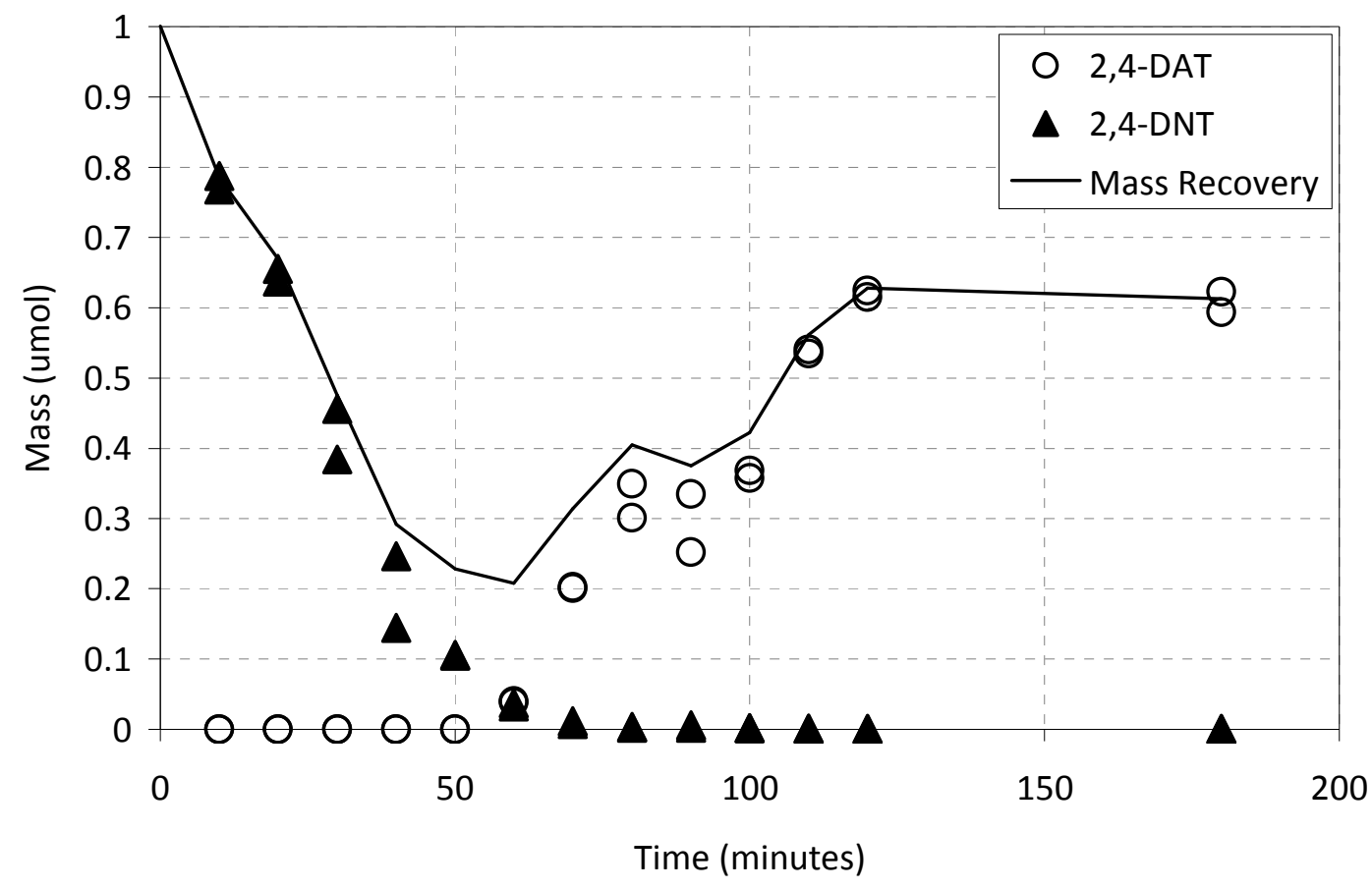

Figure A- 5: Aqueous concentrations of 2,4-DAT and 2,4-DNT measured during batch experiments and total mass in solution. The concentrations of the intermediate species $2 \mathrm{~A}-4 \mathrm{NT}$ and $4 \mathrm{~A}-2 \mathrm{NT}$ are not shown but account for a maximum of about $10 \%$ of the mass around 60 minutes. Mass error is $\pm 3 \%$ or less based on the standard deviation of multiple standard analyses. 


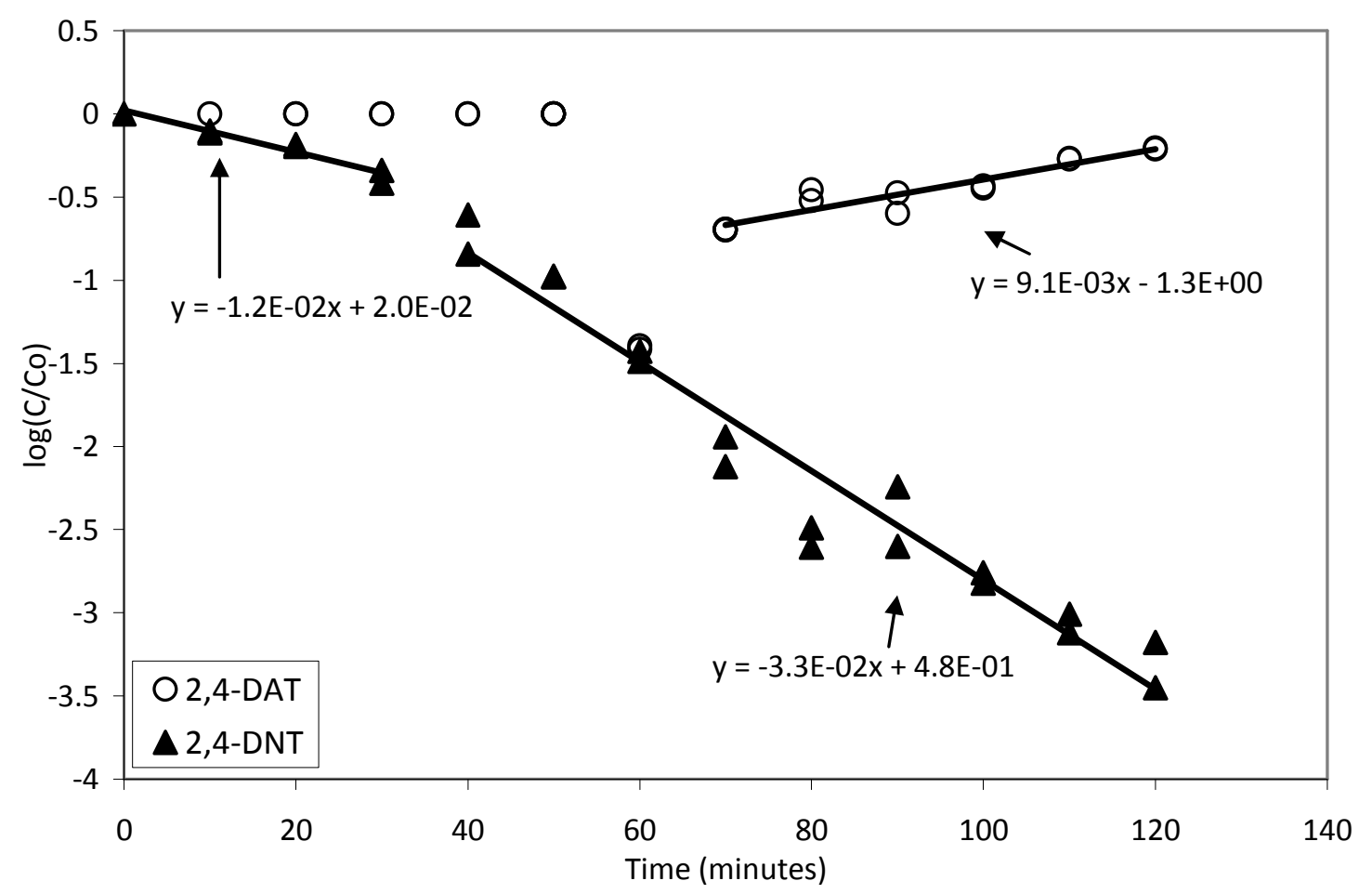

Figure A- 6: Aqueous concentrations of 2,4-DAT and 2,4-DNT plotted relative to an initial 2,4-DNT concentration of $26.6 \mathrm{mg} / \mathrm{L}$. The linear nature of the change in concentration shows that the reduction of 2,4-DNT and production of 2,4-DAT follows a first order kinetic reaction. An increase in apparent reaction rate occurs at a 2,4-DNT concentration below about $10 \mathrm{mg} / \mathrm{L}$. Concentration error is $\pm 3 \%$ or less based on the standard deviation of multiple standard analyses. 


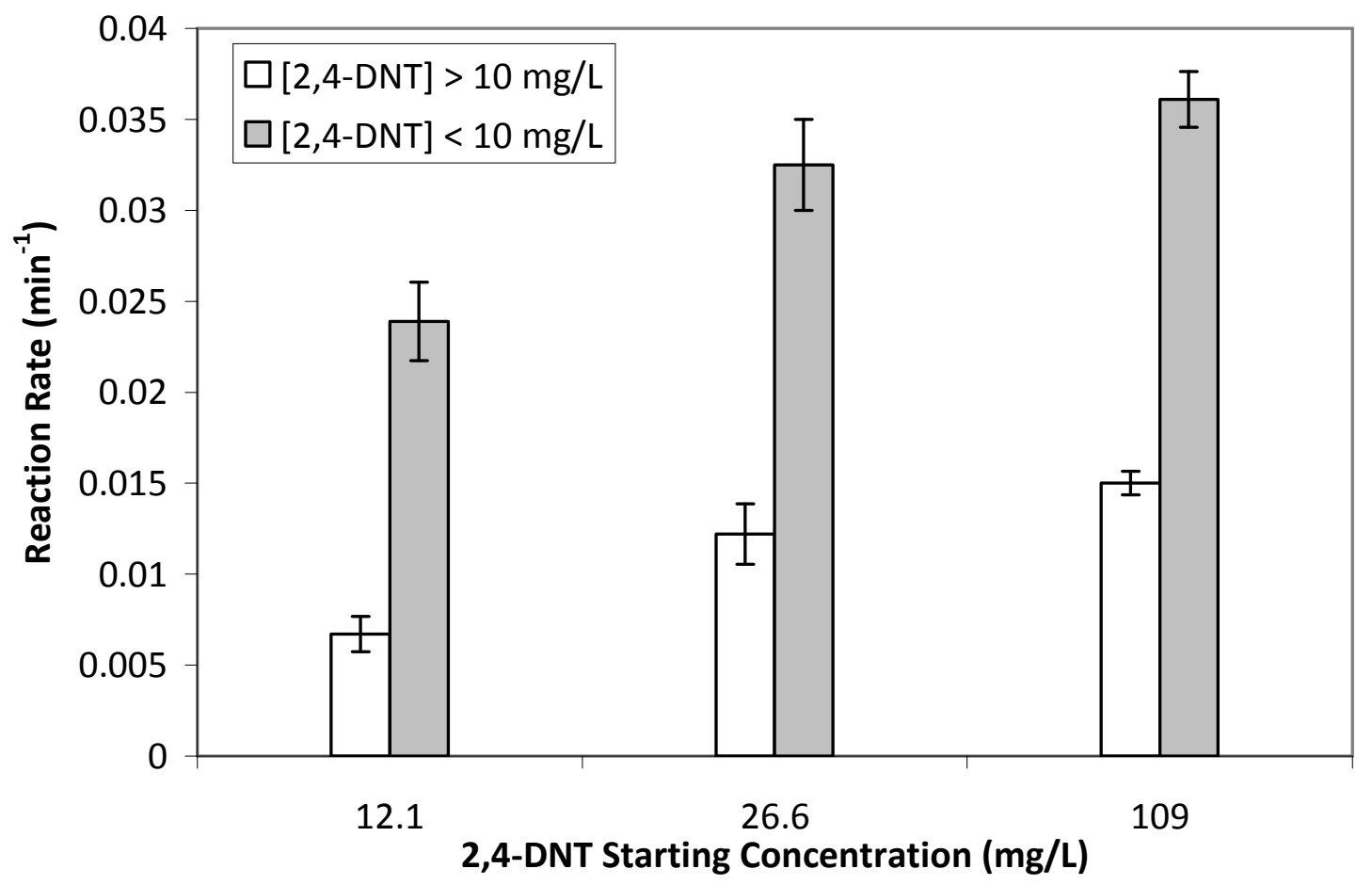

Figure A- 7: Plot comparing the reaction rate constants for different starting concentrations of 2,4-DNT for concentrations in solution greater than $10 \mathrm{mg} / \mathrm{L}$ and less than $10 \mathrm{mg} / \mathrm{L}$. Error bars are the standard error based on regression analysis of the slope of each line segment. A t-test analysis of the rates for concentrations above and below $10 \mathrm{mg} / \mathrm{L}$ for each starting concentrations showed that the rates were statistically different at the $99 \%$ confidence interval. 


\section{TABLES - APPENDIX A}

Table A- 1: Comparison of kinetic reaction rates observed using SMZ/ZVI and other reductive techniques.

\begin{tabular}{|c|c|}
\hline Reductive Media & Observed Reaction Rate $\times 10^{-2}\left(\mathrm{~min}^{-1}\right)$ \\
\hline $\mathrm{SMZ} / \mathrm{ZVI}{ }^{1}$ & $1.5 \pm 0.1$ \\
\hline Ozonation $^{2}$ & $0.90 \pm 0.40$ \\
\hline $\mathrm{MnO}_{2}$ and Ozone ${ }^{2}$ & $0.10 \pm 0.1$ \\
\hline Iron Oxide Coated Sand and Ozone ${ }^{2}$ & $0.60 \pm 0.10$ \\
\hline Virgin Filter Media and Ozone ${ }^{2}$ & $1.0 \pm 0.2$ \\
\hline Zero Valent Iron (High Purity) ${ }^{3}$ & $1.5 \pm 0.2$ \\
\hline Zero Valent Iron (Scrap Iron) ${ }^{3}$ & $1.5 \pm 0.1$ \\
\hline
\end{tabular}

1-This study. Values reported are reported for concentration $>10 \mathrm{mg} / \mathrm{L}$, Initial Concentration of 2,4-DNT=100 mg/L

2-Bower and Miller (2002)- First order observed 2,4-DNT degradation rates in a $\left[\mathrm{PO}_{4}{ }^{3-}\right]=13 \mathrm{mM}$ buffer in the presence of ozone at a flow rate of $4 \mathrm{~L} / \mathrm{hr}$ and indicated filter material.

3- Oh et al. (2002)- estimated from Alfa Aesar high-purity iron data and Master Builders scrap iron data contained in the paper 


\section{APPENDIX B - Supplementary Data for Article III.}

Appendix B contains supplementary data from Appendix A-Article III that is related to the removal of 2,4-Dinitrotoluene using SMZ/ZVI.

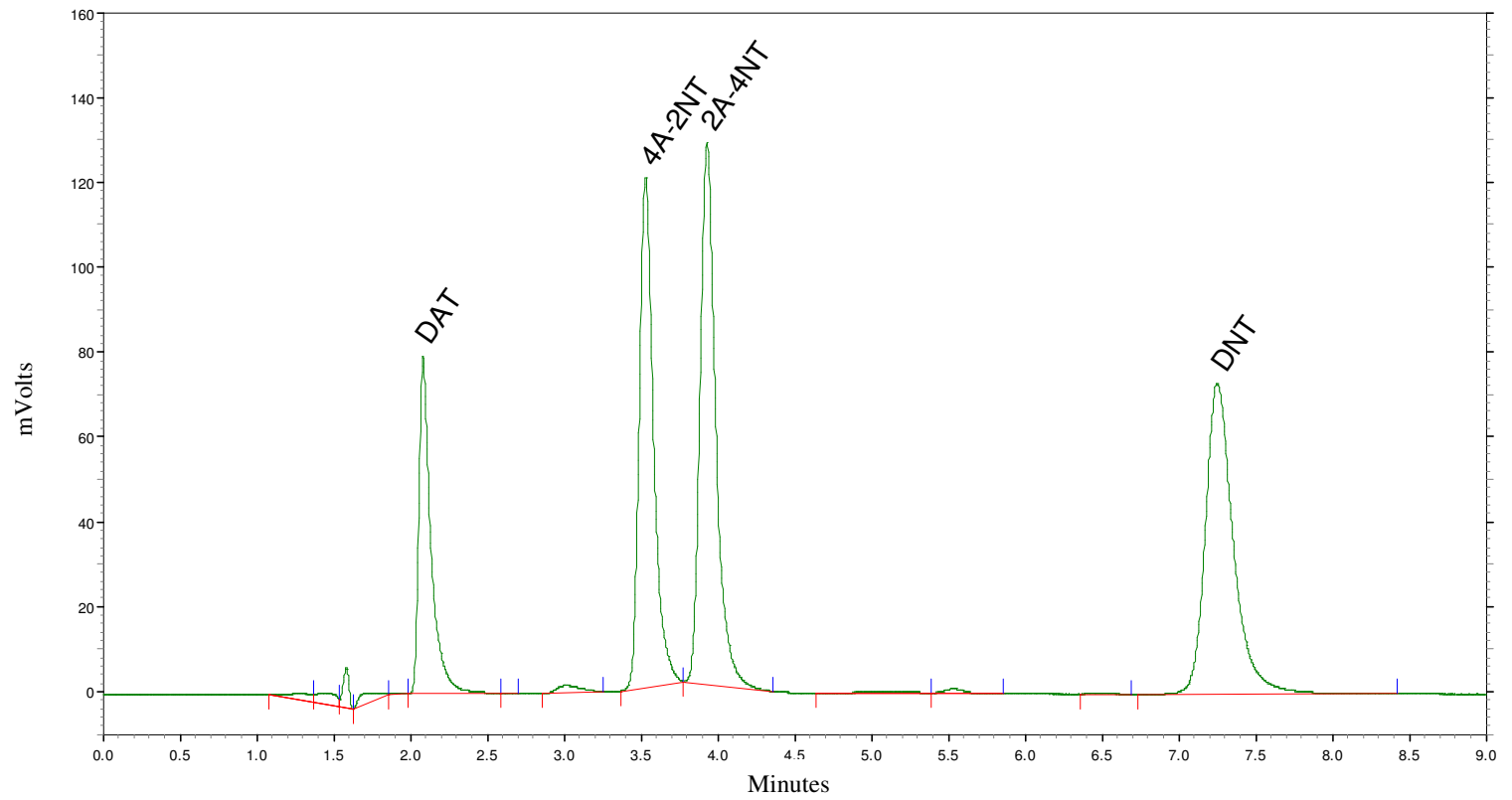

Figure B- 1: Computer image of the retention times and peak heights from the HPLC EZ Chrome Elite software. The mobile phase consisted of $45 \% 4 \mathrm{mM} \mathrm{KH}_{2} \mathrm{PO}_{4}$ and $55 \%$ Methanol. The concentration of each compound was about $13 \mathrm{ppm}$. 
Table B- 1: Measured concentrations in solution of 2,4-DNT and its three reaction products from the batch experiment data with an initial 2,4-DNT concentration of $12.2 \mathrm{mg} / \mathrm{L}$. Concentration error is $\pm 3 \%$ or less based on the standard deviation of multiple standard analyses. A detection limit of $0.01 \mathrm{mg} / \mathrm{L}$ is estimated from three times the signal to noise ratio.

\begin{tabular}{ccccc}
\hline Equilibration Time (min) & DAT (mg/L) & 4A-2NT (mg/L) & 2A-4NT (mg/L) & 2,4-DNT (mg/L) \\
\hline 0 & 0.00 & 0.01 & 0.00 & 12.2 \\
5 & 0.00 & 0.02 & 0.01 & 9.95 \\
5 & 0.00 & 0.02 & 0.01 & 10.1 \\
10 & 0.01 & 0.05 & 0.02 & 9.51 \\
10 & 0.01 & 0.06 & 0.02 & 9.53 \\
15 & 0.02 & 0.12 & 0.03 & 8.89 \\
15 & 0.01 & 0.12 & 0.04 & 8.95 \\
20 & 0.02 & 0.17 & 0.05 & 8.58 \\
20 & 0.02 & 0.20 & 0.05 & 8.57 \\
25 & 0.02 & 0.22 & 0.06 & 8.25 \\
25 & 0.02 & 0.34 & 0.08 & 7.59 \\
30 & 0.02 & 0.41 & 0.09 & 7.14 \\
30 & 0.02 & 0.70 & 0.15 & 5.58 \\
35 & 0.02 & 0.63 & 0.14 & 5.88 \\
35 & 0.02 & 0.66 & 0.14 & 5.70 \\
40 & 0.02 & 0.95 & 0.19 & 4.37 \\
40 & 0.02 & 0.69 & 0.15 & 5.60 \\
45 & 0.05 & 1.33 & 0.29 & 2.99 \\
45 & 0.02 & 1.00 & 0.20 & 4.11 \\
50 & 0.03 & 1.26 & 0.26 & 3.32 \\
50 & 0.06 & 1.52 & 0.31 & 2.33 \\
55 & 0.07 & 1.88 & 0.39 & 1.58 \\
55 & 0.03 & 1.76 & 0.33 & 1.73 \\
60 & 0.27 & 2.13 & 0.46 & 0.95 \\
60 & 0.07 & 1.67 & 0.36 & 1.92 \\
\hline & & & &
\end{tabular}


Table B- 2: Measured concentrations in solution of 2,4-DNT and its three reaction products from the batch experiment data with an initial 2,4-DNT concentration of $26.6 \mathrm{mg} / \mathrm{L}$.

\begin{tabular}{ccccc}
\hline Equilibration Time (min) & DAT (mg/L) & 4A-2NT (mg/L) & 2A-4NT (mg/L) & 2,4-DNT (mg/L) \\
\hline 0 & 0.00 & 0.00 & 0.00 & 26.5 \\
0 & 0.00 & 0.00 & 0.00 & 26.6 \\
10 & 0.00 & 0.11 & 0.03 & 21.0 \\
10 & 0.00 & 0.13 & 0.04 & 20.4 \\
20 & 0.00 & 0.38 & 0.11 & 17.4 \\
20 & 0.00 & 0.43 & 0.12 & 17.0 \\
30 & 0.00 & 0.85 & 0.13 & 12.1 \\
30 & 0.00 & 1.17 & 0.31 & 10.2 \\
40 & 0.00 & 1.90 & 0.47 & 3.83 \\
40 & 0.00 & 1.53 & 0.40 & 6.55 \\
50 & 0.00 & 2.13 & 0.54 & 2.82 \\
50 & 0.00 & 2.22 & 0.57 & 2.79 \\
60 & 0.72 & 2.41 & 0.57 & 0.87 \\
60 & 0.69 & 2.38 & 0.55 & 1.00 \\
70 & 3.61 & 1.83 & 0.43 & 0.30 \\
70 & 3.58 & 1.85 & 0.46 & 0.20 \\
80 & 5.37 & 1.43 & 0.34 & 0.09 \\
80 & 6.23 & 1.33 & 0.32 & 0.07 \\
90 & 5.98 & 1.21 & 0.28 & 0.07 \\
90 & 4.50 & 1.59 & 0.35 & 0.15 \\
100 & 6.38 & 1.06 & 0.25 & 0.05 \\
100 & 6.57 & 1.03 & 0.24 & 0.04 \\
110 & 9.55 & 0.45 & 0.11 & 0.02 \\
110 & 9.66 & 0.36 & 0.09 & 0.03 \\
120 & 11.0 & 0.17 & 0.05 & 0.02 \\
120 & 11.1 & 0.08 & 0.04 & 0.00 \\
180 & 10.6 & 0.05 & 0.04 & 0.02 \\
180 & 11.1 & 0.05 & 0.04 & 0.02 \\
\hline & & & &
\end{tabular}


Table B- 3: Measured concentrations in solution of 2,4-DNT and its three reaction products from the batch experiment data with an initial 2,4-DNT concentration of $108 \mathrm{mg} / \mathrm{L}$.

\begin{tabular}{cccccc}
\hline $\begin{array}{l}\text { Equilibration Time } \\
\text { (min) }\end{array}$ & $\begin{array}{l}\text { DAT } \\
\text { (mg/L) }\end{array}$ & $\begin{array}{l}\text { 4A-2NT } \\
\text { (mg/L) }\end{array}$ & $\begin{array}{l}\text { 2A-4NT } \\
\text { (mg/L) }\end{array}$ & $\begin{array}{l}\text { 2,4-DNT } \\
\text { (mg/L) }\end{array}$ \\
\hline 0 & 0.00 & 0.00 & 0.00 & 108 \\
10 & 0.02 & 1.99 & 0.66 & 71.9 \\
10 & 0.01 & 0.87 & 0.27 & 81.2 \\
10 & 0.01 & 1.70 & 0.45 & 72.3 \\
20 & 0.02 & 3.14 & 1.01 & 59.5 \\
30 & 0.03 & 4.09 & 1.49 & 43.5 \\
40 & 0.02 & 5.42 & 1.82 & 29.8 \\
50 & 0.15 & 5.97 & 1.91 & 19.2 \\
60 & 0.84 & 5.70 & 1.73 & 13.1 \\
70 & 10.0 & 5.96 & 1.79 & 1.79 \\
80 & 12.3 & 5.70 & 1.72 & 0.96 \\
90 & 21.0 & 4.01 & 1.16 & 0.27 \\
100 & 34.1 & 1.51 & 0.41 & 0.10 \\
110 & 36.9 & 1.03 & 0.28 & 0.06 \\
120 & 43.4 & 0.22 & 0.08 & 0.03 \\
180 & 44.9 & 0.00 & 0.05 & 0.02 \\
240 & 44.7 & 0.00 & 0.05 & 0.01 \\
240 & 46.1 & 0.10 & 0.04 & 0.01 \\
480 & 44.1 & 0.06 & 0.04 & 0.01 \\
\hline
\end{tabular}


Table B- 4: Results from t-test data for comparison of the reaction rates for the 2,4-DNT concentrations above $10 \mathrm{mg} / \mathrm{L}$ and concentrations below $10 \mathrm{mg} / \mathrm{L}$. The software program Minitab 14 was used to make the analysis. In all cases, the two reaction rates were significantly different at the $99 \%$ confidence interval.

\section{Two-Sample T-Test for $10 \mathrm{ppm}$ initial starting concentration}

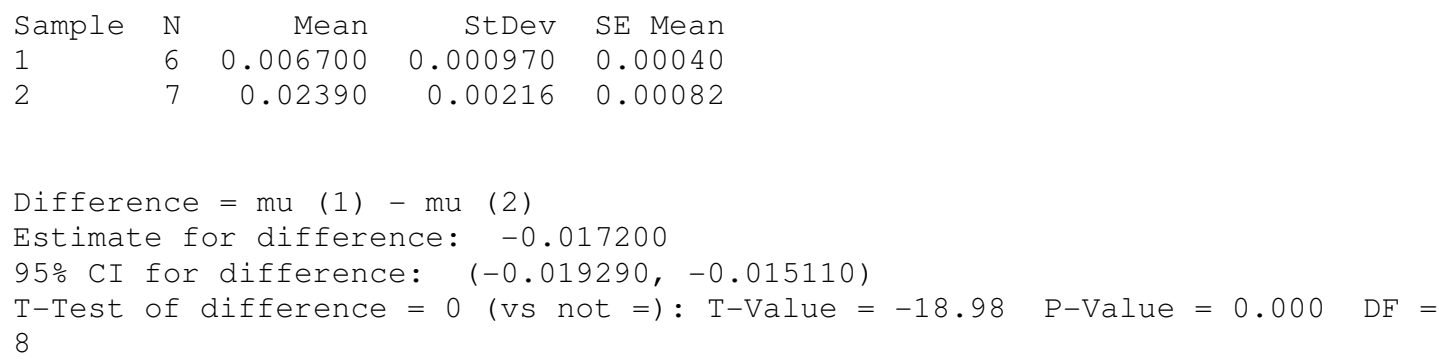

\section{Two-Sample T-Test for 25 ppm initial starting concentration}

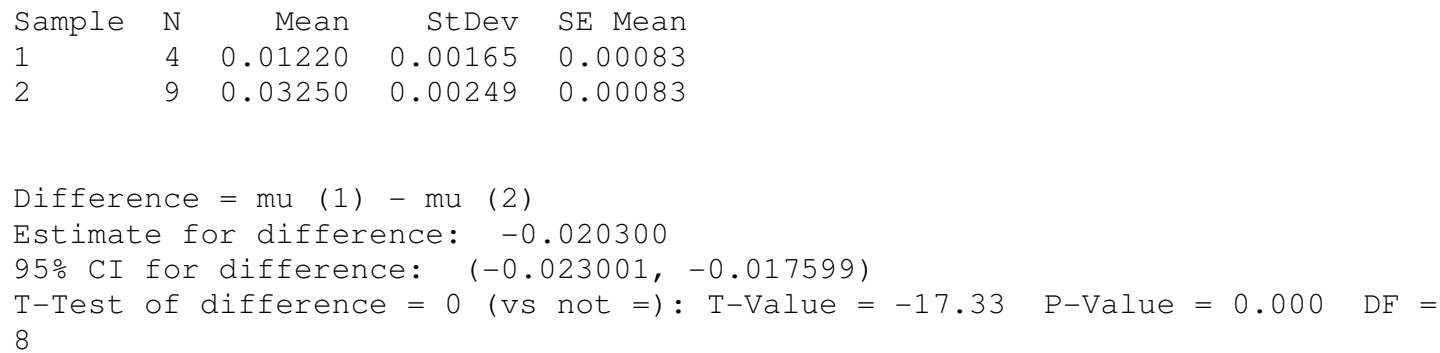

\section{Two-Sample T-Test for 100 ppm initial starting concentration}

$\begin{array}{lrrrr}\text { Sample } & \mathrm{N} & \text { Mean } & \text { StDev } & \text { SE Mean } \\ 1 & 7 & 0.015000 & 0.000652 & 0.00025 \\ 2 & 10 & 0.03610 & 0.00154 & 0.00049\end{array}$

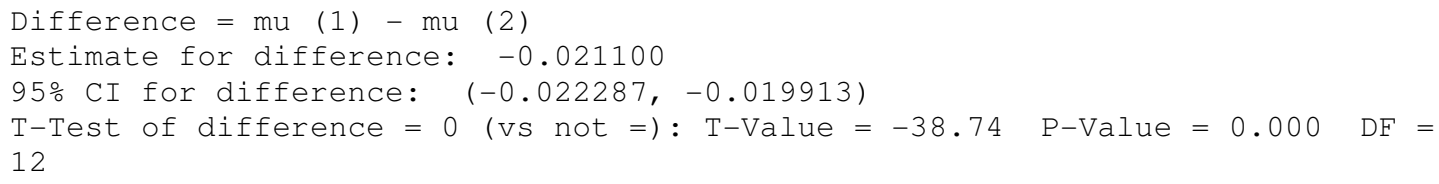




\section{APPENDIX C - Supplementary batch experiment data for Article I}

This appendix contains batch experiment data that was used in Article I “Arsenic Removal Using Iron-Modified Zeolite/ Zero-Valent Iron (SMZ/ZVI)." The tests include the water comparison using the Socorro Springs water and the synthetic lab water, kinetic data, TCLP analyses, $\mathrm{pH}$ comparison, and batch isotherm results. The procedures used in each experiment are contained within the Methods and Materials section of Article I. 
Table C- 1: Mass of reagents used in the preparation of $2 \mathrm{~L}$ of the synthetic water solution used in batch experiments. The ion concentrations of the prepared solution and the measured values from the Socorro Springs are included for comparison.

\begin{tabular}{l|cc}
\hline \multicolumn{3}{|c}{ Synthetic Water Preparation } \\
\hline Reagent & Amount (g) \\
\hline $\mathrm{NaHCO}_{3}$ & 0.210 \\
$\mathrm{CaCl}_{2}$ & 0.100 & \\
$\mathrm{MgSO}_{4}$ & 0.075 & \\
\hline \multicolumn{2}{|c|}{ Produces Following Solution when using 2 } & L of water. \\
\hline lon & Prepared (mg/L) & Socorro Springs (mg/L) \\
\hline $\mathrm{Na}^{+}$ & 28.8 & 52.1 \\
$\mathrm{Ca}^{2+}$ & 13.6 & 17.3 \\
$\mathrm{Mg}^{2+}$ & 7.60 & 4.10 \\
$\mathrm{HCO}_{3}{ }^{-}$ & 76.3 & 75.0 \\
$\mathrm{Cl}^{-}$ & 24.1 & 11.4 \\
$\mathrm{SO}_{4}{ }^{2-}$ & 29.9 & 28.6 \\
Alkalinity $^{2-}\left(\mathrm{CaCO}_{3}\right)$ & 126 & 123 \\
\hline
\end{tabular}


Table C- 2: Measured weights of materials used for comparison of adsorption isotherms between the synthetic water made in the lab (Syn), the Socorro Springs chlorinated feed water (Soco-Cl), and the Socorro Springs unchlorinated feed water (Soco). A 1 hour equilibration time was used.

\begin{tabular}{|c|c|c|c|c|c|}
\hline Sample ID & $\begin{array}{l}\text { Tube } \\
\text { (g) }\end{array}$ & $\begin{array}{l}\text { SMZ/ZVI } \\
\text { (g) }\end{array}$ & $\begin{array}{c}\text { Tube+SMZ/ZVI } \\
+20 \mathrm{~mL} \text { syn } \\
\text { water (g) }\end{array}$ & $\begin{array}{l}\text { Tube+SMZ/ZVI+20mL } \\
\text { syn water (after } \\
\text { washing) (g) }\end{array}$ & $\begin{array}{l}\text { Excess } \\
\text { Liquid } \\
\text { (g) }\end{array}$ \\
\hline Syn-1 & 13.44 & 5.01 & 38.28 & 43.61 & 5.33 \\
\hline Syn-2 & 13.54 & 5.04 & 38.40 & 43.91 & 5.51 \\
\hline Syn-3 & 8.88 & 4.99 & 33.69 & 38.74 & 5.05 \\
\hline Soco-Cl-1 & 8.74 & 5.02 & 33.63 & 38.67 & 5.04 \\
\hline Soco-Cl-2 & 13.39 & 5.01 & 38.22 & 43.29 & 5.06 \\
\hline Soco-Cl-3 & 8.96 & 4.99 & 33.84 & 39.05 & 5.21 \\
\hline Soco-1 & 13.60 & 4.97 & 38.38 & 43.92 & 5.53 \\
\hline Soco-2 & 13.60 & 4.98 & 38.40 & 43.64 & 5.24 \\
\hline Soco-3 & 13.59 & 4.97 & 38.42 & 43.64 & 5.22 \\
\hline
\end{tabular}

Table C- 3: Measured arsenic concentrations for the adsorption isotherms between the synthetic water made in the lab, the Socorro Springs chlorinated feed water, and the Socorro Springs unchlorinated feed water. Concentration measurement error is $\pm 3 \%$ based on replicate analyses of a $10 \mu \mathrm{g} / \mathrm{L}$ USGS standard reference sample. The stock solution concentration was measured from dilution of each one of the starting solutions. The initial concentration (Initial Conc.) are the calculated arsenic concentration after taking into account the excess liquid from the washing step. The equilibrium concentration in solution was the measured concentrations of each sample from the ICP-OES. The mass of SMZ/ZVI used for calculation of the amount adsorbed is contained in Table C-2. All values are reported to two significant figures.

\begin{tabular}{|c|c|c|c|c|c|}
\hline Sample ID & $\begin{array}{c}\text { Stock Soln. } \\
\text { Conc. }(\mu \mathrm{g} / \mathrm{L})\end{array}$ & $\begin{array}{c}\text { Initial } \\
\text { Conc. } \\
(\mu \mathrm{g} / \mathrm{L})\end{array}$ & $\begin{array}{c}\text { Equil. Conc. In } \\
\text { solution }(\mu \mathrm{g} / \mathrm{L}) \\
\mathbf{C}\end{array}$ & $\begin{array}{c}\text { Equil Conc. } \\
\text { Adsorbed } \\
(\mu \mathrm{g} / \mathrm{L})\end{array}$ & $\begin{array}{c}\text { Amount Sorbed } \\
(\mu \mathrm{g} / \mathrm{kg}) \\
\mathbf{S}\end{array}$ \\
\hline Syn-1 & 4200 & 3300 & 9.7 & 3300 & 17000 \\
\hline Syn-2 & 4200 & 3300 & 3.9 & 3300 & 17000 \\
\hline Syn-3 & 4200 & 3300 & 5.1 & 3300 & 17000 \\
\hline Soco-Cl-1 & 4700 & 3700 & 2.7 & 3700 & 19000 \\
\hline Soco-Cl-2 & 4700 & 3700 & 11 & 3700 & 19000 \\
\hline Soco-Cl-3 & 4700 & 3700 & 8.2 & 3700 & 19000 \\
\hline Soco-1 & 4400 & 3400 & 5.8 & 3400 & 18000 \\
\hline Soco-2 & 4400 & 3400 & 6.5 & 3400 & 17000 \\
\hline Soco-3 & 4400 & 3500 & 7.2 & 3400 & 18000 \\
\hline
\end{tabular}


Table C- 4: Measured weights of test tube, SMZ/ZVI, and excess water from the rinsing step used for kinetic batch studies for 20 minutes to 720 minutes.

\begin{tabular}{|c|c|c|c|c|c|c|}
\hline $\begin{array}{c}\text { Sample } \\
\text { ID }\end{array}$ & $\begin{array}{c}\text { Equilibration } \\
\text { Time Total } \\
\text { (min) }\end{array}$ & $\begin{array}{c}\text { Tube } \\
\text { (g) }\end{array}$ & $\begin{array}{c}\text { SMZ/ZVI } \\
\text { (g) }\end{array}$ & $\begin{array}{c}\text { Tube+SMZ/ZVI } \\
+20 \text { L syn water } \\
\text { (g) }\end{array}$ & $\begin{array}{c}\text { Tube+SMZ/ZVI } \\
+20 m L \\
\text { syn water (after } \\
\text { washing) (g) }\end{array}$ & $\begin{array}{c}\text { Excess } \\
\text { Liquid } \\
\text { (g) }\end{array}$ \\
\hline $20-1$ & 20 & 13.71 & 4.97 & 38.56 & 44.11 & 5.55 \\
\hline $20-2$ & 20 & 13.40 & 4.97 & 38.20 & 43.62 & 5.42 \\
\hline $40-1$ & 41 & 13.42 & 5.00 & 38.26 & 43.51 & 5.26 \\
\hline $40-2$ & 41 & 13.75 & 5.01 & 38.62 & 44.05 & 5.43 \\
\hline $60-1$ & 60 & 13.62 & 5.05 & 38.54 & 43.82 & 5.27 \\
\hline $60-2$ & 60 & 13.51 & 5.04 & 38.40 & 43.88 & 5.48 \\
\hline $120-1$ & 129 & 13.75 & 5.01 & 38.61 & 43.90 & 5.29 \\
\hline $120-2$ & 129 & 13.68 & 4.99 & 38.50 & 44.33 & 5.83 \\
\hline $240-1$ & 240 & 13.71 & 5.03 & 38.63 & 44.12 & 5.48 \\
\hline $240-2$ & 240 & 13.58 & 4.99 & 38.40 & 43.76 & 5.36 \\
\hline $480-1$ & 480 & 13.64 & 4.97 & 38.45 & 44.16 & 5.71 \\
\hline $480-2$ & 480 & 13.43 & 4.98 & 38.28 & 43.66 & 5.38 \\
\hline $720-1$ & 720 & 13.68 & 4.98 & 38.50 & 43.91 & 5.40 \\
\hline $720-2$ & 720 & 13.66 & 5.05 & 38.58 & 44.35 & 5.77 \\
\hline
\end{tabular}


Table C- 5: Measured arsenic concentrations for kinetic batch studies for 20 minutes to 720 minutes. Concentration measurement error is $\pm 3 \%$ based on replicate analyses of a $10 \mu \mathrm{g} / \mathrm{L}$ USGS standard reference sample. The stock solution concentration was measured from dilution of each one of the starting solutions. The initial concentration (Initial Conc.) are the calculated arsenic concentration after taking into account the excess liquid from the washing step. The equilibrium concentration in solution was the measured concentrations of each sample from the ICP-OES. The mass of SMZ/ZVI used for calculation of the amount adsorbed is contained in Table $\mathrm{C}-4$. All values are reported to two significant figures.

\begin{tabular}{|c|c|c|c|c|c|}
\hline $\begin{array}{c}\text { Sample } \\
\text { ID }\end{array}$ & $\begin{array}{c}\text { Stock Soln } \\
\text { Conc. }(\mu \mathrm{g} / \mathrm{L})\end{array}$ & $\begin{array}{c}\text { Initial Conc. } \\
(\mu \mathrm{g} / \mathrm{L})\end{array}$ & $\begin{array}{c}\text { Equil. Conc. In } \\
\text { Solution }(\boldsymbol{\mu g} / \mathbf{L}) \\
\mathbf{C}\end{array}$ & $\begin{array}{c}\text { Equil. Conc. } \\
\text { Sorbed }(\boldsymbol{\mu g} / \mathrm{L})\end{array}$ & $\begin{array}{c}\text { Amount Sorbed } \\
\boldsymbol{( \mu \mathrm { g } / \mathrm { kg } )} \\
\mathbf{S}\end{array}$ \\
\hline $20-1$ & 1000 & 780 & 1.8 & 780 & 4000 \\
\hline $20-2$ & 1000 & 790 & 1.3 & 790 & 4000 \\
\hline $40-1$ & 1000 & 790 & 0.87 & 790 & 4000 \\
\hline $40-2$ & 1000 & 790 & 2.1 & 780 & 4000 \\
\hline $60-1$ & 1000 & 790 & 2.0 & 790 & 4000 \\
\hline $60-2$ & 1000 & 790 & 1.1 & 780 & 4000 \\
\hline $120-1$ & 1000 & 790 & 0.91 & 790 & 4000 \\
\hline $120-2$ & 1000 & 770 & 1.7 & 770 & 4000 \\
\hline $240-1$ & 1000 & 790 & 1.5 & 780 & 4000 \\
\hline $240-2$ & 1000 & 790 & 1.7 & 790 & 4000 \\
\hline $480-1$ & 1000 & 780 & 1.8 & 780 & 4000 \\
\hline $480-2$ & 1000 & 790 & 1.4 & 790 & 4000 \\
\hline $720-1$ & 1000 & 790 & 3.7 & 780 & 4000 \\
\hline $720-2$ & 1000 & 780 & 1.0 & 780 & 4000 \\
\hline
\end{tabular}


Table C- 6: Measured weights of material used for kinetic batch studies at short times ( $0-60$ minutes).

\begin{tabular}{|c|c|c|c|c|c|c|}
\hline $\begin{array}{c}\text { Sample } \\
\text { ID }\end{array}$ & $\begin{array}{c}\text { Equilibration } \\
\text { Time Total } \\
\text { (min) }\end{array}$ & $\begin{array}{c}\text { Tube } \\
\mathbf{( g )}\end{array}$ & $\begin{array}{c}\text { SMZ/ZVI } \\
\mathbf{( g )}\end{array}$ & $\begin{array}{c}\text { Tube+SMZ/ZVI+20 } \\
\text { syn water (g) }\end{array}$ & $\begin{array}{c}\text { Tube+SMZ/ZVI+20mL } \\
\text { syn water (after } \\
\text { washing) (g) }\end{array}$ & $\begin{array}{c}\text { Excess } \\
\text { Liquid } \\
\mathbf{( g )}\end{array}$ \\
\hline $2-1$ & 2.4 & 13.59 & 5.01 & 38.44 & 24.39 & 5.79 \\
\hline $2-2$ & 2.4 & 13.54 & 4.98 & 38.36 & 23.84 & 5.33 \\
\hline $4-1$ & 4.1 & 13.62 & 4.96 & 38.44 & 23.84 & 5.26 \\
\hline $4-2$ & 4.1 & 13.30 & 5.00 & 38.13 & 23.35 & 5.05 \\
\hline $6-1$ & 6.2 & 13.82 & 5.01 & 38.68 & 24.08 & 5.26 \\
\hline $6-2$ & 6.2 & 13.61 & 4.97 & 38.44 & 24.15 & 5.57 \\
\hline $10-1$ & 11.1 & 13.66 & 4.99 & 38.47 & 24.06 & 5.41 \\
\hline $10-2$ & 11.1 & 13.43 & 5.01 & 38.32 & 23.64 & 5.21 \\
\hline $20-1$ & 21.1 & 13.84 & 4.98 & 38.69 & 23.95 & 5.14 \\
\hline $20-2$ & 21.1 & 13.53 & 5.00 & 38.42 & 23.82 & 5.29 \\
\hline $30-1$ & 30.1 & 13.77 & 4.98 & 38.63 & 24.24 & 5.48 \\
\hline $30-2$ & 30.1 & 13.66 & 4.99 & 38.53 & 24.07 & 5.41 \\
\hline $60-1$ & 56.4 & 13.54 & 5.00 & 38.44 & 23.83 & 5.30 \\
\hline $60-2$ & 56.4 & 13.66 & 4.97 & 38.46 & 23.86 & 5.23 \\
\hline
\end{tabular}

Table C- 7: Measured arsenic concentrations for kinetic batch studies at short times (0-60 minutes). Concentration measurement error is $\pm 3 \%$ based on replicate analyses of a $10 \mu \mathrm{g} / \mathrm{L}$ USGS standard reference sample. The stock solution concentration was measured from dilution of each one of the starting solutions. The initial concentration (Initial Conc.) are the calculated arsenic concentration after taking into account the excess liquid from the washing step. The equilibrium concentration in solution was the measured concentrations of each sample from the ICP-OES. The mass of SMZ/ZVI used for calculation of the amount adsorbed is contained in Table C-6. All values are reported to two significant figures

\begin{tabular}{|c|c|c|c|c|c|}
\hline Sample ID & $\begin{array}{c}\text { Stock Soln } \\
\text { Conc. }(\mu \mathrm{g} / \mathrm{L})\end{array}$ & $\begin{array}{c}\text { Initial Conc. } \\
(\mu \mathrm{g} / \mathrm{L})\end{array}$ & $\begin{array}{c}\text { Equil. Conc. In } \\
\text { solution }(\mu \mathrm{g} / \mathrm{L}) \\
\mathbf{C}\end{array}$ & $\begin{array}{c}\text { Equil. Conc. } \\
\text { Sorbed }(\mu \mathrm{g} / \mathrm{L})\end{array}$ & $\begin{array}{c}\text { Amount } \\
\text { Sorbed } \\
(\boldsymbol{\mu g} / \mathbf{k g}) \\
\mathbf{S}\end{array}$ \\
\hline $2-1$ & 69 & 54 & 0.91 & 53 & 270 \\
\hline $2-2$ & 69 & 55 & 0.69 & 54 & 280 \\
\hline $4-1$ & 69 & 55 & 0.59 & 54 & 280 \\
\hline $4-2$ & 69 & 55 & 0.42 & 55 & 280 \\
\hline $6-1$ & 69 & 55 & 0.31 & 55 & 280 \\
\hline $6-2$ & 69 & 54 & 0.35 & 54 & 280 \\
\hline $10-1$ & 69 & 55 & 0.26 & 54 & 280 \\
\hline $10-2$ & 69 & 55 & 0.46 & 55 & 280 \\
\hline $20-1$ & 69 & 55 & 0.24 & 55 & 280 \\
\hline $20-2$ & 69 & 55 & 0.24 & 55 & 280 \\
\hline $30-1$ & 69 & 54 & 0.15 & 54 & 280 \\
\hline $30-2$ & 69 & 55 & 0.23 & 54 & 280 \\
\hline $60-1$ & 69 & 55 & 0.31 & 55 & 280 \\
\hline $60-2$ & 69 & 55 & 0.54 & 54 & 280 \\
\hline
\end{tabular}


Table C- 8: Measured weights of material used for the TCLP batch experiment.

\begin{tabular}{|c|c|c|c|c|c|c|c|}
\hline $\begin{array}{l}\text { Sample } \\
\text { ID }\end{array}$ & $\begin{array}{c}\text { Equilibration } \\
\text { Time Total } \\
\text { (min) }\end{array}$ & $\begin{array}{l}\text { Tube } \\
\text { (g) }\end{array}$ & $\begin{array}{l}S M Z / Z V I \\
\text { (g) }\end{array}$ & $\begin{array}{c}\text { Tube+SMZ/ZVI +extra } \\
\text { syn water (g) }\end{array}$ & $\begin{array}{l}\text { Excess } \\
\text { Liquid } \\
\text { (g) }\end{array}$ & $\begin{array}{l}\text { Weight } \\
\text { Before } \\
\text { TCLP } \\
\text { Extracts } \\
\text { (g) }\end{array}$ & $\begin{array}{c}\text { Excess } \\
\text { water } \\
(\mathrm{g})\end{array}$ \\
\hline Co-1 & 140 & 13.68 & 4.97 & 23.48 & 4.84 & 23.71 & 5.06 \\
\hline Co-2 & 140 & 13.47 & 5.04 & 23.52 & 5.02 & 23.17 & 4.67 \\
\hline Co-3 & 140 & 13.62 & 5.03 & 23.79 & 5.13 & 23.58 & 4.93 \\
\hline Co-4 & 140 & 8.77 & 4.98 & 18.70 & 4.95 & 18.37 & 4.62 \\
\hline TCLP-1 & 1215 & & & & & & \\
\hline TCLP-2 & 1215 & & & & & & \\
\hline TCLP-3 & 1215 & & & & & & \\
\hline TCLP-4 & 1215 & & & & & & \\
\hline
\end{tabular}

Table C- 9: Measured $\mathrm{pH}$ values and arsenic concentration for the TCLP batch experiment. The samples Co-1, Co-2, etc. are the solution concentrations after initial equilibration with the $\sim 6 \mathrm{ppm}$ stock solution. The samples TCLP-1, TCLP-2, etc. are the measured values after leaching with the $\mathrm{pH} 2.88$ acetic acid solution. Concentration measurement error is $\pm 3 \%$ based on replicate analyses of a $10 \mu \mathrm{g} / \mathrm{L}$ USGS standard reference sample. The stock solution concentration was measured from dilution of each one of the starting solutions. The initial concentration (Initial Conc.) are the calculated arsenic concentration after taking into account the excess liquid from the washing step. The equilibrium concentration in solution was the measured concentrations of each sample from the ICP-OES. The mass of SMZ/ZVI used for calculation of the amount adsorbed is contained in Table C-8. All values are reported to two significant figures

\begin{tabular}{|c|c|c|c|c|c|c|}
\hline Sample ID & $\mathbf{p H}$ & $\begin{array}{c}\text { Initial Soln. } \\
\text { Conc. } \\
(\mu \mathrm{g} / \mathrm{L})\end{array}$ & $\begin{array}{c}\text { Initial Conc. } \\
(\mu \mathrm{g} / \mathrm{L}) \\
\text { includes } \\
\mathbf{e x t r a} \text { water }\end{array}$ & $\begin{array}{c}\text { Equil. Conc. } \\
\text { In solution } \\
(\mu \mathrm{g} / \mathrm{L}) \\
\mathbf{C}\end{array}$ & $\begin{array}{c}\text { Equil Conc. } \\
\text { Sorbed } \\
(\mu \mathrm{g} / \mathrm{L})\end{array}$ & $\begin{array}{c}\text { Amount } \\
\text { Sorbed } \\
(\mu \mathrm{g} / \mathrm{kg}) \\
\mathbf{S}\end{array}$ \\
\hline Co-1 & 7.6 & 6300 & 5000 & 3.8 & 5000 & 20000 \\
\hline Co-2 & 7.5 & 6300 & 5100 & 2.1 & 5100 & 20000 \\
\hline Co-3 & 7.6 & 6300 & 5100 & 3.7 & 5100 & 20000 \\
\hline Co-4 & 7.5 & 6300 & 5100 & 19 & 5100 & 20000 \\
\hline & & & & & & \\
\hline TCLP-1 & 6.5 & & & 0.67 & & \\
\hline TCLP-2 & 6.6 & & & 0.64 & & \\
\hline TCLP-3 & 6.6 & & & 0.65 & & \\
\hline TCLP-4 & 6.5 & & & 0.52 & & \\
\hline
\end{tabular}


Table C- 10: Collected weights of material used for the $\mathrm{pH}$ comparison test.

\begin{tabular}{|c|c|c|c|c|c|}
\hline Sample ID & $\begin{array}{l}\text { Equilibration } \\
\text { Time (min) }\end{array}$ & $\begin{array}{l}\text { Tube } \\
\text { (g) }\end{array}$ & $\begin{array}{c}\text { SMZ/ZVI } \\
\text { (g) }\end{array}$ & $\begin{array}{c}\text { Tube+ SMZ/ZVI } \\
\text { +excess liquid (g) }\end{array}$ & $\begin{array}{l}\text { Excess } \\
\text { Liquid } \\
\text { (g) }\end{array}$ \\
\hline \multicolumn{6}{|l|}{ Syn Water } \\
\hline $\mathrm{pH} 0.15-1$ & 125 & 13.79 & 5.02 & 24.02 & 5.21 \\
\hline $\mathrm{pH} \mathrm{0.15-2}$ & 125 & 13.68 & 5.03 & 23.67 & 4.96 \\
\hline pH .5-1 & 125 & 13.83 & 5.00 & 23.18 & 4.36 \\
\hline $\mathrm{pH} .5-2$ & 125 & 13.94 & 4.99 & 23.37 & 4.44 \\
\hline $\mathrm{pH} 1-1$ & 125 & 13.78 & 4.99 & 23.38 & 4.61 \\
\hline $\mathrm{pH} 1-2$ & 125 & 13.72 & 5.02 & 23.49 & 4.75 \\
\hline $\mathrm{pH} 2-1$ & 125 & 13.68 & 5.00 & 23.55 & 4.87 \\
\hline $\mathrm{pH} 2-2$ & 125 & 13.80 & 5.03 & 23.45 & 4.62 \\
\hline $\mathrm{pH} 3-1$ & 125 & 13.68 & 4.98 & 22.56 & 3.90 \\
\hline $\mathrm{pH} 3-2$ & 125 & 13.63 & 5.00 & 23.42 & 4.79 \\
\hline $\mathrm{pH} 5-1$ & 125 & 13.69 & 5.00 & 23.13 & 4.44 \\
\hline $\mathrm{pH} 5-2$ & 125 & 13.75 & 4.98 & 22.87 & 4.14 \\
\hline pH 6-1 & 125 & 13.53 & 4.98 & 23.07 & 4.57 \\
\hline $\mathrm{pH} 6-2$ & 125 & 13.98 & 5.00 & 23.63 & 4.65 \\
\hline $\mathrm{pH} 7-1$ & 125 & 13.56 & 4.99 & 23.57 & 5.02 \\
\hline $\mathrm{pH} 7-2$ & 125 & 9.15 & 5.02 & 19.10 & 4.94 \\
\hline $\mathrm{pH} 8-1$ & 125 & 13.66 & 5.01 & 23.28 & 4.62 \\
\hline $\mathrm{pH} 8-2$ & 125 & 8.91 & 4.97 & 18.54 & 4.67 \\
\hline $\mathrm{pH} 9-1$ & 125 & 13.59 & 4.98 & 22.90 & 4.33 \\
\hline $\mathrm{pH} 9-2$ & 125 & 13.50 & 5.02 & 22.81 & 4.29 \\
\hline pH 10-1 & 125 & 13.61 & 5.04 & 23.73 & 5.08 \\
\hline pH 10-2 & 125 & 13.84 & 4.99 & 24.35 & 5.53 \\
\hline pH 11-1 -dil 1:100 & 125 & 13.78 & 5.01 & 24.22 & 5.43 \\
\hline pH 11-2 -dil 1:100 & 125 & 13.66 & 5.00 & 23.89 & 5.23 \\
\hline pH 12-1 -dil 1:100 & 125 & 9.28 & 4.98 & 19.58 & 5.32 \\
\hline pH 12-2 -dil 1:100 & 125 & 13.62 & 5.04 & 24.10 & 5.45 \\
\hline No As- Blank SMZ/ZVI & 125 & 30.52 & 4.99 & 40.76 & 5.25 \\
\hline No SMZ/ZVI- $\mathrm{pH}=8$ 1:100 dil & 125 & & & & \\
\hline stock 10ppm 1:100 dil & 125 & & & & \\
\hline
\end{tabular}


Table C- 11: Measured $\mathrm{pH}$ values and initial solution concentrations for the $\mathrm{pH}$ comparison batch experiment. Measured $\mathrm{pH}$ values and arsenic concentration for the TCLP batch experiment. Concentration measurement error is $\pm 3 \%$ based on replicate analyses of a $10 \mu \mathrm{g} / \mathrm{L}$ USGS standard reference sample. The stock solution concentration was measured from dilution of each one of the starting solutions. The initial concentration (Initial Conc.) are the calculated arsenic concentration after taking into account the excess liquid from the washing step. The equilibrium concentration in solution was the measured concentrations of each sample from the ICP-OES. The mass of SMZ/ZVI used for calculation of the amount adsorbed is contained in Table C-10. All values are reported to two significant figures except where accuracy limited.

\begin{tabular}{|c|c|c|c|c|c|c|}
\hline Sample ID & $\begin{array}{c}\text { Initial } \\
\text { pH }\end{array}$ & $\begin{array}{c}\text { Final } \\
\text { pH }\end{array}$ & $\begin{array}{l}\text { Initial pH } \\
\text { adjusted } \\
\text { Volume }\end{array}$ & $\begin{array}{c}\text { mL Acid } \\
\text { or Base } \\
\text { Added }\end{array}$ & $\begin{array}{l}\text { Stock } \\
\text { Soln } \\
\text { Conc. } \\
(\mu \mathrm{g} / \mathrm{L})\end{array}$ & $\begin{array}{c}\text { Final Initial } \\
\text { Soln. Conc } \\
\quad(\mu \mathrm{g} / \mathrm{L})\end{array}$ \\
\hline \multicolumn{7}{|l|}{ Syn Water } \\
\hline $\mathrm{pH} 0.15-1$ & 0.1 & 3.3 & 75 & 6.0 & 81000 & 75000 \\
\hline $\mathrm{pH} \mathrm{0.15-2}$ & 0.1 & 3.5 & 75 & 6.0 & 81000 & 62000 \\
\hline $\mathrm{pH} .5-1$ & 0.5 & 5.0 & 75 & 3.3 & 81000 & 69000 \\
\hline $\mathrm{pH} .5-2$ & 0.5 & 4.3 & 75 & 3.3 & 81000 & 69000 \\
\hline $\mathrm{pH}$ 1-1 & 1.0 & 5.6 & 75 & 1.0 & 81000 & 77000 \\
\hline $\mathrm{pH} 1-2$ & 1.0 & 5.6 & 75 & 1.0 & 81000 & 77000 \\
\hline $\mathrm{pH} 2-1$ & 2.0 & 6.5 & 75 & 0.1 & 81000 & 80000 \\
\hline $\mathrm{pH} \mathrm{2-2}$ & 2.0 & 6.4 & 75 & 0.1 & 81000 & 80000 \\
\hline $\mathrm{pH} 3-1$ & 2.8 & 6.8 & 75 & 0.3 & 81000 & 79000 \\
\hline $\mathrm{pH} 3-2$ & 2.8 & 7.0 & 75 & 0.3 & 81000 & 79000 \\
\hline pH 5-1 & 5.2 & 7.2 & 75 & 0.5 & 81000 & 79000 \\
\hline $\mathrm{pH} \mathrm{5-2}$ & 5.2 & 7.2 & 75 & 0.5 & 81000 & 79000 \\
\hline $\mathrm{pH} \mathrm{6-1}$ & 6.0 & 7.5 & 75 & 0.4 & 81000 & 79000 \\
\hline $\mathrm{pH} \mathrm{6-2}$ & 6.0 & 7.6 & 75 & 0.4 & 81000 & 79000 \\
\hline pH 7-1 & 7.0 & 8.1 & 75 & 0.2 & 81000 & 80000 \\
\hline $\mathrm{pH} 7-2$ & 7.0 & 8.0 & 75 & 0.2 & 81000 & 80000 \\
\hline $\mathrm{pH} 8-1$ & 7.7 & 8.1 & 75 & 0 & 81000 & 81000 \\
\hline $\mathrm{pH} 8-2$ & 7.7 & 8.3 & 75 & 0 & 81000 & 81000 \\
\hline pH 9-1 & 9.2 & 8.2 & 75 & 0.1 & 81000 & 80000 \\
\hline $\mathrm{pH} \mathrm{9-2}$ & 9.2 & 8.2 & 75 & 0.1 & 81000 & 80000 \\
\hline pH 10-1 & 10.1 & 6.5 & 75 & 0.4 & 81000 & 79000 \\
\hline $\mathrm{pH} 10-2$ & 10.1 & 8.1 & 75 & 0.4 & 81000 & 79000 \\
\hline pH 11-1 -dil 1:100 & 11.0 & 9.5 & 75 & 1.2 & 81000 & 76000 \\
\hline pH 11-2 -dil 1:100 & 11.0 & 9.6 & 75 & 1.2 & 81000 & 76000 \\
\hline pH 12-1 -dil 1:100 & 12.0 & 10.9 & 80 & 1.3 & 81000 & 76000 \\
\hline pH 12-2 -dil 1:100 & 12.0 & 11.0 & 80 & 1.3 & 81000 & 76000 \\
\hline No As- Blank SMZ/ZVI & & 7.7 & & & & \\
\hline \multicolumn{7}{|l|}{ No SMZ/ZVI- pH=8 1:100 dil } \\
\hline stock 10ppm 1:100 dil & & 8.3 & & & & \\
\hline
\end{tabular}


Table C- 12: Measured equilibration arsenic concentrations for the $\mathrm{pH}$ comparison batch experiment. Tubes with high arsenic concentrations were diluted 1:100. Concentration measurement error is $\pm 3 \%$ based on replicate analyses of a $10 \mu \mathrm{g} / \mathrm{L}$ USGS standard reference sample. The equilibrium concentration in solution was the measured concentrations of each sample from the ICP-OES. All concentration values are reported to two significant figures.

\begin{tabular}{|c|c|c|c|c|}
\hline Sample ID & $\begin{array}{l}\text { Initial Soln } \\
\text { Conc. Due } \\
\text { to Excess } \\
\text { Liquid } \\
(\mu \mathrm{g} / \mathrm{L})\end{array}$ & $\begin{array}{c}\text { Measured Conc. } \\
\text { After } \\
\text { equilibration } \\
(\mu \mathrm{g} / \mathrm{L})\end{array}$ & $\begin{array}{l}\text { Equil } \\
\text { Conc. } \\
\text { Sorbed } \\
\text { ( } \mu \mathrm{g} / \mathrm{L})\end{array}$ & $\begin{array}{c}\text { Amount } \\
\text { Sorbed } \\
\text { (mg/kg) }\end{array}$ \\
\hline \multicolumn{5}{|l|}{ Syn Water } \\
\hline $\mathrm{pH} 0.15-1$ & 59000 & 490 & 59000 & 230 \\
\hline $\mathrm{pH} \mathrm{0.15-2}$ & 50000 & 390 & 49000 & 200 \\
\hline $\mathrm{pH} .5-1$ & 57000 & 18 & 57000 & 230 \\
\hline $\mathrm{pH} .5-2$ & 57000 & 87 & 57000 & 230 \\
\hline $\mathrm{pH} \mathrm{1-1}$ & 62000 & 10 & 62000 & 250 \\
\hline $\mathrm{pH} \mathrm{1-2}$ & 62000 & 10 & 62000 & 250 \\
\hline $\mathrm{pH} \mathrm{2-1}$ & 65000 & 3.9 & 64000 & 260 \\
\hline $\mathrm{pH} \mathrm{2-2}$ & 65000 & 3.6 & 65000 & 260 \\
\hline pH 3-1 & 66000 & 4.8 & 66000 & 270 \\
\hline $\mathrm{pH} 3-2$ & 64000 & 6.6 & 64000 & 260 \\
\hline pH 5-1 & 64000 & 11 & 64000 & 260 \\
\hline $\mathrm{pH} \mathrm{5-2}$ & 65000 & 12 & 65000 & 260 \\
\hline $\mathrm{pH} \mathrm{6-1}$ & 64000 & 24 & 64000 & 260 \\
\hline $\mathrm{pH} \mathrm{6-2}$ & 64000 & 18 & 64000 & 260 \\
\hline $\mathrm{pH} \mathrm{7-1}$ & 64000 & 160 & 64000 & 250 \\
\hline $\mathrm{pH} \mathrm{7-2}$ & 64000 & 120 & 64000 & 260 \\
\hline $\mathrm{pH} \mathrm{8-1}$ & 65000 & 72 & 65000 & 260 \\
\hline $\mathrm{pH} \mathrm{8-2}$ & 65000 & 78 & 65000 & 260 \\
\hline pH 9-1 & 66000 & 75 & 66000 & 260 \\
\hline $\mathrm{pH} \mathrm{9-2}$ & 66000 & 54 & 66000 & 260 \\
\hline $\mathrm{pH} 10-1$ & 63000 & 69 & 63000 & 250 \\
\hline $\mathrm{pH} 10-2$ & 62000 & 240 & 62000 & 250 \\
\hline pH 11-1 -dil 1:100 & 60000 & 3600 & 56000 & 230 \\
\hline pH 11-2 -dil 1:100 & 60000 & 3300 & 57000 & 230 \\
\hline pH 12-1 -dil 1:100 & 60000 & 48000 & 11000 & 45 \\
\hline pH 12-2 -dil 1:100 & 59000 & 48000 & 11000 & 45 \\
\hline No As- Blank SMZ/ZVI & & 0 & & \\
\hline No SMZ/ZVI- $\mathrm{pH}=8$ 1:100 dil & & 80000 & & \\
\hline stock 10ppm 1:100 dil & & 81000 & & \\
\hline
\end{tabular}


Table C- 13: Measured weights of material used and final $\mathrm{pH}$ values for the batch experiment isotherm. The initial solution $\mathrm{pH}$ was $8.5 \pm 0.1$ for each concentration.

\begin{tabular}{|c|c|c|c|c|c|c|}
\hline Sample ID & $\begin{array}{c}\text { Equilibration } \\
\text { Time (min) }\end{array}$ & $\begin{array}{c}\text { Tube } \\
\mathbf{( g )}\end{array}$ & $\begin{array}{c}\text { SMz/ZVI } \\
\mathbf{( g )}\end{array}$ & $\begin{array}{c}\text { Tube+SMZ/ZVI+20mL } \\
\text { syn water (after } \\
\text { washing) (g) }\end{array}$ & $\begin{array}{c}\text { Excess } \\
\text { Liquid } \\
\text { (g) }\end{array}$ & $\begin{array}{c}\text { Final } \\
\mathbf{p H}\end{array}$ \\
\hline $10-1$ & 135 & 13.68 & 4.98 & 23.24 & 4.59 & 7.5 \\
\hline $10-2$ & 135 & 8.82 & 5.00 & 17.86 & 4.05 & 7.6 \\
\hline $50-1$ & 135 & 13.73 & 4.99 & 22.23 & 3.52 & 8.0 \\
\hline $50-2$ & 135 & 13.68 & 5.01 & 23.46 & 4.77 & 8.2 \\
\hline $100-1$ & 135 & 13.51 & 5.01 & 22.97 & 4.44 & 8.1 \\
\hline $100-2$ & 135 & 13.66 & 5.01 & 23.85 & 5.18 & 8.4 \\
\hline $200-1$ & 135 & 13.89 & 4.98 & 23.92 & 5.04 & 9.4 \\
\hline $200-2$ & 135 & 8.96 & 5.02 & 18.91 & 4.92 & 9.5 \\
\hline $400-1$ & 135 & 13.67 & 5.00 & 23.76 & 5.08 & 9.9 \\
\hline $400-2$ & 135 & 9.06 & 4.99 & 19.09 & 5.04 & 9.9 \\
\hline $600-1$ & 135 & 13.67 & 5.01 & 23.58 & 4.90 & 9.7 \\
\hline $600-2$ & 135 & 13.65 & 4.98 & 23.78 & 5.15 & 9.7 \\
\hline No As & 135 & 13.72 & 4.99 & 23.77 & 5.07 & 7.6 \\
\hline Blank 100 ppm & & & & & & 8.4 \\
\hline Soco Springs H20 & & & & & & 8.4 \\
\hline Syn H20 & & & & & & 8.2 \\
\hline
\end{tabular}


Table C- 14: Measured arsenic concentrations for the batch experiment isotherm. Concentration measurement error is $\pm 3 \%$ based on replicate analyses of a $10 \mu \mathrm{g} / \mathrm{L}$ USGS standard reference sample. The stock solution concentration was measured from dilution of each one of the starting solutions. The initial concentration (Initial Conc.) are the calculated arsenic concentration after taking into account the excess liquid from the washing step. The equilibrium concentration in solution was the measured concentrations of each sample from the ICP-OES. The mass of SMZ/ZVI used for calculation of the amount adsorbed is contained in Table $\mathrm{C}-13$. All values are reported to two significant figures.

\begin{tabular}{|c|c|c|c|c|c|}
\hline Sample ID & $\begin{array}{c}\text { Initial Soln } \\
\text { Conc. } \\
(\mu \mathrm{g} / \mathrm{L})\end{array}$ & $\begin{array}{c}\text { Initial Conc } \\
\text { with syn } \\
\text { dilution. } \\
(\mu \mathrm{g} / \mathrm{L})\end{array}$ & $\begin{array}{c}\text { Equil. Conc. } \\
\text { In solution } \\
(\boldsymbol{\mu g} / \mathbf{L}) \\
\mathbf{C}\end{array}$ & $\begin{array}{c}\text { Equil Conc. } \\
\text { Sorbed } \\
(\mu \mathrm{g} / \mathrm{L})\end{array}$ & $\begin{array}{c}\text { Amount } \\
\text { Sorbed } \\
(\boldsymbol{\mu g} / \mathrm{kg}) \\
\mathbf{S}\end{array}$ \\
\hline $10-1$ & 10000 & 8100 & 3.5 & 8100 & 40000 \\
\hline $10-2$ & 10000 & 8300 & 2.4 & 8300 & 40000 \\
\hline $50-1$ & 50000 & 42000 & 21 & 42000 & 200000 \\
\hline $50-2$ & 50000 & 40000 & 41 & 40000 & 200000 \\
\hline $100-1$ & 100000 & 82000 & 62 & 81000 & 400000 \\
\hline $100-2$ & 100000 & 79000 & 190 & 79000 & 400000 \\
\hline $200-1$ & 200000 & 160000 & 13000 & 150000 & 730000 \\
\hline $200-2$ & 200000 & 160000 & 11000 & 150000 & 740000 \\
\hline $400-1$ & 400000 & 320000 & 140000 & 180000 & 910000 \\
\hline $400-2$ & 400000 & 320000 & 120000 & 190000 & 980000 \\
\hline $600-1$ & 600000 & 480000 & 320000 & 160000 & 780000 \\
\hline $600-2$ & 600000 & 480000 & 330000 & 140000 & 720000 \\
\hline No As & & & 0 & & \\
\hline Blank 100 ppm SMZ/ZVI & & & 100000 & & \\
\hline
\end{tabular}




\section{APPENDIX D - Supplementary column data for Article I.}

This appendix contains column parameters that were used in Article I "Arsenic Removal Using Iron-Modified Zeolite/ Zero-Valent Iron (SMZ/ZVI).” The data includes an example set of parameters used for modeling with HYDRUS-1D and observed and measured parameters from the Socorro Springs field column study, the $30 \mathrm{~cm}$ lab column experiments, and the $9 \mathrm{~cm} \mathrm{pH}$ adjusted lab column experiments. The procedures used in each experiment are contained within the Methods and Materials section of Article I. 
Table D- 1: Example list of parameters used for HYDRUS-1D simulations.

\begin{tabular}{|c|c|}
\hline Main Processes & \\
\hline Water Flow & check \\
\hline Solute Transport & check \\
\hline General Solute Transport & check \\
\hline \multicolumn{2}{|l|}{ Geometry Information } \\
\hline Number of Soil Materials & 1 \\
\hline Number of Soil Layers & 1 \\
\hline Decline from Vertical Axis & 1 \\
\hline Depth of Soil Profile $(\mathrm{cm})$ & 10.5 \\
\hline Depth Unit & $\mathrm{cm}$ \\
\hline \multicolumn{2}{|l|}{ Time Information } \\
\hline Time Unit & days \\
\hline Initial Time & 0 \\
\hline Final Time & 20 \\
\hline Initial Time Step & 0.002 \\
\hline Minimum Time Step & 0.001 \\
\hline Maximum Time Step & 1 \\
\hline \multicolumn{2}{|l|}{ Print Information } \\
\hline T-level information & 1 \\
\hline \multicolumn{2}{|l|}{ Iteration Criteria } \\
\hline Maximum Number of Iterations & 20 \\
\hline Water Content Tolerance & 0.0001 \\
\hline Pressure Head Tolerance & 0.1 \\
\hline Lower Optimal Iteration Range & 3 \\
\hline Upper Optimal Iteration Range & 7 \\
\hline Lower Time Step Multiplication Factor & 1.3 \\
\hline Upper Time Step Multiplication Factor & 0.33 \\
\hline Lower Limit on the Tension Interval & $1.00 \mathrm{E}-06$ \\
\hline Upper Limit on the Tension Interval & 10000 \\
\hline \multicolumn{2}{|l|}{ Soil Hydraulic Model } \\
\hline Van Genucghten-0 Mualem & check \\
\hline No hysteresis & check \\
\hline \multicolumn{2}{|l|}{ Water Flow Parameters } \\
\hline Qr & 0 \\
\hline Qs & 0.62 \\
\hline Alpha & 0 \\
\hline $\mathrm{n}$ & 2 \\
\hline Ks (cm/day) & 1757 \\
\hline I & 0.5 \\
\hline
\end{tabular}


Table D-1 continued:

\begin{tabular}{|c|c|}
\hline Water Flow Boundary Conditions & \\
\hline Upper Boundary-Constant Pressure Head & check \\
\hline Lower Boundary Conditions Constant Pressure Head & check \\
\hline Initial Condition- Pressure Heads & check \\
\hline \multicolumn{2}{|l|}{ Solute Transport } \\
\hline Crank-Nicholson Scheme & check \\
\hline Galerkin Finite Elements & check \\
\hline Mass Units & ng \\
\hline Stability Criterion & 2 \\
\hline Equilibrium Model & check \\
\hline Absolute Concentration Tolerance & 0.0001 \\
\hline Relative Concentration Tolerance & 0.0001 \\
\hline Maximum Number of Iterations & 20 \\
\hline Use Tortuosity Factor & check \\
\hline Millington and Quirk & check \\
\hline Number of Solutes & 1 \\
\hline Pulse Duration & 50000 \\
\hline \multicolumn{2}{|l|}{ Solute Transport Parameters } \\
\hline Bulk D. & 0.71 \\
\hline Disp. & 30 \\
\hline Frac $=1$ & 1 \\
\hline Thlm $=0$ & 0 \\
\hline Disfus W. & 0 \\
\hline Difus G. & 0 \\
\hline \multicolumn{2}{|l|}{ Solute Transport and Reaction Parameters } \\
\hline Kd & 14600 \\
\hline $\mathrm{Nu}$ & 0.0312 \\
\hline Beta & 1 \\
\hline Henry & 0 \\
\hline Sinkwater 1 & 0 \\
\hline SinkSolid1 & 0 \\
\hline Sinkgas1 & 0 \\
\hline Sinkwater1* & 0 \\
\hline Sinksolid1* & 0 \\
\hline Sinkgas1* & 0 \\
\hline Sinkwater0 & 0 \\
\hline Sinksolid0 & 0 \\
\hline Sinkgas0 & 0 \\
\hline Alpha & 0 \\
\hline \multicolumn{2}{|l|}{ Solute Transport Boundary Conditions } \\
\hline Concentration Flux BC & check \\
\hline Zero Concentration Gradient & check \\
\hline In liquid Phase Concentration [Mass_solute/Volume_water] & check \\
\hline Bound Cond. & 44 \\
\hline \multicolumn{2}{|l|}{ HYDRUS-1D Profile Information } \\
\hline Specified Head at each end & check \\
\hline Initial Pressure Head for entire column & 1 \\
\hline Observation node at bottom & check \\
\hline
\end{tabular}


Table D- 2: Operating parameters for the four columns tested at the Socorro Springs field site. Columns 1 and 2 contained $8 \times 14$ mesh SMZ/ZVI while columns 3 and 4 contained 14 x 40 mesh SMZ/ZVI. Each column contained 4 liters of each sized material.

\begin{tabular}{|c|c|c|c|c|}
\hline Field Column Parameters & Col 1 & Col 2 & Col 3 & Col 4 \\
\hline Column diameter (cm) & 7.62 & 7.62 & 7.62 & 7.62 \\
\hline Media Height (cm) & 91 & 89 & 73 & 72 \\
\hline Media Volume (L) & 4.1 & 4.1 & 3.3 & 3.3 \\
\hline Measured Porosity & 0.71 & 0.71 & 0.65 & 0.65 \\
\hline Pore Volume Size (L) & 2.9 & 2.9 & 2.2 & 2.1 \\
\hline Avg. flowrate (L/min) & 0.78 & 0.55 & 0.93 & 0.74 \\
\hline Specific Discharge (cm/min) & 17.1 & 12.1 & 20.4 & 16.2 \\
\hline Pore water velocity (cm/min) & 24.1 & 17.0 & 28.7 & 22.9 \\
\hline Residence Time (min) & 3.8 & 5.2 & 2.5 & 3.1 \\
\hline Mass SMZ/ZVI (kg) & 3 & 3 & 3 & 3 \\
\hline Bulk Density (g/cm $/ \mathrm{cm}^{3}$ & 0.7 & 0.7 & 0.9 & 0.9 \\
\hline
\end{tabular}

Table D- 3: Measured volumes of water treated from the Socorro Springs pilot test using SMZ/ZVI. Columns 1 and 2 contained 8 x 14 mesh SMZ/ZVI while columns 3 and 4 contained 14 x 40 mesh $\mathrm{SMZ/ZVI}$. Each column contained 4 liters of each sized material. Error in volume measurements is about $\pm 2 \%$ based on meter calibration.

\begin{tabular}{|c|c|c|c|c|}
\hline \multicolumn{5}{|c|}{ Volumes } \\
\hline Date & Col 1 (L) & Col 2 (L) & Col 3 (L) & Col 4 (L) \\
\hline $10 / 29 / 0814: 41$ & 0 & 0 & 0 & 0 \\
\hline $10 / 30 / 0817: 05$ & 1260 & 2 & 1670 & 1190 \\
\hline $10 / 31 / 0815: 48$ & 2590 & 7 & 3250 & 2330 \\
\hline $11 / 2 / 0811: 00$ & 3970 & 18 & 5280 & 2370 \\
\hline $11 / 2 / 0813: 19$ & 4020 & 55 & 5310 & 4130 \\
\hline $11 / 3 / 0817: 16$ & 5500 & 470 & 7000 & 4150 \\
\hline $11 / 3 / 0817: 43$ & 5520 & 490 & 7030 & 4190 \\
\hline $11 / 3 / 0818: 25$ & 5550 & 520 & 7070 & 4200 \\
\hline $11 / 3 / 0819: 00$ & 5560 & 540 & 7080 & 5420 \\
\hline $11 / 4 / 0817: 39$ & 6690 & 1190 & 8270 & 6890 \\
\hline $11 / 5 / 0818: 35$ & 8180 & 2340 & 9770 & 8080 \\
\hline $11 / 6 / 0817: 16$ & 9460 & 3150 & 11100 & 10700 \\
\hline $11 / 10 / 089: 12$ & 11700 & 4510 & 14000 & 11500 \\
\hline $11 / 12 / 0811: 37$ & 12600 & 4600 & 14900 & 11600 \\
\hline $11 / 12 / 0820: 28$ & 12700 & 4730 & 15100 & 12300 \\
\hline $11 / 14 / 088: 20$ & 13400 & 4910 & 15800 & 14100 \\
\hline $11 / 19 / 089: 27$ & 14900 & 5190 & 17900 & \\
\hline
\end{tabular}


Table D- 4: Measured pore volumes (PV) from the Socorro Springs pilot test using SMZ/ZVI.

Columns 1 and 2 contained $8 \times 14$ mesh SMZ/ZVI while columns 3 and 4 contained $14 \times 40$ mesh SMZ/ZVI. Each column contained 4 liters of each sized material. Error in volume measurements is about $\pm 2 \%$ based on meter calibration.

\begin{tabular}{|c|c|c|c|c|}
\hline \multicolumn{5}{|c|}{ Pore Volumes } \\
\hline Date & Col 1 PV & Col 2 PV & Col 3 PV & Col 4 PV \\
\hline $10 / 29 / 0814: 41$ & 0 & 0 & 0 & 0 \\
\hline $10 / 30 / 0817: 05$ & 440 & 1 & 590 & 0 \\
\hline $10 / 31 / 0815: 48$ & 910 & 3 & 1140 & 420 \\
\hline $11 / 2 / 0811: 00$ & 1400 & 6 & 1860 & 820 \\
\hline $11 / 2 / 0813: 19$ & 1420 & 19 & 1870 & 830 \\
\hline $11 / 3 / 0817: 16$ & 1940 & 170 & 2470 & 1450 \\
\hline $11 / 3 / 0817: 43$ & 1940 & 170 & 2480 & 1460 \\
\hline $11 / 3 / 0818: 25$ & 1950 & 180 & 2490 & 1480 \\
\hline $11 / 3 / 0819: 00$ & 1960 & 190 & 2490 & 1480 \\
\hline $11 / 4 / 0817: 39$ & 2360 & 420 & 2910 & 1910 \\
\hline $11 / 5 / 0818: 35$ & 2880 & 830 & 3440 & 2430 \\
\hline $11 / 6 / 0817: 16$ & 3330 & 1110 & 3900 & 2850 \\
\hline $11 / 10 / 089: 12$ & 4110 & 1590 & 4920 & 3760 \\
\hline $11 / 12 / 0811: 37$ & 4430 & 1620 & 5260 & 4030 \\
\hline $11 / 12 / 0820: 28$ & 4480 & 1670 & 5310 & 4090 \\
\hline $11 / 14 / 088: 20$ & 4700 & 1730 & 5580 & 4330 \\
\hline $11 / 19 / 089: 27$ & 5250 & 1830 & 6310 & 4980 \\
\hline
\end{tabular}

Table D- 5: Measured arsenic concentrations from the Socorro Springs pilot test using SMZ/ZVI. Columns 1 and 2 contained $8 \times 14$ mesh SMZ/ZVI while columns 3 and 4 contained $14 \times 40$ mesh SMZ/ZVI. Each column contained $3 \mathrm{~kg}$ of each sized material. Concentration measurement error is \pm $3 \%$ based on replicate analyses of a $10 \mu \mathrm{g} / \mathrm{L}$ USGS standard reference sample. Blank cells indicated that the parameter was not measured.

\begin{tabular}{|c|c|c|c|c|c|}
\hline \multicolumn{7}{|c|}{ Arsenic Concentrations $(\boldsymbol{\mu g} / \mathbf{L})$} \\
\hline Date & Col 1 & Col 2 & Col 3 & Col 4 & Influent \\
\hline $10 / 29 / 0814: 41$ & 12 & & 6.7 & & 45 \\
\hline $10 / 30 / 0817: 05$ & 20 & 10 & 5.5 & 5.2 & 45 \\
\hline $10 / 31 / 0815: 48$ & 27 & & 14 & 5.7 & \\
\hline $11 / 2 / 0811: 00$ & & & 23 & 12 & \\
\hline $11 / 2 / 0813: 19$ & 32 & 14 & 29 & 25 & \\
\hline $11 / 3 / 0817: 16$ & & 11 & 34 & & 39 \\
\hline $11 / 3 / 0817: 43$ & 36 & & & & \\
\hline $11 / 3 / 0818: 25$ & & & & & \\
\hline $11 / 3 / 0819: 00$ & & & & & \\
\hline $11 / 4 / 0817: 39$ & 38 & 17 & 37 & 33 & 44 \\
\hline $11 / 5 / 0818: 35$ & 37 & 20 & 37 & 36 & 44 \\
\hline $11 / 6 / 0817: 16$ & 41 & 28 & 41 & 41 & 45 \\
\hline $11 / 10 / 089: 12$ & 33 & 26 & 32 & 32 & \\
\hline $11 / 12 / 0811: 37$ & 34 & 21 & 33 & 33 & \\
\hline $11 / 12 / 0820: 28$ & & 22 & 35 & 34 & 40 \\
\hline $11 / 14 / 088: 20$ & 35 & 27 & 36 & 36 & 40 \\
\hline
\end{tabular}


Table D- 6: Measured water quality parameters for the influent water in the Socorro Springs SMZ/ZVI field test. A range of values is listed for the free $\mathrm{Cl}_{2}$ based on the color of the test strip used for determining the free chlorine content.

\begin{tabular}{|c|c|c|c|c|c|}
\hline \multicolumn{7}{|c|}{ Influent Parameters } \\
\hline Date and Time & $\mathbf{p H}$ & $\begin{array}{c}\text { Conductivity } \\
(\mu \mathrm{S} / \mathrm{cm})\end{array}$ & $\begin{array}{c}\text { DO } \\
(\mathbf{m g} / \mathrm{L})\end{array}$ & $\begin{array}{c}\text { Temp } \\
(\mathbf{C})\end{array}$ & $\begin{array}{c}\text { Free } \mathrm{Cl}_{2} \\
(\mathbf{m g} / \mathbf{L})\end{array}$ \\
\hline $10 / 29 / 200815: 00$ & 7.8 & 654 & 4.4 & 31.3 & $.6-.7$ \\
\hline $10 / 29 / 200818: 10$ & 8.0 & 353 & 4.4 & 31.8 & 0.6 \\
\hline $10 / 29 / 200819: 15$ & 8.0 & 352 & 4.4 & 31.7 & $.4-.5$ \\
\hline $10 / 30 / 200816: 45$ & 8.0 & 351 & 4.2 & 33.0 & $.6-.7$ \\
\hline $10 / 30 / 200819: 35$ & 7.9 & 354 & 4.3 & 32.7 & $.4-.5$ \\
\hline $10 / 31 / 200815: 10$ & 8.0 & 354 & 4.0 & 32.7 & $.6-.8$ \\
\hline $11 / 2 / 200811: 00$ & 8.0 & 352 & 4.1 & 32.8 & $.4-.6$ \\
\hline $11 / 3 / 200817: 08$ & 7.9 & 352 & 3.9 & 33.0 & $.4-.6$ \\
\hline $11 / 4 / 200816: 40$ & 8.0 & 352 & 3.8 & 32.5 & $.4-.6$ \\
\hline $11 / 5 / 200816: 15$ & 8.0 & 351 & 4.4 & 32.1 & $.4-.6$ \\
\hline $11 / 6 / 200816: 30$ & 8.0 & 351 & 4.4 & 32.3 & $.2-.4$ \\
\hline $11 / 7 / 200818: 21$ & 8.0 & 350 & 4.4 & 31.3 & $.4-.6$ \\
\hline $11 / 10 / 20088: 45$ & 8.1 & 350 & 4.2 & 30.9 & $.4-.6$ \\
\hline $11 / 12 / 200811: 35$ & 8.1 & 351 & 4.2 & 30.8 & $.4-.6$ \\
\hline $11 / 14 / 20088: 20$ & 8.1 & 353 & 4.1 & 31.6 & $.4-.6$ \\
\hline
\end{tabular}

Table D- 7: Measured effluent water quality parameters for column 1 during the Socorro Springs SMZ/ZVI field test. Column 1 was filled with 8-14 mesh of SMZ/ZVI

\begin{tabular}{|c|c|c|c|c|c|}
\hline \multicolumn{7}{|c|}{ Column 1 Effluent Parameters } \\
\hline Date and Time & $\mathbf{p H}$ & $\begin{array}{c}\text { Conductivity } \\
(\mu \mathrm{S} / \mathrm{cm})\end{array}$ & $\begin{array}{c}\text { DO } \\
(\mathbf{m g} / \mathbf{L})\end{array}$ & $\begin{array}{c}\text { Temp } \\
(\mathbf{C})\end{array}$ & $\begin{array}{c}\text { Free } \mathbf{C l}_{2} \\
(\mathbf{m g} / \mathbf{L})\end{array}$ \\
\hline $10 / 29 / 200815: 00$ & & & & & \\
\hline $10 / 29 / 200818: 10$ & 8.3 & 355 & 2.8 & 31.5 & 0 \\
\hline $10 / 29 / 200819: 15$ & 8.2 & 354 & 3.0 & 31.5 & 0 \\
\hline $10 / 30 / 200816: 45$ & 8.1 & 351 & 2.4 & 33.1 & $0-.1$ \\
\hline $10 / 30 / 200819: 35$ & 8.0 & 353 & 3.3 & 32.0 & 0 \\
\hline $10 / 31 / 200815: 10$ & 8.0 & 354 & 3.2 & 32.6 & $0-.1$ \\
\hline $11 / 2 / 200811: 00$ & 8.0 & 351 & 3.6 & 31.8 & 0 \\
\hline $11 / 3 / 200817: 08$ & 8.0 & 352 & 3.5 & 32.5 & $0-.1$ \\
\hline $11 / 4 / 200816: 40$ & 8.0 & 352 & 3.5 & 31.3 & 0 \\
\hline $11 / 5 / 200816: 15$ & 8.0 & 352 & 4.0 & 31.0 & 0 \\
\hline $11 / 6 / 200816: 30$ & 8.0 & 351 & 4.0 & 31.7 & 0 \\
\hline $11 / 7 / 200818: 21$ & 8.0 & 351 & 4.2 & 30.4 & 0 \\
\hline $11 / 10 / 20088: 45$ & 8.1 & 350 & 3.6 & 29.0 & 0 \\
\hline $11 / 12 / 200811: 35$ & 8.1 & 351 & 3.8 & 28.3 & 0 \\
\hline $11 / 14 / 20088: 20$ & 8.1 & 351 & 3.6 & 29.7 & $0-.1$ \\
\hline
\end{tabular}


Table D- 8: Measured effluent water quality parameters for column 2 during the Socorro Springs SMZ/ZVI field test. Column 2 was started at a later date due to problems with the plumbing leaking.

Column 2 contained 8-14 mesh SMZ/ZVI

\begin{tabular}{|c|c|c|c|c|c|}
\hline \multicolumn{7}{|c|}{ Column 2 Effluent Parameters } \\
\hline Date and Time & $\mathbf{p H}$ & $\begin{array}{c}\text { Conductivity } \\
(\mu \mathrm{S} / \mathrm{cm})\end{array}$ & $\begin{array}{c}\text { DO } \\
(\mathbf{m g} / \mathbf{L})\end{array}$ & $\begin{array}{c}\text { Temp } \\
(\mathbf{C})\end{array}$ & $\begin{array}{c}\text { Free } \mathbf{~ C l}_{2} \\
(\mathbf{m g} / \mathbf{L})\end{array}$ \\
\hline $10 / 29 / 200815: 00$ & & & & & \\
\hline $10 / 29 / 200818: 10$ & & & & & \\
\hline $10 / 29 / 200819: 15$ & & & & & \\
\hline $10 / 30 / 200816: 45$ & & & & & \\
\hline $10 / 30 / 200819: 35$ & & & & & \\
\hline $10 / 31 / 200815: 10$ & & & 0.9 & 32.0 & 0 \\
\hline $11 / 2 / 200811: 00$ & 8.0 & 354 & 1.1 & 32.1 & $0-.1$ \\
\hline $11 / 3 / 200817: 08$ & 8.0 & 353 & 2.1 & 30.9 & 0 \\
\hline $11 / 4 / 200816: 40$ & 8.0 & 351 & 2.4 & 30.3 & 0 \\
\hline $11 / 5 / 200816: 15$ & 8.1 & 351 & 3.0 & 30.9 & 0 \\
\hline $11 / 6 / 200816: 30$ & 8.0 & 350 & 3.5 & 29.3 & 0 \\
\hline $11 / 7 / 200818: 21$ & 8.0 & 350 & 2.6 & 27.0 & 0 \\
\hline $11 / 10 / 20088: 45$ & 8.1 & 351 & 2.1 & 25.6 & 0 \\
\hline $11 / 12 / 200811: 35$ & 8.1 & 352 & 2.9 & 27.7 & 0 \\
\hline $11 / 14 / 20088: 20$ & 8.1 & 351 & & & \\
\hline
\end{tabular}

Table D- 9: Measured effluent water quality parameters for column 3 during the Socorro Springs SMZ/ZVI field test. Column 3 contained 14-40 mesh SMZ/ZVI.

\begin{tabular}{|c|c|c|c|c|c|}
\hline \multicolumn{6}{|c|}{ Column 3 Effluent Parameters } \\
\hline Date and Time & $\mathrm{pH}$ & $\begin{array}{c}\text { Conductivity } \\
(\mu \mathrm{S} / \mathrm{cm})\end{array}$ & $\begin{array}{c}\mathrm{DO} \\
\text { (mg/L) }\end{array}$ & $\begin{array}{l}\text { Temp } \\
\text { (C) }\end{array}$ & $\begin{array}{l}\text { Free } \mathrm{Cl}_{2} \\
\text { (mg/L) }\end{array}$ \\
\hline \multicolumn{6}{|l|}{ 10/29/2008 15:00 } \\
\hline 10/29/2008 18:10 & 8.3 & 355 & 2.8 & 31.5 & 0 \\
\hline 10/29/2008 19:15 & 8.2 & 353 & 2.6 & 31.2 & 0 \\
\hline 10/30/2008 16:45 & 8.2 & 352 & 2.7 & 32.6 & 0 \\
\hline \multicolumn{6}{|l|}{$10 / 30 / 200819: 35$} \\
\hline 10/31/2008 15:10 & 8.1 & 355 & 3.3 & 32.6 & $0-.1$ \\
\hline $11 / 2 / 200811: 00$ & 8.0 & 351 & 3.6 & 32.0 & 0 \\
\hline $11 / 3 / 200817: 08$ & 8.0 & 353 & 3.6 & 32.2 & $0-.1$ \\
\hline 11/4/2008 16:40 & 8.0 & 351 & 3.7 & 31.4 & 0 \\
\hline $11 / 5 / 200816: 15$ & 8.0 & 351 & 4.1 & 30.8 & $0-.1$ \\
\hline 11/6/2008 16:30 & 8.0 & 351 & 4.1 & 31.2 & 0 \\
\hline 11/7/2008 18:21 & 8.0 & 351 & 4.3 & 29.5 & 0 \\
\hline $11 / 10 / 20088: 45$ & 8.1 & 350 & 3.8 & 27.6 & 0 \\
\hline 11/12/2008 11:35 & 8.1 & 351 & 4.1 & 27.8 & 0 \\
\hline 11/14/2008 8:20 & 8.1 & 350 & 3.9 & 28.7 & $0-.1$ \\
\hline
\end{tabular}


Table D- 10: Measured effluent water quality parameters for column 4 during the Socorro Springs SMZ/ZVI field test. Column 4 was started at a later date due to leaks in the plumbing. Column 4 contained 14-40 mesh SMZ/ZVI.

\begin{tabular}{|c|c|c|c|c|c|}
\hline \multicolumn{7}{|c|}{\begin{tabular}{c} 
Column 4 Effluent Parameters \\
\hline Date and Time
\end{tabular}} & pH & $\begin{array}{c}\text { Conductivity } \\
(\mu \mathrm{S} / \mathrm{cm})\end{array}$ & $\begin{array}{c}\text { DO } \\
(\mathrm{mg} / \mathrm{L})\end{array}$ & $\begin{array}{c}\text { Temp } \\
(\mathbf{C})\end{array}$ & $\begin{array}{c}\text { Free } \mathrm{Cl}_{2} \\
(\mathbf{m g} / \mathbf{L})\end{array}$ \\
\hline $10 / 29 / 200815: 00$ & & & & & \\
\hline $10 / 29 / 200818: 10$ & & & & & \\
\hline $10 / 29 / 200819: 15$ & & & & & \\
\hline $10 / 30 / 200816: 45$ & 8.2 & 356 & 2.3 & 32.0 & 0 \\
\hline $10 / 30 / 200819: 35$ & 8.2 & 355 & 1.8 & 31.8 & 0 \\
\hline $10 / 31 / 200815: 10$ & 8.1 & 355 & 2.6 & 32.5 & 0 \\
\hline $11 / 2 / 200811: 00$ & 8.0 & 353 & 3.4 & 32.0 & 0 \\
\hline $11 / 3 / 200817: 08$ & 8.0 & 353 & 3.6 & 32.2 & $0-.1$ \\
\hline $11 / 4 / 200816: 40$ & 8.2 & 351 & 3.7 & 31.4 & 0 \\
\hline $11 / 5 / 200816: 15$ & 8.1 & 351 & 4.2 & 30.7 & 0 \\
\hline $11 / 6 / 200816: 30$ & 8.1 & 350 & 4.2 & 31.1 & 0 \\
\hline $11 / 7 / 200818: 21$ & 8.1 & 351 & 4.3 & 29.1 & 0 \\
\hline $11 / 10 / 20088: 45$ & 8.2 & 350 & 3.9 & 26.9 & 0 \\
\hline $11 / 12 / 200811: 35$ & 8.2 & 351 & 4.0 & 27.3 & 0 \\
\hline $11 / 14 / 20088: 20$ & 8.1 & 350 & 3.8 & 28.4 & $0-.1$ \\
\hline
\end{tabular}

Table D- 11: List of operating parameters for the $30 \mathrm{~cm}$ lab operated column. Three other columns nearly identical to the column listed here were tested in the same fashion, but filtering of the effluent before analysis was not conducted. Those column tests have similar results, but are not included in the data or analysis.

\begin{tabular}{|l|r|}
\hline \multicolumn{1}{|c|}{ Column Parameter } & \multicolumn{1}{c|}{ Value } \\
\hline Column diameter $(\mathrm{cm})$ & 5.0 \\
\hline Media Mass $(\mathrm{g})$ & 369.9 \\
\hline Bedlength $(\mathrm{cm})$ & 30.0 \\
\hline SMZ/ZVI Bulk Density $\left(\mathrm{g} / \mathrm{cm}^{\wedge} 3\right)$ & 0.70 \\
\hline Porosity & 0.74 \\
\hline Pore Volume $(\mathrm{mL})$ & 395 \\
\hline Avg. Flowrate $(\mathrm{mL} / \mathrm{min})$ & 10.9 \\
\hline Specific Discharge $(\mathrm{cm} / \mathrm{min})$ & 0.56 \\
\hline Pore Velocity $(\mathrm{cm} / \mathrm{min})$ & 0.75 \\
\hline Residence Time $(\mathrm{min})$ & 40.0 \\
\hline
\end{tabular}


Table D- 12: Measured column discharge volumes, arsenic concentrations, and flowrates for the $30 \mathrm{~cm}$ lab column. Errors in volume measurements are less than $100 \mathrm{~mL}$ per day; all volumes were measured in a $1 \mathrm{~L}$ graduated cylinder. Flowrates were measured using a $25 \mathrm{~mL}$ graduated cylinder and are accurate to $\pm 0.1 \mathrm{~mL} / \mathrm{min}$. Concentration measurement error is $\pm 3 \%$ based on replicate analyses of a 10 $\mu \mathrm{g} / \mathrm{L}$ USGS standard reference sample.

\begin{tabular}{|c|c|c|c|c|c|}
\hline Date & $\begin{array}{c}\text { Volume } \\
(\mathbf{L})\end{array}$ & $\begin{array}{c}\text { Cumulative } \\
\text { Volume (L) }\end{array}$ & $\begin{array}{c}\text { Pore } \\
\text { Volumes }\end{array}$ & $\begin{array}{c}\text { Flowrate } \\
(\mathbf{m L} / \mathbf{m i n})\end{array}$ & $\begin{array}{c}\text { As Concentration } \\
(\boldsymbol{\mu g} / \mathbf{L})\end{array}$ \\
\hline $1 / 22 / 2009$ & 1.8 & 2 & 5 & 11.2 & 1.0 \\
\hline $1 / 23 / 2009$ & 15.9 & 18 & 45 & 11.2 & 1.6 \\
\hline $1 / 24 / 2009$ & 12.9 & 31 & 78 & 10.9 & 3.1 \\
\hline $1 / 25 / 2009$ & 16.4 & 47 & 120 & 11.1 & 7.2 \\
\hline $1 / 26 / 2009$ & 18.4 & 66 & 170 & 10.8 & 7.0 \\
\hline $1 / 27 / 2009$ & 16.1 & 82 & 210 & 10.8 & 9.4 \\
\hline $1 / 28 / 2009$ & 14.4 & 96 & 240 & 10.9 & 11 \\
\hline $1 / 29 / 2009$ & 15.9 & 110 & 290 & 10.8 & 13 \\
\hline $1 / 30 / 2009$ & 14.9 & 130 & 320 & 10.6 & 17 \\
\hline $1 / 31 / 2009$ & 16.7 & 140 & 370 & 10.5 & 18 \\
\hline $2 / 1 / 2009$ & 13.2 & 160 & 400 & 10.9 & 20 \\
\hline $2 / 2 / 2009$ & 19.5 & 180 & 450 & 10.6 & 21 \\
\hline $2 / 3 / 2009$ & 13.0 & 190 & 480 & 10.7 & 22 \\
\hline $2 / 4 / 2009$ & 15.5 & 200 & 520 & 10.9 & 26 \\
\hline $2 / 5 / 2009$ & 17.9 & 220 & 570 & 10.9 & 26 \\
\hline $2 / 6 / 2009$ & 13.7 & 240 & 600 & 10.9 & 27 \\
\hline $2 / 7 / 2009$ & 16.4 & 250 & 640 & 10.9 & 28 \\
\hline $2 / 8 / 2009$ & 12.8 & 270 & 680 & 10.9 & 29 \\
\hline $2 / 9 / 2009$ & 16.7 & 280 & 720 & 10.9 & 29 \\
\hline $2 / 10 / 2009$ & 18.8 & 300 & 770 & 10.9 & 29 \\
\hline $2 / 11 / 2009$ & 16.2 & 320 & 810 & 10.9 & 31 \\
\hline $2 / 12 / 2009$ & 14.6 & 330 & 840 & 10.9 & 32 \\
\hline $2 / 13 / 2009$ & 16.1 & 350 & 890 & 10.9 & 33 \\
\hline $2 / 14 / 2009$ & 15.3 & 360 & 920 & 11.0 & 34 \\
\hline & & & & & \\
\hline
\end{tabular}


Table D- 13: Operating parameters measured during the operation of the $9 \mathrm{~cm} \mathrm{pH}$ adjusted SMZ/ZVI and zeolite column. The zeolite column was run in series after the SMZ/ZVI column. Concentration measurement error is $\pm 3 \%$ based on replicate analyses of a $10 \mu \mathrm{g} / \mathrm{L}$ USGS standard reference sample.

\begin{tabular}{|l|c|c|}
\hline & SMZ/ZVI & Raw Zeolite \\
\hline Column diameter $(\mathrm{cm})$ & 2.5 & 2.5 \\
\hline Empty Column weight $(\mathrm{g})$ & 222.5 & 221.5 \\
\hline Filled Column weight $(\mathrm{g})$ & 263.2 & 265.8 \\
\hline Media Mass $(\mathrm{g})$ & 40.7 & 44.31 \\
\hline Bedlength $(\mathrm{cm})$ & 9.0 & 9.2 \\
\hline Porosity & 0.71 & 0.60 \\
\hline Column wet $(\mathrm{g})$ & 294.6 & 292.9 \\
\hline Pore Volume $(\mathrm{mL})$ & 31.5 & 27.1 \\
\hline Flowrate $(\mathrm{mL} / \mathrm{min})$ & 6.0 & 6.0 \\
\hline Specific Discharge $(\mathrm{cm} / \mathrm{min})$ & 1.2 & 1.2 \\
\hline Residence Time $(\mathrm{min})$ & 5.2 & 4.5 \\
\hline Pore Velocity $(\mathrm{cm} / \mathrm{min})$ & 1.7 & 2.0 \\
\hline
\end{tabular}

Table D- 14: Measured column discharge volumes, arsenic concentrations, and flowrates for the $9 \mathrm{~cm}$ $\mathrm{pH}$ adjusted lab column. The measured pore volumes are in terms of the SMZ/ZVI column. The zeolite column had a slightly smaller pore volume (Table D-8) and would have had $\sim 115 \%$ more pore volumes. The volumes were based on measurements of a collection bottle that was weighed after each sampling. Concentration measurement error is $\pm 3 \%$ based on replicate analyses of a $10 \mu \mathrm{g} / \mathrm{L}$ USGS standard reference sample.

\begin{tabular}{|c|c|c|c|c|c|}
\hline Days & Volume & Pore Volumes & $\begin{array}{c}\text { SMZ/ZVI } \\
\text { As Conc. }(\mu \mathrm{g} / \mathbf{L})\end{array}$ & $\begin{array}{c}\text { Zeolite } \\
\text { As Conc. }(\mu \mathrm{g} / \mathbf{L})\end{array}$ & Flowrate $(\mathrm{mL} / \mathrm{min})$ \\
\hline 0.1 & 0.44 & 14 & 0.29 & 1.0 & 6.0 \\
\hline 0.1 & 1.18 & 38 & 0.23 & 1.0 & 6.1 \\
\hline 0.3 & 2.24 & 71 & 1.5 & 0.74 & 6.1 \\
\hline 0.5 & 3.99 & 127 & 0.59 & 0.28 & 6.0 \\
\hline 0.9 & 7.36 & 234 & 0.57 & 1.0 & 6.0 \\
\hline 1.0 & 8.72 & 277 & 0.86 & 0.05 & \\
\hline 1.2 & 10.21 & 324 & 1.0 & 0.60 & 5.9 \\
\hline 1.5 & 12.66 & 402 & 1.6 & 0.0 & \\
\hline 1.8 & 15.96 & 507 & 3.0 & 0.13 & 6.2 \\
\hline 2.1 & 17.95 & 570 & 3.4 & 0.23 & 5.9 \\
\hline 2.4 & 20.35 & 646 & 4.1 & 0.20 & \\
\hline 2.8 & 24.18 & 768 & 5.5 & 0.91 & 5.5 \\
\hline 3.3 & 28.44 & 903 & 8.1 & 9.8 & 14 \\
\hline 3.7 & 31.63 & 1004 & 11 & & \\
\hline
\end{tabular}


Table D- 15: Measured column discharge parameters for the $9 \mathrm{~cm} \mathrm{pH}$ adjusted SMZ/ZVI - raw zeolite column. The parameters were measured in a small flow cell using a PCD-650 Oakton multiparameter water meter. The $\mathrm{pH}$, conductivity, and dissolved oxygen (DO) were calibrated or checked against standards every day. The volumes were based on measurements of a collection bottle that was weighed after each sampling.

\begin{tabular}{|c|c|c|c|c|c|}
\hline Vol. (L) & PV & pH & Cond. $(\boldsymbol{\mu S})$ & DO $(\mathbf{m g} / \mathbf{L})$ & Temp (C) \\
\hline 0.44 & 14 & 6.6 & 937 & 3.3 & 19.8 \\
\hline 1.18 & 38 & 7.0 & 483 & 2.6 & 19.4 \\
\hline 2.24 & 71 & 7.0 & 474 & 1.9 & 19.3 \\
\hline 3.99 & 127 & 6.9 & 456 & 1.7 & 19.2 \\
\hline 7.36 & 234 & 6.8 & 440 & 1.8 & 19.7 \\
\hline 8.72 & 277 & 6.8 & 433 & 1.8 & 19.9 \\
\hline 10.21 & 324 & 6.8 & 426 & 1.8 & 19.6 \\
\hline 12.66 & 402 & 6.8 & 411 & 2.7 & 18.1 \\
\hline 15.96 & 507 & 6.9 & 417 & 2.5 & 18.0 \\
\hline 17.95 & 570 & 6.8 & 414 & 2.3 & 20.9 \\
\hline 20.35 & 646 & 6.8 & 411 & 2.4 & 21.5 \\
\hline 24.18 & 768 & 6.9 & 411 & 2.8 & 21.5 \\
\hline 28.44 & 903 & 6.9 & 411 & 3.2 & 21.1 \\
\hline 31.63 & 1004 & 7.2 & 414 & 3.3 & 18.4 \\
\hline
\end{tabular}

Table D- 16: Measured influent parameters for the $9 \mathrm{~cm} \mathrm{pH}$ adjusted SMZ/ZVI and raw zeolite column. The influent water consisted of Socorro Springs water that was hauled in using $50 \mathrm{~L}$ carboys and then $\mathrm{pH}$ adjusted using concentrated $\mathrm{HCl}$. Blank cells indicated that the parameter was not measured.

\begin{tabular}{|c|c|c|c|c|c|}
\hline Vol. (L) & PV & $\mathrm{pH}$ & Cond. $(\mu S)$ & DO (mg/L) & Temp (C) \\
\hline 0.44 & 14 & 6.6 & 408 & 6.6 & 21.1 \\
\hline 1.18 & 38 & & & & \\
\hline 2.24 & 71 & 6.6 & 404 & 5.6 & 21.4 \\
\hline 3.99 & 127 & & & & \\
\hline 7.36 & 234 & & & & \\
\hline 8.72 & 277 & & & & \\
\hline 10.21 & 324 & 6.6 & 438 & 5.3 & 21.6 \\
\hline 12.66 & 402 & & & & \\
\hline 15.96 & 507 & 6.7 & 407 & 5.3 & 19.9 \\
\hline 17.95 & 570 & & & & \\
\hline 20.35 & 646 & & & & \\
\hline 24.18 & 768 & & & & \\
\hline 28.44 & 903 & 6.6 & 403 & 5.6 & 21.3 \\
\hline 31.63 & 1004 & 7.1 & 414 & 6.1 & 20.3 \\
\hline
\end{tabular}




\section{APPENDIX E - Supplementary data for Article II.}

This Appendix contains all of the data used in Article II. "Arsenic Removal using Iron-Modified Zeolite (IMZ)." This includes data from the iron leaching analyses, surface area analyses, batch experiment isotherms, $\mathrm{pH}$ dependence, and $10.5 \mathrm{~cm}$ column data. 
Table E- 1: Measured iron concentrations of each IMZ preparation. IMZ-4 preparation was not completed and no analyses on the media were performed.

\begin{tabular}{|c|c|c|c|c|c|c|c|}
\hline IMZ & $\begin{array}{c}\text { Sample 1 } \\
(\mathbf{m g} / \mathbf{k g})\end{array}$ & $\begin{array}{c}\text { Sample 2 } \\
(\mathbf{m g} / \mathbf{k g})\end{array}$ & $\begin{array}{c}\text { Sample 3 } \\
(\mathbf{m g} / \mathbf{k g})\end{array}$ & $\begin{array}{c}\text { Average } \\
\text { Iron } \\
\text { Content } \\
(\mathbf{m g} / \mathbf{k g})\end{array}$ & $\begin{array}{c}\text { Std Dev. } \\
(\mathbf{m g} / \mathbf{k g})\end{array}$ & $\begin{array}{c}\text { Average } \\
\text { Loading } \\
(\mathbf{m g} / \mathbf{k g})\end{array}$ & $\begin{array}{c}\text { Loading } \\
\text { Std dev. } \\
\text { (mg/kg) }\end{array}$ \\
\hline 1 & 11000 & 9000 & 8000 & 9000 & 2000 & 5000 & 1000 \\
\hline 2 & 9000 & 8000 & 8500 & 8500 & 500 & 3700 & 200 \\
\hline 3 & 7500 & 9300 & 9100 & 8600 & 1000 & 3800 & 400 \\
\hline 5 & 8800 & 9900 & 8500 & 9100 & 700 & 4200 & 300 \\
\hline 6 & 25000 & 23000 & 21000 & 23000 & 2000 & 18000 & 2000 \\
\hline 7 & 12000 & 12000 & 12000 & 12000 & 200 & 7100 & 100 \\
\hline 8 & 29000 & 31000 & 26000 & 28000 & 3000 & 24000 & 2000 \\
\hline Raw Zeolite & 5000 & 4500 & 4900 & 4800 & 300 & & \\
\hline
\end{tabular}

Table E- 2: Measured surface area for selected IMZ preparations. MBET stands for multi-point BET surface area analysis; SBET stands for single-point BET surface area analysis. The time and temperature listed after the sample ID is the degassing time and degassing temperature. The corrected surface area was multiplied by the average correction factor calculated each day from the quantachrome standards.

\begin{tabular}{|l|c|c|c|c|}
\hline \multicolumn{1}{|c|}{ Zeolite Material } & Date & $\begin{array}{c}\text { MBET } \\
\text { Measured } \\
\text { Surface Area } \\
\text { ( } \mathbf{m}^{2} / \text { gram) }\end{array}$ & $\begin{array}{c}\text { SBET } \\
\text { Measured } \\
\text { Surface Area } \\
\text { (P/Po)=0.3 }\end{array}$ & $\begin{array}{c}\text { Corrected Surface } \\
\text { Area (m²/gram) }\end{array}$ \\
\hline Raw Zeolite-1 3hrs 200C & $8 / 24 / 2009$ & 12.4 & 12.5 & 13.7 \\
\hline Raw Zeolite-2 3hrs 200C & $8 / 25 / 2009$ & 11.6 & 11.5 & 13.8 \\
\hline Raw Zeolite-3 11 hrs 200C & $8 / 26 / 2009$ & 11.8 & 11.7 & 13.9 \\
\hline IMZ-1 200C 2 hrs & $8 / 26 / 2009$ & 9.0 & 8.9 & 10.6 \\
\hline IMZ-3 200C 3 hrs & $8 / 26 / 2009$ & 11.0 & 10.9 & 12.9 \\
\hline IMZ-5 200C 3 hrs & $8 / 26 / 2009$ & 11.4 & 11.4 & 13.6 \\
\hline IMZ-6 200C 3 hrs & $8 / 25 / 2009$ & 11.4 & 12.5 & 14.8 \\
\hline IMZ-8 3hrs at 200C & $8 / 25 / 2009$ & 16.6 & 16.5 & 19.6 \\
\hline IMZ-8 Ambient & $8 / 25 / 2009$ & 21.4 & 20.8 & 24.7 \\
\hline IMZ-8 2 hrs at 200C & $8 / 26 / 2009$ & 19.9 & 19.6 & 23.3 \\
\hline IMZ-8 ambient -2 & $8 / 26 / 2009$ & 15.4 & 15.1 & 18.0 \\
\hline
\end{tabular}


Table E- 3: Measured surface area of the supplied Quantachrome standard. The standard was measured each time with a $3 \mathrm{hr}$ degassing period at $300^{\circ} \mathrm{C}$. The listed surface area for the standard was 107.56 $\mathrm{m}^{2} / \mathrm{g}$. The measured surface area for each IMZ preparation was corrected based on these surface area analyses.

\begin{tabular}{|l|c|c|c|c|}
\hline \multicolumn{1}{|c|}{ Sample } & Date & MBET $\left(\mathbf{m}^{2} / \mathbf{g}\right)$ & $\begin{array}{c}\text { MBET \% } \\
\text { Difference }\end{array}$ & $\begin{array}{c}\text { Correction Factor } \\
\text { to apply }\end{array}$ \\
\hline Quantachrome std & $8 / 24 / 2009$ & 97.5 & 0.91 & 1.10 \\
\hline Quantachrome std & $8 / 25 / 2009$ & 90.4 & 0.84 & 1.19 \\
\hline Quantachrome std-2 & $8 / 25 / 2009$ & 91.2 & 0.85 & 1.18 \\
\hline Quantachrome std & $8 / 26 / 2009$ & 92.1 & 0.86 & 1.17 \\
\hline Quantachrome std -2 & $8 / 26 / 2009$ & 90.2 & 0.84 & 1.19 \\
\hline
\end{tabular}


Table E- 4: Raw data obtained for the batch experiment isotherms. All concentrations reflect measured total arsenic. Concentration measurement error is $\pm 3 \%$ based on replicate analyses of a $10 \mu \mathrm{g} / \mathrm{L}$ USGS standard reference sample. The stock solution concentration was measured from dilution of each one of the starting solutions. The initial concentration (Initial Conc.) are the calculated arsenic concentration after taking into account the excess liquid from the washing step. The equilibrium concentration in solution was the measured concentrations of each sample from the ICP-OES. All concentration values are reported to two significant figures.

\begin{tabular}{|c|c|c|c|c|c|c|c|c|}
\hline Sample ID & $\begin{array}{l}\text { Tube } \\
\text { (g) }\end{array}$ & $\begin{array}{c}\text { IMZ } \\
\text { (g) }\end{array}$ & $\begin{array}{l}\text { Mixing } \\
\text { Time } \\
(\min )\end{array}$ & $\begin{array}{c}\text { Final } \\
\text { pH }\end{array}$ & $\begin{array}{l}\text { Initial } \\
\text { Conc. } \\
\text { ( } \mu \mathrm{g} / \mathrm{L})\end{array}$ & $\begin{array}{c}\text { Equil. Conc. } \\
\text { in solution } \\
(\mu \mathrm{g} / \mathrm{L})\end{array}$ & $\begin{array}{l}\text { Equil. Conc. } \\
\text { Sorbed } \\
(\mu \mathrm{g} / \mathrm{L})\end{array}$ & $\begin{array}{l}\text { Arsenic } \\
\text { Sorbed } \\
(\mu \mathrm{g} / \mathrm{kg})\end{array}$ \\
\hline IMZ-1 10-1 & 13.74 & 5.05 & 180 & 3.9 & 9900 & 23 & 9900 & 39000 \\
\hline IMZ-1 10-2 & 13.60 & 5.04 & 180 & 3.7 & 9900 & 15 & 9900 & 39000 \\
\hline IMZ-1 25-1 & 8.84 & 5.01 & 180 & 3.8 & 25000 & 92 & 25000 & 98000 \\
\hline IMZ-1 25-2 & 13.66 & 4.97 & 180 & 3.8 & 25000 & 110 & 25000 & 99000 \\
\hline IMZ-1 50-1 & 8.80 & 4.97 & 180 & 3.9 & 50000 & 390 & 49000 & 200000 \\
\hline IMZ-1 50-2 & 8.92 & 5.03 & 180 & 3.8 & 50000 & 610 & 49000 & 190000 \\
\hline IMZ-1 100-1 & 13.59 & 5.00 & 180 & 4.1 & 99000 & 5800 & 93000 & 370000 \\
\hline IMZ-1 100-2 & 13.84 & 4.97 & 180 & 4.1 & 99000 & 3800 & 95000 & 380000 \\
\hline IMZ-1 200-1 & 13.70 & 5.04 & 180 & 4.0 & 200000 & 15000 & 180000 & 730000 \\
\hline IMZ-1 200-2 & 8.87 & 4.99 & 180 & 4.1 & 200000 & 15000 & 180000 & 730000 \\
\hline IMZ-2 10-1 & 8.87 & 5.03 & 180 & 7.6 & 9900 & 2000 & 8200 & 32000 \\
\hline IMZ-2 10-2 & 13.90 & 4.99 & 180 & 7.7 & 9900 & 3000 & 7100 & 28000 \\
\hline IMZ-2 25-1 & 13.90 & 5.01 & 180 & 7.9 & 25000 & 8000 & 17000 & 67000 \\
\hline IMZ-2 25-2 & 13.88 & 4.96 & 180 & 8.1 & 25000 & 8000 & 17000 & 67000 \\
\hline IMZ-2 50-1 & 8.96 & 5.05 & 180 & 8.3 & 50000 & 12000 & 37000 & 150000 \\
\hline IMZ-2 50-2 & 13.65 & 4.99 & 180 & 8.5 & 50000 & 13000 & 37000 & 150000 \\
\hline IMZ-2 100-1 & 13.73 & 4.99 & 180 & 8.3 & 99000 & 16000 & 83000 & 330000 \\
\hline IMZ-2 100-2 & 13.67 & 5.04 & 180 & 8.4 & 99000 & 16000 & 83000 & 330000 \\
\hline IMZ-2 200-1 & 8.96 & 4.97 & 180 & 8.3 & 200000 & 19000 & 180000 & 720000 \\
\hline IMZ-2 200-2 & 13.61 & 4.96 & 180 & 8.4 & 200000 & 19000 & 180000 & 720000 \\
\hline IMZ-3 10-1 & 13.36 & 4.99 & 180 & 6.6 & 9900 & 24 & 9900 & 40000 \\
\hline IMZ-3 10-2 & 13.58 & 4.99 & 180 & 6.7 & 9900 & 15 & 9900 & 40000 \\
\hline IMZ-3 25-1 & 13.67 & 5.00 & 180 & 6.5 & 25000 & 150 & 25000 & 98000 \\
\hline IMZ-3 25-2 & 13.65 & 4.98 & 180 & 6.6 & 25000 & 100 & 25000 & 99000 \\
\hline IMZ-3 50-1 & 8.82 & 4.96 & 180 & 7.9 & 50000 & 1100 & 48000 & 200000 \\
\hline IMZ-3 50-2 & 13.78 & 5.03 & 180 & 7.9 & 50000 & 800 & 49000 & 190000 \\
\hline IMZ-3 100-1 & 13.65 & 5.05 & 180 & 7.6 & 99000 & 10000 & 89000 & 350000 \\
\hline IMZ-3 100-2 & 13.63 & 5.02 & 180 & 7.6 & 99000 & 9200 & 90000 & 360000 \\
\hline IMZ-3 200-1 & 13.61 & 5.02 & 180 & 7.6 & 200000 & 17000 & 180000 & 720000 \\
\hline
\end{tabular}


Table E-4 continued:

\begin{tabular}{|c|c|c|c|c|c|c|c|c|}
\hline Sample ID & $\begin{array}{l}\text { Tube } \\
\text { (g) }\end{array}$ & $\begin{array}{c}\text { IMZ } \\
\text { (g) }\end{array}$ & $\begin{array}{l}\text { Mixing } \\
\text { Time } \\
\text { (min) }\end{array}$ & $\begin{array}{c}\text { Final } \\
\text { pH }\end{array}$ & $\begin{array}{l}\text { Initial } \\
\text { Conc. } \\
\text { ( } \mu \mathrm{g} / \mathrm{L} \text { ) }\end{array}$ & $\begin{array}{l}\text { Equil. Conc. } \\
\text { in solution } \\
(\mu \mathrm{g} / \mathrm{L})\end{array}$ & $\begin{array}{c}\text { Equil. } \\
\text { Conc. } \\
\text { Sorbed } \\
(\mu \mathrm{g} / \mathrm{L}) \\
\end{array}$ & $\begin{array}{l}\text { Arsenic } \\
\text { Sorbed } \\
(\mu \mathrm{g} / \mathrm{kg})\end{array}$ \\
\hline IMZ-6 10-1 & 13.83 & 4.98 & 180 & 6.6 & 9900 & 3.6 & 9900 & 40000 \\
\hline IMZ-6 10-2 & 13.62 & 5.03 & 180 & 6.9 & 9900 & 3.5 & 9900 & 39000 \\
\hline IMZ-6 25-1 & 13.36 & 5.01 & 180 & 7.2 & 25000 & 5.6 & 25000 & 99000 \\
\hline IMZ-6 25-2 & 13.39 & 5.02 & 180 & 7.3 & 25000 & 5.9 & 25000 & 99000 \\
\hline IMZ-6 50-1 & 13.88 & 4.99 & 180 & 7.7 & 50000 & 18 & 50000 & 200000 \\
\hline IMZ-6 50-2 & 13.71 & 5.00 & 180 & 7.8 & 50000 & 15 & 50000 & 200000 \\
\hline IMZ-6 100-1 & 13.82 & 4.99 & 180 & 7.9 & 99000 & 88 & 99000 & 400000 \\
\hline IMZ-6 100-2 & 13.69 & 5.00 & 180 & 7.9 & 99000 & 70 & 99000 & 400000 \\
\hline IMZ-6 200-1 & 13.44 & 5.04 & 180 & 7.9 & 200000 & 580 & 200000 & 780000 \\
\hline IMZ-6 200-2 & 13.51 & 4.99 & 180 & 8.1 & 200000 & 860 & 200000 & 790000 \\
\hline IMZ-7-10-1 & $\mathrm{N} / \mathrm{A}$ & 5.03 & 180 & 8.2 & 9900 & 150 & 9700 & 39000 \\
\hline IMZ-7 20-1 & $\mathrm{N} / \mathrm{A}$ & 5.05 & 180 & 8.5 & 25000 & 490 & 24000 & 96000 \\
\hline IMZ-7 50-1 & $\mathrm{N} / \mathrm{A}$ & 4.97 & 180 & 8.7 & 50000 & 2100 & 47000 & 190000 \\
\hline IMZ-7 100-1 & $\mathrm{N} / \mathrm{A}$ & 5.01 & 180 & 8.9 & 99000 & 8900 & 90000 & 360000 \\
\hline IMZ-7 200-1 & $\mathrm{N} / \mathrm{A}$ & 4.98 & 180 & 9.0 & 200000 & 16000 & 180000 & 730000 \\
\hline IMZ-8 10.1 & $\mathrm{~N} / \mathrm{A}$ & 5.04 & 180 & 8.7 & 9900 & 8900 & 1000 & 4100 \\
\hline IMZ-8 10.2 & $\mathrm{~N} / \mathrm{A}$ & 5.02 & 180 & 8.8 & 9900 & 8700 & 1200 & 4700 \\
\hline IMZ-8 25.1 & $\mathrm{~N} / \mathrm{A}$ & 5.00 & 180 & 8.8 & 25000 & 24000 & 1000 & 3700 \\
\hline IMZ-8 25.2 & $\mathrm{~N} / \mathrm{A}$ & 4.98 & 180 & 8.9 & 25000 & 24000 & 1000 & 4900 \\
\hline IMZ-8 50.1 & $\mathrm{~N} / \mathrm{A}$ & 4.98 & 180 & 8.9 & 50000 & 49000 & 1000 & 3800 \\
\hline IMZ-8 50.2 & $\mathrm{~N} / \mathrm{A}$ & 5.03 & 180 & 8.9 & 50000 & 47000 & 2000 & 9300 \\
\hline IMZ-8 100.1 & $\mathrm{~N} / \mathrm{A}$ & 5.03 & 180 & 8.8 & 99000 & 95000 & 4000 & 16000 \\
\hline IMZ-8 100.2 & $\mathrm{~N} / \mathrm{A}$ & 4.98 & 180 & 8.8 & 99000 & 94000 & 5000 & 21000 \\
\hline IMZ-8 200.1 & $\mathrm{~N} / \mathrm{A}$ & 5.00 & 180 & 8.8 & 200000 & 180000 & 10000 & 53000 \\
\hline IMZ-8 200.2 & $\mathrm{~N} / \mathrm{A}$ & 5.01 & 180 & 8.8 & 200000 & 190000 & 10000 & 41000 \\
\hline Raw Zeo 10-1 & 13.75 & 4.97 & 180 & 8.1 & 9900 & 17 & 9900 & 39000 \\
\hline Raw Zeo 10-2 & 13.48 & 5.03 & 180 & 7.9 & 9900 & 13 & 9900 & 39000 \\
\hline Raw Zeo 25-1 & 13.59 & 4.98 & 180 & 7.9 & 25000 & 33 & 25000 & 99000 \\
\hline Raw Zeo 25-2 & 13.68 & 5.04 & 180 & 8.3 & 25000 & 36 & 25000 & 99000 \\
\hline Raw Zeo 50-1 & 13.62 & 4.96 & 180 & 7.8 & 50000 & 100 & 49000 & 200000 \\
\hline Raw Zeo 50-2 & 13.63 & 4.99 & 180 & 7.8 & 50000 & 110 & 49000 & 200000 \\
\hline Raw Zeo 100-1 & 13.51 & 4.98 & 180 & 7.9 & 99000 & 410 & 99000 & 390000 \\
\hline Raw Zeo 100-2 & 13.75 & 5.00 & 180 & 7.6 & 99000 & 420 & 99000 & 400000 \\
\hline Raw Zeo 200-1 & 13.68 & 4.97 & 180 & 7.6 & 200000 & 3000 & 200000 & 780000 \\
\hline Raw Zeo 200-2 & 13.59 & 4.98 & 180 & 8.0 & 200000 & 3400 & 190000 & 780000 \\
\hline
\end{tabular}


Table E- 5: Graphically fitted parameters to each isotherm using the linear Freundlich equation. Note that IMZ-2 had a very poor fit to the Freundlich Isotherm. The \pm values are based on standard errors from regression analysis.

\begin{tabular}{|l|rr|r|}
\hline \multicolumn{3}{|c|}{ Freundlich Parameters for Modeling } \\
\hline \multicolumn{3}{|c|}{$S=K_{F} C^{N}$} \\
& $\log (S)=\log \left(K_{F}\right)+N \log (C)$ \\
\hline \multicolumn{3}{|c|}{$\operatorname{IMZ-1}$} \\
\hline $\mathrm{Kf}=$ & 13500 & \pm & 1900 \\
\hline $\mathrm{N}=$ & 0.412 & \pm & 0.020 \\
\hline Slope & 0.412 & \pm & 0.020 \\
\hline Intercept & 4.13 & \pm & 0.06 \\
\hline
\end{tabular}

\begin{tabular}{|c|c|c|c|}
\hline \multicolumn{4}{|c|}{ IMZ-2 } \\
\hline$K f=$ & 1.01 & \pm & 2.02 \\
\hline$N=$ & 1.30 & \pm & 0.22 \\
\hline Slope & 1.30 & \pm & 0.22 \\
\hline Intercept & $5.17 \mathrm{E}-3$ & \pm & $8.68 \mathrm{E}-01$ \\
\hline
\end{tabular}

\begin{tabular}{|c|c|c|c|}
\hline \multicolumn{4}{|c|}{ IMZ-3 } \\
\hline$K f=$ & 13800 & \pm & 2500 \\
\hline$N=$ & 0.383 & \pm & 0.026 \\
\hline Slope & 0.383 & \pm & 0.026 \\
\hline Intercept & 4.14 & \pm & 0.08 \\
\hline
\end{tabular}

\begin{tabular}{|c|c|c|c|}
\hline \multicolumn{4}{|c|}{ IMZ-6 } \\
\hline$K f=$ & 33900 & \pm & 7600 \\
\hline$N=$ & 0.516 & \pm & 0.058 \\
\hline Slope & 0.516 & \pm & 0.058 \\
\hline Intercept & 4.53 & \pm & 0.10 \\
\hline
\end{tabular}

\begin{tabular}{|c|c|c|c|}
\hline \multicolumn{4}{|c|}{ IMZ-7 } \\
\hline $\mathrm{Kf}=$ & 2240 & \pm & 800 \\
\hline$N=$ & 0.580 & \pm & 0.046 \\
\hline Slope & 0.580 & \pm & 0.046 \\
\hline Intercept & 3.35 & \pm & 0.15 \\
\hline
\end{tabular}

\begin{tabular}{|c|c|c|c|}
\hline \multicolumn{4}{|c|}{ IMZ-8 } \\
\hline$K f=$ & 13200 & \pm & 3100 \\
\hline$N=$ & 0.530 & \pm & 0.043 \\
\hline Slope & 0.530 & \pm & 0.043 \\
\hline Intercept & 4.12 & \pm & 0.101 \\
\hline
\end{tabular}

\begin{tabular}{|c|c|c|c|}
\hline \multicolumn{4}{|c|}{ Raw Zeolite } \\
\hline $\mathrm{Kf}=$ & 2.02 & \pm & 3.41 \\
\hline $\mathrm{N}=$ & 0.794 & \pm & 0.157 \\
\hline Slope & 0.794 & \pm & 0.157 \\
\hline Intercept & 0.305 & \pm & 0.734 \\
\hline
\end{tabular}


Table E- 6: Graphically fitted parameters to each isotherm using the linear Langmuir equation. Note that the adsorption behavior of IMZ-2 and raw zeolite was poorly described by the Langmuir Isotherm. The \pm values are based on standard errors from regression analysis.

\begin{tabular}{|c|c|c|c|c|c|c|c|c|c|}
\hline \multicolumn{10}{|c|}{ Langmuir Parameters for Modeling } \\
\hline \multicolumn{10}{|c|}{$S=\frac{S_{m} K_{L} C}{1+K_{L} C}$} \\
\hline \multicolumn{10}{|c|}{$\frac{1}{S}=\frac{1}{S_{m}}+\frac{1}{K_{L} S_{m}} \frac{1}{C}$} \\
\hline \multicolumn{10}{|c|}{ IMZ-1 } \\
\hline$K_{L}$ & $9.66 \mathrm{E}+00$ & \pm & $3.09 \mathrm{E}+00$ & $\mathrm{~L} / \mathrm{mg}$ & $S_{m}$ & 271 & \pm & 81 & $\mathrm{mg} / \mathrm{kg}$ \\
\hline Slope & $3.82 \mathrm{E}-04$ & \pm & $4.30 \mathrm{E}-05$ & $\mathrm{~kg} / \mathrm{L}$ & & & & & \\
\hline Intercept & $3.69 \mathrm{E}-03$ & \pm & $1.10 \mathrm{E}-03$ & $\mathrm{~kg} / \mathrm{mg}$ & $K_{d}$ in Hydrus & $2.62 \mathrm{E}+03$ & \pm & 1150 & $\mathrm{~L} / \mathrm{kg}$ \\
\hline
\end{tabular}

\begin{tabular}{|l|rlll|l|rrrr|}
\hline \multicolumn{10}{|c|}{$\mathrm{IMZ}-2$} \\
$\mathrm{~K}_{\mathrm{L}}$ & $2.97 \mathrm{E}-02$ & \pm & $4.03 \mathrm{E}-02$ & $\mathrm{~L} / \mathrm{mg}$ & $\mathrm{S}_{\mathrm{m}}$ & 526 & \pm & 706 & $\mathrm{mg} / \mathrm{kg}$ \\
\hline Slope & $6.39 \mathrm{E}-02$ & \pm & $1.13 \mathrm{E}-02$ & $\mathrm{~kg} / \mathrm{L}$ & & & & \\
\hline Intercept & $1.90 \mathrm{E}-03$ & \pm & $2.55 \mathrm{E}-03$ & $\mathrm{~kg} / \mathrm{mg}$ & $\mathrm{K}_{\mathrm{d}}$ in Hydrus & $1.56 \mathrm{E}+01$ & \pm 30 & $\mathrm{~L} / \mathrm{kg}$ \\
\hline
\end{tabular}

\begin{tabular}{|l|rlll|l|rlll|}
\hline \multicolumn{10}{|c|}{$\mathrm{IMZ}-3$} \\
\hline $\mathrm{K}_{\mathrm{L}}$ & $1.14 \mathrm{E}+01$ & \pm & $3.75 \mathrm{E}+01$ & $\mathrm{~L} / \mathrm{mg}$ & $\mathrm{S}_{\mathrm{m}}$ & 239 & \pm & 69 & $\mathrm{mg} / \mathrm{kg}$ \\
\hline Slope & $3.68 \mathrm{E}-04$ & \pm & $1.21 \mathrm{E}-03$ & $\mathrm{~kg} / \mathrm{L}$ & & & & & \\
\hline Intercept & $4.18 \mathrm{E}-03$ & \pm & $4.73 \mathrm{E}-05$ & $\mathrm{~kg} / \mathrm{mg}$ & $\mathrm{K}_{\mathrm{d}}$ in Hydrus & $2.72 \mathrm{E}+03$ & \pm & $8.96 \mathrm{E}+03$ & $\mathrm{~L} / \mathrm{kg}$ \\
\hline
\end{tabular}

\begin{tabular}{|l|rlll|l|rlll|}
\hline \multicolumn{10}{|c|}{$\mathrm{IMZ}-6$} \\
\hline $\mathrm{K}_{\mathrm{L}}$ & $5.42 \mathrm{E}+00$ & \pm & $1.41 \mathrm{E}+01$ & $\mathrm{~L} / \mathrm{mg}$ & $\mathrm{S}_{\mathrm{m}}$ & 2330 & \pm 6070 & $\mathrm{mg} / \mathrm{kg}$ \\
\hline Slope & $7.94 \mathrm{E}-05$ & \pm & $7.46 \mathrm{E}-06$ & $\mathrm{~kg} / \mathrm{L}$ & & & & & \\
\hline Intercept & $4.30 \mathrm{E}-04$ & \pm & $1.12 \mathrm{E}-03$ & $\mathrm{~kg} / \mathrm{mg}$ & $\mathrm{K}_{\mathrm{d}}$ in Hydrus & $1.26 \mathrm{E}+04$ & \pm & $4.65 \mathrm{E}+04$ & $\mathrm{~L} / \mathrm{kg}$ \\
\hline
\end{tabular}

\begin{tabular}{|l|rlll|l|rlll|}
\hline \multicolumn{10}{|c|}{$\mathrm{IMZ}-7$} \\
\hline $\mathrm{K}_{\mathrm{L}}$ & $6.80 \mathrm{E}-01$ & \pm & $1.66 \mathrm{E}-01$ & $\mathrm{~L} / \mathrm{mg}$ & $\mathrm{S}_{\mathrm{m}}$ & 405 & \pm & 97 & $\mathrm{mg} / \mathrm{kg}$ \\
\hline Slope & $3.63 \mathrm{E}-03$ & \pm & $1.93 \mathrm{E}-04$ & $\mathrm{~kg} / \mathrm{L}$ & & & & & \\
\hline Intercept & $2.47 \mathrm{E}-03$ & \pm & $5.89 \mathrm{E}-04$ & $\mathrm{~kg} / \mathrm{mg}$ & $\mathrm{K}_{\mathrm{d}}$ in Hydrus & $2.75 \mathrm{E}+02$ & \pm & 94 & $\mathrm{~L} / \mathrm{kg}$ \\
\hline
\end{tabular}

\begin{tabular}{|l|rlll|l|rlll|}
\hline \multicolumn{10}{|c|}{$\mathrm{IMZ}-8$} \\
\hline $\mathrm{K}_{\mathrm{L}}$ & $4.65 \mathrm{E}+00$ & \pm & $2.31 \mathrm{E}+00$ & $\mathrm{~L} / \mathrm{mg}$ & $\mathrm{S}_{\mathrm{m}}$ & 654 & \pm & 322 & $\mathrm{mg} / \mathrm{kg}$ \\
\hline Slope & $3.29 \mathrm{E}-04$ & \pm & $2.19 \mathrm{E}-05$ & $\mathrm{~kg} / \mathrm{L}$ & & & & \\
\hline Intercept & $1.53 \mathrm{E}-03$ & \pm & $7.55 \mathrm{E}-04$ & $\mathrm{~kg} / \mathrm{mg}$ & $\mathrm{K}_{\mathrm{d}}$ in Hydrus & $3.04 \mathrm{E}+03$ & \pm 2130 & $\mathrm{~L} / \mathrm{kg}$ \\
\hline
\end{tabular}

\begin{tabular}{|l|rlll|l|rlll|}
\hline \multicolumn{10}{|c|}{ Raw Zeolite } \\
\hline $\mathrm{K}_{\mathrm{L}}$ & $5.35 \mathrm{E}-02$ & \pm & $3.26 \mathrm{E}-02$ & $\mathrm{~L} / \mathrm{mg}$ & $\mathrm{S}_{\mathrm{m}}$ & 12 & \pm & $\mathrm{mg} / \mathrm{kg}$ \\
\hline Slope & $1.58 \mathrm{E}+00$ & \pm & $6.69 \mathrm{E}-01$ & $\mathrm{~kg} / \mathrm{L}$ & & & & \\
\hline Intercept & $8.46 \mathrm{E}-02$ & \pm & $3.70 \mathrm{E}-02$ & $\mathrm{~kg} / \mathrm{mg}$ & $\mathrm{K}_{\mathrm{d}}$ in Hydrus & $6.33 \mathrm{E}-01$ & \pm & $4.74 \mathrm{E}-01$ & $\mathrm{~L} / \mathrm{kg}$ \\
\hline
\end{tabular}


Table E- 7: Measured parameters from the $10.5 \mathrm{~cm}$ IMZ-8 column. All concentrations reflect total arsenic concentrations. Concentration measurement error is $\pm 3 \%$ based on replicate analyses of a 10 $\mu \mathrm{g} / \mathrm{L}$ USGS standard reference sample. Volumes were measured by weighing an effluent container with each sampling.

\begin{tabular}{|c|c|c|c|c|c|}
\hline Date & Volume (L) & Pore Volume & $\begin{array}{c}\text { Effluent } \\
\text { Conc. }(\mu \mathrm{g} / \mathrm{L})\end{array}$ & $\begin{array}{l}\text { Flowrate } \\
\text { (mL/min) }\end{array}$ & $\begin{array}{l}\text { Influent Conc. } \\
(\mu \mathrm{g} / \mathrm{L})\end{array}$ \\
\hline $8 / 4 / 2009$ & 0.0 & 0 & 0 & & \\
\hline $8 / 4 / 2009$ & 2.6 & 80 & 7.8 & 6.0 & 42 \\
\hline $8 / 5 / 2009$ & 6.4 & 200 & 0.54 & 5.5 & \\
\hline $8 / 5 / 2009$ & 10.4 & 330 & 0.93 & 6.1 & \\
\hline $8 / 6 / 2009$ & 15.3 & 480 & 2.5 & 7.0 & 43 \\
\hline $8 / 6 / 2009$ & 19.3 & 600 & 4.7 & & \\
\hline $8 / 7 / 2009$ & 22.9 & 720 & 8.3 & 5.9 & \\
\hline $8 / 7 / 2009$ & 26.0 & 810 & 10 & 5.3 & \\
\hline $8 / 8 / 2009$ & 32.7 & 1020 & 16 & 6.1 & \\
\hline $8 / 9 / 2009$ & 39.9 & 1240 & 23 & 6.3 & \\
\hline $8 / 10 / 2009$ & 48.0 & 1500 & 28 & & \\
\hline $8 / 10 / 2009$ & \multicolumn{5}{|c|}{ Regenerated Media using $500 \mathrm{~mL}$ of $0.5 \mathrm{M} \mathrm{NaOH}$, then rinsed with $6 \mathrm{~L}$ of RO H2O } \\
\hline
\end{tabular}

\begin{tabular}{|l|c|c|c|c|c|}
\hline $8 / 11 / 2009$ & 0.6 & 20 & 0.00 & 5.6 & 42 \\
\hline $8 / 12 / 2009$ & 8.3 & 260 & 0.49 & 5.9 & \\
\hline $8 / 12 / 2009$ & 11.1 & 350 & 1.2 & 5.8 & \\
\hline $8 / 13 / 2009$ & 15.0 & 470 & 2.9 & 5.7 & \\
\hline $8 / 13 / 2009$ & 18.8 & 590 & 5.4 & & \\
\hline $8 / 14 / 2009$ & 22.4 & 700 & 8.9 & 5.8 & \\
\hline $8 / 15 / 2009$ & 30.3 & 940 & 16 & 5.4 & \\
\hline $8 / 15 / 2009$ & 35.0 & 1090 & 21 & 5.5 & \\
\hline $8 / 16 / 2009$ & 42.1 & 1310 & 37 & 5.5 & \\
\hline $8 / 17 / 2009$ & 46.6 & 1450 & 30 & & 45 \\
\hline $8 / 18 / 2009$ & 55.2 & 1720 & 33 & 5.7 & \\
\hline $8 / 19 / 2009$ & 63.8 & 1990 & 35 & 5.6 & \\
\hline $8 / 20 / 2009$ & 71.0 & 2210 & 40 & 5.6 & \\
\hline $8 / 20 / 2009$ & \multicolumn{7}{|l}{ Regenerated Media using $1000 \mathrm{~mL}$ of $0.25 \mathrm{M} \mathrm{NaOH}$, then rinsed with 6.281 L of RO } \\
& \multicolumn{7}{l}{} \\
\hline
\end{tabular}


Table E-7 continued:

\begin{tabular}{|c|c|c|c|c|c|}
\hline Date & Volume (L) & Pore Volume & $\begin{array}{c}\text { Effluent } \\
\text { Conc. }(\mu \mathrm{g} / \mathrm{L})\end{array}$ & $\begin{array}{l}\text { Flowrate } \\
(\mathrm{mL} / \mathrm{min})\end{array}$ & $\begin{array}{c}\text { Influent Conc. } \\
(\mu \mathrm{g} / \mathrm{L})\end{array}$ \\
\hline $8 / 21 / 2009$ & 1.1 & 40 & 0.38 & & 41 \\
\hline $8 / 22 / 2009$ & 6.1 & 190 & 0.80 & 5.6 & \\
\hline $8 / 22 / 2009$ & 10.3 & 320 & 1.5 & 5.6 & \\
\hline $8 / 23 / 2009$ & 14.5 & 450 & 3.4 & 5.6 & \\
\hline $8 / 24 / 2009$ & 21.2 & 660 & 6.3 & 5.6 & \\
\hline $8 / 24 / 2009$ & 25.4 & 790 & 9.6 & 5.9 & \\
\hline $8 / 25 / 2009$ & 29.2 & 910 & 13 & 5.6 & \\
\hline $8 / 25 / 2009$ & 33.0 & 1030 & 19 & 5.6 & \\
\hline $8 / 26 / 2009$ & 37.4 & 1160 & 22 & 5.6 & 42 \\
\hline $8 / 26 / 2009$ & \multicolumn{5}{|c|}{$\begin{array}{l}\text { Regenerated Media using } 1000 \mathrm{~mL} \text { of } 0.25 \mathrm{M} \mathrm{NaOH} \text {, then rinsed with } 6.489 \mathrm{~L} \text { of } \mathrm{RO} \\
\mathrm{H} 20 \text {-did not use zeolite column }\end{array}$} \\
\hline $8 / 27 / 2009$ & 3.2 & 100 & 0 & 5.6 & \\
\hline $8 / 28 / 2009$ & 7.4 & 230 & 0.82 & 5.6 & \\
\hline $8 / 28 / 2009$ & 10.0 & 310 & 1.1 & 5.6 & 41 \\
\hline $8 / 29 / 2009$ & 17.7 & 550 & 3.5 & 5.6 & \\
\hline $8 / 30 / 2009$ & 24.9 & 770 & 8.8 & 5.6 & \\
\hline $8 / 31 / 2009$ & 27.9 & 870 & 12 & 5.6 & \\
\hline
\end{tabular}


Table E- 8: Measured effluent water parameters of the $10.5 \mathrm{~cm} \mathrm{IMZ-8} \mathrm{column.}$

\begin{tabular}{|c|c|c|c|c|c|c|}
\hline Date & Volume (L) & PV & $\mathrm{pH}$ & $\begin{array}{l}\text { Conductivity } \\
(\mu \mathrm{S} / \mathrm{cm})\end{array}$ & $\mathrm{DO}(\mathrm{mg} / \mathrm{L})$ & Temp (C) \\
\hline $8 / 4 / 2009$ & 0.0 & 0 & 7.5 & 444 & 5.4 & 19.7 \\
\hline $8 / 4 / 2009$ & 2.6 & 80 & 7.3 & 1100 & 3.6 & 19.6 \\
\hline $8 / 5 / 2009$ & 6.4 & 200 & 8.2 & 368 & 5.0 & 19.3 \\
\hline $8 / 5 / 2009$ & 10.4 & 330 & 8.3 & 363 & 5.4 & 19.1 \\
\hline $8 / 6 / 2009$ & 15.3 & 480 & 8.3 & 357 & 5.2 & 19.3 \\
\hline $8 / 6 / 2009$ & 19.3 & 600 & 8.3 & 357 & 4.7 & 19.6 \\
\hline $8 / 7 / 2009$ & 22.9 & 720 & 8.3 & 354 & 5.0 & 19.3 \\
\hline $8 / 7 / 2009$ & 26.0 & 810 & 8.3 & 356 & 4.7 & 19.5 \\
\hline $8 / 8 / 2009$ & 32.7 & 1020 & 8.3 & 355 & 4.6 & 19.6 \\
\hline $8 / 9 / 2009$ & 39.9 & 1240 & 8.4 & 354 & 4.6 & 19.5 \\
\hline $8 / 10 / 2009$ & 48.0 & 1500 & 8.3 & 356 & 4.7 & 19 \\
\hline $8 / 11 / 2009$ & \multicolumn{6}{|c|}{ Regenerated Media using $500 \mathrm{~mL}$ of $0.5 \mathrm{M} \mathrm{NaOH}$, then rinsed with $6 \mathrm{~L}$ of $\mathrm{RO} \mathrm{H} 20$} \\
\hline $8 / 11 / 2009$ & 0.6 & 20 & 7.5 & 560 & 4.7 & 19.6 \\
\hline $8 / 12 / 2009$ & 8.3 & 260 & 8.0 & 354 & 4.4 & 18.9 \\
\hline $8 / 12 / 2009$ & 11.1 & 350 & 8.2 & 356 & 4.7 & 18.5 \\
\hline $8 / 13 / 2009$ & 15.0 & 470 & 8.3 & 357 & 4.5 & 18.5 \\
\hline $8 / 13 / 2009$ & 18.8 & 590 & 8.3 & 349 & & 19.1 \\
\hline $8 / 14 / 2009$ & 22.4 & 700 & 8.3 & 346 & & 19.3 \\
\hline $8 / 15 / 2009$ & 30.3 & 940 & 8.4 & 345 & & 19.7 \\
\hline $8 / 15 / 2009$ & 35.0 & 1090 & 8.4 & 346 & & 20.1 \\
\hline $8 / 16 / 2009$ & 42.1 & 1310 & 8.4 & 348 & 4.6 & 19.7 \\
\hline $8 / 17 / 2009$ & 46.6 & 1450 & 8.4 & 346 & & 19.4 \\
\hline $8 / 18 / 2009$ & 55.2 & 1720 & 8.3 & 347 & & 19.9 \\
\hline $8 / 19 / 2009$ & 63.8 & 1990 & 8.3 & 347 & & 19.8 \\
\hline $8 / 20 / 2009$ & 71.0 & 2210 & 8.4 & 352 & & 19.5 \\
\hline $8 / 11 / 2009$ & \multicolumn{6}{|c|}{$\begin{array}{l}\text { Regenerated Media using } 1000 \mathrm{~mL} \text { of } 0.25 \mathrm{M} \mathrm{NaOH} \text {, then rinsed with } 6.281 \mathrm{~L} \text { of } \mathrm{RO} \mathrm{H} 20- \\
\text { stopped using raw zeolite column }\end{array}$} \\
\hline $8 / 21 / 2009$ & 1.1 & 40 & 9.5 & 370 & 4.9 & 20.1 \\
\hline $8 / 22 / 2009$ & 6.1 & 190 & 8.5 & 370 & & 19.9 \\
\hline $8 / 22 / 2009$ & 10.3 & 320 & 8.4 & 360 & 5.3 & 19.3 \\
\hline $8 / 23 / 2009$ & 14.5 & 450 & 8.4 & 359 & 5.3 & 20 \\
\hline $8 / 24 / 2009$ & 21.2 & 660 & 8.4 & 359 & 5.3 & 19.5 \\
\hline $8 / 24 / 2009$ & 25.4 & 790 & 8.4 & 358 & 5.4 & 20 \\
\hline $8 / 25 / 2009$ & 29.2 & 910 & 8.4 & 354 & & 19.8 \\
\hline $8 / 25 / 2009$ & 33.0 & 1030 & 8.4 & 353 & 5.9 & 19.9 \\
\hline $8 / 26 / 2009$ & \multicolumn{6}{|c|}{$\begin{array}{l}\text { Regenerated Media using } 1000 \mathrm{~mL} \text { of } 0.25 \mathrm{M} \mathrm{NaOH} \text {, then rinsed with } 6.489 \mathrm{~L} \text { of RO H2O- } \\
\text { did not use zeolite column }\end{array}$} \\
\hline $8 / 27 / 2009$ & 2.2 & 70 & 6.6 & 342 & 5.2 & 20 \\
\hline $8 / 27 / 2009$ & 3.2 & 100 & 7.7 & 345 & 4.9 & 20 \\
\hline $8 / 28 / 2009$ & 7.4 & 230 & 8.0 & 348 & 4.7 & 19.9 \\
\hline $8 / 28 / 2009$ & 10.0 & 310 & 8.2 & 350 & 4.9 & 20.2 \\
\hline $8 / 29 / 2009$ & 17.7 & 550 & 8.3 & 351 & 5.0 & 20.1 \\
\hline $8 / 30 / 2009$ & 24.9 & 770 & 8.3 & 349 & 4.9 & 20 \\
\hline
\end{tabular}


Table E- 9: Measured influent parameters for the $9 \mathrm{~cm} \mathrm{pH}$ adjusted SMZ/ZVI and raw zeolite column. The influent water consisted of Socorro Springs water that was hauled in using $50 \mathrm{~L}$ carboys and then $\mathrm{pH}$ adjusted using concentrated $\mathrm{HCl}$.

\begin{tabular}{|c|c|c|c|c|}
\hline Date & $\mathbf{p H}$ & Conductivity $(\boldsymbol{\mu S} / \mathrm{cm})$ & $\mathbf{D O}(\mathrm{mg} / \mathrm{L})$ & Temp $(\mathrm{C})$ \\
\hline $8 / 4 / 2009$ & 8.0 & 355 & 6.1 & 20.0 \\
\hline $8 / 5 / 2009$ & 8.1 & 352 & 4.3 & 19.6 \\
\hline $8 / 8 / 2009$ & 8.3 & 352 & 4.9 & 19.9 \\
\hline $8 / 10 / 2009$ & 8.2 & 354 & 5.6 & 19.9 \\
\hline $8 / 13 / 2009$ & 8.3 & 368 & 4.7 & 19.4 \\
\hline $8 / 21 / 2009$ & 8.3 & 366 & 5.9 & 20.1 \\
\hline $8 / 24 / 2009$ & 8.3 & 366 & 5.0 & 20.0 \\
\hline
\end{tabular}




\section{APPENDIX F - Arsenic Analysis using Inductively Coupled Plasma- Optical Emission Spectrometer (ICP-OES) and Hydride Generation}

The following report is a Standards Operating Procedure (SOP) that was

prepared for New Mexico Bureau of Geology and Mineral Resources (NMBGMR)

Chemistry Lab. The SOP details the steps and procedures that were taken to analyze arsenic on one of the instruments in their lab. A great deal of thanks and gratitude is given to Bonnie Frey, Frederick Partey, James Quarles, and Dustin Baca for the use of their lab and their help in operating the instrument. 


\section{Arsenic Analysis using Inductively Coupled Plasma-Optical Emission Spectrometer (ICP-OES) and Hydride Generation}

\section{F-1. INTRODUCTION}

The primary purpose of this standard operating procedure (SOP) is to provide a detailed record of the steps needed to conduct arsenic hydride analysis using the Optima 5300 DV Inductively Coupled Plasma (ICP) Optical-Emission Spectrometer (OES) along with the Perkin Elmer chemifold assembly. The hydride generation

method can be used to analyze As, Sb, Ge, Se and Te (Thompson et al., 1978); this report will detail the steps required for arsenic analysis. Details concerning the analysis of other cations can be found in the Perkin Elmer reports (Bosnak and Davidowski, 2004), (Davidowski, 1993), and the journal article (Thompson et al., 1978).

The hydride generation method used is known as a continuous-flow system where an acidified sample is continuously pumped and mixed with a reductant (sodium borohydride- $\mathrm{NaBH}_{4}$ ) in a mixing manifold. The hydrogen gas produced as a byproduct of the reaction between the acid and $\mathrm{NaBH}_{4}$ combines with arsenic in the sample and produces a gaseous hydride according to the reaction below (Bosnak and Davidowski, 2004):

$$
\mathrm{NaBH}_{4}+3 \mathrm{H}_{2} \mathrm{O}+\mathrm{HCl} \rightarrow \mathrm{H}_{3} \mathrm{BO}_{4}+\mathrm{NaCl}+8 \mathrm{H}^{-}+\mathrm{As}^{3+} \rightarrow \mathrm{AsH}_{3}+\mathrm{H}_{2}
$$


The solutions necessary for analysis include an acidified and reduced sample and a reducing agent. A solution of $\mathrm{KI}$ and ascorbic acid, as well as strong hydrochloric acid is added to each sample such that the arsenic is reduced from $\mathrm{As}(\mathrm{V})$ to $\mathrm{As}(\mathrm{III})$. The As(III) combines with $\mathrm{NaBH}_{4}$ to produce an arsenic gas. The arsenic hydride is then carried to the ICP flame via argon gas that is pumped in through the gas/liquid separator. The gaseous arsenic is then detected through emission spectroscopy from the ionized molecules. Arsenic detection limits are generally improved by about two orders of magnitude compared to solution nebulization (Bosnak and Davidowski, 2004). 


\section{F-2. PROCEDURE}

The following reagent preparation and chemifold assembly setup is modeled after the procedure in the Perkin Elmer Report by (Bosnak and Davidowski, 2004).

\section{F-2.1 Reagent Preparation:}

\section{Solution 1- 5\% KI/Ascorbic Acid Solution}

Weigh $5 \mathrm{~g}$ potassium iodide and $5 \mathrm{~g}$ ascorbic acid into a $100 \mathrm{~mL}$ polypropylene bottle. Dilute to $100 \mathrm{~mL}$ with deionized water.

\section{Solution 2- 0.5\% Sodium Borohydride in $0.05 \%$ Sodium Hydroxide}

Weigh $0.25 \mathrm{~g}$ of $\mathrm{NaOH}$ into a $500 \mathrm{~mL}$ polypropylene bottle. Add approximately $100 \mathrm{~mL}$ deionized water and swirl to dissolve the $\mathrm{NaOH}$. Weigh $2.5 \mathrm{~g} \mathrm{NaBH}_{4}$ and add to the $\mathrm{NaOH} /$ deionized water mixture. Dilute to $500 \mathrm{~mL}$ volume with deionized water. Prepare fresh daily.

\section{Solution 3- Wash solution}

Prepare $1 \mathrm{~L}$ of wash solution by combining $50 \mathrm{~mL}$ of trace-metal grade strong hydrochloric acid with $500 \mathrm{~mL}$ of deionized water. Dilute to 1L.

\section{F-2.2 Sample Preparation:}

All water samples should be immediately acidified after sampling to prevent As adsorption onto plastic surfaces. Sample should be acidified using trace metal grade 
$\mathrm{HCL}$ (not $\mathrm{HNO}_{3}$ due to interferences) to less than $\mathrm{pH}$ 2.0. All standards should be prepared in the same manner as the samples.

1) Add $5 \mathrm{~mL}$ of a water sample to a sample vial.*

2) Add $1 \mathrm{~mL}$ of strong trace-metal grade hydrochloric acid.*

3) Add $1 \mathrm{~mL}$ of the $\mathrm{KI} /$ ascorbic acid solution.*

4) Shake sample to ensure full mixing

5) Wait one to two hours before analysis

*Preparation volumes may be scaled proportionately if more or less sample is desired.

\section{F-2.3 Preparing the Optima 5300 DV}

Replacing the Torch

1. Carefully remove nebulizer and glass spray chamber and all associated tubing

2. Remove the injector nozzle by depressing the small black button on bottom and then pulling the torch straight out.

3. Turn large black torch coupler counterclockwise and carefully pull out the glass tube that shrouds the ceramic torch. Be careful when removing the coupler as there is a small glass bonnet on the inside may fall if the torch is not pulled straight out.

4. Remove the torch coupler to a work bench

5. Before proceeding, note the location of the copper foil relative to the torch coupler, and the plastic housing for the torch. (See Figure 5-5 on Page 5-21 of the Perkin Elmer Manual) 
6. Unscrew the black ring that secures the glass torch in place, noting the order and location of where the O-rings on the torch.

7. Replace the Hydride Generation torch with another torch, making sure that the replacement torch has the small copper foil in place, and the O-rings are put back in the correct order.

8. Fully seat the glass torch such that when the injector nozzle is inserted, it lines up with the ring marking on the glass torch.

9. Align the piece of copper foil with the mark on the torch coupler, and the mark on the base of the torch holder.

10. Screw the black retaining ring back in place, and check alignment of the injector nozzle and the copper foil piece.

11. Open up the side door and note the location of the guided pin on the torch coupler and the receiving notch on the OES.

12. Carefully reinsert the torch back into the OES. Make sure that the glass bonnet does not fall by opening the side door and holding onto it while inserting the torch and torch coupler.

13. Turn the torch coupler clockwise to lock it back into place and shut and lock the side door.

\section{F-2.4 Installing the Hydride Generation Manifold}

1. Replace the torch as outlined in "Replacing the Torch" instructions. 
2. Attach the tubing as shown below in Figure F-1 such that the sample line from the auto-sampler and the tube from the sodium borohydride solution feed into the mixing block as labeled on the aluminum plate. Attach a waste tube connection large enough such that there is sufficient drainage from the gas/liquid separator. All materials needed for the hydride generation manifold are listed in Bosnak and Davidowski (2004), or it can be bought as a package from Perkin Elmer.

3. Remove the injector nozzle on the ICP-OES and attach the line from the top of the gas/liquid separator to the injector nozzle on the ICP-OES. Make sure that the plastic adaptor is fully seated onto both O-rings on the injector nozzle.

4. Attach an argon or nitrogen carrier gas source to the base of the liquid gas separator onto the gas/liquid separator.

5. Periodic replacement of the filter on top of the liquid gas separator may be necessary based on usage and sample cleanliness.

6. During warm-up of the ICP-OES instrument, a wash solution of $5 \% \mathrm{HCl}$ and water should be run through the chemifold assembly. 


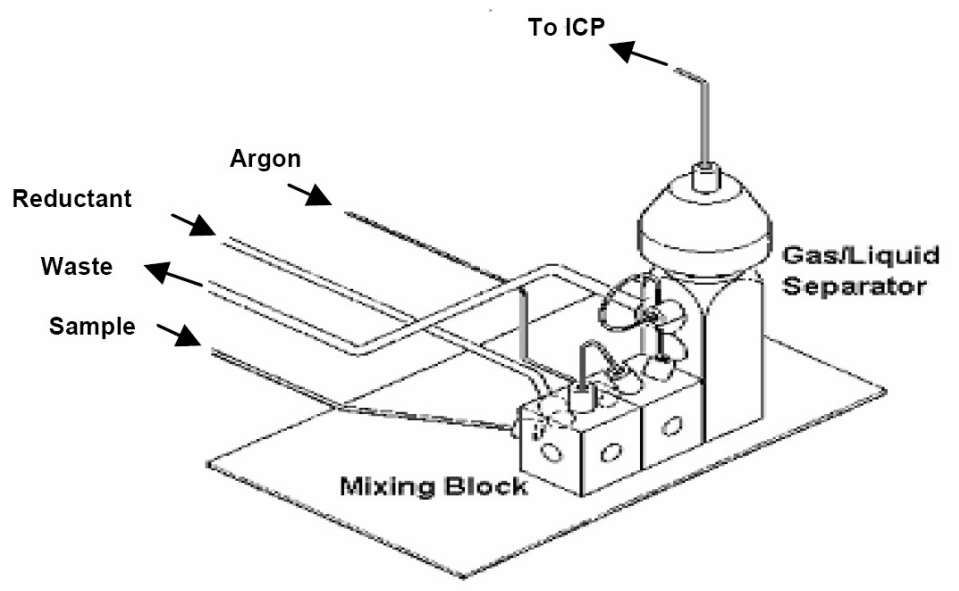

Figure F- 1: Chemifold assembly with appropriate tubing.

(Bosnak and Davidowski, 2004) 


\section{F-3. SAMPLE ANALYSIS}

The parameters necessary for the hydride generation method are listed in Section F-4. A sample wavelength of $188.978 \mathrm{~nm}$ was used for all analyses. Startup and maintenance procedures for the ICP-OES can be found in SOP 30. After the ICPOES has been warmed up and the plasma has been lit for 30 minutes to one hour, sample analysis may begin. The linear range for arsenic has been found to be from less than one $\mu \mathrm{g} / \mathrm{L}$ up to several hundred $\mathrm{mg} / \mathrm{L}$. All analysis should be performed within the concentrations of the standards.

When running arsenic concentrations that are above $100 \mu \mathrm{g} / \mathrm{L}$, samples run directly afterwards may experience an increased background concentration due to residual gas particles left in the machine. If samples with low As concentrations $(<50$

$\mu \mathrm{g} / \mathrm{L}$ ) will be run with samples containing higher As concentrations (> $500 \mu \mathrm{g} / \mathrm{L}$ ), then an extended rinse time of 3-5 minutes, or a blank sample run in between samples should be conducted.

Standards should be checked periodically in accordance with SOP 22, SOP 30 , and SOP 68. In addition, Standard Reference Water Samples from the USGS are a valuable resource in verifying standard concentrations and data reproducibility.

\section{F-3.1 Detection Limits}

The detection limits using the methods and procedure above was found to be $0.01 \mu \mathrm{g} / \mathrm{L}$ by Bosnak and Davidowski (2004). An arsenic detection limit of $0.05 \mu \mathrm{g} / \mathrm{L}$ was found based on the standard deviation of 10 consecutive measurements of a 1 
$\mu \mathrm{g} / \mathrm{L}$ standard. Low detection limits will be determined by the quality of water used to make the solutions and the purity of the reagents.

Figure 2 below plots the observed and actual concentration of the USGS standard reference sample T-135. The sample was analyzed at the beginning of each analysis directly after the standards. The sample was selected as its reported concentration was found to be $10.0 \pm 1.1 \mu \mathrm{g} / \mathrm{L}$, which is near the EPA MCL of 10 $\mu \mathrm{g} / \mathrm{L}$. The average concentration from all 14 analyses was $10.5 \mu \mathrm{g} / \mathrm{L}$. Though this value is higher than the reported average, it is well within the reported standard deviation. Further information about detection limits for the ICP-OES can be found in NMBGMR SOP 30.

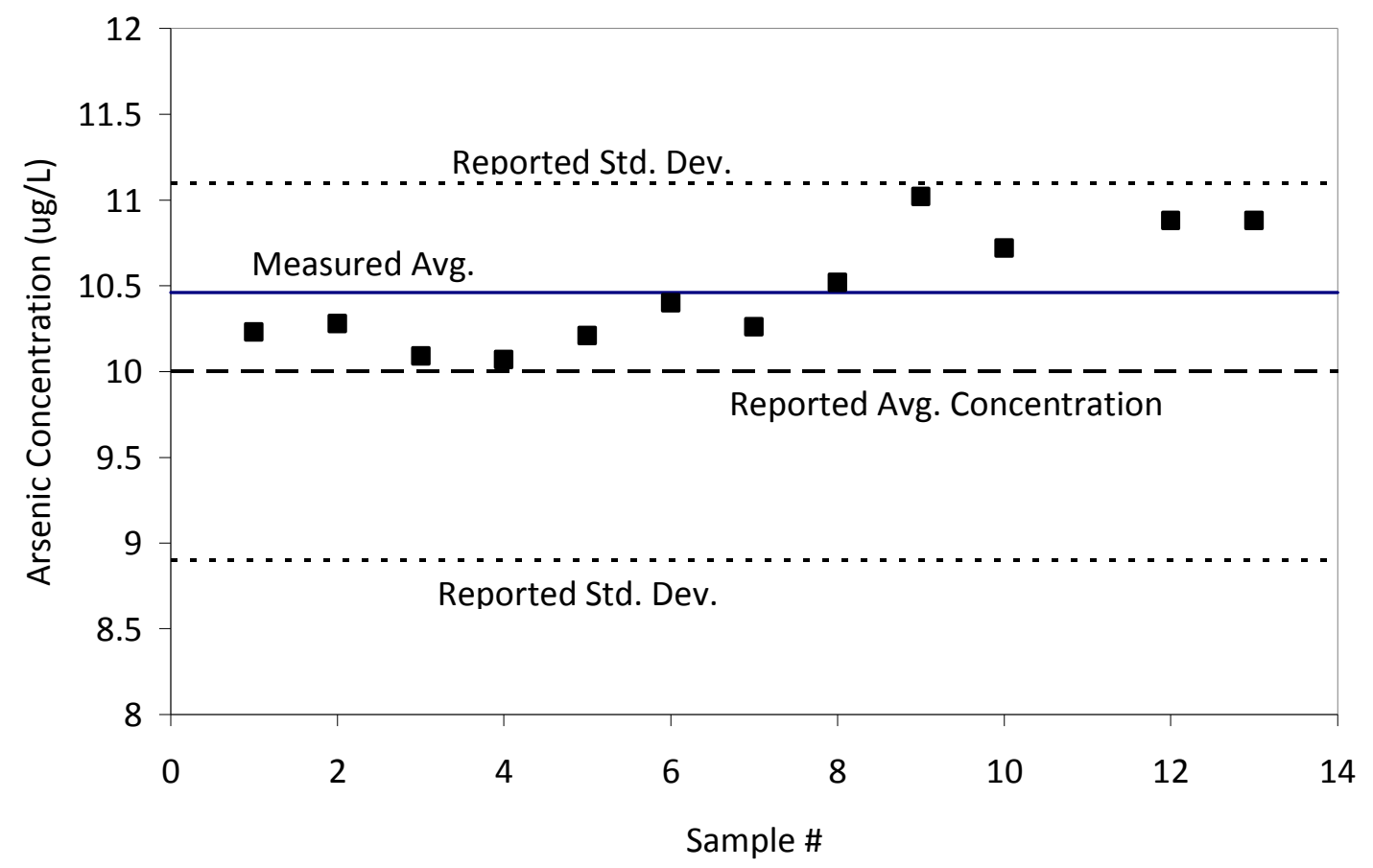

Figure F- 2: Plot of the measured values of the sample T-135. The USGS standard reference sample has a reported value of $10.0 \pm 1.1 \mu \mathrm{g} / \mathrm{L}$. The average value from 14 different analyses was $10.5 \mu \mathrm{g} / \mathrm{L}$. 


\section{F-4. ICP-OES Operating Conditions \\ For use with WINLAB 32 PC software \\ As Hydride Method}

\section{Spectrometer Tab}

Define Elements Tab

4 Analytes- As at $188.978 \mathrm{~nm}, 193.694 \mathrm{~nm}, 197.197 \mathrm{~nm}, 228.812 \mathrm{~nm}$

\section{Settings Tab}

Purge Gas Flow= Normal

Spectral Profiling=NO

Resolution $=$ Fixed Normal

Read Parameters $=$ Auto 10min 10 max

Delay Time $=10 \mathrm{sec}$

Replicates $=3$

\section{Spectral Window}

4 analyte wavelengths- As at $188.978 \mathrm{~nm}, 193.694 \mathrm{~nm}, 197.197 \mathrm{~nm}, 228.812 \mathrm{~nm}$

\section{Sampler Tab}

\section{Plasma Tab}

Source Equilibration Delay $=5 \mathrm{sec}$

Same for all elements

Dry

Instant

Plasma Gas Flow $=15 \mathrm{~L} / \mathrm{min}$

Aux $=.2 \mathrm{~L} / \mathrm{min}$

$\mathrm{Neb}=.7 \mathrm{~L} / \mathrm{min}$

Power $=1400 \mathrm{~W}$

View Dist $=15.0$

View Type $=$ Axial

Peristaltic Pump Tab

Sample Flow Rate $=2 \mathrm{~mL} / \mathrm{min}$

Flush Time $=60 \mathrm{sec}$

Autosampler Tab

Wash Frequency $=$ Between Samples

Rate $=2 \mathrm{~mL} / \mathrm{min}$

Normal Time $=75 \mathrm{sec}$

Wash Location $=0$ 


\section{Process Tab}

Peak Processing

F'n=A

Elements $=$ All 4 arsenic wavelengths

Peak Algorithm $=$ Peak Area

Points per Peak=3

Spectral Corrections Tab

F'n=A

Elements $=$ All 4 arsenic wavelengths

Overlap Correction=None

Background Correction= 2-Point 


\section{F-5. REFERENCES}

Bosnak, C.P.; Davidowski, L. 2004. Continuous Flow Hydride Generation Using the Optima ICP: Perkin Elmer, Field Application Report

Davidowski, L. 1993. A Simple Continuous Flow Hydride Generator for ICP-OES: ICP Application Study Number 67

Perkin Elmer, 2004: Optima 5000 Series Hardware Guide

Thompson, M.; Pahlavanpour, B.; Walton, S. J.; Kirkbright, G. F.; 1978.

Simultaneous determination of trace concentrations of arsenic, antimony, bismuth, selenium and tellurium in aqueous solution by introduction of the gaseous hydrides into an inductively coupled plasma source for emission spectrometry. Part II. Interference studies: Analyst, Vol. 103, pp. 705-713 
This is a License Agreement between Jaron R Andrews ("You") and Elsevier ("Elsevier") provided by Copyright Clearance Center ("CCC"). The license consists of your order details, the terms and conditions provided by Elsevier, and the payment terms and conditions.

\begin{tabular}{|c|c|}
\hline \multicolumn{2}{|c|}{$\begin{array}{l}\text { All payments must be made in full to CCC. For payment instructions, please see } \\
\text { information listed at the bottom of this form. }\end{array}$} \\
\hline Supplier & $\begin{array}{l}\text { Elsevier Limited } \\
\text { The Boulevard, Langford } \\
\text { Lane } \\
\text { Kidlington, Oxford, OX5 } \\
\text { 1GB,UK }\end{array}$ \\
\hline Registered Company Number & 1982084 \\
\hline Customer name & Jaron R Andrews \\
\hline \multirow[t]{2}{*}{ Customer address } & 801 Fitch St. \\
\hline & Socorro, NM 87801 \\
\hline License Number & 2253300415843 \\
\hline License date & Aug 20, 2009 \\
\hline Licensed content publisher & Elsevier \\
\hline Licensed content publication & $\begin{array}{l}\text { Journal of Contaminant } \\
\text { Hydrology }\end{array}$ \\
\hline Licensed content title & $\begin{array}{l}\text { Quantification and modelling } \\
\text { of } 2,4 \text {-dinitrotoluene } \\
\text { reduction with high-purity } \\
\text { and cast iron }\end{array}$ \\
\hline Licensed content author & $\begin{array}{l}\text { Benham Jafarpour, Paul T. } \\
\text { Imhoff and Pei C. Chiu }\end{array}$ \\
\hline Licensed content date & January 2005 \\
\hline Volume number & 76 \\
\hline Issue number & $1-2$ \\
\hline Pages & 21 \\
\hline Type of Use & Thesis / Dissertation \\
\hline Portion & $\begin{array}{l}\text { Figures/table/illustration } \\
\text { /abstracts }\end{array}$ \\
\hline Portion Quantity & 1 \\
\hline Format & Both print and electronic \\
\hline You are an author of the Elsevier article & No \\
\hline Are you translating? & No \\
\hline \multicolumn{2}{|l|}{ Order Reference Number } \\
\hline Expected publication date & Dec 2009 \\
\hline
\end{tabular}

